\title{
Field Performance and Rating Evaluation of a Modular Press- Brake-Formed Steel Tub Girder with a Steel Sandwich Plate Deck
}

Nicole Marie Hegele Underwood

West Virginia University, nahegele@mix.wvu.edu

Follow this and additional works at: https://researchrepository.wvu.edu/etd

Part of the Civil Engineering Commons, and the Structural Engineering Commons

\section{Recommended Citation \\ Underwood, Nicole Marie Hegele, "Field Performance and Rating Evaluation of a Modular Press-Brake- Formed Steel Tub Girder with a Steel Sandwich Plate Deck" (2019). Graduate Theses, Dissertations, and Problem Reports. 3871.}

https://researchrepository.wvu.edu/etd/3871

This Thesis is protected by copyright and/or related rights. It has been brought to you by the The Research Repository @ WVU with permission from the rights-holder(s). You are free to use this Thesis in any way that is permitted by the copyright and related rights legislation that applies to your use. For other uses you must obtain permission from the rights-holder(s) directly, unless additional rights are indicated by a Creative Commons license in the record and/ or on the work itself. This Thesis has been accepted for inclusion in WVU Graduate Theses, Dissertations, and Problem Reports collection by an authorized administrator of The Research Repository @ WVU. For more information, please contact researchrepository@mail.wvu.edu. 
2019

Field Performance and Rating Evaluation of a Modular Press-Brake-Formed Steel Tub Girder with a Steel Sandwich Plate Deck

Nicole Marie Hegele Underwood

Follow this and additional works at: https://researchrepository.wvu.edu/etd

Part of the Civil Engineering Commons, and the Structural Engineering Commons 


\title{
Field Performance And Rating Evaluation of a Modular Press-Brake-Formed Steel Tub Girder With a Steel SANDWich Plate DeCK
}

Nicole M. Hegele Underwood, E.I.

\author{
Thesis submitted to the \\ Benjamin M. Statler College of Engineering and Mineral Resources \\ at \\ West Virginia University \\ on partial fulfillment of the requirements \\ for the degree of \\ Master of Science \\ in \\ Civil and Environmental Engineering
}

\author{
Karl E. Barth, Ph.D., Chair \\ Gregory K. Michaelson, Ph.D. \\ Huang-Liang Roger Chen, Ph.D. \\ Department of Civil and Environmental Engineering \\ Morgantown, West Virginia \\ 2019
}

Keywords: steel bridge, press-brake-formed tub girders, sandwich plate steel deck, live load distribution factors, load rating 


\section{AbSTRACT \\ Field Performance and Rating Evaluation of a Modular \\ Press-Brake-Formed Steel Tub Girder With a STEel \\ SAndWich Plate Deck}

Nicole M. Hegele Underwood, E.I.

The Short Span Steel Bridge Alliance (SSSBA) is a group of bridge and culvert industry leaders (including steel manufacturers, fabricators, service centers, coaters, researchers, and representatives of related associations and government organizations) who have joined together to provide educational information on the design and construction of short span steel bridges in installations up to 140 feet in length. The SSSBA technical working group has developed a shallow press-brake-formed tub girder, a trapezoidal cold bent girder, to address the demand in the short span steel bridge market for rapid infrastructure replacement solutions.

Following extensive experimental testing and design work at West Virginia University, members of the SSSBA in collaboration with Intelligent Engineering of Ottowa, Canada and County Engineer Douglas Davis, P.E., designed and constructed the Cannelville Road Bridge in Muskingum County, Ohio. The structure is composed of two modular, tub girder and sandwich plate steel (SPS $\left.{ }^{\circledR}\right)$ deck units that were constructed offsite and erected using accelerated bridge construction $(\mathrm{ABC})$ methods. The structure is the second press-brake-formed steel tub girder bridge to be erected and is the first structure with a composite SPS ${ }^{\circledR}$ deck system. One year after construction, the structure was live load field tested by researchers from West Virginia University and Marshall University to assess its performance.

This study presents the analysis and conclusions of experimental testing and analytical modeling of the Cannelville Road Bridge. The procedure for both experimental and analytical testing is outlined within the content of this study. The results of these analyses were used to generate bottom flange bending stress, live load distribution factors (LLDFs), and interior and exterior girder ratings. These values, experimental and analytical, were then compared with equivalent LLDFs and live load girder ratings computed referencing American Association of Highway and Transportation Officials (AASHTO) LRFD Specifications. The result of this testing evidences that current AASHTO LRFD Specifications for analyzing shallow press-brake-formed tub girders are conservative, with field performance exceeding the performance calculated. In addition to high performance, tub girders are practical in $\mathrm{ABC}$ applications and compatible with various deck designs as modular units. With a growing demand and need for rapid infrastructure replacement, shallow press-brake-formed tub girders have been proven to be an effective application in response to the growing industry demand. 


\section{ACKNOWLEDGEMENTS}

I would like to thank my advisor and committee chairman Dr. Karl Barth for his guidance, support, and faith in me as a student. Dr. Barth has been committed to my education as an engineer and has helped me to develop in my capacity as such. His assistance throughout the research and development of this thesis was critical to its success. I am privileged to have him as a mentor.

I would additionally like to express my thanks for committee members Drs. Michaelson and Chen. Dr. Michaelson aided me throughout the research process. His assistance during field testing and troubleshooting were critical to the successful testing of the Cannelville Road Bridge. Further, his willingness to talk through problems and share solutions to modeling challenges was critical to my success. I want to thank Dr. Chen for inspiring me in my undergraduate curriculum. I am now thankful for the exams that took three hours to finish and the lectures that left my head teeming. They have served me well in my professional life and his passion continues to inspire.

I want to thank Robert (Robby) Tennant and Cory Gibbs for their help throughout this process. Robby gave his precious time to help me in this endeavor in so many and varied ways that I could never express enough thanks. Further, his model to me as an upperclassman was inspirational and drove me to seek a master's education. I thank Cory for helping me sort through the chaos of working full time for Michael Baker and completing this degree. His willingness to work through the nuances of professional and school life has been a gift. I would also like to thank Adam Roh and Guilherme de Oliveira Petty Santana for their help and humor during bridge testing.

I express my gratitude to Michael Baker International for affording my graduate education. I want to thank my colleagues in the Bridge and Transportation Groups in the Charleston, WV Office for their support and patience in helping me further understand the bridge design process as I have completed my education. I would also like to thank Kanawaha Scales and Systems for allowing me to use their offices and resources to complete my thesis, specifically Darryl King.

Finally, and most importantly I want to express my utmost appreciation and love for my family, old and new, who have supported me through this and all my endeavors. Especially, my

husband, Benjamin Underwood, who has made enumerable personal sacrifices for me to further my education and pursue my passions unencumbered. 


\section{TABLE OF CONTENTS}

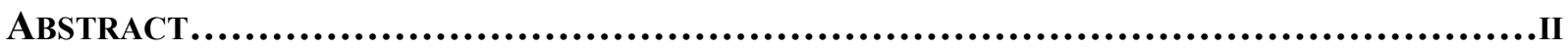

ACKNOWLEDGEMENTS.........................................................................................................................II

TABLE OF CONTENTS ................................................................................................................................ IV

LIST OF TABLES......................................................................................................................................... VIII

LIST OF FIGURES..................................................................................................................................

CHAPTER 1: INTRODUCTION ..................................................................................................... 1

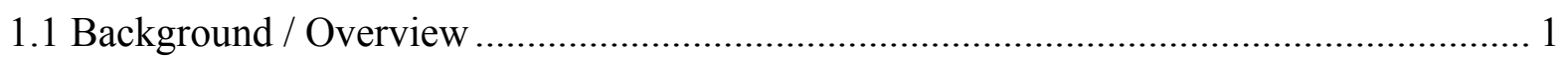

1.2 Project Scope \& Objectives ……………………................................................. 2

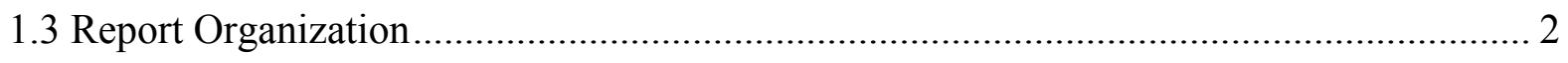

CHAPTER 2: LITERATURE REVIEW ........................................................................................... 4

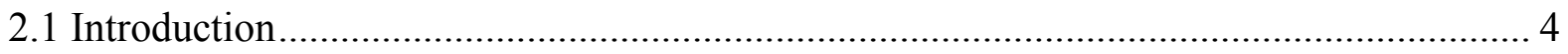

2.2 Previous Applications of Cold-Bent Steel Girders ........................................................... 4

2.2.1 Prefabricated Press-Formed Steel T-Box Girder Bridge System (Taly \& Gangarao,

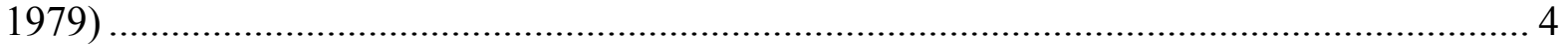

2.2.2 Composite Girders with Cold Formed Steel U-sections (Nakamura, 2002) ................ 6

2.2.3 Folded Plate Girders (Developed at the University of Nebraska) ................................ 7

2.2.4 Texas Department of Transportation Rapid Economical Bridge Replacement............ 8

2.3 Previous Research at WVU on Press-Brake-Formed Steel Tub Girders ............................ 9

2.3.1 Development and Feasibility Assessment of Shallow Press-Brake-Formed Steel Tub Girders for Short-Span Bridge Applications (Michaelson 2014) ............................................ 9

2.3.2 Experimental Evaluation of Non-Composite Shallow Press-Brake-Formed Steel Tub

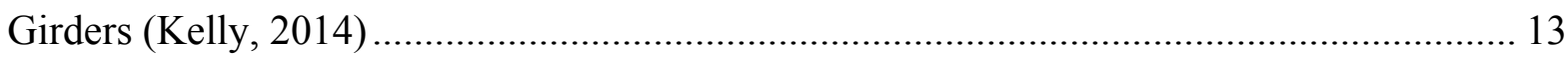

2.3.3 Evaluation of Modular Press-Brake-Formed Tub Girders with UHPC Joints

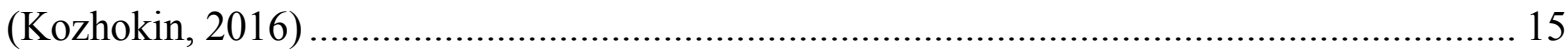


2.3.4 Field Performance Assessment of Press-Brake-Formed Steel Tub Girder

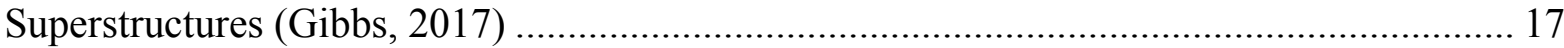

2.3.5 Fatigue Performance of Uncoated and Galvanized Composite Press-Brake-Formed

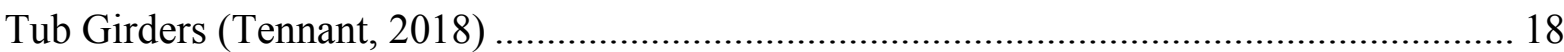

2.4 Sandwich Plate Steel (SPS $\left.{ }^{\circledR}\right)$ Deck Applications (Intelligent Engineering)................... 20

2.5 FHWA's Accelerated Innovation Deployment Demonstration Program (AID Demo).... 21

2.6 Current AASHTO Specifications for Tub Girder Design and Application...................... 22

2.6.1 Multiple Presence Factor, Section 3.6.1.1.2 (AASHTO, 2017) ……………………. 22

2.6.2 Beam-Slab Bridges - Live Load Distribution Factors, Section 4.6.2.2 (AASHTO, $2017)$

2.6.3 Box-Section Flexural Members, Section 6.11 (AASHTO, 2017) ………………...... 24

2.7 Current AASHTO Specifications for Superstructure Load Rating (MBE, 2018) ............ 44

CHAPTER 3: DESIGN AND CONSTRUCTION OF THE CANNELVILLE RoAd BRIDGE............... 47

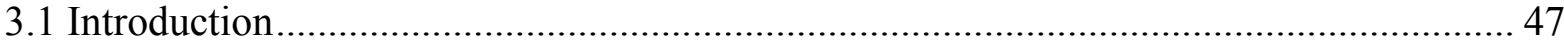

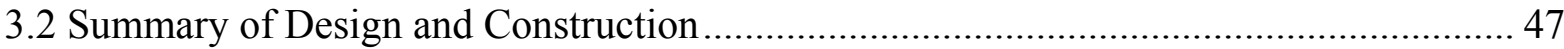

3.2.1 Galvanic Coated Steel Press-Brake Tub Girder....................................................... 48

3.2.2 Sandwich Plate Steel Deck System............................................................................ 49

3.2.3 Accelerated Bridge Construction Methods................................................................ 49

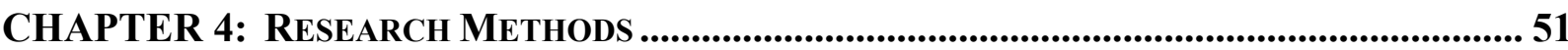

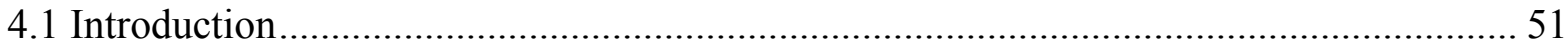

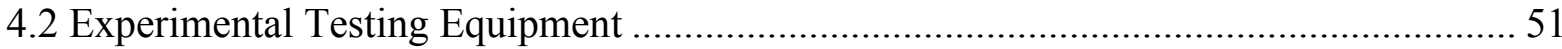

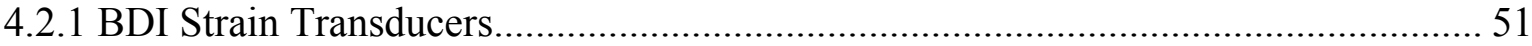

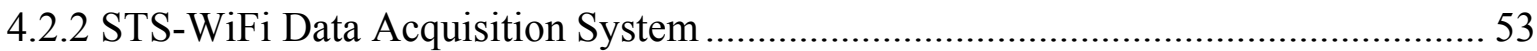

4.2.3 Load Truck and Wheel Scales .............................................................................. 56

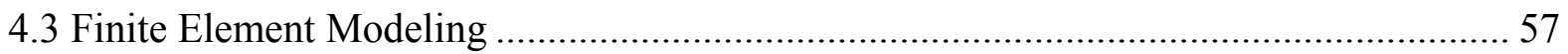




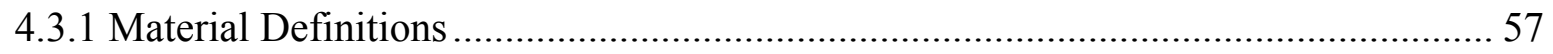

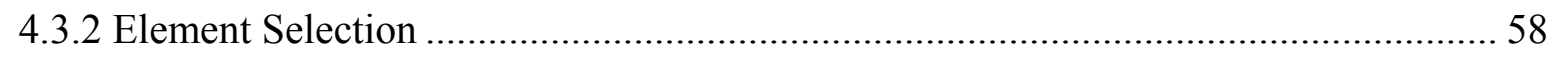

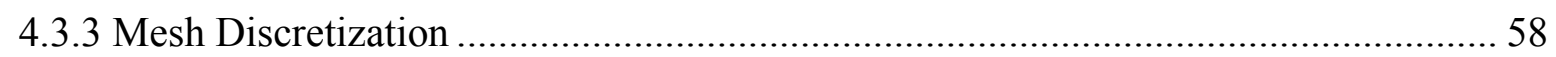

4.3.4 Multiple Point Constraints and Boundary Conditions ................................................. 59

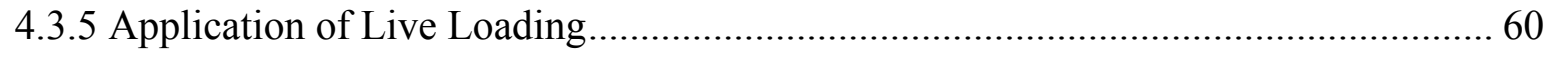

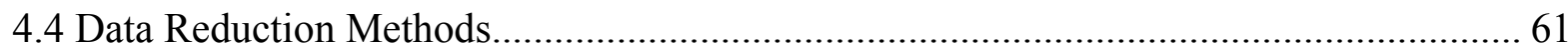

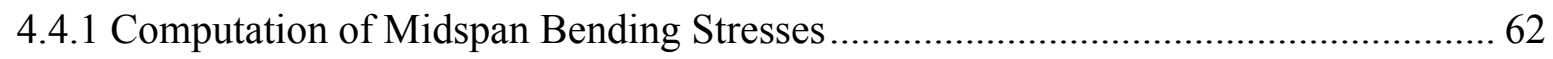

4.4.2 Computation of Live Load Distribution Factors.......................................................... 63

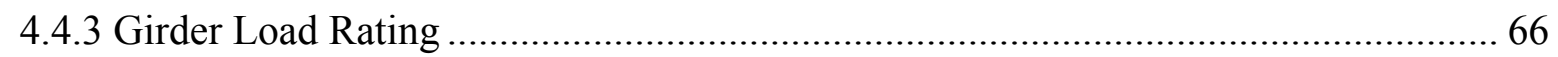

CHAPTER 5: FIELD TESTING OF THE CANNELVILLE ROAD BRIDGE....................................... 70

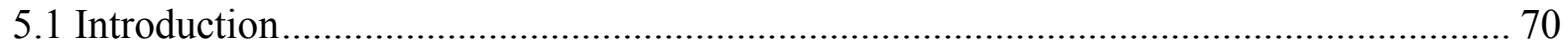

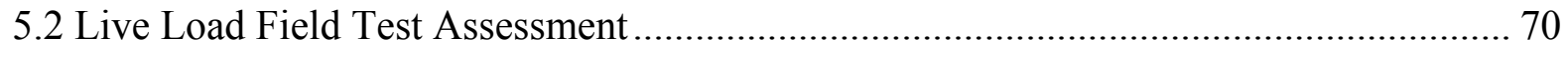

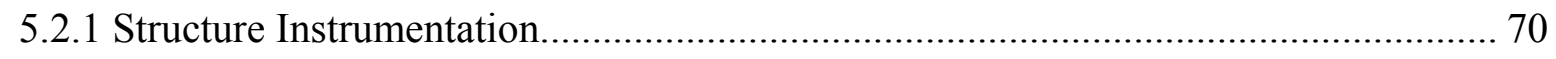

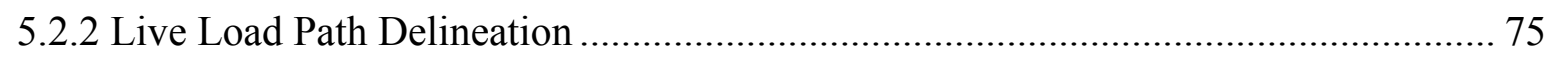

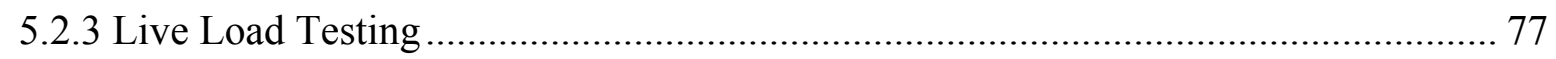

CHAPTER 6: RESULTS AND ANALYSIS................................................................................... 79

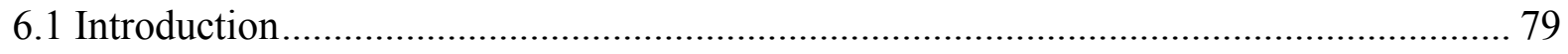

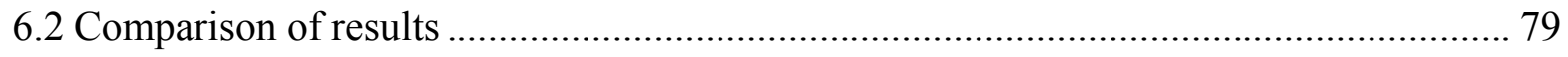

6.2.1 Finite Element Modeling Results.......................................................................... 79

6.2.2 Live Load Field Test Results ............................................................................... 85

6.2.3 Comparison of Analytical and Experimental Results ............................................... 89

6.3 Comparison of Live Load Distribution Factors with AASHTO Specifications ................ 97

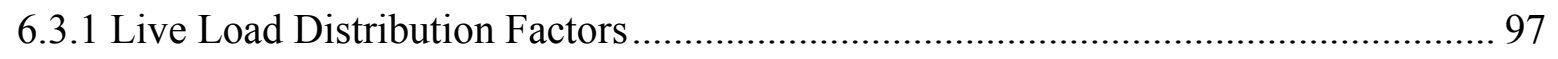

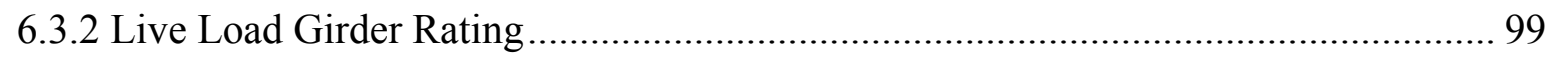


6.4 Conclusions 102

CHAPTER 7: CONCLUSIONS AND RECOMMENDATIONS .......................................................... 103

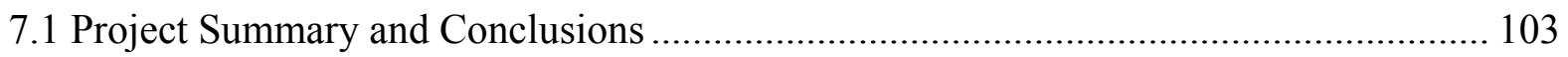

7.2 Recommendations for Continued Work ………………............................................. 104

\section{REFERENCES 105}

APPENDIX A: RESULTS FOR ALL TRUCK RUNS............................................................................. 108

A.1 Average Midspan Bending Stress ................................................................................. 109

A.1.1 Live Load Field Test Results ………………………………………………….... 109

A.1.2 Finite Element Analysis Results ………………………………………………..... 113

A.1.3 Results Comparison: Live Load Field Test vs. Finite Element Analysis ................. 117

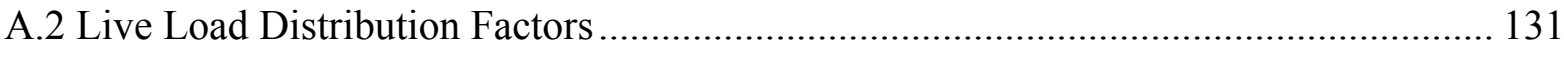

A.2.1 Live Load Field Test Results ............................................................................ 131

A.2.2 Finite Element Analysis Results .................................................................... 135

A.2.3 Results Comparison: Live Load Field Test vs. Finite Element Analysis ................ 139

A.2.4 Results Comparison: Live Load Field Test , Finite Element Analysis, AASHTO

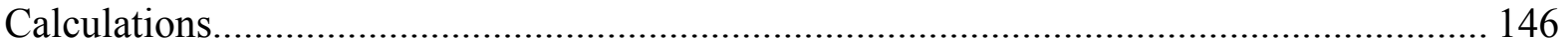

APPENDIX B: LARS BRIDGE CONNECT LOAD RATING OUTPUT .......................................... 150

APPendix C: CANNELVILle RoAd BRIDge Design Plans ....................................................... 168 


\section{LIST OF TABLES}

Table 2.1: Summary Distribution Factors, Direct Girder Loading (Kozhokin, 2016)............... 16

Table 2.2: Multiple Presence Factors, Section 3.6.1.1.2 (AASHTO, 2017) ............................. 22

Table 2.3: Chapter 2 Equation Legend ( AASHTO, 2017) ................................................... 42

Table 2.4: Condition Factor, Table 6A.4.2.3-1 (MBE, 2018) .................................................. 45

Table 4.1: Tub Girder Edge Seeding and Aspect Ratio, Typical All Girders............................ 59

Table 4.2: Equivalent Truck Wheel Loads, Finite Element Model......................................... 60

Table 4.3: Midspan Bending Stress (ksi), Sample Calculation .............................................. 62

Table 4.4: LLDFs Single Lane Loaded, Sample Calculation ................................................ 63

Table 4.5: LLDFs Two Lanes Loaded, Sample Calculation..................................................... 64

Table 6.1: Run 2 Bottom Flange Average Bending Stress, Finite Element Analysis ................. 81

Table 6.2: Run 2 Live Load Distribution Factors, Finite Element Analysis ............................ 82

Table 6.3: Live Load Interior and Exterior Girder Ratings, Finite Element Analysis................ 83

Table 6.4: Run 2 Bottom Flange Average Bending Stress, Live Load Field Test ..................... 85

Table 6.5: Run 2 Live Load Distribution Factors, Live Load Field Test ................................. 86

Table 6.6: Live Load Interior and Exterior Girder Ratings, Field Test Results ....................... 87

Table 6.7: Run 2 Bottom Flange Average Bending Stress, Live Load Field Test vs. Finite Element

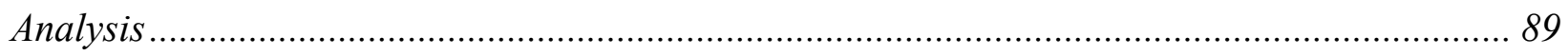

Table 6.8: Run 2 Average Live Load Distribution Factors, Live Load Field Test vs. Finite Element

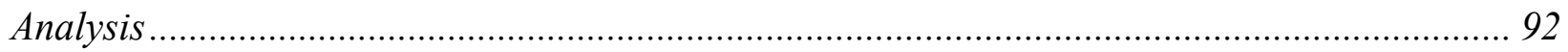

Table 6.9: Run 2, Average Live Load Distribution Factors, Live Load Field Test, Finite Element

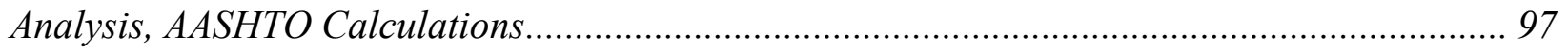

Table 6.10: Runs 2 and 5, Average Live Load Distribution Factors, Live Load Field Test, Finite

Element Analysis, AASHTO Calculations.......................................................................... 98 


\section{LIST OF FIGURES}

Figure 2.1: T-Box Girder System, Typical Girder Section with 5” Pre-cast, Prestressed Concrete Slab (Taly \& Gangarao, 1979).

Figure 2.2: T-Box Girder System, Typical Girder Section with 3/8” Braced Steel Plate Deck (Taly

\& Gangarao, 1979) .............................................................................................................. 5

Figure 2.3: System Proposed at the University of Nebraska (Burner, 2010)............................. 7

Figure 2.4: Typical Section, Bridge FM 3267(Chandar et al., 2010)..................................... 8

Figure 2.5: Typical TxDOT Steel Tub Girder Section, Bridge FM 3267 (Chandar et al., 2010).. 8

Figure 2.6: Design Comparison of 84” Wide Standard Mill Plate (Michaelson, 2014)............. 10

Figure 2.7: Typical Section, Non-Composite Test Specimen (Michaelson, 2014) .................... 11

Figure 2.8: Typical Section, Composite Test Specimen (Michaelson, 2014) ........................... 11

Figure 2.9: Typical Failure of Non-Composite Girder Section (Michaelson, 2014) ................. 12

Figure 2.10: Typical Failure of Composite Girder Section (Michaelson, 2014) ...................... 12

Figure 2.11: System Lateral Torsional Buckling of Tub Girder Steel Specimen (Kelly, 2014) ... 14

Figure 2.12: Trapezoidal Shear Key Prior to UHPC Pour, Note Exposed Rebar and Aggregate

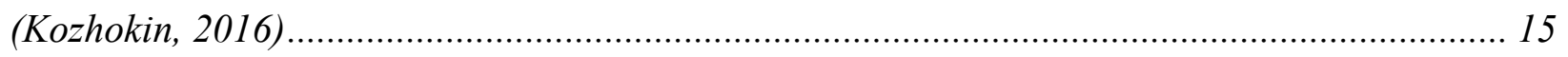

Figure 2.13: New Amish Sawmill Bridge (Gibbs, 2017) ........................................................ 17

Figure 2.14: FEA v. Experimental v. AASHTO LLDFs (Gibbs, 2017) .................................. 18

Figure 2.15: Uncoated Steel Girder Fatigue Loaded (Tennant 2018) ................................... 19

Figure 2.16: Galvanized Coated Tub Girder (Tennant 2018).............................................. 19

Figure 2.17: Intelligent Engineering Sandwich Plate Steel (SPS®) Deck.............................. 20

Figure 2.18: Center to Center Flange Distances, Section 6.11.2.3 (AASHTO, 2017)............... 23

Figure 3.1: Cannelville Road Bridge, Upstream Elevation looking Backstation....................... 47

Figure 3.2: Cannelville Road Bridge Modular Girder Unit................................................... 48

Figure 3.3: Cannelville Road Bridge SPS® Deck ............................................................. 49

Figure 3.4: Cannelville Road Bridge, Modular Unit 1-Girders 1\& 2 Erection, Looking Upstation

Figure 3.5: Cannelville Road Bridge, Modular Unit 1 on Bearings, Looking Upstream ........... 50

Figure 4.1: BDI Strain Transducer Schematic (BDI) ...................................................... 52

Figure 4.2: BDI Strain Transducer Application, Cannelville Road Bridge Field Test............... 52 
Figure 4.3: BDI Strain Gage Tabs Adhered to Bottom of Girder, Cannelville Road Bridge Field Test. 53

Figure 4.4: STS Wi-fi Wireless 4-Channel Node, Cannelville Road Bridge Field Test .............. 54

Figure 4.5: STS Wi-fi Wireless Base Station (BDI) ........................................................... 54

Figure 4.6: STS Wi-fi Data Acquisition System, Cannelville Road Bridge Field Test............... 55

Figure 4.7: Tandem-Axle Dump Truck, Cannelville Road Bridge Field Test.......................... 56

Figure 4.8: Tub Girder Edge Seeding, Typical for All Girders ............................................... 58

Figure 4.9: Nodal Distribution of Point Loads (Michaelson, 2010) ......................................... 60

Figure 4.10: AASHTO HL-93 Design Truck (AASHTO, 2017) .............................................. 69

Figure 5.1: Gage Locations on Girders, Looking Backstation ............................................. 71

Figure 5.2: Gage Location Measurements, Bottom Flange Girder 3, Looking Backstation ....... 71

Figure 5.3: Gage Location Measurements, Left Web Girder 1, Looking Upstream................... 72

Figure 5.4: Disk Grinding of Girder Surface, Bottom Flange Girder 4, Looking Upstream ...... 73

Figure 5.5: Adhering Strain Transducer Tabs to Girder, Left Web Girder 1, Looking Upstream 73

Figure 5.6: Failed Tab Connection, Bottom Flange Girder 2, Looking Upstream.................... 74

Figure 5.7: Nodes and Strain Transducer Attached to Bridge, Upstream Elevation.................. 74

Figure 5.8: Live Load Truck Placement, Looking Back ....................................................... 75

Figure 5.9: Midspan Measurement from Rail to Deck Edge, Looking Upstream...................... 76

Figure 5.10: Final Delineation of Load Path, Looking Down Station from Abutment 2 ............ 77

Figure 5.11: Truck Dimensions and Field Weight Measurements ......................................... 77

Figure 5.12: Run 5, Grid Point 2 Load Sample Location, Wheel 4, Looking Downstream ......... 78

Figure 6.1: Longitudinal Strain, Run 2 - Grid Point 5 FEM Model, Looking Downstream....... 80

Figure 6.2: Longitudinal Strain, Run 2- Grid Point 5 FEM Model, Framing Plan.................... 80

Figure 6.3: Interior Girder Load Rating - Moment Capacity vs. Load Applied,....................... 84

Figure 6.4: Exterior Girder Load Rating - Moment Capacity vs. Load Applied,...................... 84

Figure 6.5:Interior Girder Load Rating - Moment Capacity vs. Load Applied,........................ 88

Figure 6.6: Exterior Girder Load Rating - Moment Capacity vs. Load Applied,...................... 88

Figure 6.7: Run 2, Girder 1 Bottom Flange Average Bending Stress, Live Load Field Test vs.

Finite Element Analysis ................................................................................................. 90 
Figure 6.8: Run 2, Girder 3 Bottom Flange Average Bending Stress, Live Load Field Test vs. Finite Element Analysis 90

Figure 6.9: Runs 2 and 5, Girder 1 Bottom Flange Average Bending Stress, Live Load Field Test vs. Finite Element Analysis..... 91

Figure 6.10: Runs 2 and 5, Girder 3 Bottom Flange Average Bending Stress, Live Load Field Test vs. Finite Element Analysis.....

Figure 6.11: Run 2, Average Live Load Distribution Factors with Multiple Presence Factor, Live Load Field Test vs. Finite Element Analysis. 92

Figure 6.12: Run 2, Average Live Load Distribution Factors with Multiple Presence Factor, Q-Q Plot Live Load Field Test vs. Finite Element Analysis ........................................................ 93

Figure 6.13: Run 3, Average Live Load Distribution Factors with Multiple Presence Factor, Live Load Field Test vs. Finite Element Analysis. 94

Figure 6.14: Runs 2 and 5, Average Live Load Distribution Factors with Multiple Presence Factor, Live Load Field Test vs. Finite Element Analysis ................................................... 94 Figure 6.15: All Runs, Average Live Load Distribution Factors with Multiple Presence Factor, QQ Plot Live Load Field Test vs. Finite Element Analysis ................................................... 95

Figure 6.16: Minimum Interior Girder Single and Multi-Lane Loaded Ratings, ..................... 96

Figure 6.17: Minimum Exterior Girder Single and Multi-Lane Loaded Ratings,.................... 96 Figure 6.18: Run 2, Average Live Load Distribution Factors, Live Load Field Test, Finite Element

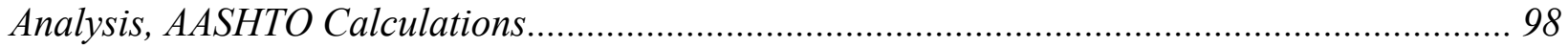

Figure 6.19: Runs 2 and 5, Average Live Load Distribution Factors, Live Load Field Test, Finite Element Analysis, AASHTO Calculations. 99

Figure 6.20: Minimum Interior Single and Multi-Lane Girder Rating, Live Load Field Test, Finite Element Analysis, AASHTO Calculations..... 100

Figure 6.21: Minimum Exterior Single and Multi-Lane Girder Rating, Live Load Field Test, Finite Element Analysis, AASHTO Calculations..... 100 


\section{CHAPTER 1: INTRODUCTION}

\subsection{BACKGROUND / OVERVIEW}

The Short Span Steel Bridge Alliance (SSSBA) is dedicated to developing innovative solutions to address the demand for high quality, rapid replacement of deficient short span structures. The SSSBA is a group of bridge and culvert industry leaders (including steel manufacturers, fabricators, service centers, coaters, researchers, and representatives of related associations and government organizations) who have joined together to provide educational information on the design and construction of short span steel bridges in installations up to 140 feet in length. Through several years of research a technical group within the SSSBA have developed and tested the applicability of modular shallow press-brake-formed steel tub girders, trapezoidal box girders cold formed from standard steel plate, in both lab and field applications. Initial study within the SSSBA began in the fall of 2011, with the first field application of the technology on the Amish Sawmill Bridge in Buchanan County, Iowa. In collaboration with former Muskingum County Engineer Douglas Davis, P.E., the SSSBA worked with Intelligent Engineering Ltd., of Ottowa, Canada and U.S. Bridge to construct the Cannelville Road Bridge, the first bridge in the United States composed of modular decked beams. The galvanic modular beams are composed of a sandwich plate steel (SPS®) deck system and press-brake-formed steel tub girders. The entire bridge was built in twenty-six of the thirty allotted days for construction, with a majority of the superstructure erection occurring in approximately twenty minutes.

Live load field testing was conducted on the Cannelville Road Bridge to assess its performance. Finite element modeling of the structure was completed and compared with the results of the field tests. Strain data was obtained from both the field test and finite element model. This data was used to compute live load distribution factors (LLDFs) for individual girders. These numbers were compared with LLDFs calculated in accordance with American Association of Highway and Transportation Officials (AASHTO) Specifications. The LLDFs were used to load both the interior and exterior girders using AASHTO approved methods and software. The results of this research confirm the field performance of press-brake-formed tub girders in short span applications is adequate, and current AASHTO Specifications (2017) are conservative when applied for system design and evaluation. 


\subsection{Project Scope \& ObJeCtives}

The scope of this thesis was to analyze the field performance of a steel sandwich plate modular decked, press-brake-formed steel tub girders in Muskingum County, Ohio. This analysis was then compared with analytical results determined using finite element modeling. These results were then used to generate LLDFs and load ratings for both interior and exterior girders. This report exhibits that AASHTO specifications conservative with respect to field performance of modular decked, press-brake-formed steel tub girders, and therefore may be applied in design. This assessment was completed as follows:

- A review and discussion of previous research related to the design and implementation of press-brake-formed tub girders and sandwich plate steel deck systems

- An overview of the current AASHTO specifications for box section flexural members (this includes tub girders), including exhibits of the methods for computing LLDFs and load rating of a flexural member

- An explanation of the research methods and field testing performed on the Cannelville Road Bridge, including descriptions of the experimental procedure used in the field and the methods employed in finite element modeling

- A summary of the results of the analysis and conclusions comparing the experimental data, analytical data, and values computed in accordance with AASHTO specifications

\subsection{REPORT ORGANIZATION}

The organization of this thesis is as follows:

- Chapter 2:

○ This chapter discusses the previous research on cold-bent tub girder applications at West Virginia University and elsewhere, research conducted on sandwich plate steel deck systems, the application of accelerated bridge construction $(\mathrm{ABC})$ and the Accelerated Innovation Deployment (AID) 
Demonstration Program, current AASHTO Load Resistance Factor Design standards for tub girders, their application, and load rating

- Chapter 3:

- This chapter details the design and construction of the Cannelville Road Bridge, a modular decked, press-brake-formed steel tub girder beam bridge.

- Chapter 4:

- This chapter discusses the research methods utilized. This includes the field-testing equipment and procedures, a detailed discussion of the finite element analysis, procedures for data reduction, and computation of LLDFs and girder load rating.

- Chapter 5:

- This chapter describes the field test performed on the Cannelville Road Bridge.

- Chapter 6:

- This chapter presents the results of the experimental and analytical testing. It includes a comparison of the experimental and analytical LLDFs and load rating results, in addition to a comparison with AASHTO specification results.

- Chapter 7:

- This chapter concludes the study, providing highlights of the key findings and conclusions. Finally, it proposes topics for further study and efforts in this area of research. 


\section{CHAPTER 2: LITERATURE REVIEW}

\subsection{INTRODUCTION}

This chapter discusses the previous work related to the topic of cold-bent steel tub girders in bridge applications that has been conducted throughout the country. It specifically focuses on the research practicum at West Virginia University related to the design of press-brake-formed steel tub girders and their application in existing structures. This chapter presents the data regarding the material properties and performance of sandwich plate steel (SPS $®$ ) decks developed by Intelligent Engineering Ltd., and the use of this system in bridge deck applications. This chapter additionally discusses the Federal Highway Administration's (FHWA) Accelerated Innovation Deployment Demonstration (AID Demo) Program, specifically highlighting the requirements to qualify for AID Demo funding that was received for the construction of the Cannelville Road Bridge. To conclude the chapter, there is a review of current AASHTO LRFD Specifications that are applicable for the design and load rating of steel press-brake-formed tub girders and steel box girders.

\subsection{Previous Applications of Cold-Bent Steel Girders}

There has been an increased focus on the application of steel tub girders within the bridge industry, specifically in short span applications of lengths up to sixty feet. However, the technology is not a new development. Research in the use of prefabricated steel girder beams has been ongoing for almost five decades as an alternative to traditional built-up box girder members and prefabricated concrete beams. This section provides a brief review of the research efforts that have been exercised in the area of cold-bent steel girders.

\subsubsection{Prefabricated Press-Formed Steel T-Box Girder Bridge System (Taly \& Gangarao, 1979)}

Taly and Gangarao (1979) investigated a design for a composite cold-formed box girder with varying composite deck types. The "T-Box" girders were fabricated from 3/8" thick, A36 steel plate that was cold formed using press brakes into a trapezoidal section. One of the composite deck options was a pre-cast, prestressed concrete slab 5" thick with a shear stud plate embedded 
into the slab designed to be shop welded to the top flange of the girder, see Figure 2.1. The alternative composite deck was a 3/8" steel plate that was braced longitudinally using 5-WT 5x7.5 sections and transversely using W8x13 sections spaced 6'-6" center to center, see Figure 2.2.

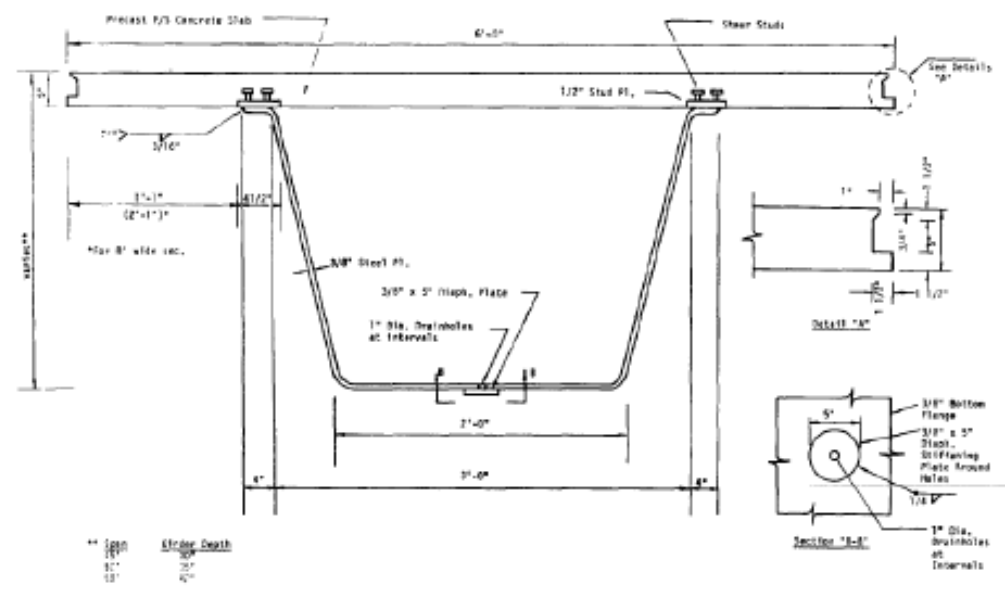

Figure 2.1: T-Box Girder System, Typical Girder Section with 5” Pre-cast, Prestressed Concrete Slab (Taly \& Gangarao, 1979)

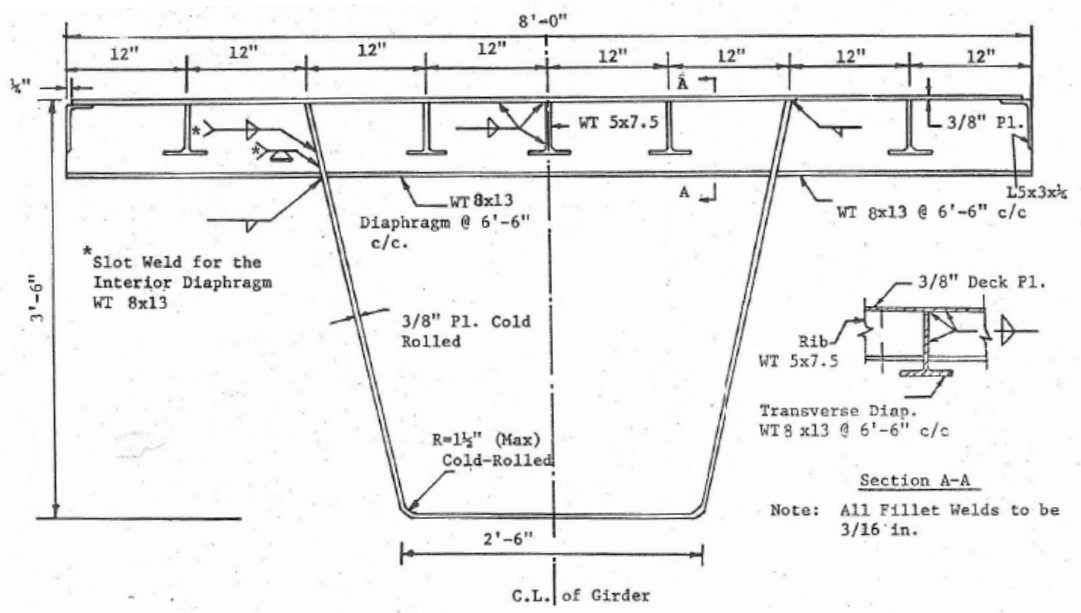

Figure 2.2: T-Box Girder System, Typical Girder Section with 3/8” Braced Steel Plate Deck (Taly \& Gangarao, 1979) 
Both composite units were designed to be constructed in an offsite fabrication shop and were developed using appropriate specifications. Girders with the composite concrete deck were analyzed for applications between $40^{\prime}-0$ " to $100^{\prime}-0$ ”. Girders with composite steel deck were analyzed using 1977 American Iron and Steel Institute (AISI) Specifications for applications up to 65 '-0" in length. Care was taken to ensure the designs were lightweight and could be lifted by low capacity equipment. Each unit was a total of 6'-0" wide, see Figures 2.1 and 2.2, and were designed to be joined by a longitudinal, field construction pour or field weld, as appropriate, to additional superstructure units. The structural benefits of the system included high torsional stiffness and increased efficacy in load distribution.

The conclusions of the study were that, in addition to the structural benefits of using the "T-Box" member, the proposed designs proved to be both economical and practical for short span applications. Fabrication costs would be less than traditional box style and other members due to the cold forming system. Ninety-five percent of the system could be constructed in a controlled environment, fabrication shop, minimizing the required manual labor at the construction site and related delays. The size and weight of the girders would reduce the relative transportation and construction costs of the system. Overall, the total time of construction would be significantly reduced and the quality of the product increased.

\subsubsection{Composite Girders with Cold Formed Steel U-sections (Nakamura, 2002)}

Nakamura (2002) studied the application of press-brake formed, twin "Steel U-Sections" in multi-span applications, composite with a pre-cast prestressed bridge deck. The behavior of continuous multi-span structures causes the concrete deck to experience tension and the steel bottom flange to experience compression at pier connections. A prestressed deck was used to account for the tension experienced in the deck, but there were additional concerns that the bottom flange of the "U-Section" would be prone to buckling. Nakamura addressed this by installing

prestressing bars and filling the base of the girder with concrete at bearing locations, using the girders as formwork for creation of the prestressed beam. 
Bending tests were conducted to evaluate the performance of the girders at various locations throughout the structure. Nakamura concluded that the system behaved like a traditional composite beam along much of the structure length and displayed the structural advantages common to box type members. The structure was found to behave like a prestressed concrete beam at negative bending locations. The study concluded that although the design was unconventional and required additional materials, the overall design was economical. This conclusion was based on the overall reduction in fabrication costs that often exceed material costs in bridge construction.

\subsubsection{Folded Plate Girders (Developed at the University of Nebraska)}

Research conducted at the University of Nebraska evaluated the use of an inverted coldbent steel girder, see Figure 2.3. The justifications for this approach are varied, but were reported to include: safer means of construction, ease in maintenance, and greater accessibility for bridge inspection. Glaser (2010) studied the construction phase of the inverted steel tub girder and found it responded appropriately with little concern for excessive deformations. Burner (2010) subjected the composite structure to fatigue testing and found it to be capable of withstanding a 75-year life cycle.

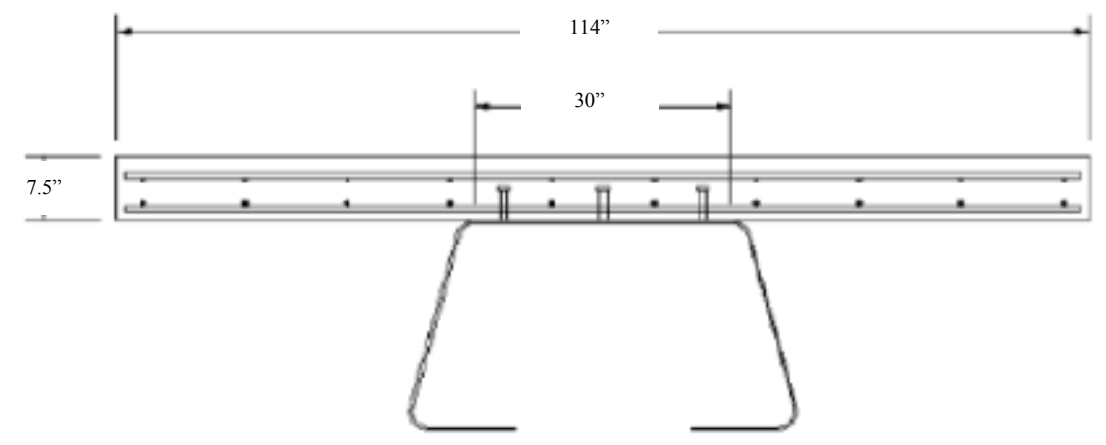

Figure 2.3: System Proposed at the University of Nebraska (Burner, 2010) 


\subsubsection{Texas Department of Transportation Rapid Economical Bridge Replacement}

The Texas Department of Transportation (TxDOT) replaced the FM 3267 as part of a "multi-year corridor improvement" of I-35 using light-weight, shallow trapezoidal steel box girders (Chandar et al., 2010). The structure is composed of four, independent spans 45'-0", 100'0 ", 100 '- 0 ", and $65^{\prime}-0$ ". The tub girders are so light, that they are each individually supported by columns rather than constructing full substructure units. Accelerated bridge construction (ABC) was implemented reducing the time and cost of the project. The tub girders used in this application were composed of welded steel plates and constructed in a similar fashion to traditional steel box girder members. They were not cold brake formed. See Figures 2.4 and 2.5 for typical sections of the structure and individual girder.

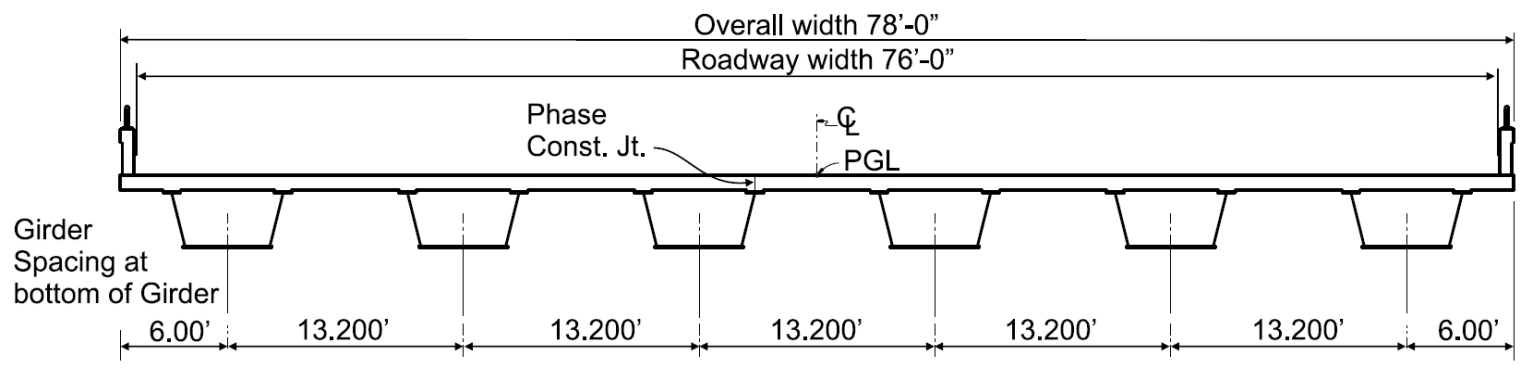

Figure 2.4: Typical Section, Bridge FM 3267(Chandar et al., 2010)

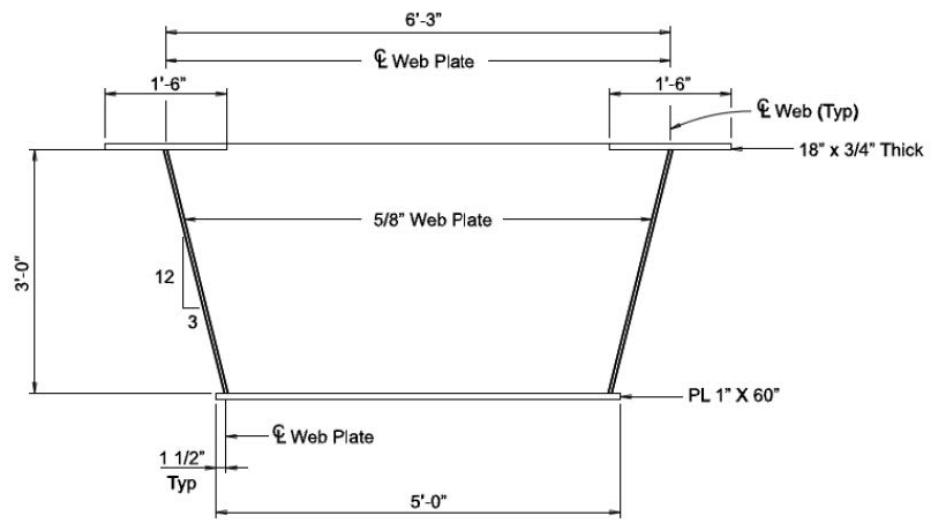

Figure 2.5: Typical TxDOT Steel Tub Girder Section, Bridge FM 3267 (Chandar et al., 2010) 


\subsection{Previous Research at WVU on Press-Brake-Formed Steel Tub Girders}

The body of research concerning press-brake-formed steel tub girders at West Virginia University began in October 2011. In conjunction with the Short Span Steel Bridge Alliance (SSSBA), West Virginia University researchers worked to develop the press-brake-formed steel tub girders that are used in this study and previous studies. The following section details the research, to date, that has been conducted at West Virginia University in this area.

\subsubsection{Development and Feasibility Assessment of Shallow Press-Brake-Formed Steel Tub Girders} for Short-Span Bridge Applications (Michaelson 2014)

The goals of the SSSBA are similar to the ones of the studies presented in Section 2.2. The group desired a system that could be predominately prefabricated, easily transported and assembled, and result in reduction of overall cost of construction for small span structures using steel as the primary superstructure material. Michaelson (2014) in collaboration with Barth and Baker (Barth et al., 2015), developed a solution to this demand by generating general specifications and analysis for steel press-brake-formed tub girders.

This work included the optimization of girder section properties (Michaelson 2014). First, standard variables were established for girder properties, including: web slope, interior bend radii, and top flange width. An analysis was conducted using standard plate thicknesses (7/16", 1/2", and 5/8") and standard widths (60", 72", 84", 96", 108", 120") to develop a set of functional girders

to consider for analysis by varying the girder depth. This was an iterative process that was completed using Microsoft Excel and MATLAB applications. Optimum designs were determined by comparing the girder depth to the yield moment, see Figure 2.6. 


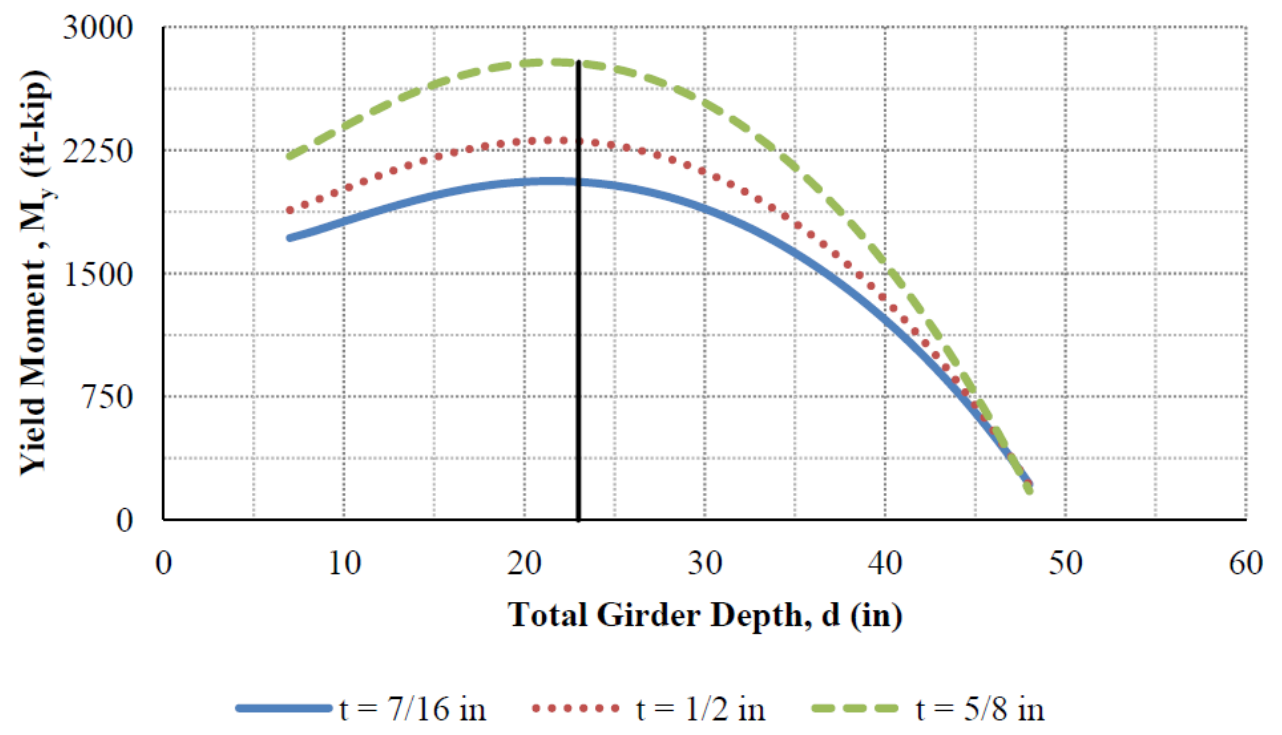

Figure 2.6: Design Comparison of 84” Wide Standard Mill Plate (Michaelson, 2014)

Following this numerical analysis, a series of flexural tests were conducted on both noncomposite and composite samples, see Figures 2.7 and 2.8. The girders were constructed out of 84 " $x$ 7/16" thick plate. The specimens were 35 '-0" long and placed in a simply supported bearing condition for physical testing. Two of the samples were tested in the non-composite condition, this simulated the condition prior to deck placement. The conclusions of the analysis were that the girders were highly susceptible to failure due to excessive lateral deflection and twist under relatively small applied loads, see Figure 2.9. It was determined that additional bracing would be required to ensure stability of the girders during deck casting. 


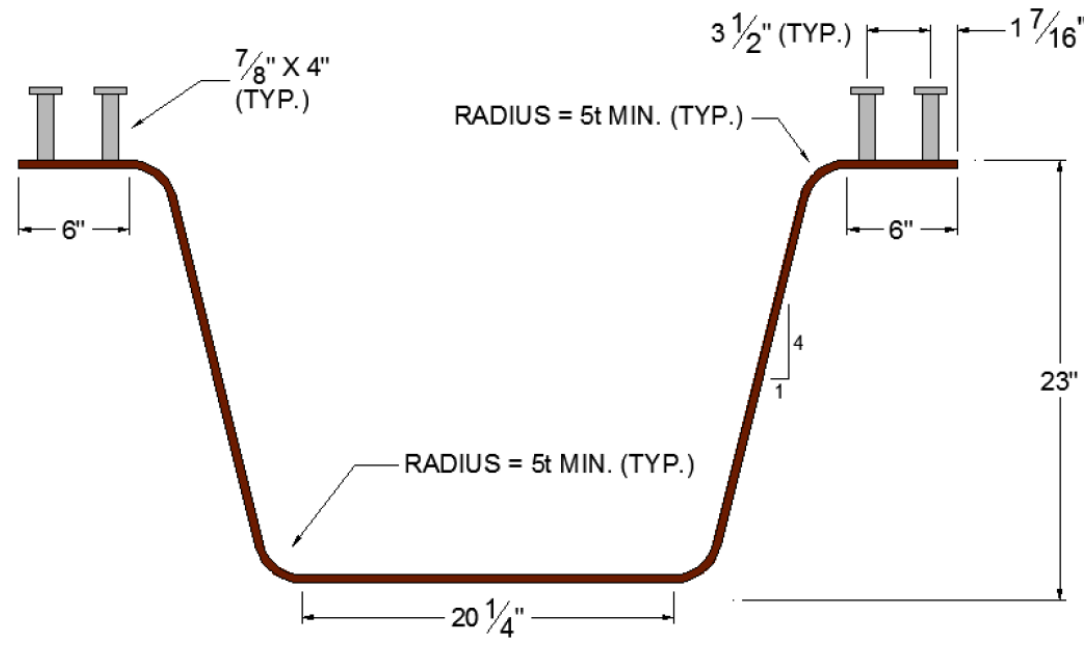

Figure 2.7: Typical Section, Non-Composite Test Specimen (Michaelson, 2014)

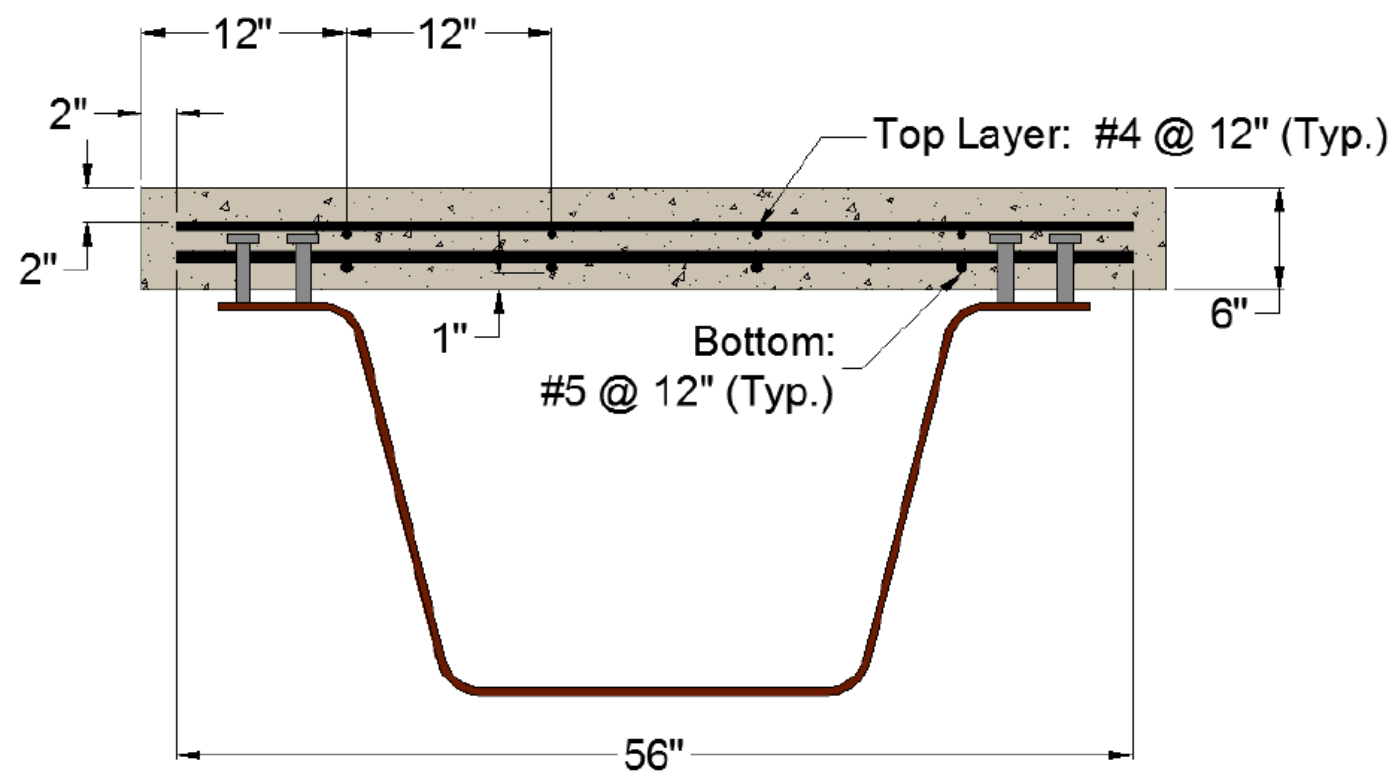

Figure 2.8: Typical Section, Composite Test Specimen (Michaelson, 2014) 


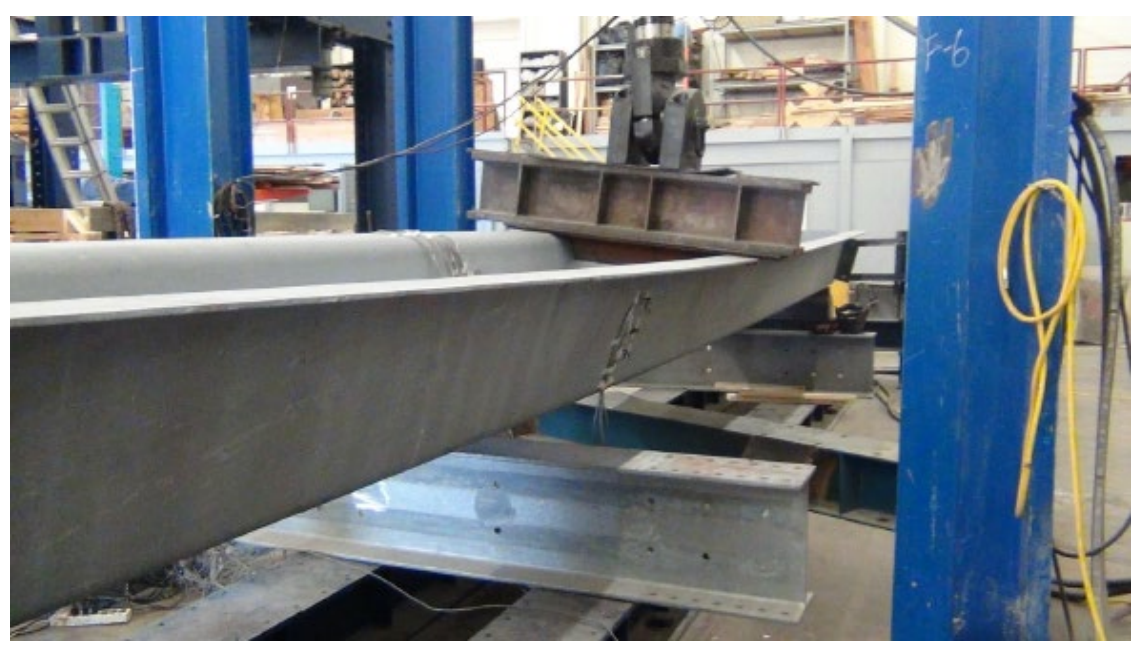

Figure 2.9: Typical Failure of Non-Composite Girder Section (Michaelson, 2014)

Flexural testing of composite sections was also conducted. The composite sections were composed of the same steel girder type, in addition to a 6 " cast-in place reinforced concrete deck with AASHTO minimum reinforcement, see Figure 2.8. A smaller deck thickness than the AASHTO required 8" was used to ensure the specimen could be tested to failure. The composite girders were loaded to failure at approximately 304 kips, with a total vertical deflection of 3.1". The members experienced ductile failure at this limit, see Figure 2.10.

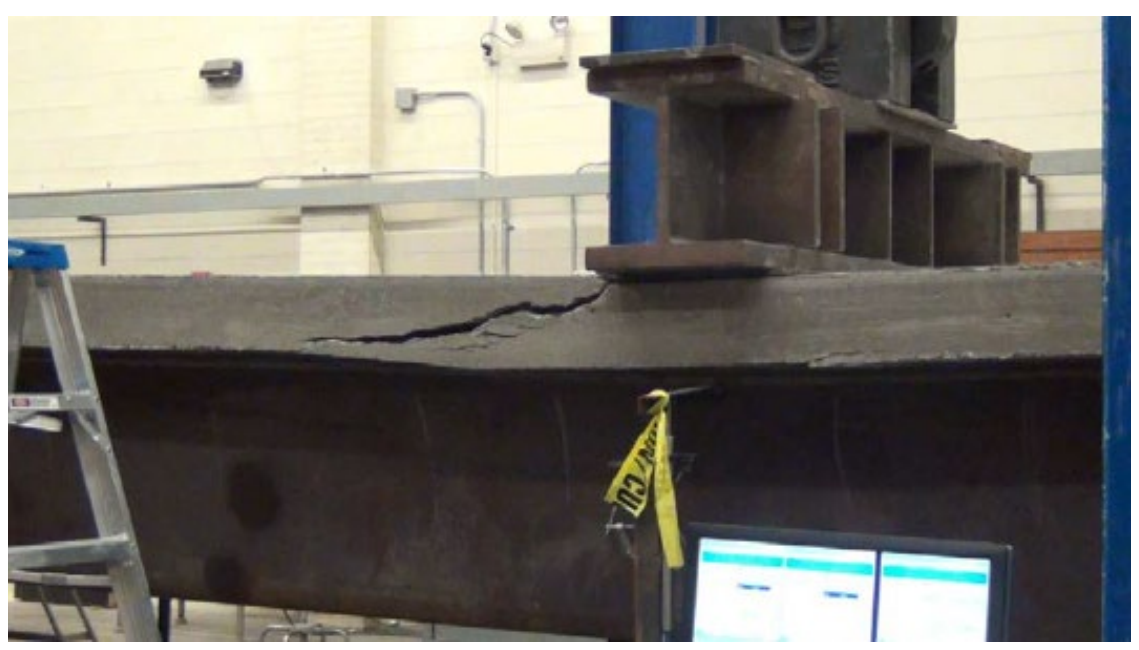

Figure 2.10: Typical Failure of Composite Girder Section (Michaelson, 2014) 
In addition to laboratory assessment, Michaelson developed finite element analysis models of the testing to compare with the results of the experimental data. Strain data was used to assess the overall capacity of the girder sections in both the non-composite and composite states. These studies ultimately led to a review of the applicability of AASHTO Load Resistance Factor Design (LRFD) standards to press-brake-formed tub girders. It was determined that the specifications were conservative for the computation of the nominal capacity of the section given the laboratory data and finite element analysis. Michaelson proposed the following expression, simplified from the AASHTO LRFD Specifications (2014).

$$
M_{n}=\left\{\begin{array}{lr}
M_{p} & D_{p} \leq 0.1 D_{p} \\
M_{p}\left(1.025-0.25 \frac{D_{p}}{D_{t}}\right) & 0.1 D_{t} \leq D_{p} \leq 0.42 D_{t}
\end{array}\right.
$$

Michaelson, further, evaluated the economy and constructability of these bridge systems. A variety of girder sizes, composed of different plate thicknesses and lengths, were analyzed in this study. The conclusions of this analysis were that common plate widths are 72", 96", and 120" plate. More importantly, however, the tub girder systems employing 120 " x $5 / 8$ " plate were determined to be the highest performing, working in up to $80^{\prime}-0$ " applications. Their competitiveness on the market, however, was limited to $60^{\prime}-0$ " span lengths or less.

\subsubsection{Experimental Evaluation of Non-Composite Shallow Press-Brake-Formed Steel Tub Girders} (Kelly, 2014)

Working with Barth and Michaelson, Kelly (2014) conducted tests to assess the torsional stability and response of non-composite press-brake-formed steel tub girders. This study was completed to ensure press-brake-formed tub girders of this type could withstand the construction loads required for use of a cast-in-place concrete deck. This was an essential study because, despite the desire of the SSSBA to use these girders as components of modular units, the ability to understand the noncomposite behavior and subsequent stability requirements is critical. Kelly 
subjected two non-composite sections to flexural testing to understand the girders' buckling capacity and structural behavior, see Figure 2.11 .

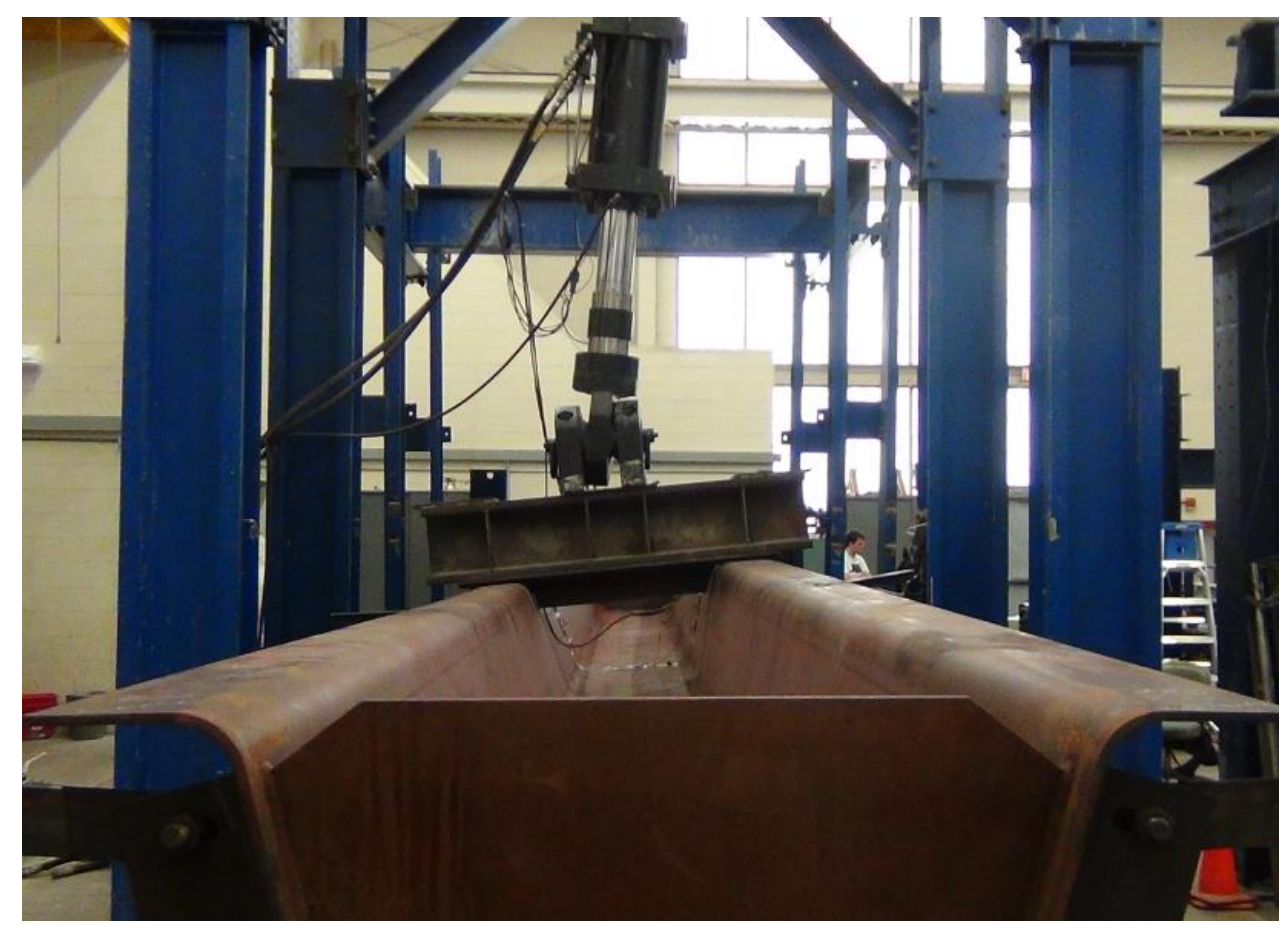

Figure 2.11: System Lateral Torsional Buckling of Tub Girder Steel Specimen (Kelly, 2014)

In addition to laboratory analysis, Kelly (2014) conducted finite element analysis for comparison with experimental results. This analysis was used to analyze potential bracing options for the girder systems that addressed the lack of torsional stiffness in the system. The first-order analysis conducted using finite element analysis determined that the torsional buckling capacity of the girder was determined to be around 10,600 k*in with an approximate load of 92 kips applied at mid-span. Laboratory testing of one of the girders was consistent with these results. The second specimen contained noticeable geometric imperfections and testing indicated significant susceptibility to second-order effects from member imperfections. 


\subsubsection{Evaluation of Modular Press-Brake-Formed Tub Girders with UHPC Joints (Kozhokin,}

2016)

Kozhokin (2016) analyzed the efficacy of the press-brake-formed tub girder in a modular system application. Two modular girder systems were assembled and connected with an ultrahigh-performance concrete joint (UHPC). This testing served two purposes: one, it tested the capability of the UHPC joint in this application given its infancy in application as a modular bridge joint and two, it tested the applicability of press-brake-formed tub girders as modular bridge units. The researchers worked with Dr. Benjamin (Ben) Graybeal of the Federal Highway Administration (FHWA) to ascertain the ideal joint configuration and material specifications that would be ideal for this application based on his previous UHPC research (Graybeal et. al., s2012). A trapezoidal shear key design, Figure 2.12, was determined for the system. This required the decks on each of the modular units to have exposed aggregate faces and extruding rebar for appropriate bonding of the shear key to the separate units. Methods were investigated to determine the ideal method for exposing the aggregate face. Once the joint had cured, a concrete deck was cast and cured over the entire system.

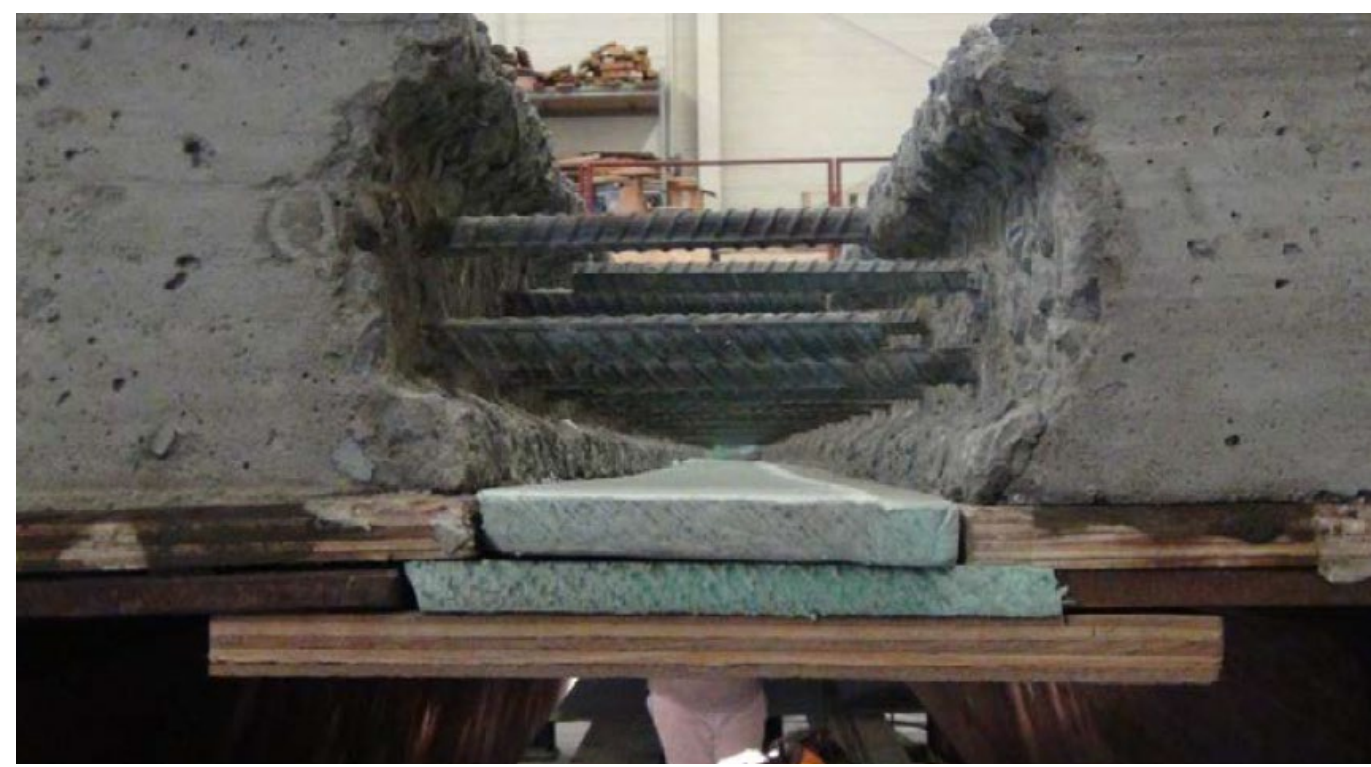

Figure 2.12: Trapezoidal Shear Key Prior to UHPC Pour, Note Exposed Rebar and Aggregate (Kozhokin, 2016) 
Load was applied along the centerline at the midspan of one of the girders. The applied fatigue load was determined to induce the Fatigue I moment in three-point bending in the test specimen. The modular system was cyclically loaded using a 67.93 kip Fatigue I load for over 2.7 million cycles, the number of cycles required to simulate infinite fatigue life, to determine the load distribution within the system. In addition to this fatigue load, the required Service II load was applied at ten different intervals throughout the duration of the study for thorough structural analysis. The concrete deck failed a little over halfway through the study. The load was shifted to the other girder in the modular system for the remainder of the analysis. The joint connecting the systems continued to transfer load throughout the duration of the study. The load distribution factors determined from this study are presented in Table 2.1.

Table 2.1: Summary Distribution Factors, Direct Girder Loading (Kozhokin, 2016)

\begin{tabular}{|r|c|c|}
\hline \multicolumn{3}{|c|}{ Average Distribution Factor } \\
\hline $\begin{array}{c}\text { Cycle } \\
\text { Count }\end{array}$ & $\begin{array}{c}\text { Directly Loaded } \\
\text { Girder }\end{array}$ & $\begin{array}{c}\text { Indirectly Loaded } \\
\text { Girder }\end{array}$ \\
\hline 0 & 0.691 & 0.309 \\
\hline 100,000 & 0.631 & 0.369 \\
\hline 250,000 & 0.676 & 0.324 \\
\hline 500,000 & 0.678 & 0.322 \\
\hline $1,000,000$ & 0.690 & 0.310 \\
\hline $1,500,000$ & 0.717 & 0.283 \\
\hline $2,000,000$ & 0.707 & 0.293 \\
\hline $2,100,000$ & 0.708 & 0.292 \\
\hline $2,200,000$ & 0.707 & 0.293 \\
\hline $2,300,000$ & 0.706 & 0.294 \\
\hline $2,500,000$ & 0.711 & 0.289 \\
\hline $2,700,000$ & 0.712 & 0.288 \\
\hline $2,800,000$ & 0.743 & 0.257 \\
\hline & & \\
\hline
\end{tabular}




\subsubsection{Field Performance Assessment of Press-Brake-Formed Steel Tub Girder Superstructures}

(Gibbs, 2017)

Gibbs (2017) analyzed the field performance of the first bridge using press-brake-formed tub girders, Figure 2.13. The structure was constructed in Buchanan County, Iowa. It was field assembled with an 8-1/2" cast in place deck and geosynthetic reinforced soil (GRS) support fill retained by steel sheet piling. The study was conducted by a group of researchers from West Virginia University and Marshall University. The field testing utilized Bridge Diagnostic Incorporated (BDI) instrumentation to measure the strain in the bottom flange of each of the four galvanized tub girders and on four of the eight girder webs. These values were then compared with a finite element model of the structure. This data was used to generate live load distribution factors (LLDFs) for direct comparison. In addition to comparison between the two data sets, experimental and FEA, the study also determined the appropriate LLDFs from the 2014 AASHTO LRFD Specifications. These results were compared with the results of the study. The study concluded the application of AASHTO LLDFs is conservative for composite press-brake-formed tub girder applications. A sample of these results is presented in Figure 2.14.

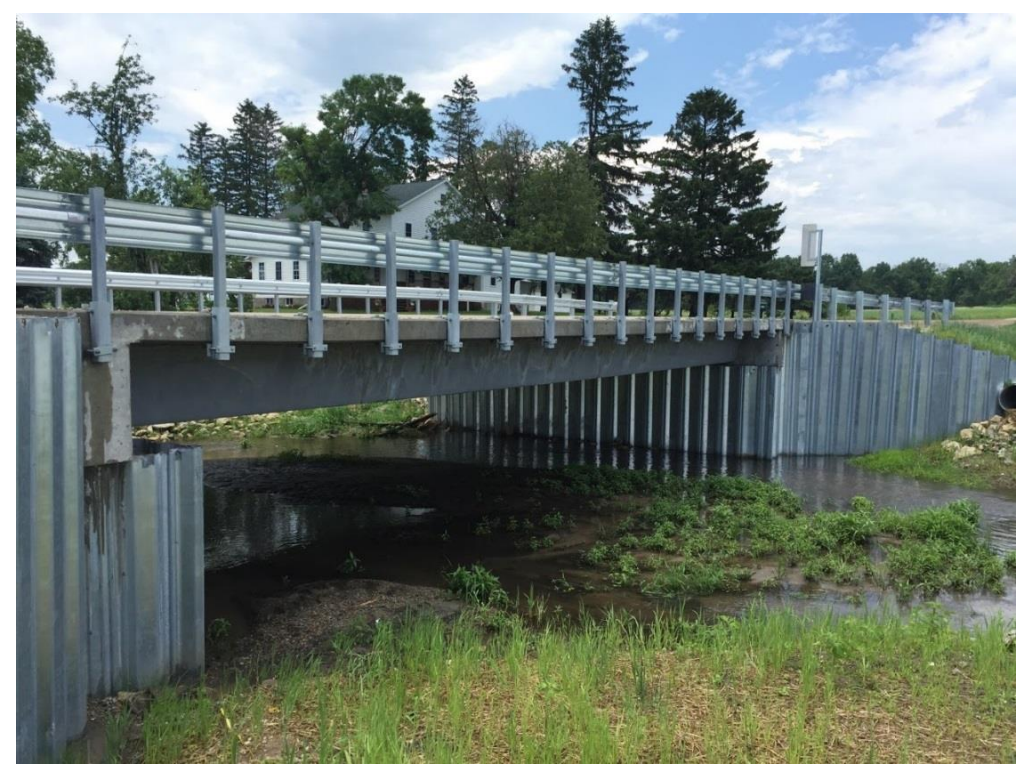

Figure 2.13: New Amish Sawmill Bridge (Gibbs, 2017) 


\section{Truck Run \#2 Average LLDFs}

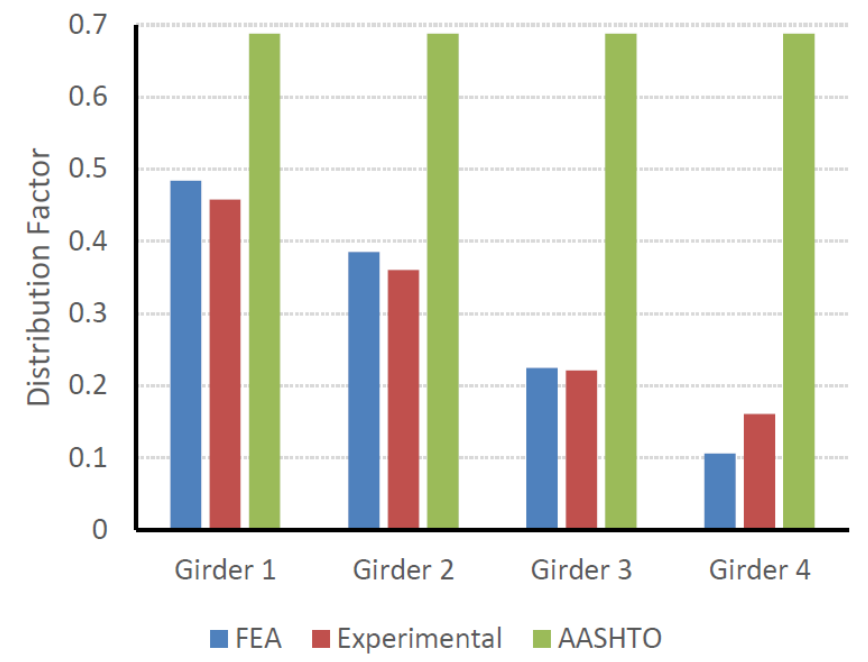

Figure 2.14: FEA v. Experimental v. AASHTO LLDFs (Gibbs, 2017)

\subsubsection{Fatigue Performance of Uncoated and Galvanized Composite Press-Brake-Formed Tub} Girders (Tennant, 2018)

The scope of this study was to analyze the performance of press-brake-formed tub girders with variable steel protective coatings. Concerns had been expressed by industry that the galvanic surface treatment process negatively impacted girder performance. Tennant (2018) studied the fatigue response of two ASTM A709 Grade steel girders, one was uncoated, plain steel and the other was hot-dipped galvanized, see Figures 2.16 and 2.17. Each girder was fatigue loaded over a simulated 75- year fatigue life for a non-interstate rural environment with a Service II moment induced statically throughout the duration of the study at fixed intervals to assess girder performance over the simulated life. The girders were analyzed for rural loading given the general location of short span bridges within the country that are eligible for this kind of replacement. Strain gage and linear variable differential transformer (LVDT) data were collected on each sample for comparison. The theoretical load applied to the girder was compared with experimental loads calculated from strain data to confirm the precision of the testing procedure. 


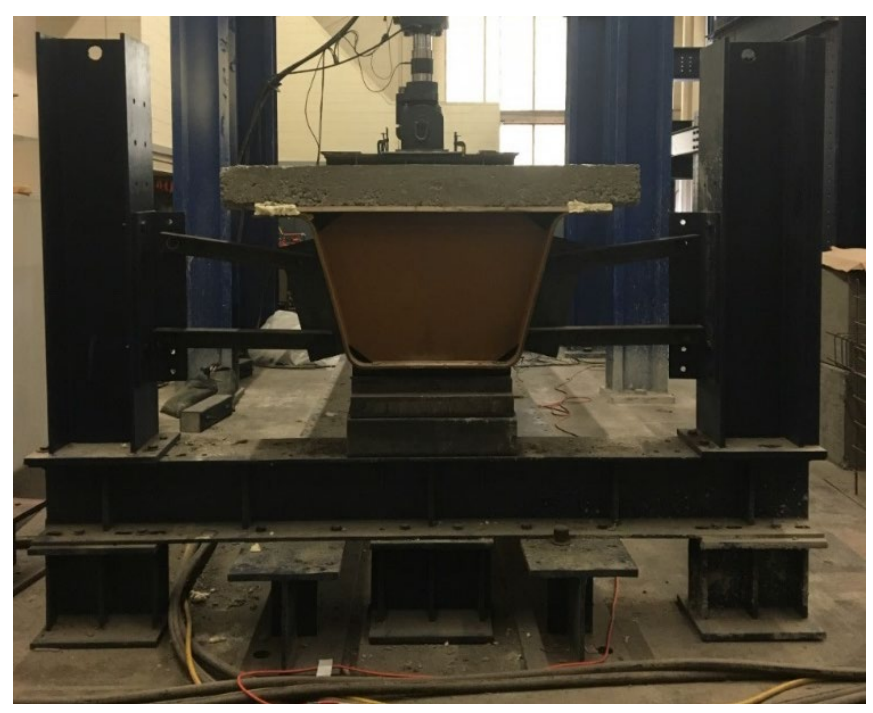

Figure 2.15: Uncoated Steel Girder Fatigue Loaded (Tennant 2018)

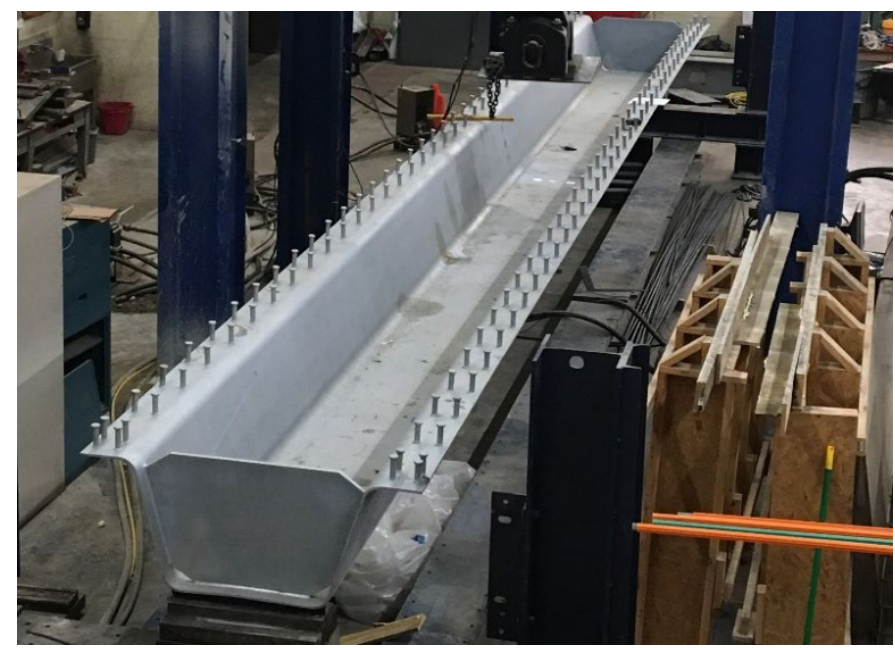

Figure 2.16: Galvanized Coated Tub Girder (Tennant 2018)

Each girder was made composite with a 6" thick cast-in place concrete deck. The deck placed on the galvanized girder had a significantly lower compressive strength than that cast on the uncoated steel girder. The results of the study, however, concluded the galvanizing process did not affect the girder's strength performance. Also, the experimental load applications measured closely matched that of the theoretical calculations. 


\subsection{SANdWich Plate Steel (SPS®) Deck ApPlications (Intelligent Engineering)}

Sandwich plate steel (SPS $\left.{ }^{\circledR}\right)$ deck is a product of Intelligent Engineering Limited. These decks have historically been used in the rehabilitation of boat decks, drill riggs, and other similar maritime structures. Recently, Intelligent Engineering has been expanding the application of SPS ${ }^{\circledR}$ into the bridge industry, using the product in both rehabilitation and new construction projects.

SPS ${ }^{\circledR}$ is a lightweight material composed of two variable thickness steel plates bound together by a polyurethane elastomer core, see Figure 2.17 . The average bond strength between the elastomer and steel plates is greater than 1160 psi. The advantages of using SPS $®$, cited by Intelligent Engineering (Intelligent Engineering), include: the material is lighter than traditional cast-in place concrete decks, the construction time is significantly less than competing deck systems, and it is accepted throughout the industry as an acceptable material for various applications. Additionally, SPS ${ }^{\circledR}$ provides certain advantages for rehabilitation and sustainability of both the deck and bridge superstructure. Lastly, the installation of SPS ${ }^{\circledR}$ decks on modular units is simple and cost effective. In application at the Cannelville Road Bridge, the two steel plates that composed the SPS ${ }^{\circledR}$ unit were 3/8" thick and hot-dipped galvanized. A proper bond was developed between the polyurethane elastomer layer and the steel plates. To support accelerated bridge construction, the deck was designed so separate modular units could be connected for load transfer using exterior stiffener plate connections.

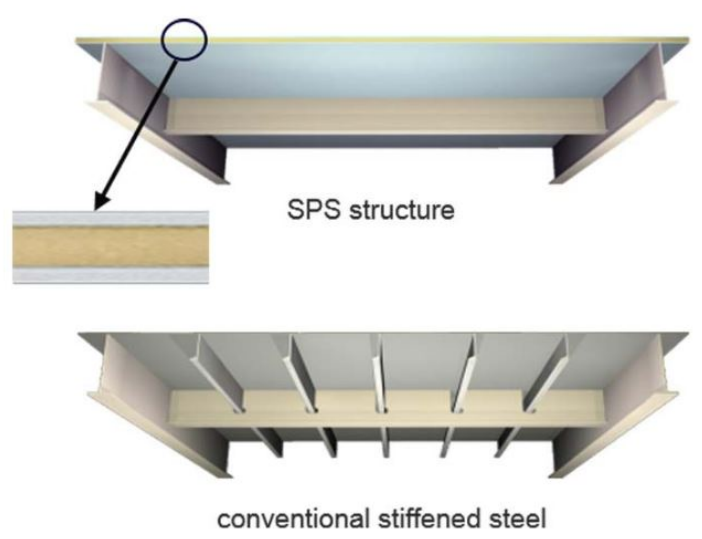

Figure 2.17: Intelligent Engineering Sandwich Plate Steel (SPS®) Deck (Intelligent Engineering) 


\subsection{FHWA's Accelerated Innovation Deployment Demonstration Program (AID DEMO)}

The Federal Highway Administration (FHWA) created the Accelerated Innovation Deployment Demonstration (AID Demo) Program to grant funding to innovative highway projects that meet a set of requirements. The program is a product of the Technology Innovation Deployment Program (TIDP) created under the Fixing America's Surface Transportation (FAST) Act of 2015. Projects are awarded funds to supplement the cost of the innovation being included in the design project in an amount up to one million dollars. Participants agree to an eighty percent federal share, with local participants shouldering twenty percent of the innovation cost.

Agencies eligible for AID Demo funding include state departments of transportation (DOTs), federal land management agencies, and tribal governments. Local governments and municipalities are only able to apply through the state DOT as a "subrecipient". For a project to qualify for grant funding the following must be applicable. One, the subject is eligible for assistance under Title 23, the United States Code relating to highways. Two, the project should be ready to start within 12 months of applying for funding. Third, all phases of project development should occur within the limits of the grant funds. Fourth and finally, the project should include at least one uncommon, proven highway innovation. These criteria had to be met for use of this grant money for construction of the Cannelville Road Bridge. The structure is composed of modular beams containing two non-traditional superstructure materials, steel press-brake-formed tub girders and a SPS ${ }^{\circ}$ deck. The structure was built using accelerated bridge construction (ABC) methods. 


\subsection{Current AASHTO Specifications for Tub Girder Design ANd APPLiCATion}

AASHTO publishes a variety of guides for designing and analyzing bridges within the United States and its territories. For the purposes of this study, the AASHTO LRFD Bridge Design Specifications published in 2017 were used to analyze the Cannelville Road Bridge. In the current specifications, the multiple presence factor is discussed in Section 3.6.1.1.2, live load distribution factors (LLDFs) for beam slab bridges are covered in Section 4.6.2.2, and specifications for design of box-section girders, including tubs, are included in Section 6.11. This section summarizes the current specifications governing the design of steel tub girders and the appropriate application of live load for analysis.

\subsubsection{Multiple Presence Factor, Section 3.6.1.1.2 (AASHTO, 2017)}

The multiple presence factor is an empirical value developed to account for the possibility of multiple vehicles loading a structure simultaneously. These values were determined assuming an average daily truck traffic (ADTT) of 5,000 trucks in a single direction and were calculated through a series of empirical tests. Table 2.2 contains the multiple presence factors that should be applied to any load distribution calculations that are not completed in accordance with Sections 4.6.2.2 and 4.6.2.3 of the specifications. These calculations already include the multiple presence factors (MPFs) provided by AASHTO. Per AASHTO regulations, the number of loaded lanes is equivalent to the number of twelve-foot-wide lanes possible on a structure. A smaller lane width may be specified within the plan set if desired by the engineer. Note, that regardless of the number of lanes loaded, no MPFs are applied for fatigue loading scenarios.

Table 2.2: Multiple Presence Factors, Section 3.6.1.1.2 (AASHTO, 2017)

\begin{tabular}{|c|c|}
\hline Number of Loaded Lanes & $\begin{array}{c}\text { Multiple Presence } \\
\text { Factors, } m\end{array}$ \\
\hline 1 & 1.20 \\
\hline 2 & 1.00 \\
\hline 3 & 0.85 \\
\hline$>3$ & 0.65 \\
\hline
\end{tabular}


To apply the LLDF calculations specified in this section, the bridge being analyzed must meet certain geometric requirements provided within the section. For box girder bridges, the criteria in Section 4.6.2.2.1 directs the user to Section 6.11.2.3 for geometric restrictions that must be met for the use of live load distribution factors presented in Section 4.6.2.2.b. The criteria include: bearing lines may not be skewed, center to center distance of flanges is between 80 and 120 percent of the distance center to center of a single girder's top flanges, the web slope may not be greater than 1:4, and the cantilever deck overhang may not be greater than 60 percent of the center to center distance between girder flanges or 6'-0". See the Figure 2.18 for a schematic of a set of these conditions.

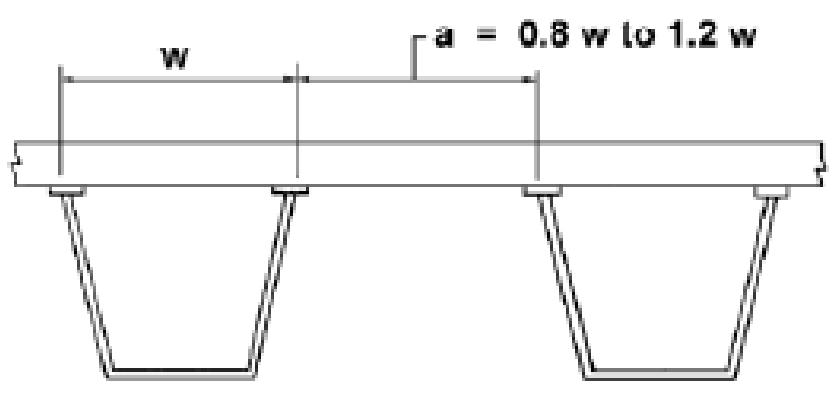

Figure 2.18: Center to Center Flange Distances, Section 6.11.2.3 (AASHTO, 2017)

If the system meets these conditions, the following conditions from Table 4.6.2.2.2b-1 apply to the system for calculation of the interior live load distribution factors. Table 4.6.2.2.2d-1 further specifies that the criteria for interior LLDFs applies for the calculation of exterior girder LLDFs. Equation 2-1 is used for determination of LLDFs for multiple box girder systems.

$$
\begin{aligned}
L L D F_{I N T} & =0.05+0.85\left(\frac{N_{L}}{N_{b}}\right)+\frac{0.425}{N_{L}} \\
\text { where: } 0.5 & \leq \frac{N_{L}}{N_{b}} \leq 1.5 \\
\mathrm{~N}_{\mathrm{L}} & =\text { number of design lanes } \\
\mathrm{N}_{\mathrm{b}} & =\text { number of girders }
\end{aligned}
$$


This section reviews the current specifications for the design of box-section flexural members. Section 6.11 relates to the flexure of straight or curved steel box girder sections.

\subsubsection{Cross Section Proportion Limits, Section 6.11.2 (AASHTO, 2017)}

Box girder webs are permitted to be inclined up to 4:1. Distance along the web should be checked where webs are angled. Webs must also meet the following criteria:

Webs without longitudinal stiffeners:

$$
\frac{D}{t_{w}} \leq 150
$$

Equation 2-2

Webs with longitudinal stiffeners:

$$
\begin{aligned}
& \frac{D}{t_{w}} \leq 300 \\
& \text { Where: } \mathrm{D}=\text { web depth (in) } \\
& \qquad \mathrm{t}_{\mathrm{w}}=\text { web thickness (in) }
\end{aligned}
$$

The top flange must meet the following criteria, whether subjected to tension or compression:

$$
\begin{array}{ll}
\frac{b_{f}}{2 t_{f}} \leq 12.0 & \text { Equation 2-4 } \\
b_{f} \leq D / 6 & \text { Equation 2-5 } \\
t_{f} \geq 1.1 t_{w} & \text { Equation 2-6 } \\
\text { Where: } \quad \mathrm{tf}_{\mathrm{f}}=\text { flange thickness (in) } & \\
\qquad \mathrm{b}_{\mathrm{f}}=\text { flange width (in) } & \\
\mathrm{D} & =\text { web depth, measured along the slope (in) }
\end{array}
$$




\subsubsection{Constructability, Section 6.11.3 (AASHTO, 2017)}

During construction, tub girders must meet the following flexural and shear requirements. In addition to these requirements, individual girder geometry should be maintained during all stages of construction. Bracing, either temporary or permanent, may be used to control deformations in the section. Where exceptions are not specified within the section, the provisions of Article 6.10.3 for the constructability of I-girder sections apply. Load factors for construction loads at applicable limit states are determined in reference to Article 3.4.2.

The following are the governing specifications for flexure during critical construction stages. The unbraced length of the girder is the distance between interior bracing for all calculations. The flexural criteria for tub girder sections are as follows:

Top flanges of tub girder section must meet the following conditions during construction per Articles 6.10.3.2.1 through 6.10.3.2.3. These conditions cannot be applied to bottom flanges of tub girder sections.

Discretely braced flanges in compression:

$$
\begin{aligned}
& f_{b u}+f_{l} \leq \varphi_{f} R_{h} F_{y c} \\
& f_{b u}+\frac{1}{3} f_{l} \leq \varphi_{f} F_{n c} \\
& f_{b u} \leq \varphi_{f} F_{c r w}
\end{aligned}
$$

Where: $\varphi_{f}=$ flexure resistance factor provided in Article 6.5.4.2 $=1.00$

$f_{b u}=$ longitudinal flange stress due to factored loads with no consideration of longitudinal warping (ksi)

$\mathrm{fl}=$ lateral bending flange stress determined in accordance with Article 6.10.1.6 (ksi) 
$\mathrm{F}_{\mathrm{crw}}=$ nominal web bend-buckling resistance determined in reference to Article

$$
\text { 6.10.1.9 (ksi) }
$$

$\mathrm{F}_{\mathrm{nc}}=$ nominal flexural resistance of box flanges in compression calculated referencing Article 6.11.8.2 (ksi), where the load shedding factor, $\mathrm{R}_{\mathrm{b}}=1.0$ for construction conditions

$\mathrm{R}_{\mathrm{h}}=$ hybrid factor as specified in Article 6.10.1.10.1., where fbu does not exceed the yield strength, $\mathrm{R}_{\mathrm{h}}=1.0$

Discretely braced flanges in tension:

$f_{b u}+f_{l} \leq \varphi_{f} R_{h} F_{y t}$

Equation 2-10

Continuously braced flanges in tension or compression:

$f_{b u} \leq \varphi_{f} R_{h} F_{y f}$

Equation 2-11

In addition to the conditions of Article 6.10.3, noncomposite flanges of tub girders must meet the following conditions during construction per Article 6.11.3.2.

Flanges in compression:

$f_{b u} \leq \varphi_{f} F_{n c}$

Equation 2-12

$f_{b u} \leq \varphi_{f} F_{c r w}$

Equation 2-13

Flanges in tension or continuously braced flanges in tension or compression:

$f_{b u} \leq \varphi_{f} R_{h} F_{y f} \Delta$

Equation 2-14 
Where: $\Delta=\sqrt{1-3\left(\frac{f_{v}}{F_{y f}}\right)^{2}}$

$f_{v}=\frac{T}{2 A_{o} t_{f}}$

Equation 2-16

$F_{\mathrm{v}}=$ St. Venant torsional shear stress in the flange due to factored loads at the section under consideration (ksi)

$\mathrm{A}_{\mathrm{o}}=$ enclosed are of box section $\left(\mathrm{in}^{2}\right)$

$\mathrm{R}_{\mathrm{h}}=$ hybrid factor determined as specified in Article 6.10.1.10.1

$\mathrm{T}=$ internal torque due to factored load applied (kip*in)

The following are the governing specifications for shear during critical construction stages. Sections must meet the following requirements from Article 6.10.3.3 in addition to the requirements of Article 6.11.9, where they apply. Webs of box girder sections must satisfy the following:

$$
\begin{gathered}
V_{u} \leq \varphi_{v} V_{c r} \\
V_{u i} \leq \frac{V_{u}}{\cos (\Theta)}
\end{gathered}
$$

Where: $\varphi_{v}=$ shear resistance factor provided in Article 6.5.4.2 $=1.00$

$\mathrm{V}_{\mathrm{u}}=$ shear in the web due to the factored permanent and construction loads applied to the noncomposite section (kip)

$\mathrm{V}_{\mathrm{cr}}=$ shear-yielding or shear buckling resistance per Article 6.10.9.3.3

$\mathrm{V}_{\text {ui }}=$ vertical shear due to the factored loads on one inclined web

$\Theta=$ angle of inclination of the web plate to the vertical (degrees) 


\subsubsection{Service Limit State, Section 6.11.4 (AASHTO, 2017)}

The service limit state controls the deformation of the structure and ensures its functionality for the duration of use. Tub girder sections must meet the requirements of Article 6.10 .4 with the following exceptions specified in Article 6.11.4. The flange lateral bending stress ( $\mathrm{f}_{\mathrm{l}}$ ) shall be taken as equal to zero in Equation 2-20. Equation 2-21 does not apply for box girder sections. Flexure should be analyzed in accordance with Section 6.11.2.1.2 where applicable. The Service II load combination, detailed in Article 3.4.1, should be applied for systems of this type.

The following are the governing specifications for elastic deformations. Short term section properties are used for all calculations. The suggested load application is the largest of the following the design truck plus impact or $25 \%$ of the design truck plus impact including the design load lane. Further, it is assumed that the applied loads are distributed uniformly, and the system deflects equally throughout. Systems must meet the following requirements from Article 2.5.2.6.2:

General vehicular load deformation limit $=\mathrm{L} / 800$

Vehicular load deformation limit for cantilever arms $=\mathrm{L} / 300$

The following are the governing specifications for permanent deformations. There are currently no provisions for the use of sandwich-plate-steel (SPS ${ }^{\circledR}$ ) deck composite girder systems. For the purpose of analysis and design, it is assumed behavior is similar to a concrete deck composite girder system with sufficient shear connectors. The following specifications apply per Article 6.10.4.2.

Flexure:

Top steel flange, composite sections

$$
f_{f} \leq 0.95 R_{h} F_{y f}
$$


Bottom steel flange, composite sections

$$
f_{f}+\frac{f_{l}}{2} \leq 0.95 R_{h} F_{y f}
$$

Both steel flanges, noncomposite sections

$$
f_{f}+\frac{f_{l}}{2} \leq 0.80 R_{h} F_{y f}
$$

Where: $f_{f}=$ flange stress at the section considered due to the Service II loads calculated, without consideration of lateral flange bending ( $\mathrm{fi})(\mathrm{ksi})$ $\mathrm{f}_{\mathrm{l}}=$ flange lateral bending stress due to Service II loads $=0$ (Article 6.11.4) $\mathrm{R}_{\mathrm{h}}=$ hybrid factor determined per Article 6.10.2.10.1

In addition to the requirements for bottom and top flange stress, the web of the composite section should be evaluated for buckling to prevent excessive deck deflection and reduce potential for rupture. Except for sections in positive flexure with webs that meet the requirements of Article 6.11.2.1.2, webs must meet the following criteria:

$$
f_{c} \leq F_{c r w}
$$

Where: $f_{c}=$ compression flange stress at the section considered due to the Service II loads calculated, without consideration of lateral flange bending $\left(\mathrm{f}_{\mathrm{l}}\right)(\mathrm{ksi})$ $F_{\text {crw }}=$ nominal bend-buckling resistance for webs with or without longitudinal stiffeners per Article 6.10.1.9 (ksi) 


\subsubsection{Fatigue and Fracture Limit State, Article 6.11.5 (AASHTO 2017)}

The fatigue and fracture limit state controls the live load stress range due to cyclic loading experienced by structures. The fatigue standards are intended to limit the development and growth of cracks in steel members. The fracture limit state reduces the potential for fracture of steel members. Tub girder sections must meet the requirements of Article 6.10 .5 with the following exceptions specified in Article 6.11.5. Longitudinal warping should be considered for crosssections of the following type: single box sections in straight or curved bridges, multiple box sections in straight bridges that do not meet the requirements of 6.11.2.3, multiple box section in horizontally curved structures, or single or multiple box section with a box flange that is not fully effective according to Article 6.11.1.1.

Fatigue is induced by either loading of the member or inherent distortion in member geometry. The Fatigue I and Fatigue II load factors, specified in Article 3.4.1, should be considered based on the fatigue life of the system. Fatigue I load factors apply for systems with infinite fatigue life, and Fatigue II load factors apply for systems with finite fatigue life. The long term composite section properties should be used for consideration of dead loads, and the short term composite section for live load application. The following provisions should be applied for fatigue according to Article 6.6.1:

Load Induced Fatigue:

$$
\gamma(\Delta f) \leq(\Delta F)_{n}
$$

Where: $\gamma=$ load factor specified in Article 3.4.1 for the applicable fatigue load combination $\Delta \mathrm{f}=$ force effect, live load stress range due to the fatigue load applied per Article 3.6.1.4

$\Delta \mathrm{F}_{\mathrm{n}}=$ nominal fatigue resistance per Article 6.6.1.2.5 
Fatigue I Load Combination nominal fatigue resistance:

$$
(\Delta F)_{n}=(\Delta F)_{T H}
$$

Fatigue II Load Combination nominal fatigue resistance:

$$
\begin{aligned}
& (\Delta F)_{n}=\left(\frac{A}{N}\right)^{\frac{1}{3}} \\
& N=(365)(75) n(A D T T)_{S L}
\end{aligned}
$$$$
\text { Equation 2-25 }
$$

\author{
Where: $\mathrm{A}=$ constant from Table 6.6.1.2.5-1 $(\mathrm{ksi})^{3}$ relating to fatigue detail type \\ specified in Table 6.6.1.2.3-1 \\ $\mathrm{N}=$ number of stress range cycler per truck passage, from \\ Table 6.6.1.2.5-2 \\ $(\mathrm{ADDT})_{\mathrm{SL}}=$ single-lane ADTT per Article 3.6.1.4 \\ $(\Delta \mathrm{F})_{\mathrm{TH}}=$ constant-amplitude fatigue threshold, from Table 6.6.1.2.5-3
}

Distortion Induced Fatigue:

Load paths should be established within steel systems to account for intended and unintended loads. Specifically, transverse connections should be made using appropriately sized members to individual longitudinal members of the system using either welding or bolted connections. Rigid load paths should be provided to resist the load conditions within the system, including provisions for distortion of members. Where the load is unknown or cannot be determined, members should be designed to withstand a minimum, nominal lateral load of 20.0 kip per Article 6.6.1.3.1. 
Fracture requirements vary depending on the member designations provided in Table 6.6.2.1-1. Primary members, members whose failure would result in structural failure, and members subjected to net tensile stress due to the application of the Strength I Load Combination are subject to Charpy V-Notch testing requirements. These requirements must be noted on all design plans for primary members.

\subsubsection{5 $\underline{\text { Strength Limit State, Articles 6.11.6 - 6.11.9 (AASHTO 2017) }}$}

The strength limit state ensures the structure has sufficient strength to withstand the loads applied throughout the life of the structure. The following sections outline the requirements for steel tub girder bridges for the Strength Limit State. All applicable strength load combinations presented in Article 3.4.1 should be investigated for the strength limit state.

\subsection{General Flexure Requirements, Article 6.11.6.2 (AASHTO 2017)}

Sections in straight bridges must meet the following requirements to be considered compact sections.

- Maximum flange yield strength, $70 \mathrm{ksi}$

- Web satisfies the requirements of Article 6.11.2.1.2, presented in Section 2.6.3.1 of this report

- The section meets the requirements for Article 6.11.2.3

- The box flange is fully effective per Article 6.11.1.1

- The section meets the following web slenderness limit

$$
\frac{2 D_{c p}}{t_{w}} \leq 3.76 \sqrt{\frac{E}{F_{y c}}}
$$

Where: $D_{\mathrm{cp}}=$ depth of the web in compression at the plastic moment determined as specified in Article D6.3.2 (in) 


$$
\begin{aligned}
& t_{w}=\text { web thickness (in) } \\
& E=\text { modulus of elasticity, steel (ksi) } \\
& F_{y c}=\text { minimum compression strength of compression flange (ksi) }
\end{aligned}
$$

Both compact and noncompact sections must also meet the ductility requirements of Article 6.10.7.3 as follows:

$$
D_{p} \leq 0.42 D_{t}
$$

Equation 2-28

Where: $D_{p}=$ distance from the top of the concrete deck to the neutral axis of the composite section at the plastic moment (in)

$$
D_{t}=\text { total depth of the composite section (in) }
$$

\subsection{Flexural Capacity of Composite Sections, Positive Flexure}

For compact sections, the following should be satisfied at the strength limit state:

$$
M_{u} \leq \varphi_{f} M_{n}
$$

Where: $\varphi_{\mathrm{f}}=$ resistance factor for flexure specified in AASHTO Article 6.5.4.2 $=1.00$

$\mathrm{M}_{\mathrm{u}}=$ bending moment about the major axis of the cross section due to the factored loads at the section under consideration ( $\mathrm{ft}{ }^{*} \mathrm{kip}$ )

$\mathrm{M}_{\mathrm{n}}=$ nominal flexural resistance determined as specified in Article 6.11.7.1.2 
For simple spans, the nominal flexural resistance $\left(\mathrm{M}_{\mathrm{n}}\right)$ is calculated as follows:

Where: $\mathrm{D}_{\mathrm{p}} \leq 0.1 \mathrm{D}_{\mathrm{t}}$

$$
\mathrm{M}_{\mathrm{n}}=\mathrm{M}_{\mathrm{p}}
$$

Equation 2-30

Otherwise: $M_{n}=M_{p}\left(1.07-0.7 \frac{D_{p}}{D_{t}}\right)$

Where: $D_{p}=$ distance from the top of the concrete deck to the neutral axis of the composite section at the plastic moment (in)

$D_{t}=$ total depth of the composite section (in)

$\mathrm{M}_{\mathrm{p}}=$ plastic moment of the composite section, calculated using

Article D6.1 (kip-in)

Michaelson's work found that this calculation of the nominal flexural resistance is conservative for press-brake-formed tub girders (Michaelson 2014). The proposed change to calculating the nominal capacity of simple span sections is presented in Section 2.3.1 of this chapter.

For continuous spans, the nominal flexural resistance $\left(\mathrm{M}_{\mathrm{n}}\right)$ is calculated as follows:

$$
M_{n} \leq 1.3 R_{h} M_{y}
$$

Equation 2-32

Where: $\mathrm{M}_{\mathrm{y}}=$ yield moment determined as specified in Article D6.2 (kip*in)

$$
\mathrm{R}_{\mathrm{h}}=\text { hybrid factor determined as specified in Article 6.10.1.10.1 }
$$

For noncompact sections, the following should be satisfied at the strength limit state:

Compression Flange:

$f_{b u} \leq \varphi_{f} F_{n c}$

Equation 2-33

Where: $\varphi_{\mathrm{f}}=$ resistance factor for flexure specified in AASHTO Article 6.5.4.2 $=1.00$ 
$f_{b u}=$ longitudinal flange stress at the section under consideration with no consideration of the flange lateral bending or longitudinal warping (ksi)

$\mathrm{F}_{\mathrm{nc}}=$ nominal flexural resistance of the compression flange determined as follows for tub

$$
\text { sections }=\mathrm{R}_{b} \mathrm{R}_{h} \mathrm{~F}_{\mathrm{yc}}
$$

Where: $\mathrm{R}_{\mathrm{b}}=$ web load-shedding factor determined as specified in Article 6.10.1.10.2

$$
\begin{aligned}
& \mathrm{R}_{\mathrm{h}}=\text { hybrid factor determined as specified in Article 6.10.1.10.1 } \\
& \mathrm{F}_{\mathrm{yc}}=\text { minimum yield strength of the compression flange }(\mathrm{ksi})
\end{aligned}
$$

Tension Flange:

$f_{b u} \leq \varphi_{f} F_{n t}$

Where: $\varphi_{\mathrm{f}}=$ resistance factor for flexure specified in AASHTO Article 6.5.4.2 $=1.00$ $\mathrm{f}_{\mathrm{bu}}=$ longitudinal flange stress at the section under consideration with no consideration of the flange lateral bending or longitudinal warping (ksi) $F_{n t}=$ nominal flexural resistance of the tension flange determined as follows for tub sections $=\mathrm{R}_{b} \mathrm{R}_{\mathrm{h}} \mathrm{F}_{\mathrm{yt}} \Delta$

Equation 2-36

Where: $\mathrm{R}_{\mathrm{h}}=$ hybrid factor determined as specified in Article 6.10.1.10.1

$$
\begin{aligned}
& \mathrm{F}_{\mathrm{yt}}=\text { minimum yield strength of the tension flange (ksi) } \\
& \Delta=\sqrt{1-3\left(\frac{f_{v}}{F_{y t}}\right)^{2}} \\
& f_{v}=\frac{T}{2 A_{o} t_{f}}
\end{aligned}
$$


$\mathrm{f}_{\mathrm{v}}=$ St. Venant torsional shear stress in the flange due to factored loads at the section under consideration (ksi)

$\mathrm{A}_{\mathrm{o}}=$ enclosed are of box section $\left(\mathrm{in}^{2}\right)$

$\mathrm{T}=$ internal torque due to factored load applied (kip*in)

\subsection{Flexural Capacity of Noncomposite Sections}

For noncompact sections, the following should be satisfied at the strength limit state for compression flanges:

Compression Flange, Unstiffened:

$f_{b u} \leq \varphi_{f} F_{n c}$

Equation 2-39

Where: $\varphi_{\mathrm{f}}=$ resistance factor for flexure specified in AASHTO Article 6.5.4.2 $=1.00$

$f_{b u}=$ longitudinal flange stress at the section under consideration with no consideration of the flange lateral bending or longitudinal warping (ksi)

$F_{n c}=$ nominal flexural resistance of the compression flange determined as follows for tub sections $=F_{c b} \sqrt{1-\left(\frac{f_{v}}{\varphi_{v} F_{c v}}\right)^{2}}$

Equation 2-40

Where: $\mathrm{F}_{\mathrm{cb}}=$ nominal axial compression buckling resistance of the flange under compression alone calculated given the following limits:

- If $\lambda_{\mathrm{f}} \leq \lambda_{\mathrm{p}}$

$F_{c b}=R_{b} R_{h} F_{y c} \Delta$

Equation 2-41

- If $\lambda_{\mathrm{p}}<\lambda_{\mathrm{f}} \leq \lambda_{\mathrm{r}}$

$$
F_{c b}=R_{b} R_{h} F_{y c}\left[\Delta-\left(\Delta-\frac{\Delta-0.3}{R_{h}}\right)\left(\frac{\lambda_{f}-\lambda_{p}}{\lambda_{r}-\lambda_{p}}\right)\right] \quad \text { Equation 2-42 }
$$


- If $\lambda_{\mathrm{f}}>\lambda_{\mathrm{r}}$

$$
F_{c b}=\frac{0.9 E R_{b} k}{\lambda_{f}^{2}}
$$

$\mathrm{F}_{\mathrm{cv}}=$ nominal shear buckling resistance of the flange under shear alone calculated given the following limits:

- If $\lambda_{f} \leq 1.12 \sqrt{\frac{E k_{s}}{F_{y c}}}$

$$
F_{c v}=0.58 F_{y c}
$$

- If $1.12 \sqrt{\frac{E k_{s}}{F_{y c}}} \leq \lambda_{f} \leq 1.40 \sqrt{\frac{E k_{s}}{F_{y c}}}$

$$
F_{c v}=\frac{0.65 \sqrt{F_{y c} E k_{s}}}{\lambda_{f}}
$$

Equation 2-

45

- If $\lambda_{f}>1.40 \sqrt{\frac{E k_{s}}{F_{y c}}}$

$$
F_{c v}=\frac{0.9 E k_{S}}{\lambda_{f}^{2}}
$$

Where $\lambda_{\mathrm{f}}, \lambda_{\mathrm{p}}$, and $\lambda_{\mathrm{r}}$ are calculated as follows:

$$
\begin{aligned}
& \lambda_{f}=\frac{b_{f c}}{t_{f c}} \\
& \lambda_{p}=0.57 \sqrt{\frac{E k}{F_{y c} \Delta}} \\
& \lambda_{p}=0.95 \sqrt{\frac{E k}{F_{y r}}} \\
& \Delta=\sqrt{1-3\left(\frac{f_{v}}{F_{y t}}\right)^{2}} \\
& f_{v}=\frac{T}{2 A_{o} t_{f}}
\end{aligned}
$$


$f_{v}=S t$. Venant torsional shear stress in the flange due to factored loads at the section under consideration (ksi)

$\mathrm{A}_{\mathrm{o}}=$ enclosed are of box section (in $\left.{ }^{2}\right)$

$\mathrm{T}=$ internal torque due to factored load applied (kip*in)

Where: $F_{y}=$ smaller of the compression-flange stress at the onset of nominal yielding, with consideration of residual stress effects of the specified minimum yield strength of the web (ksi)

$\mathrm{k}=$ plate buckling coefficient for uniform normal stress $=4.0$

$\mathrm{k}_{\mathrm{s}}=$ plate buckling coefficient for shear stress $=5.34$

$\varphi_{\mathrm{f}}=$ resistance factor for flexure provided in Article 6.5.4.2 $=1.00$

$\varphi_{\mathrm{v}}=$ resistance factor for shear provided in Article 6.5.4.2 $=1.00$

$\mathrm{b}_{\mathrm{fc}}=$ compression flange width between webs (in)

$\mathrm{R}_{\mathrm{b}}=$ web load shedding factor determined in accordance with Article

$6.10 .1 \cdot 10.2$

$\mathrm{R}_{\mathrm{h}}=$ hybrid factor determined as specified in ARtilc 6.10.1.10.1

Compression Flange, Stiffened:

Where compression flanges are stiffened, the following changes in the provisions for unstiffened compression flanges should be made for evaluation at the strength limit state:

- $\mathrm{w}$, the larger of the width of the flange between longitudinal stiffeners or the distance form a web to the nearest stiffener, should replace $b_{f c}$ 
- the plate buckling coefficient for uniform normal stress, $\mathrm{k}$, should be calculated as follows based on the number, $\mathrm{n}$, of longitudinal stiffeners where $1.0 \leq \mathrm{k} \leq 4.0$ :

$$
\begin{aligned}
& \mathrm{n}=1 ; \quad k=\left(\frac{8 I_{s}}{w t_{f c}^{3}}\right)^{\frac{1}{3}} \\
& \mathrm{n}=2 ; \quad k=\left(\frac{0.894 I_{s}}{w t_{f c}^{3}}\right)^{\frac{1}{3}}
\end{aligned}
$$

- the plate buckling coefficient for shear stress, $\mathrm{k}_{\mathrm{s}}$, should be calculated as follows

$$
k_{s}=\frac{5.34+2.84\left(\frac{I_{s}}{w t_{f c}^{3}}\right)^{\frac{1}{3}}}{(n+1)^{2}} \leq 5.34
$$

Where: $\mathrm{I}_{\mathrm{a}}=$ moment of inertial of a single longitudinal flange stiffener about the axis parallel to the flange, computed at the base of the stiffener $\left(\mathrm{in}^{4}\right)$

\subsection{Shear Capacity}

The shear capacity of tub sections should be evaluated in accordance with Articles 6.11.9 and 6.10.9 as appropriate as follows:

$$
V_{u} \leq \varphi_{v} V_{n}
$$

Equation 2-55

Where: $\varphi_{v}=$ shear resistance factor provided in Article 6.5.4.2 $=1.00$

$\mathrm{V}_{\mathrm{u}}=$ shear in the web due to the factored permanent and construction loads applied to the noncomposite section, calculated per Equation 2-18 (kip) $\mathrm{V}_{\mathrm{n}}=$ nominal shear resistance for unstiffened and stiffened webs calculated as follows:

For unstiffened webs:

$$
\mathrm{V}_{\mathrm{n}}=\mathrm{V}_{\mathrm{cr}}=\mathrm{CV}_{\mathrm{p}}
$$


Where: $\mathrm{V}_{\mathrm{p}}=0.58 \mathrm{~F}_{\mathrm{yw}} \mathrm{Dt}_{\mathrm{w}}$

Equation 2-57

$\mathrm{C}=$ ratio of the shear buckling resistance to the shear yield strength calculated using Equations 2-61, 2-62, 2-63, with $\mathrm{k}=5.0$

$\mathrm{V}_{\mathrm{cr}}=$ shear yielding or shear buckling resistance (kip)

$\mathrm{V}_{\mathrm{n}}=$ nominal shear resistance (kip)

$\mathrm{V}_{\mathrm{cr}}=$ plastic shear force (kip)

For stiffened webs:

Interior web panels:

Where the section is proportioned such that the following is satisfied.

$\frac{2 D t_{w}}{\left(b_{f c} t_{f c}+b_{f t} t_{f t}\right)} \leq 2.5$

Equation 2-58

The nominal shear resistance of an interior web panel is as follows;

$V_{n}=V_{p}\left[C+\frac{0.87(1-C)}{\sqrt{1+\left(\frac{d_{o}}{D}\right)^{2}}}\right]$

Equation 2-59

Where: $V_{p}=0.58 F_{y w} D t_{w}$

Equation 2-60

$\mathrm{d}_{\mathrm{o}}=$ transverse stiffener spacing (in)

$V_{n}=$ nominal shear resistance of the web panel (kip)

$\mathrm{V}_{\mathrm{p}}=$ plastic shear force (kip)

$\mathrm{C}=$ ratio of the shear buckling resistance to the shear yield strength calculated given the following limits:

- If $\frac{D}{t_{w}} \leq 1.12 \sqrt{\frac{E k}{F_{y w}}}$

$C=1.00$

Equation 2-61 
- If $1.12 \sqrt{\frac{E k}{F_{y w}}} \leq \frac{D}{t_{w}} \leq 1.40 \sqrt{\frac{E k}{F_{y w}}}$

$C=\frac{1.12}{\frac{D}{t_{w}}} \sqrt{\frac{E k}{F_{y w}}}$

Equation 2-62

- If $\frac{D}{t_{w}}>1.40 \sqrt{\frac{E k}{F_{y w}}}$

$C=\frac{1.57}{\left(\frac{D}{t_{w}}\right)^{2}}\left(\frac{E k}{F_{y w}}\right)$

Equation 2-63

Where: $\mathrm{k}=$ shear buckling coefficient $=5+\frac{5}{\left(\frac{d_{o}}{D}\right)^{2}}$

Equation 2-64

Where the section does not meet the above proportions, the nominal resistance is calculated as follows:

$V_{n}=V_{p}\left[C+\frac{0.87(1-C)}{\left(\sqrt{1+\left(\frac{d_{o}}{D}\right)^{2}+\frac{d_{o}}{D}}\right)}\right]$

Equation 2-65

End panels:

$\mathrm{V}_{\mathrm{n}}=\mathrm{V}_{\mathrm{cr}}=\mathrm{CV}_{\mathrm{p}}$

Equation 2-66

Where: $\mathrm{V}_{\mathrm{p}}=0.58 \mathrm{~F}_{\mathrm{yw}} \mathrm{Dt}_{\mathrm{w}}$

Equation 2-67

$\mathrm{C}=$ ratio of the shear buckling resistance to the shear yield strength calculated using Equations 2-61, 2-62, 2-63

$\mathrm{V}_{\mathrm{cr}}=$ shear yielding or shear buckling resistance (kip)

$\mathrm{V}_{\mathrm{n}}=$ nominal shear resistance (kip)

$\mathrm{V}_{\mathrm{cr}}=$ plastic shear force (kip)

The transverse stiffener spacing for end panels with or without longitudinal stiffeners should not exceed $1.5 \mathrm{D}$, the depth of the web section. 


\subsubsection{AASHTO Equation References}

Table 2.3 includes a summary of the equations referenced and included in this chapter from the ASHTO LRFD Specifications with the appropriate AASHTO equation references.

Table 2.3: Chapter 2 Equation Legend ( AASHTO, 2017)

\begin{tabular}{|c|c|}
\hline Chapter 2 Equations & AASHTO 8 ${ }^{\text {th }}$ Edition \\
\hline Equation 2-1 & Table 4.6.2.2.2b-1 \\
\hline Equation 2-2 & Equation 6.11.2.1.2-1 \\
\hline Equation 2-3 & Equation 6.11.2.1.3-1 \\
\hline Equation 2-4 & Equation 6.11.2.2-1 \\
\hline Equation 2-5 & Equation 6.11.2.2-2 \\
\hline Equation 2-6 & Equation $6.11 .2 .2-3$ \\
\hline Equation 2-7 & Equation 6.10.3.2.1-1 \\
\hline Equation 2-8 & Equation 6.10.3.2.1-2 \\
\hline Equation 2-9 & Equation 6.10.3.2.1-3 \\
\hline Equation 2-10 & Equation 6.10.3.2.2-1 \\
\hline Equation 2-11 & Equation 6.10.3.2.3-1 \\
\hline Equation 2-12 & Equation 6.11.3.2-1 \\
\hline Equation 2-13 & Equation 6.11.3.2-2 \\
\hline Equation 2-14 & Equation 6.11.3.2-3 \\
\hline Equation 2-15 & Equation 6.11.3.2-4 \\
\hline Equation 2-16 & Equation 6.11.3.2-5 \\
\hline Equation 2-17 & Equation 6.10.3.3-1 \\
\hline Equation 2-18 & Equation 6.11.9-1 \\
\hline Equation 2-19 & Equation 6.10.4.2.2-1 \\
\hline Equation 2-20 & Equation 6.10.4.2.2-2 \\
\hline Equation 2-21 & Equation 6.10.4.2.2-3 \\
\hline Equation 2-22 & Equation 6.10.4.2.2-4 \\
\hline Equation 2-23 & Equation 6.6.1.2.2-1 \\
\hline Equation 2-24 & Equation 6.6.1.2.5-1 \\
\hline Equation 2-25 & Equation 6.6.1.2.5-2 \\
\hline Equation 2-26 & Equation 6.6.1.2.5-3 \\
\hline Equation 2-27 & Equation 6.11.6.2.2-1 \\
\hline Equation 2-28 & Equation $6.10 .7 .3-1$ \\
\hline Equation 2-29 & Equation 6.11.7.1.1-1 \\
\hline Equation 2-30 & Equation 6.10.7.1.2-1 \\
\hline
\end{tabular}


Table 2.3 (cont.): Chapter 2 Equation Legend (AASHTO 2017)

Chapter 2 Equations

\begin{tabular}{|c|c|}
\hline Chapter 2 Equations & AASHTO 8 ${ }^{\text {th }}$ Edition \\
\hline Equation 2-31 & Equation 6.10.7.1.2-2 \\
\hline Equation 2-32 & Equation 6.10.7.1.2-3 \\
\hline Equation 2-33 & Equation 6.11.7.2.1-1 \\
\hline Equation 2-34 & Equation 6.11.7.2.2-1 \\
\hline Equation 2-35 & Equation 6.11.7.2.1-2 \\
\hline Equation 2-36 & Equation 6.11.7.2.2-5 \\
\hline Equation 2-37 & Equation 6.11.7.2.2-6 \\
\hline Equation 2-38 & Equation 6.11.7.2.2-7 \\
\hline Equation 2-39 & Equation 6.11.8.1.1-1 \\
\hline Equation 2-40 & Equation 6.11.8.2.2-1 \\
\hline Equation 2-41 & Equation 6.11.8.2.2-2 \\
\hline Equation 2-42 & Equation 6.11.8.2.2-3 \\
\hline Equation 2-43 & Equation 6.11.8.2.2-4 \\
\hline Equation 2-44 & Equation 6.11.8.2.2-5 \\
\hline Equation 2-45 & Equation 6.11.8.2.2-6 \\
\hline Equation 2-46 & Equation 6.11.8.2.2-7 \\
\hline Equation 2-47 & Equation 6.11.8.2.2-8 \\
\hline Equation 2-48 & Equation 6.11.8.2.2-9 \\
\hline Equation 2-49 & Equation 6.11.8.2.2-10 \\
\hline Equation 2-50 & Equation 6.11.8.2.2-11 \\
\hline Equation 2-51 & Equation 6.11.8.2.2-12 \\
\hline Equation 2-52 & Equation 6.11.8.2.3-1 \\
\hline Equation 2-53 & Equation 6.11.8.2.3-2 \\
\hline Equation 2-54 & Equation 6.11.8.2.3-3 \\
\hline Equation 2-55 & Equation 6.10.9.1-1 \\
\hline Equation 2-56 & Equation 6.10.9.2-1 \\
\hline Equation 2-57 & Equation 6.10.9.2-2 \\
\hline Equation 2-58 & Equation 6.10.9.3.2-1 \\
\hline Equation 2-59 & Equation 6.10.9.3.2-2 \\
\hline Equation 2-60 & Equation 6.10.9.3.2-3 \\
\hline Equation 2-61 & Equation 6.10.9.3.2-4 \\
\hline Equation 2-62 & Equation 6.10.9.3.2-5 \\
\hline Equation 2-63 & Equation 6.10.9.3.2-6 \\
\hline Equation 2-64 & Equation 6.10.9.3.2-7 \\
\hline Equation 2-65 & Equation 6.10.9.3.2-8 \\
\hline Equation 2-66 & Equation 6.10.9.3.3-1 \\
\hline Equation 2-67 & \\
\hline & \\
\hline & \\
\hline & $10.9 .3 .3-2$ \\
\hline
\end{tabular}




\subsection{CURRENT AASHTO SPECIFICATIONS FOR SUPERSTRUCTURE LOAD RATING (MBE, 2018)}

The Manual for Bridge Evaluation (MBE) is a publication of the American Association of Highway and Transportation Officials (AASHTO) that includes specifications for bridge inspection, classification, and rating. Load ratings analyze the live load structural performance and capacity of bridges. The MBE provides direction for load rating structures in Section 6 - Load Rating, including load resistance factor rating (LRFR) methods which are consistent with the LRFD Bridge Design Specifications (MBE, 2018) discussed in Section 2.6. Structures are analyzed for inventory and operating conditions. Both the inventory and operating live load ratings must be equal to or exceed one for the structure to be serviceable. Inventory level load ratings evaluate the structure for original design load reliability, per AASTHO LRFD Specifications, while reflecting the existing bridge and material conditions including section loss and deterioration (AASTHO, 2017). Operating level load ratings evaluate the structure for the maximum load level to which the structure is subjected (MBE, 2018). Structures are evaluated by analyzing the load path of the structure and investigating the capacity of individual, primary load carrying members. Primary members are rated as follows:

$R F=\frac{C-\left(\gamma_{D C}\right)(D C)-\left(\gamma_{D w}\right)(D W) \pm\left(\gamma_{p}\right)(P)}{\left(\gamma_{L L}\right)(L L+I M)}$

Equation 2-68

For Strength Limit States:

$C=\varphi_{c} \varphi_{s} \varphi R_{n}$

Equation 2-69

For Service Limit States:

$C=f_{R}$

Equation 2-70

Where: $\mathrm{RF}=$ rating factor

$\mathrm{C}=$ capacity

$f_{R}=$ allowable stress specified in LRFD code

$\mathrm{R}_{\mathrm{n}}=$ nominal member resistance (as inspected) 
$\mathrm{DC}=$ dead load effect due to structural components and attachments

DW $=$ dead load effect due to wearing surface and utilities

$\mathrm{P}=$ permanent loads other than dead loads

$\mathrm{LL}=$ live load effect

$\mathrm{IM}=$ dynamic load allowance

$\gamma_{\mathrm{DC}}=\mathrm{LRFD}$ load factor for structural components and attachments

$\gamma_{\mathrm{DW}}=\mathrm{LRFD}$ load factor for wearing surfaces and utilities

$\gamma_{\mathrm{p}}=$ LRFD load factor for permanent loads other than dead loads $=1.00$

$\gamma_{\mathrm{LL}}=$ evaluation live load factor

$\varphi_{\mathrm{c}}=$ condition factor $=1.00($ new construction, Table 2.4)

$\varphi_{\mathrm{s}}=$ system factor $=1.00\left(\right.$ girder bridges with Girder Spacing $>4^{\prime}-0 "$, Table 2.5) $=1.00$

$\varphi=$ LRFD resistance factor

Table 2.4: Condition Factor, Table 6A.4.2.3-1 (MBE, 2018)

Table 6.4.4.2.3-1-Condition Factor: $\varphi_{e}$

\begin{tabular}{||l|c||}
\hline \hline Structural Condition of Member & $\varphi_{c}$ \\
\hline Good or Satisfactory & 1.00 \\
\hline Fair & 0.95 \\
\hline Poor & 0.85 \\
\hline \hline
\end{tabular}


Table 2.5: System Factor, Table 6A.4.2.4-1 (MBE, 2018)

Table 6.4.4.2.4-1-System Factor: $\varphi_{\text {, }}$ for Flexural and

Axial Effects

\begin{tabular}{||l|c||}
\hline Superstructure Type & $\varphi_{i}$ \\
\hline $\begin{array}{l}\text { Welded Members in Two-Grder Truss/Arch } \\
\text { Bridges }\end{array}$ & 0.85 \\
\hline $\begin{array}{l}\text { Riveted Members in Two-Girder Truss/Arch } \\
\text { Bridges }\end{array}$ & 0.90 \\
\hline Multiple Eyebar Members in Truss Bridges & 0.90 \\
\hline Three-Girder Bridges with Girder Spacing 6 ft & 0.85 \\
\hline Four-Girder Bridges with Girder Spacing c4 ft & 0.95 \\
\hline All Other Girder Bridges and Slab Bridges & 1.00 \\
\hline $\begin{array}{l}\text { Floorbeams with Spacing >12 ft and } \\
\text { Noncontinuous Stringers }\end{array}$ & 0.85 \\
\hline $\begin{array}{l}\text { Redundant Stringer Subsystems between } \\
\text { Floorbeams }\end{array}$ & 1.00 \\
\hline \hline
\end{tabular}

Per AASHTO regulations, live load models for load rating should include the following: HL-93 Design Load, AASHTO Legal Loads, Nominal Rating Loads, and permit loads (MBE, 2018). Load rating of members can be completed manually. Dead load is distributed to interior and exterior girders using tributary area methods. Applied live load is calculated by developing influence lines for transient live loads and applying the resultant moments, using LLDF's, to line girders representing the structural elements. Finally, capacity is determined from AASHTO Specifications discussed in Section 2.5. AASHTO permits the use of approved software, at local Department of Transportation (DOT) discretion, for the load rating of structures. A Bentley Systems product, LARS Bridge CONNECT, is one of the approved software packages commonly used by industry professionals (Bentley). 


\section{CHAPTER 3:Design AND CONSTRUCTION OF THE CANNELVILLE ROAD BRIDGE}

\subsection{INTRODUCTION}

This chapter details the design and construction of the Cannelville Road Bridge. The modular decked, press-brake-formed steel tub girder beam bridge was completed on May 27, 2017 in the Village of Roseville in Muskingum County, Ohio. It was the first press-brake-formed tub girder in Ohio and the first bridge in the United States to be constructed of modular units of this type. It was constructed with support from the FHWA's AID Demo Program discussed in Section 2.5 .

\subsection{SUMmary OF DESIGN AND CONSTRUCTION}

The following section summarizes the key elements of the Cannelville Road Bridge design and construction. The photograph shown in Figure 3.1 was taken during the November 2018 test, and presents the bridge in its final condition one year after completion of construction. The entirety of the steel superstructure was hot-dipped galvanized to extend the bridge life up to 100 years.

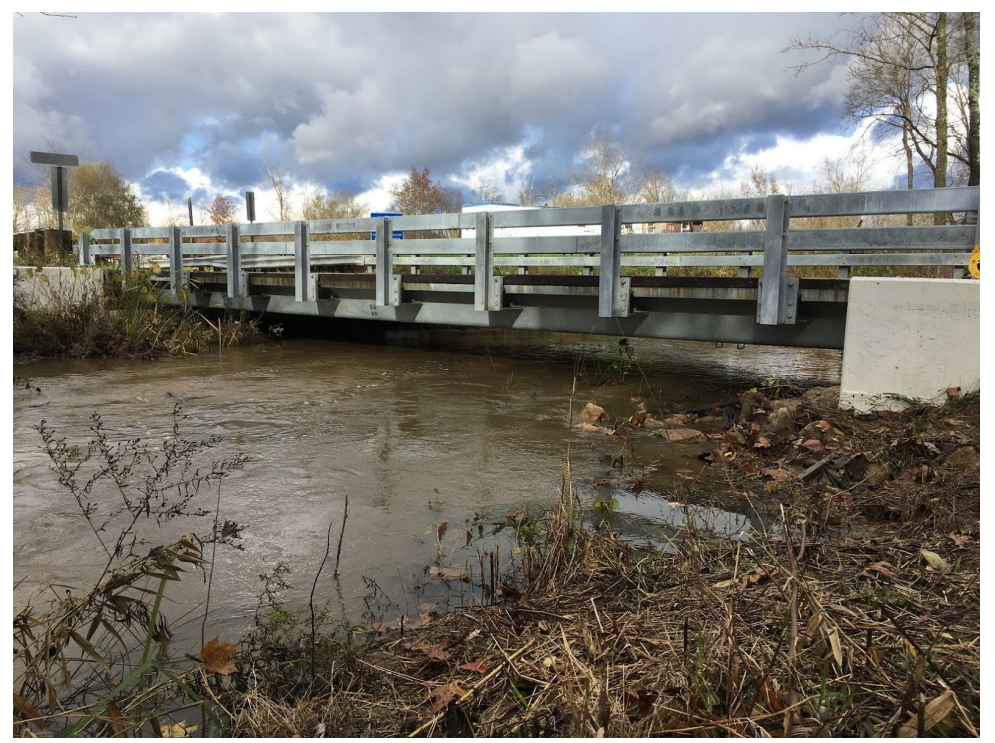

Figure 3.1: Cannelville Road Bridge, Upstream Elevation looking Backstation 


\subsubsection{Galvanic Coated Steel Press-Brake Tub Girder}

The superstructure is composed of 4-hot-dipped galvanized, press-brake-formed tub girders. The girder plate is 5/8" thick and meets the applicable standards to be analyzed as a box girder. There are 3/4" thick steel plate end diaphragms placed over the centerline of bearing in each girder at each bearing. The exterior girders are braced internally every 6'-0" centerline to centerline, with bracing spacing reduced near bearing locations. The interior girders are braced internally at the first and third quarter points of the girder. Girders are braced externally every 6'-0" centerline to centerline, with spacing reduced near bearing locations. The girders were prefabricated by MAICO Industries and delivered in modular, composite sections to the construction site for erection. Each modular unit consisted of two tub girders, see Figure 3.2.

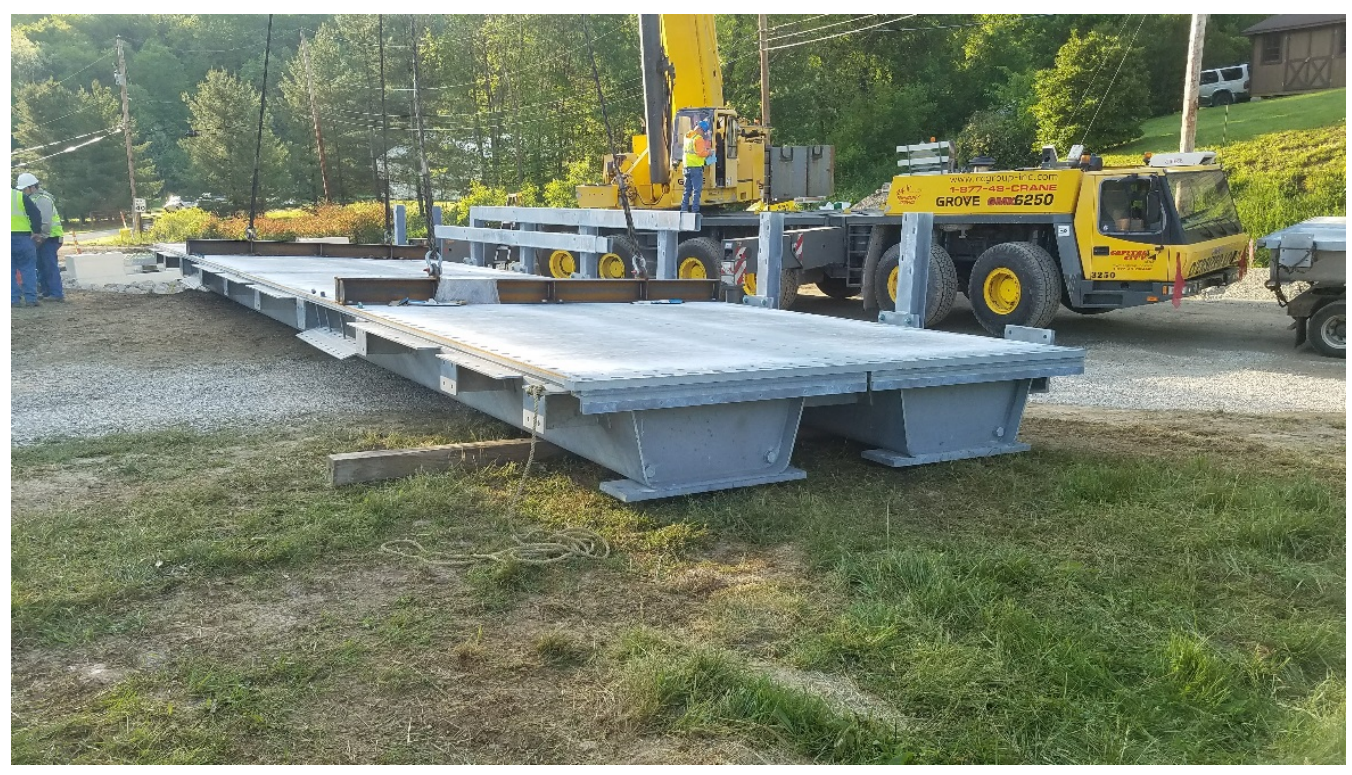

Figure 3.2: Cannelville Road Bridge Modular Girder Unit 


\subsubsection{Sandwich Plate Steel Deck System}

The press-brake-formed girders described in Section 3.3.1 were delivered to the construction site as modular superstructure units with a sandwich plate steel (SPS®) deck attached, Figure 3.3. This deck system is discussed in detail in Section 2.4. SPS ${ }^{\circledR}$ decks are a lightweight innovative solution to address the need for longevity in bridges and rapid construction methods.

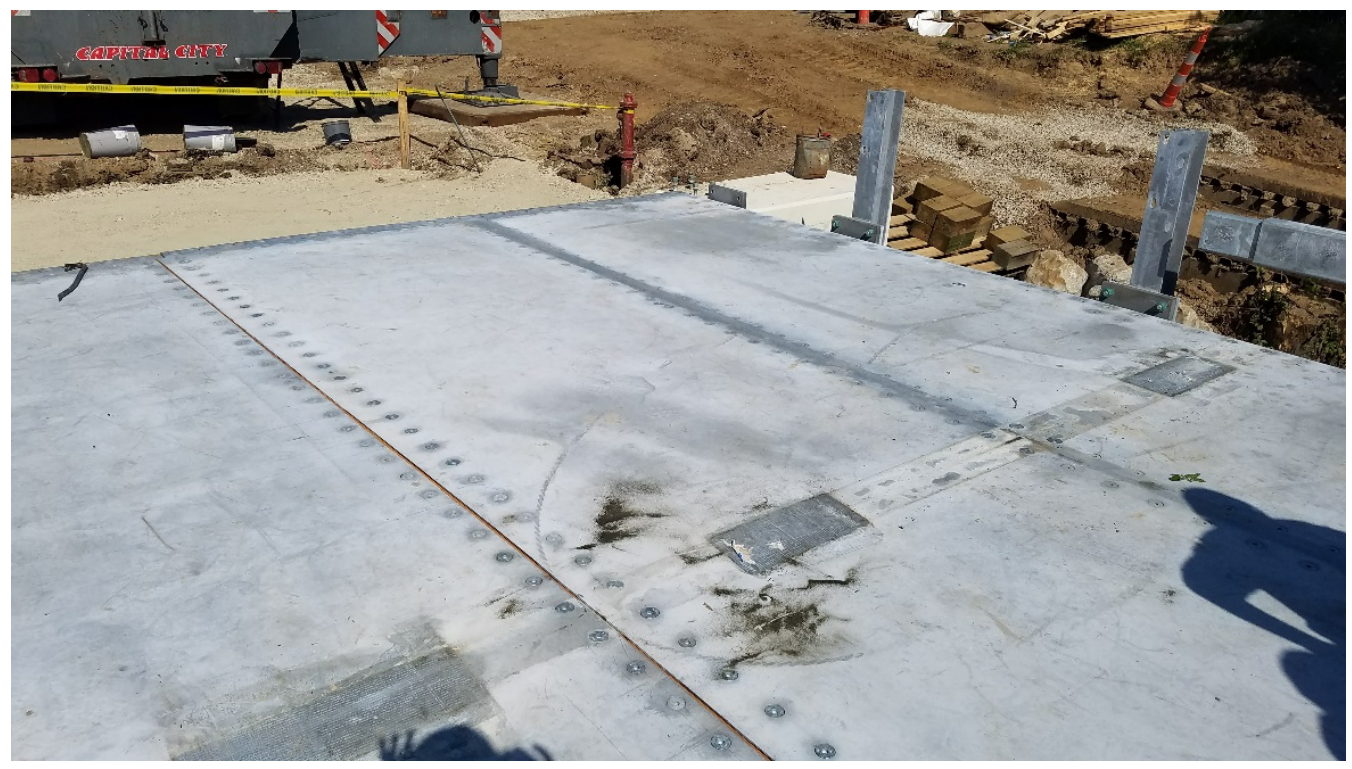

Figure 3.3: Cannelville Road Bridge SPS ${ }^{\circledR}$ Deck

\subsubsection{Accelerated Bridge Construction Methods}

Total construction of the Cannelville Bridge, including: demolition, driven pile foundations, cast-in place abutments, and girder erection, was completed in a total of twenty-six days. Thirty days were allotted for the project duration due to the location of the stream crossing. This was possible due to use of accelerated bridge construction (ABC) methods, specifically the use of modular superstructure components. The pile foundations and cast-in place stub abutments are standard details used by most DOTs. The time for construction and curing of these components required most of the construction window. The modular superstructure units were delivered to the site preassembled, including the necessary guardrail. The erection of the modular girder units occurred in approximately 20 minutes. Once the superstructure was assembled, the approach slabs 
were cast. Then an impermeable layer was placed over the steel deck to protect it and an asphalt overlay was lain at $1.56 \%$ cross slope across the structure. The Figures 3.4 and 3.5 exhibit the girder erection and placement.

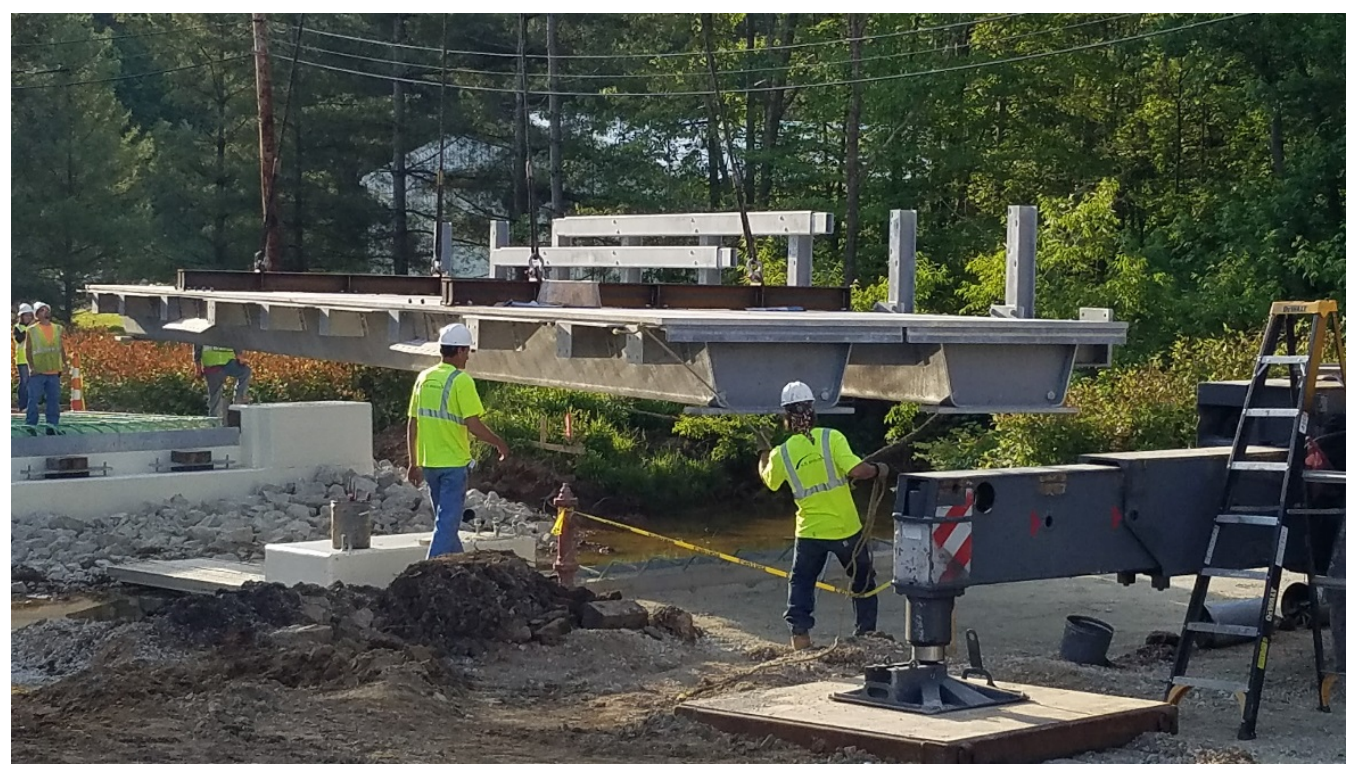

Figure 3.4: Cannelville Road Bridge, Modular Unit 1-Girders 1\& 2 Erection, Looking Upstation

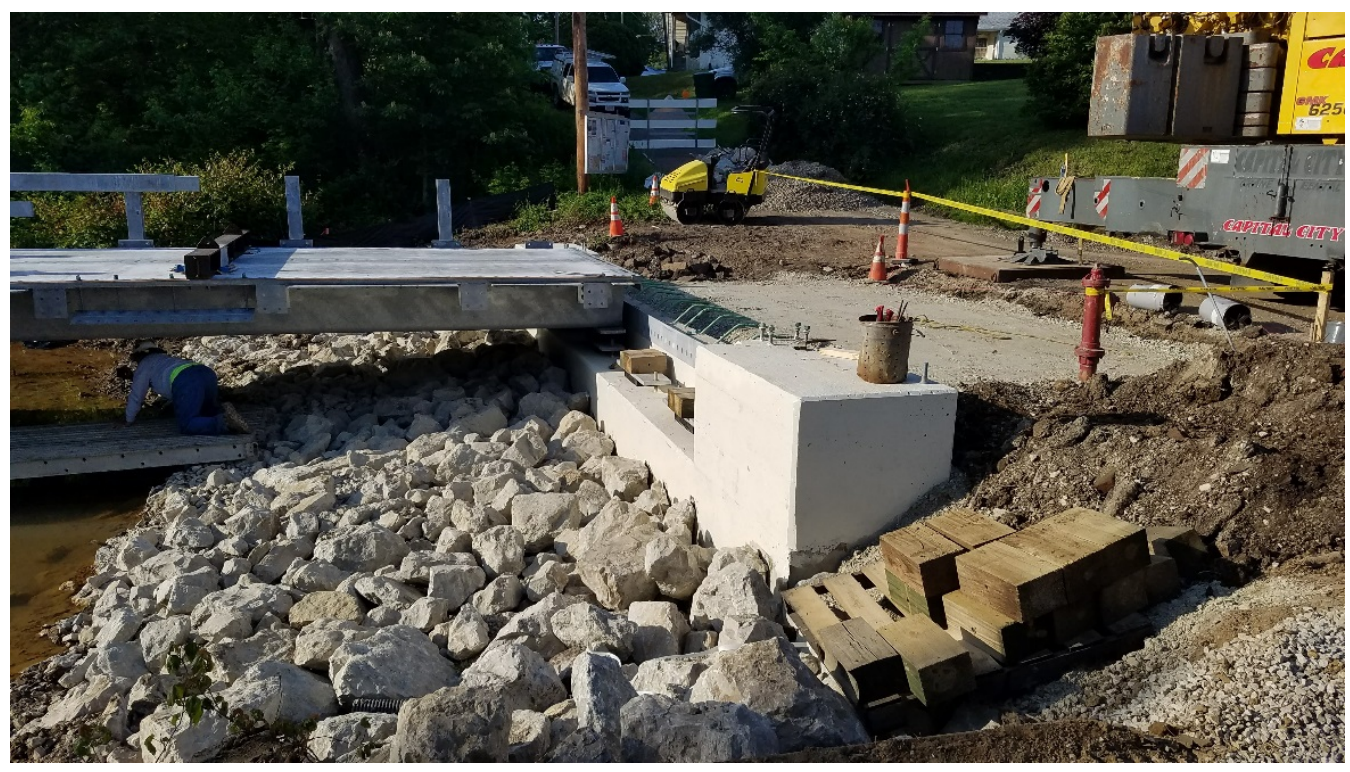

Figure 3.5: Cannelville Road Bridge, Modular Unit 1 on Bearings, Looking Upstream 


\section{CHAPTER 4: RESEARCH METHODS}

\subsection{INTRODUCTION}

This chapter discusses the research methods utilized to assess the Cannelville Road Bridge's structural performance. This includes details about the field-testing equipment and subsequent data reduction methods.

\subsection{EXPERIMENTAL TESTING EQUIPMENT}

This section provides information regarding the testing equipment utilized for performing the live load field test of the Cannelville Road Bridge. The instrumentation and software used for the test are products developed by Bridge Diagnostics, Inc. (BDI). The load truck was provided by the Muskingum County Engineer's Office (MCEO).

\subsubsection{BDI Strain Transducers}

BDI's reusable strain transducers, shown in Figures 4.1 and 4.2, were selected as the strain gages to be used during the live load field test. The gage is a full Wheatstone bridge with four active $350 \Omega$ foil gages. Each gage was calibrated to a strain range of $\pm 2000 \mu \varepsilon$, with a variation of \pm 2 percent. These gages were primarily selected due to the advantages of their application in outdoor applications. The temperature limit of the gage is broad, $-60^{\circ} \mathrm{F}$ to $+250^{\circ} \mathrm{F}$, and is governed by the instrumentation cable operating temperatures. The gages are weather resistant and designed to exceed IP67, a rating defined by the International Electrotechnical Commission (IEC) for dust and water exposure. Most important, the gage is designed to be attached using reusable connectors. These connectors or tabs are designed to be adhered to the structure being analyzed using a template provided by BDI that mirrors the hole configuration on the strain gage. In the case of this test, the tabs were glued to the girders using Loctite 410 Black Toughened Adhesive. The surface of the girder was buffed using a disk grinder to prepare the location and ensure a strong bond, see Figure 4.3. The threaded bolt on the tabs fits through the holes at either end of the gage and the gage is secured with 7/16" nuts. The wires on the strain gages are connected to the wireless nodes 
of the STS Wi-fi Data Acquisition System to transmit the strain data to the STS Base Station, discussed in Section 4.2.2.
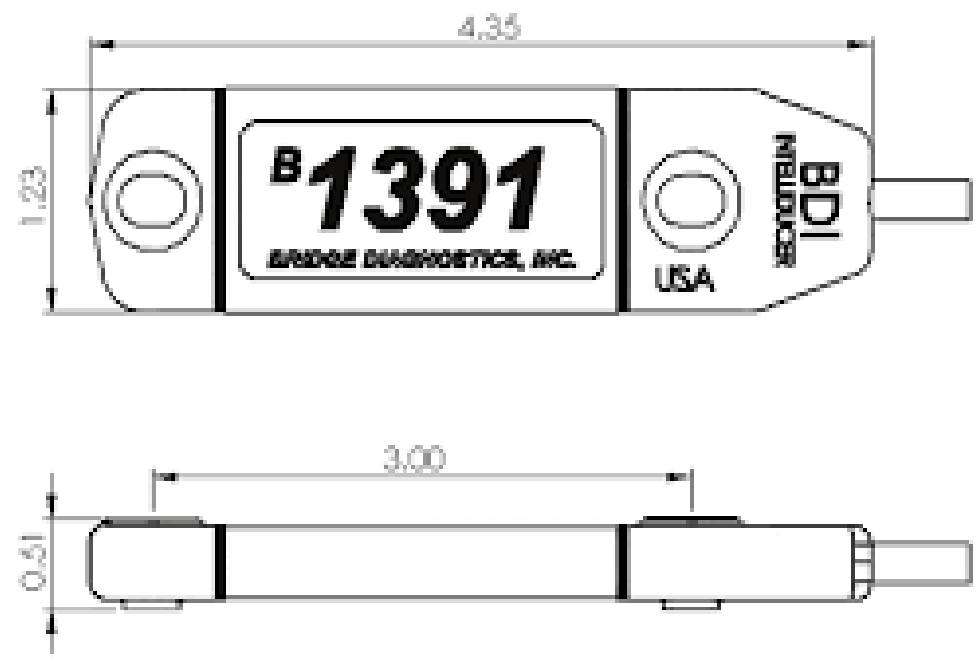

Figure 4.1: BDI Strain Transducer Schematic (BDI)

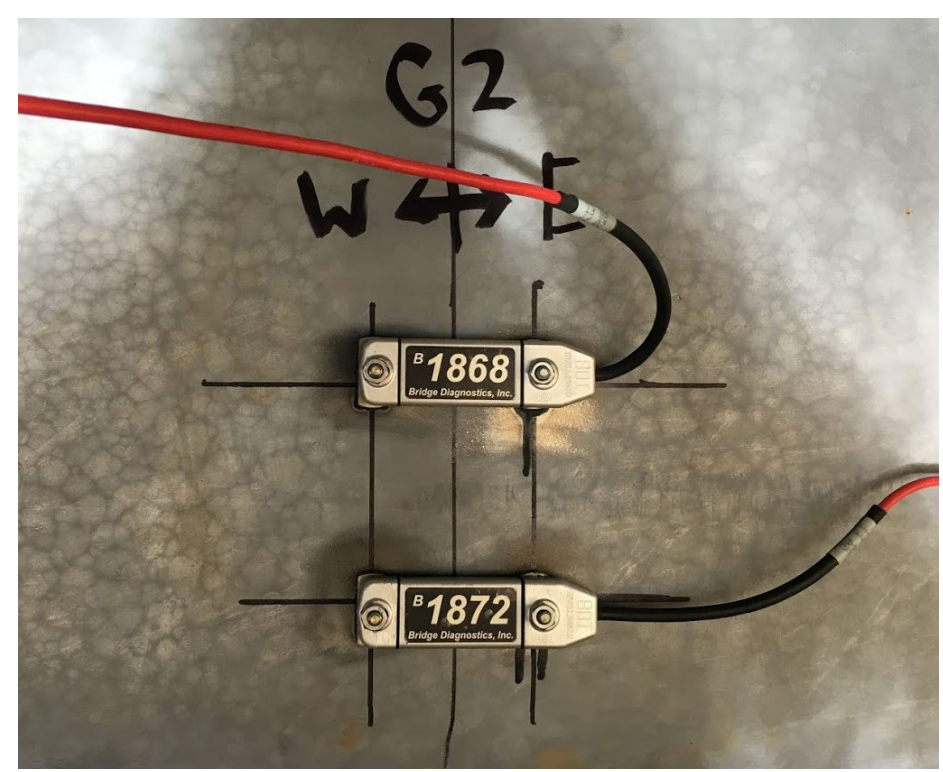

Figure 4.2: BDI Strain Transducer Application, Cannelville Road Bridge Field Test 


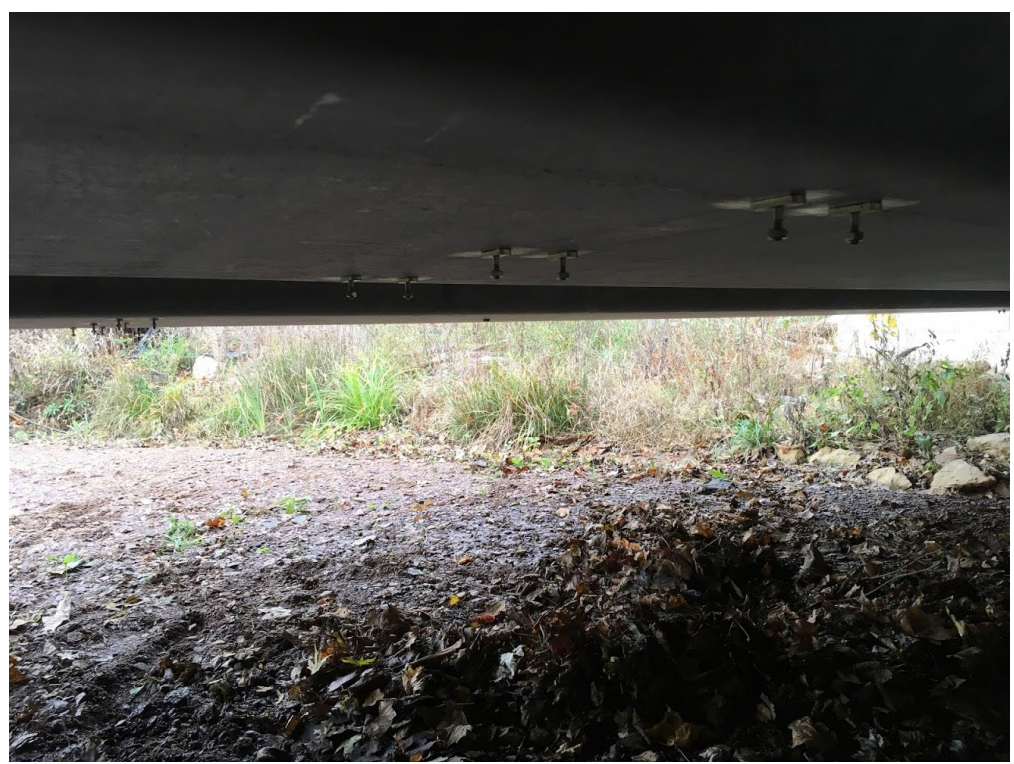

\section{Figure 4.3: BDI Strain Gage Tabs Adhered to Bottom of Girder, Cannelville Road Bridge Field Test}

\subsubsection{STS-WiFi Data Acquisition System}

Data was collected during the field test from the strain gages using BDI's STS Wi-fi Data Acquisition System. There are numerous advantages that governed the selection of this system for testing. The system may be run on battery power for up to six hours of continuous use, making it ideal for remote and challenging test locations. It is composed of two independent unit types: four channel nodes (See Figure 4.4) and the base station (See Figure 4.5). The nodes communicate data wirelessly from the gages to the base station. In the event the wireless connection does not function wired connections may be used to communicate the data from the nodes to the base. The base station can process up to 500 samples per second $(500 \mathrm{~Hz})$ through monitoring of real-time broadband signals. It can communicate with anywhere from 4 to 128 different strain gage inputs. The base station transmits information wirelessly to a computer or laptop that is equipped with the appropriate BDI software. Each component contains a BDI "Intelliducer" chip that identifies the entity in the software. When data is collected, it is denoted with the appropriate node and gage numbers due to this innovation. This simplifies the data reduction required for analysis. BDI's equipment is rated for significant exposure and weather limits, making it a durable choice for 
analyzing structures. Within reason, these components may be left in the elements to perform testing with little concern for damage.

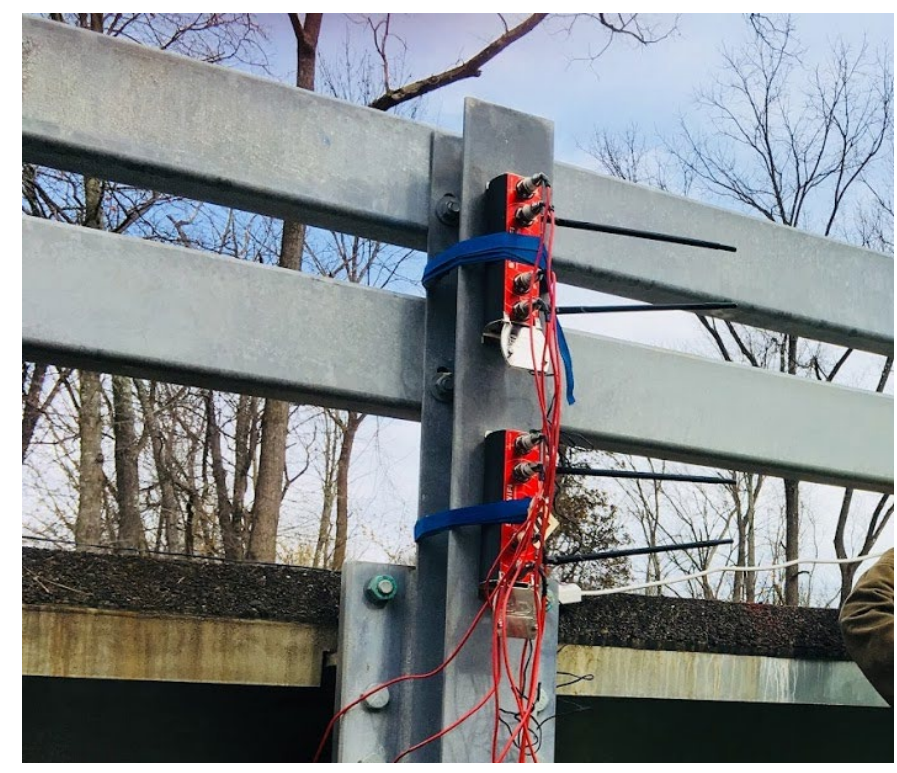

Figure 4.4: STS Wi-fi Wireless 4-Channel Node, Cannelville Road Bridge Field Test

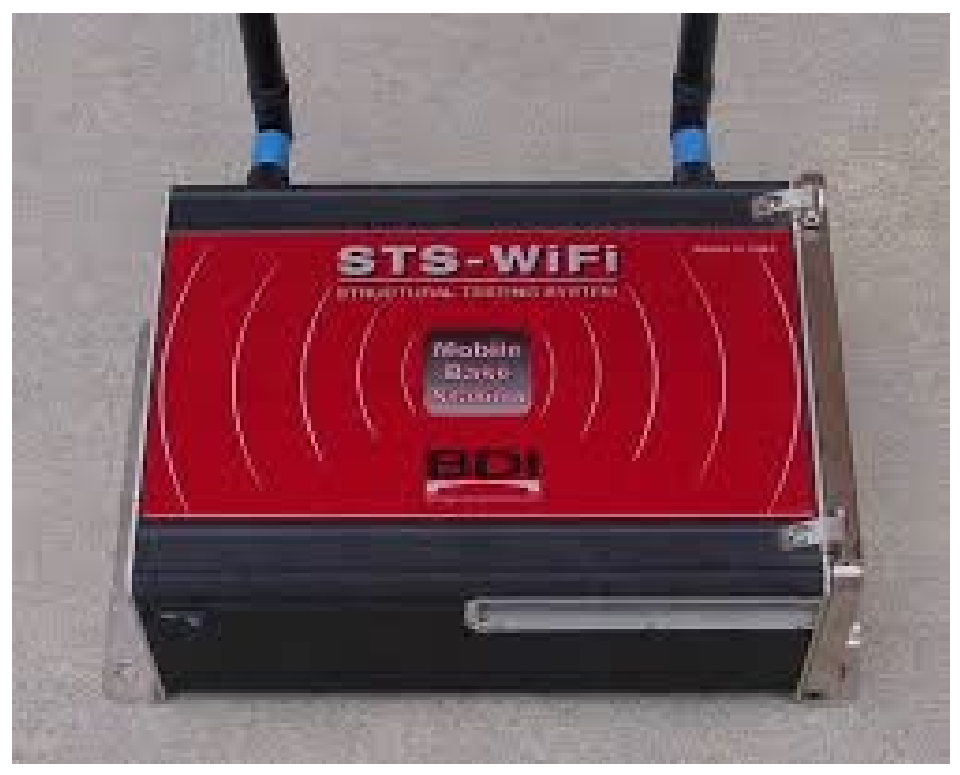

Figure 4.5: STS Wi-fi Wireless Base Station (BDI) 
The system used for this test included a set of five, 4-channel nodes, each collecting data from four strain transducers and transmitting the data to the base station, see Figure 4.6. Four of the nodes transmitted data wirelessly to the base station, the fifth node was connected to the base station using a wired ethernet cable connection. The base station communicated wirelessly with the laptop computer and appropriate BDI software. A generator was used for this test to minimize the chance for power failure and decrease the impact to local traffic due to prolonged testing.

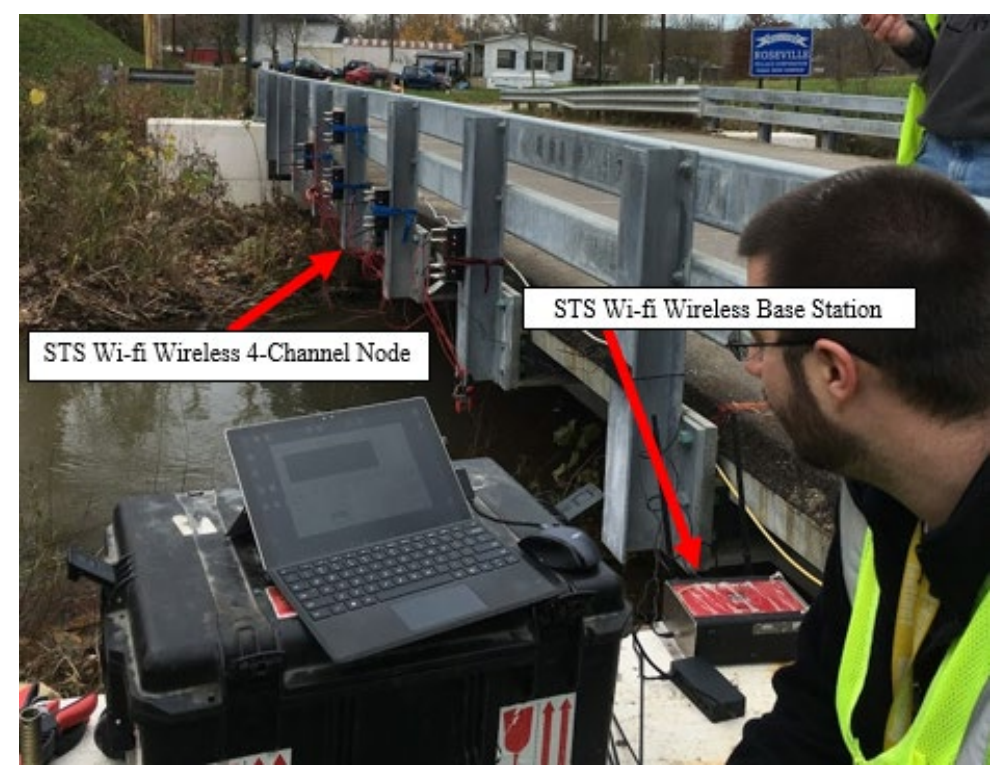

Figure 4.6: STS Wi-fi Data Acquisition System, Cannelville Road Bridge Field Test 


\subsubsection{Load Truck and Wheel Scales}

The live load analyzed in the field test was produced by a tandem axle, loaded dump truck provided by the MCEO, see Figure 4.7. The truck was weighed in its entirety by the MCEO. At the test site, each tire was weighed using a wheel load scale to determine the proportion of weight transferred to each axle. These proportions were used to develop equivalent loads for modeling from the total load measured by Muskingum County. The truck was driven across the bridge five times to simulate various loading conditions or runs for single lane and two lane loaded response. This procedure is discussed further in Chapter 5. The truck was stopped at grid points, designated locations every tenth of the structure length, to collect static strain response due to the physical load. See Section 4.3.5 for further information regarding this analysis.

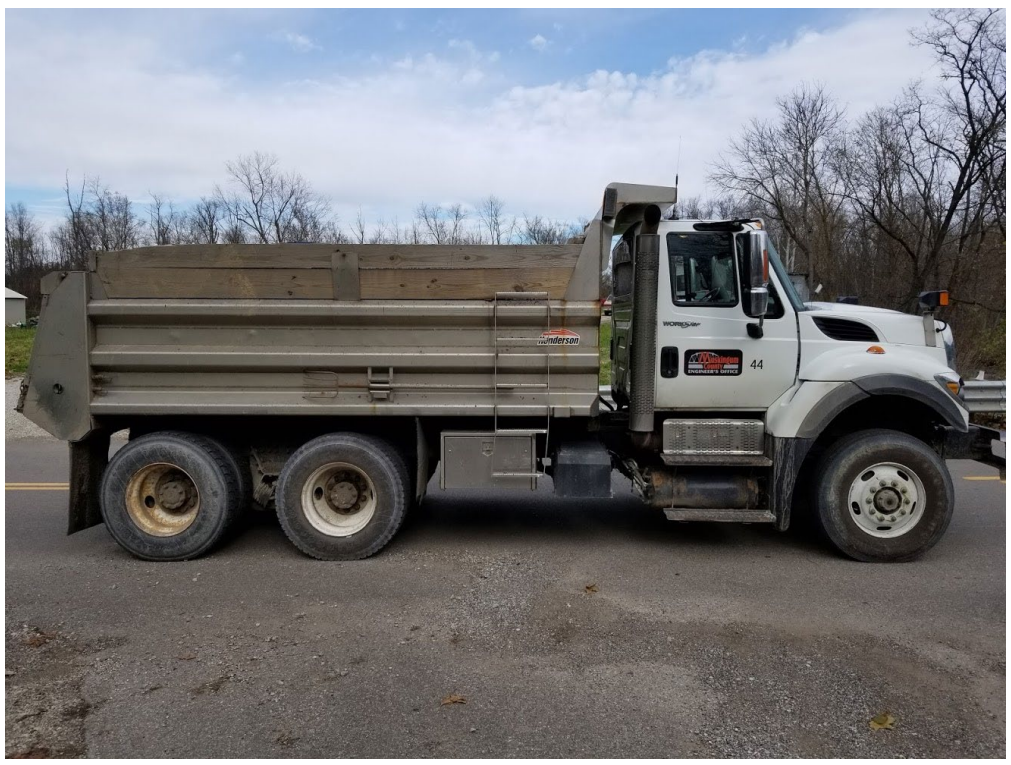

Figure 4.7: Tandem-Axle Dump Truck, Cannelville Road Bridge Field Test 


\subsection{Finite Element Modeling}

This section discusses the process used to generate a finite element model used in this analysis. Abaqus/CAE 6.14-1 (Dassault Systèmes, 2014) was used to develop a finite element model of the Cannelville Road Bridge. The model was developed in deference to Section 4.6.3.3

of the AASHTO LRFD Specifications which outlines the requirements for refined methods of analysis for beam slab bridges. Equivalent loads were determined for the loaded dump truck and were applied to the structure to mirror the series of physical truck runs conducted during the field test. This analysis is discussed further in Section 4.3.5. The results of this model were compared with the data collected during the field test. This data was used to calculate bottom flange stress, live load distribution factors, and girder load ratings.

\subsubsection{Material Definitions}

The Cannelville Road Bridge is a press-brake-formed steel girder bridge with interior and exterior bracing. The deck is a SPS ${ }^{\circledR}$ deck system that is composed of two $3 / 8$ " thick steel plates with a 1-1/8" thick polyurethane elastomer interior. All steel components are galvanized coated. The elastomer interior of the SPS ${ }^{\circledR}$ is a proprietary material developed by Intelligent Engineering Ltd. The structure was modeled using a single steel material specification. The material was modeled as a linear-elastic, isotropic material with yielding stress ( $\left.f_{\mathrm{y}}\right)$ of $50 \mathrm{ksi}$, modulus of elasticity (E) of 29,000 ksi, and shear modulus (G) of 11,165 ksi, in accordance with AASHTO LRFD Sections 6.4.1 and 6.9.4.1.3. From these values, a Poisson's ratio ( $v$ ) of 0.3 was determined. It was determined that the stresses analyzed do not exceed the yielding stress of the material. Therefore, an assumption of linear behavior is appropriate for this analysis. 


\subsubsection{Element Selection}

Due to the nature of the geometry of the Cannelville Road Bridge, all of the elements used within the analysis are shell elements. The elements are standard, linear elements. They are quadrilateral elements, doubly curved with finite member strain and reduced integration. The Abaqus/Standard User's Manual defines elements of this type as S4R elements. The model produced accurate results upon analysis of all runs.

\subsubsection{Mesh Discretization}

Section 4.6.3.3.1 of the AASHTO LRFD Code specifies that the aspect ratio for finite elements in a beam slab bridge be less than or equal to 5.0 and rapid changes in size or shape of element should be restricted. Assurances were made to meet these requirements within the model developed.

The 52'-6" bridge was discretized into 3" elements along the depth of the system for the following two reasons. One, to appropriately model the complex geometry of the girders the element size needed to be smaller for certain regions to meet the aspect ratio requirements. Two, to accurately model the location of the systems' interior and exterior bracing the discretization needed to be tight. Both the deck and girder components of the structure were modeled using structured mesh constraints. Each girder was seeded individually by girder section to define elements, see Figure 4.8. The number of elements used for each section of the tub girder, the length and depth of the element, and aspect ratio of each element are presented in Table 4.1.

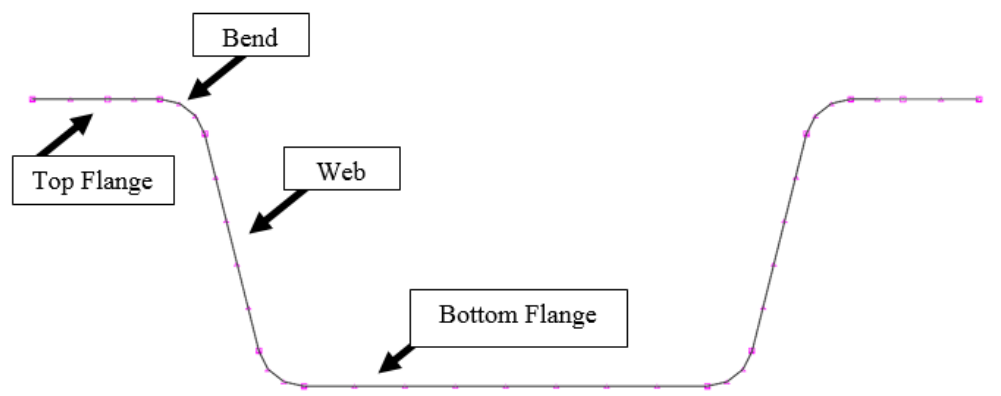

Figure 4.8: Tub Girder Edge Seeding, Typical for All Girders 
Table 4.1: Tub Girder Edge Seeding and Aspect Ratio, Typical All Girders

\begin{tabular}{|c|c|c|c|c|}
\hline Component & Elements & Depth (D) (in) & Length (L) (in) & Aspect Ratio (D/L) \\
\hline Top Flange & 4 & 3.00 & 2.38 & 1.26 \\
\hline Bend & 3 & 3.00 & 1.52 & 1.97 \\
\hline Web & 5 & 3.00 & 3.34 & 0.90 \\
\hline Bottom Flange & 8 & 3.00 & 3.75 & 0.80 \\
\hline
\end{tabular}

The bridge deck was also discretized in sections to assist with the definition of multiple point constraints, discussed in Section 4.3.4. The minimum element length is 2-15/16", the maximum element length is $4-3 / 8$ ", and the average length of a deck element is 3-7/16". All element aspect ratios meet AASHTO LRFD requirements. The remaining structural elements: end diaphragms, interior stiffener assemblies, and exterior stiffener assemblies were seeded to match the geometry of the girder and deck structures. These members, due to the nature of their geometry, were modeled as free, quadrilateral meshes. Element shape and size varies within these members, specifically the plate components of these members.

\subsubsection{Multiple Point Constraints and Boundary Conditions}

Multiple point constraints are utilized in Abaqus/CAE to translate degrees of freedom between separate entities within a model. The definition of multiple point constraints ensures composite action is developed between entities where composite action exists. In the Cannelville Road Bridge model, the deck was made composite with the girders using multiple point, beam constraints. Additionally, all interior and exterior stiffeners, and the end diaphragms were connected to the girders using multiple point constraints.

Boundary conditions were applied to the structure assuming a "hinge-roller" end condition. These simple span boundary conditions limited vertical movement at both ends and horizontal movement at one end of the structure. The boundaries were applied along the full length of the bottom flange to each node at the centerline of bearing. The system was also restrained from lateral movement to mirror similar restrictions as those seen in the field. 


\subsubsection{Application of Live Loading}

Truck placement on the structure was determined during the field test to maximize the stress in each girder. See Section 5.2 for further details on truck placement. Each wheel or set of wheels was weighed on site to determine the proportion of weight in each axle. These proportions were used in conjunction with the weight provided by the MCEO to generate the following wheel set loads for modeling purposes, see Table 4.2.

\section{Table 4.2: Equivalent Truck Wheel Loads, Finite Element Model}

\begin{tabular}{|c|c|c|c|c|c|c|}
\hline $\begin{array}{l}\text { Wheel } \\
\text { Set No. }\end{array}$ & Wheel Location & $\begin{array}{l}\text { Field Wheel } \\
\text { Weight (kips) }\end{array}$ & $\begin{array}{c}\text { Total Field } \\
\text { Weight (kips) }\end{array}$ & $\begin{array}{l}\text { Total Nominal } \\
\text { Weight (kips) }\end{array}$ & $\begin{array}{l}\text { Analysis Weight/Axle } \\
\text { (kips) }\end{array}$ & $\begin{array}{c}\text { Analysis Weight/Wheel } \\
\text { Set (kips) }\end{array}$ \\
\hline 1 & Front Left & 7.74 & \multirow{6}{*}{56.28} & \multirow{6}{*}{53.02} & \multirow{2}{*}{14.39} & 7.20 \\
\hline 2 & Front Right & 7.54 & & & & 7.20 \\
\hline 3 & Front Rear Left Tandem & 10.60 & & & \multirow{2}{*}{19.41} & 9.70 \\
\hline 4 & Front Rear Right Tandem & 10.00 & & & & 9.70 \\
\hline 5 & Back Rear Left Tandem & 10.82 & & & \multirow{2}{*}{19.22} & 9.61 \\
\hline 6 & Back Rear Right Tandem & 9.58 & & & & 9.61 \\
\hline
\end{tabular}

These loads were then overlain onto a grid that mirrored the mesh generated for the deck component in the finite element model. Due to the variable location of the wheel point loads and their inconsistencies with node locations in the model, the loads were linearly interpolated to be applied to the 4 nodes of the element upon which the load fell for each load case and position. Figure 4.10 and Equations 4-1 through Equation 4-5 exhibit this principal.

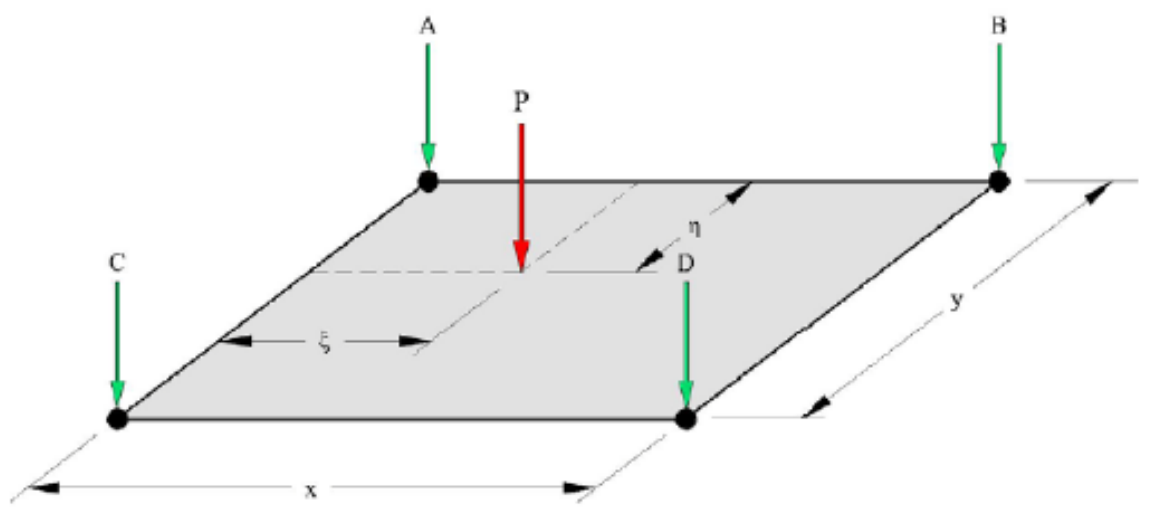

Figure 4.9: Nodal Distribution of Point Loads (Michaelson, 2010) 


$$
\begin{aligned}
& N W=A=P\left(1-\frac{\xi}{x}\right)\left(1-\frac{\eta}{y}\right) \\
& N E=B=P\left(\frac{\xi}{x}\right)\left(1-\frac{\eta}{y}\right) \\
& S W=C=P\left(1-\frac{\xi}{x}\right)\left(\frac{\eta}{y}\right) \\
& S E=D=P\left(\frac{\xi}{x}\right)\left(\frac{\eta}{y}\right) \\
& N W+N E+S W+S E=P
\end{aligned}
$$

Equation 4-2

Equation 4-5

AASHTO LRFD specifications for statically equivalent loads outlined in Section 4.6.3.3.1 are met, see Equation 4-5. For this study the coordinates A, B, C, and D were defined as NW, NE, $\mathrm{SW}$, and SE respectively for each wheel set to clarify load location in the model.

\subsection{DATA REDUCTION MethodS}

This section includes a detailed description of the methods used to calculate the midspan bending stress, live load distribution factors, and interior/exterior girder ratings based on both the field test and finite element modeling analyses and output. This section also includes an example of employing the AASHTO LRFD Standards discussed in Section 2.6 for calculating the LLDFs and girder ratings. Three strain gages were fastened to the bottom flange of the tub girders at midspan during field testing, see Section 5.2 for further details. Elements in the finite element model were identified that mirrored the location of these gages and were denoted as sets. Values were generated into reports for review by the software. The data collected from both the live load test and the finite element model were microstrain $(\mu \varepsilon)$ values at the locations of the gages throughout the runs conducted. Strains were recorded at tenth points, grid points, along the girder in both analyses. These values were averaged to determine the girder's overall response to the loading. From this data, the midspan bending stress, live load distribution factors, and exterior and 
interior girder ratings were computed. For further information regarding the experimental setup, see Chapter 5.

\subsubsection{Computation of Midspan Bending Stresses}

The data collected from the strain gages and gage locations in the finite element model were averaged for each run at each grid point. These values were then used to determine the average bending stress at midspan in response to the loading at grid points along the bridge span. To calculate the bending stress, Hooke's Law was applied. The average strain values were converted from microstrain $(\mu \varepsilon)$ to strain, and then multiplied by the Young's Modulus of the material, 29,000 ksi for steel. A detailed example of this calculation is presented below for reference.

Table 4.3: Midspan Bending Stress (ksi), Sample Calculation

\begin{tabular}{|c|c|c|c|c|}
\hline \multicolumn{5}{|c|}{ SAMPLE TRUCK RUN, GRID POINT 5 (MID-SPAN) } \\
\hline \multicolumn{2}{|c|}{ GRID POINT } & \multicolumn{3}{c|}{ SAMPLE GIRDER, GAGES $(\mu \varepsilon)$} \\
\hline $\mathrm{x}(\mathrm{ft})$ & $\mathrm{x} / \mathrm{L}$ & $\mathrm{G} 01$ & $\mathrm{G} 02$ & $\mathrm{G} 03$ \\
\hline 26.25 & 0.5 & 126.64 & 138.32 & 118.55 \\
\hline
\end{tabular}

Average Values:

$$
\varepsilon_{\text {avg }}=\sum_{i=1}^{3} \varepsilon_{i} / 3=\frac{126.64+138.32+118.55}{3}=127.84 \mu \varepsilon:=1.278^{-4} \mathrm{in} / \mathrm{in}
$$

Application of Hooke's Law to Compute Bending Stress:

$$
\begin{aligned}
\sigma & =E_{s} \varepsilon \\
\sigma & =29,000 \mathrm{ksi} * 1.278^{-4} \mathrm{in} / \text { in }=\mathbf{3 . 7 1} \mathbf{k s i}
\end{aligned}
$$

where: $\quad \sigma=$ bottom flange bending stress (ksi)

$$
\begin{aligned}
& \varepsilon_{\text {avg }}=\text { average bottom flange strain (in/in) } \\
& E_{s}=\text { Young's Modulus of steel (ksi) }
\end{aligned}
$$




\subsubsection{Computation of Live Load Distribution Factors}

Live load distribution factors were calculated for each girder, for each run using the following relation.

$$
g_{i}=\frac{n \varepsilon_{i}}{\sum_{i=1}^{k} \varepsilon_{i}} * m
$$

where: $g_{i}=$ distribution factor for the " $i$ 'th" girder

$\varepsilon_{\mathrm{i}}=$ bottom flange static strain for the " $\mathrm{i}$ 'th" girder

$\mathrm{n}=$ number of design trucks/lanes loaded

$\mathrm{k}=$ number of girders

$\mathrm{m}=$ AASHTO LRFD multiple presence factor

The LLDF values were determined from the strain data collected in both the field testing and finite element modeling analyses. The three strain gage values, or the comparable element information from the model were averaged for each grid point of a run for each girder. These average values were then used to compute the LLDFs for each girder at a specific grid point. The following is an example of this procedure.

Table 4.4: LLDFs Single Lane Loaded, Sample Calculation

\begin{tabular}{|c|c|c|c|c|c|}
\hline \multicolumn{5}{|c|}{ SAMPLE TRUCK RUN, GRID POINT 5 (MID-SPAN) } \\
\hline \multicolumn{2}{|c|}{ GRID POINT } & \multicolumn{4}{|c|}{ GIRDER AVERAGE STRAIN $(\mu \varepsilon)$} \\
\hline $\mathrm{x}(\mathrm{ft})$ & $\mathrm{x} / \mathrm{L}$ & $\mathrm{G} 1$ & $\mathrm{G} 2$ & $\mathrm{G} 3$ & $\mathrm{G} 4$ \\
\hline 26.25 & 0.5 & 127.84 & 97.67 & 19.78 & 35.35 \\
\hline
\end{tabular}

$$
L L D F_{G 1, G P 5}=\frac{n \varepsilon_{G 1, P P 5}}{\sum_{i=1}^{k} \varepsilon_{i}}=\frac{1 * 127.84}{(127.84+97.67+19.78+35.35)}=0.460
$$

Note: The multiple presence factor was not applied in this calculation. It will be applied once all LLDF factors are averaged as specified below. The application of the multiple presence factor, however, may occur at any time during the calculation of the LLDFs. 
The LLDF factors for each grid point for each individual girder were then averaged to determine the average load distribution to the individual girder for the entirety of the run. The sum of these values is \pm 1.0 , one truck weight distributed amongst the four girders. These values were then multiplied by the appropriate multiple presence factor (1.2), see Section 2.6.1, to be compared with calculations completed in accordance with AASHTO LRFD specifications. The following provides an example of this procedure. For the purposes of the example, the sum of all the distribution factors is 3.939 .

$$
L L D F_{G 1 \text { avg }}=\frac{\sum_{i=1}^{9} L L D F_{G 1, G P i}}{9 \text { grid points }} * m=\frac{3.939}{9} * 1.2=0.438 * 1.2=\mathbf{0 . 5 2 6}
$$

Though only a single truck was used in both the field testing and finite element analysis data collection, the loading scenarios can be summed to determine the girder response due to multiple lane loading. Two individual truck runs meeting the AASHTO Specifications for twolane loaded scenarios were summed to analyze the structural response to two lane loading. The structure is 24' wide, and therefore the maximum number of lanes it can accommodate is two. The following computation details the calculation of LLDFs for the two-lane loaded scenario.

Table 4.5: LLDFs Two Lanes Loaded, Sample Calculation

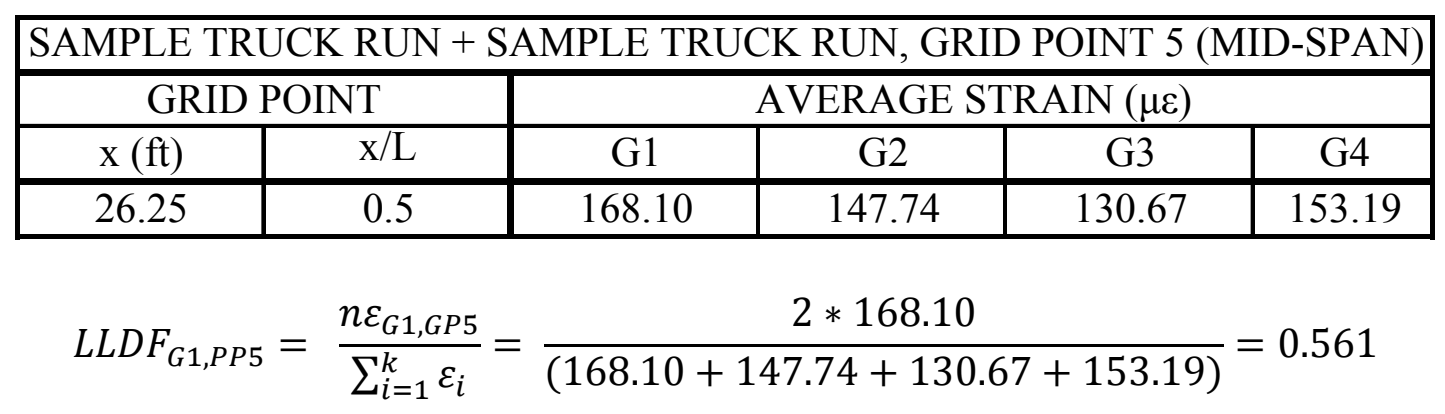


These factors were also calculated at each grid point for each individual girder, then averaged accordingly. The sum of these values is \pm 2.0 , two equivalent truck weights distributed across the four girders. The multiple presence factor specified for a two-lane loaded system is 1.0, so no additional multipliers need be applied for comparison with AASHTO LRFD specifications. For the purposes of the example, the sum of all the distribution factors is 4.968 .

$$
L L D F_{G 1_{\text {avg }}}=\frac{\sum_{i=1}^{9} L L D F_{G 1, G P i}}{9 \text { grid points }} * m=\frac{4.968}{9} * 1.0=\mathbf{0 . 5 5 2}
$$

In addition to the comparison of LLDFs determined from field testing data and finite element modeling, this study aims to compare the LLDFs calculated with values determined in adherence to the AASHTO LRFD specifications. The equations and procedure outlined within the specifications is presented in Section 2.6.2. The calculation of LLDFs for single and two-lane loading for steel box girders is presented below. All necessary multiple presence factors are accounted for in the empirical equation provided within the AASHTO Specifications.

$$
\begin{array}{ll}
L L D F_{I N T}= & 0.05+0.85\left(\frac{N_{L}}{N_{b}}\right)+\frac{0.425}{N_{L}} \\
\text { where: } \quad & 0.5 \leq \frac{N_{L}}{N_{b}} \leq 1.5 \\
& \mathrm{~N}_{\mathrm{L}}=\text { number of design lanes } \\
& \mathrm{N}_{\mathrm{b}}=\text { number of girders }
\end{array}
$$

\section{Single Lane Loaded:}

$$
L L D F_{I N T}=0.05+0.85 *\left(\frac{1}{4}\right)+\left(\frac{0.425}{1}\right)=\mathbf{0 . 6 8 7 5}
$$




\section{Two Lanes Loaded:}

$$
L L D F_{I N T}=0.05+0.85 *\left(\frac{2}{4}\right)+\left(\frac{0.425}{2}\right)=\mathbf{0 . 6 8 7 5}
$$

There is no specification outlining the LLDF calculations for structures with sandwich plate steel $(\mathrm{SPS} \otimes)$ decks due to the relative infancy of the technology in bridge applications. For the purposes of this analysis, the specifications for interior beams with concrete decks was followed. Exterior beam LLDFs for multiple box girder structures are equivalent to interior girders pursuant to Article 4.6.2.2.2d.

\subsubsection{Girder Load Rating}

Minimum interior and exterior girder ratings were calculated for the Cannelville Road Bridge using a Bentley Systems program LARS Bridge CONNECT (Bentley). Girder section properties were computed using the methods developed by Michaelson (Michaelson 2014) and manually added to the section directory of LARS Bridge CONNECT. The distributed dead load applied to the interior and exterior girders was calculated as follows:

Interior Girder:

Girder (self-weight calculated by LARS)

Unit weight steel: $0.490 \mathrm{kip} / \mathrm{ft}^{3}$

Plate thickness: 0.625 in

Plate width: 100.625 in

$\mathrm{DC}=\left(0.490 \mathrm{kip} / \mathrm{ft}^{3}\right) *(0.625 \mathrm{in})(100.625 \mathrm{in}) /\left(144 \mathrm{in}^{2}\right)=0.214 \mathrm{k} / \mathrm{ft}$

$.15 * \mathrm{DC}=.15 *(0.214 \mathrm{k} / \mathrm{ft})=\mathbf{0 . 0 3 2} \mathbf{k} / \mathbf{f t}($ additional $15 \%$ contingency $)$ 


\section{$\underline{\text { Deck }}$}

Unit weight steel: $0.490 \mathrm{kip} / \mathrm{ft}^{3}$

Tributary deck width: 5'-10 1/2" + $15 / 8^{\prime \prime}=66^{\prime}-1 / 8 "$

SPS $®$ Plate Thickness: 5/16" = 5/8” (two steel plates)

$\mathrm{DC}=\left(0.490 \mathrm{kip} / \mathrm{ft}^{3}\right) *(6.01 \mathrm{ft}) *(0.052 \mathrm{ft})=0.153 \mathrm{k} / \mathrm{ft}$

$1.15^{*} \mathrm{DC}=1.15^{*}(0.153 \mathrm{k} / \mathrm{ft})=\mathbf{0 . 1 7 6} \mathbf{~ k / f t}$

Bridge Railing (1/4 per girder, composite)

Unit weight steel: $0.490 \mathrm{kip} / \mathrm{ft}^{3}$

Bridge length: 52'-6"'

Rail components

$10-\mathrm{W} 6 \times 25$ posts ea. side (20 total), Area $=7.36$ sq.in., Height $=3$ ' -11 1/2”'

$2-$ HSS $8 \times 485 / 16$ rails ea. side (4 total), Area $=6.43$ in $^{2}$

$\mathrm{DC}=\left(0.490 \mathrm{kip} / \mathrm{ft}^{3}\right) *\left(20 * 7.36 \mathrm{in}^{2} * 47.563 \mathrm{in} / 1728 \mathrm{in}^{3} / 52.5 \mathrm{ft}+2 * 6.43 \mathrm{in}^{2} / 144 \mathrm{in}^{2}\right) / 4=0.021 \mathrm{k} / \mathrm{ft}$

$1.15^{*} \mathrm{DC}=1.15^{*}(0.021 \mathrm{k} / \mathrm{ft})=\mathbf{0 . 0 2 4} \mathbf{~ k / f t}$

Sum DC $=0.032 \mathrm{k} / \mathrm{ft}+0.176 \mathrm{k} / \mathrm{ft}+0.024 \mathrm{k} / \mathrm{ft}=\mathbf{0 . 2 3 2} \mathbf{k} / \mathbf{f t}$ 
Fascia/Exterior Girder:

Girder (self-weight calculated by LARS)

Unit weight steel: $0.490 \mathrm{kip} / \mathrm{cf}$

Plate thickness: 0.625 in

Plate width: 100.625 in

$\mathrm{DC}=(0.490 \mathrm{kip} / \mathrm{cf}) *(0.625 \mathrm{in})(100.625 \mathrm{in}) /\left(144 \mathrm{in}^{2}\right)=0.214 \mathrm{k} / \mathrm{ft}$

$.15 * \mathrm{DC}=.15 *(0.214 \mathrm{k} / \mathrm{ft})=\mathbf{0 . 0 3 2} \mathbf{~} / \mathbf{f t}($ additional $\mathbf{1 5 \%}$ contingency)

$\underline{\text { Deck }}$

Unit weight steel: $0.490 \mathrm{kip} / \mathrm{cf}$

Tributary deck width: $5^{\prime}-101 / 2 "+0.5^{*}\left(15 / 8^{\prime \prime}\right)+9 / 16^{\prime \prime}=5 '-117 / 8^{\prime \prime}$

SPS $®$ Plate Thickness: 5/16" = 5/8” (two steel plates)

$\mathrm{DC}=(0.490 \mathrm{kip} / \mathrm{cf}) *(5.99 \mathrm{ft}) *(0.052 \mathrm{ft})=0.153 \mathrm{k} / \mathrm{ft}$

$1.15^{*} \mathrm{DC}=1.15^{*}(0.153 \mathrm{k} / \mathrm{ft})=\mathbf{0 . 1 7 6} \mathbf{k} / \mathbf{f t}$

Bridge Railing (1/4 per girder, composite)

Unit weight steel: $0.490 \mathrm{kip} / \mathrm{cf}$

Bridge length: 52'-6”'

Rail components

$10-\mathrm{W} 6 \times 25$ posts ea. side (20 total), Area $=7.36$ sq.in., Height $=3$ ' $-11 \frac{1}{1}{ }^{\prime \prime}$

2 - HSS $8 \times 485 / 16$ rails ea. side (4 total), Area $=6.43$ sq.in. 


$$
\begin{aligned}
& \mathrm{DC}=(0.490 \mathrm{kip} / \mathrm{ft}) *\left(20 * 7.36 \mathrm{in}^{2} * 47.563 \mathrm{in} / 1728 \mathrm{in}^{3} / 52.5 \mathrm{ft}+2 * 6.43 \mathrm{in}^{2} / 144 \mathrm{in}^{2}\right) / 4=0.021 \mathrm{k} / \mathrm{ft} \\
& 1.15 * \mathrm{DC}=1.15 *(0.021 \mathrm{k} / \mathrm{ft})=\mathbf{0 . 0 2 4} \mathbf{~ k / f t}
\end{aligned}
$$

Sum DC $=0.032 \mathrm{k} / \mathrm{ft}+0.176 \mathrm{k} / \mathrm{ft}+0.024 \mathrm{k} / \mathrm{ft}=\mathbf{0 . 2 3 2} \mathbf{k} / \mathbf{f t}$

A fifteen percent contingency was added to all components to account for bracing connections, additional hardware, and bituminous wearing surface throughout the system. LARS accounts for the self-weight of the girder, therefore only the contingency weight was calculated for the girder. The roadway barrier was added equally to each girder, taking advantage of the composite behavior of the system. There was no evident section loss or material disintegration present that needed to be considered for the load rating. Live load ratings were produced for one lane and two lane loaded conditions using the appropriate LLDFs. The maximum average LLDFs for interior and exterior girders, calculated in accordance with Section 4.4.2 and presented in Appendix A, were used in the load rating analysis. Dimensions and material properties for the system are included in the plan set provided in Appendix C. For the purposes of this study, girders were rated for HL-93 vehicle operating and inventory (Figure 4.10) and were permit rated for the HS20 vehicle used during the field test. The results of this analysis found that both interior and exterior girders exceeded the performance determined in reference to AASHTO specifications.

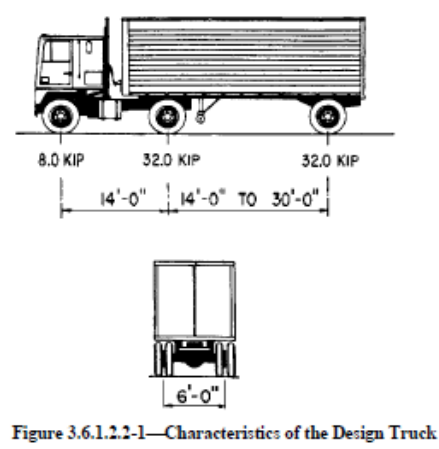

Figure 4.10: AASHTO HL-93 Design Truck (AASHTO, 2017) 


\section{CHAPTER 5: FIELD TESTING OF THE CANNELVILLE ROAD BRIDGE}

\subsection{INTRODUCTION}

This section describes the physical load testing and data collection method used for the assessment of the Cannelville Road Bridge. Field testing of the Cannelville Road Bridge in Muskingum County Ohio was conducted in November 2018. Researchers from both West Virginia University and Marshall University traveled to Roseville, Ohio to perform live load field testing on the structure. The objective of the analysis was to collect strain data resulting from physical loading for comparison with analytical results from finite element modeling of the structure.

\subsection{Live LoAd Field TeSt ASSESSMENT}

The field test was completed over the course of three days. Days one and two were used to instrument the structure and troubleshoot the analysis system. Day three was used to delineate the load path and perform the live load analysis. The content of this section details the steps required to complete the field assessment.

\subsubsection{Structure Instrumentation}

The structure was instrumented with the BDI STS Wi-fi Wireless Data Acquisition System and Strain Transducers, discussed in Section 4.2. The total instrumentation of the structure took one day. Twenty gage locations were identified for the analysis of the structure, three gage locations on the bottom of each girder (12 total) and two gage locations on each web of Girders 1 and 2 ( 8 total). The following details how gage locations were determined, and gages secured to the structure. It also briefly discusses the setup of the BDI STS Wi-fi Wireless Data Acquisition System.

The midspan of the girder was identified by measuring 26'-3" from the centerline of bearing of the abutment along the length of the girder. The location was marked on the web of each girder and a level was used to generate a reference line along the bottom flange and webs of 
the girder. A line was drawn tangent to the midspan line at the center of the bottom flange. From that intersection, 12" were measured on either side to denote the centerline of the remaining two gages. A line was then drawn 1-1/2" on either side of the midspan line for placement of the gage tabs. Using an angled rule, two 6" increments were measured along the slope of the girder web and marked using the same procedure described previously. See Figure 5.1 for a schematic of the strain gage placement. Figures 5.2 and 5.3 are images from the field test of the Cannelville Road Bridge illustrating this procedure.

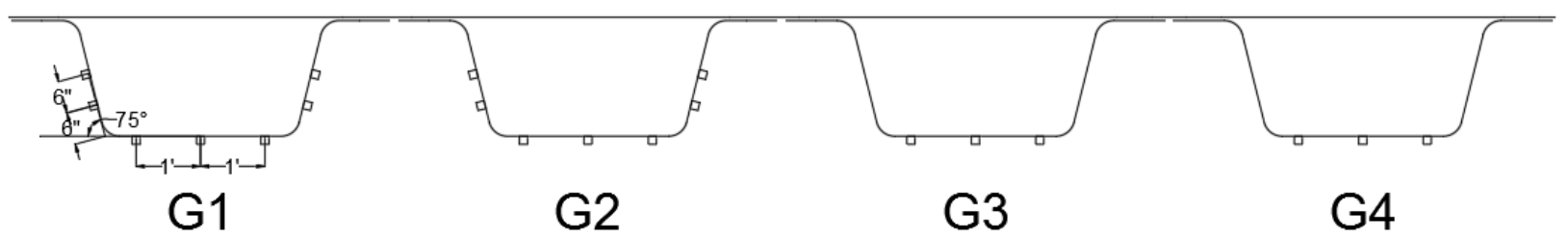

Figure 5.1: Gage Locations on Girders, Looking Backstation

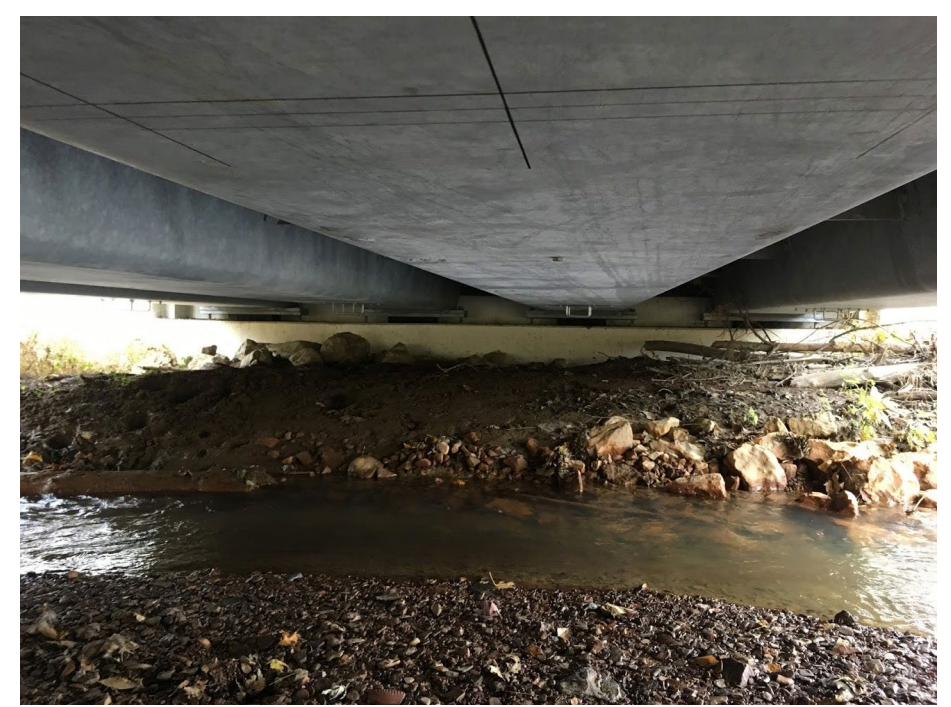

Figure 5.2: Gage Location Measurements, Bottom Flange Girder 3, Looking Backstation 


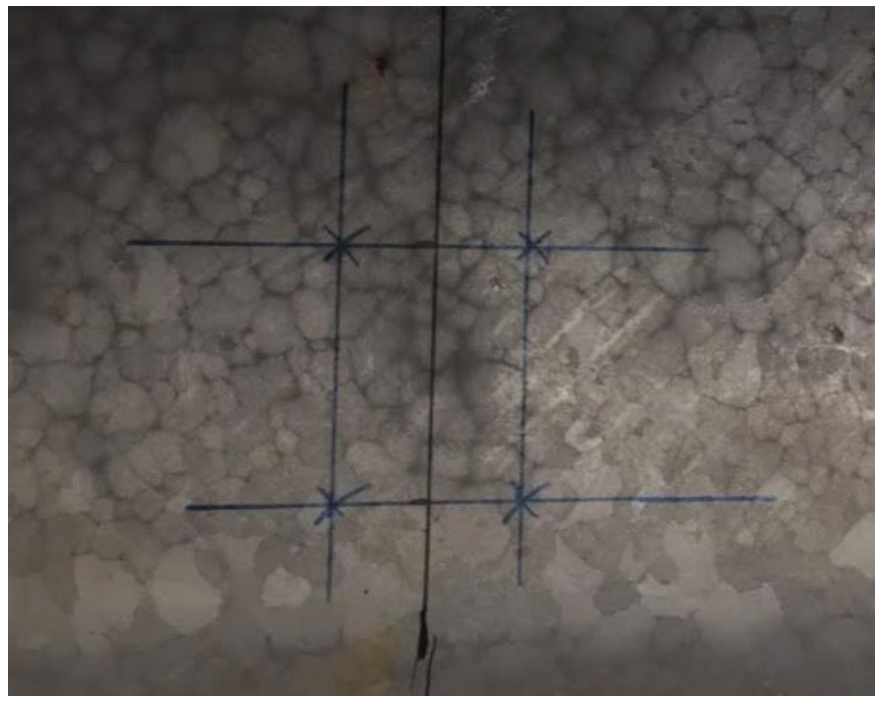

Figure 5.3: Gage Location Measurements, Left Web Girder 1, Looking Upstream

The intersection locations are where the connector tabs were glued to the steel girders. The surface layer of the girder was buffed using a disk grinder to ensure a tight bond between the tabs and the steel. After the girders were treated, the tabs were adhered to the girders using the form guide provided by BDI. The tabs were placed in the form and then they were attached to a gage using the hex nut, with the gage pulled as far right as possible. Once attached, the Loctite adhesive was applied to the tab and adhered to the girder. The tabs were held against the steel for at least one minute to ensure proper bonding. See Figures 5.4 and 5.5 for images of this procedure. In the event a tab did not seal to the girder, both tabs required to hold the gage in place were cleaned with acetone and the girder surface was buffed again prior to reconnecting the tabs to the girder. Figure 5.6. exhibits a failed tab connection. 


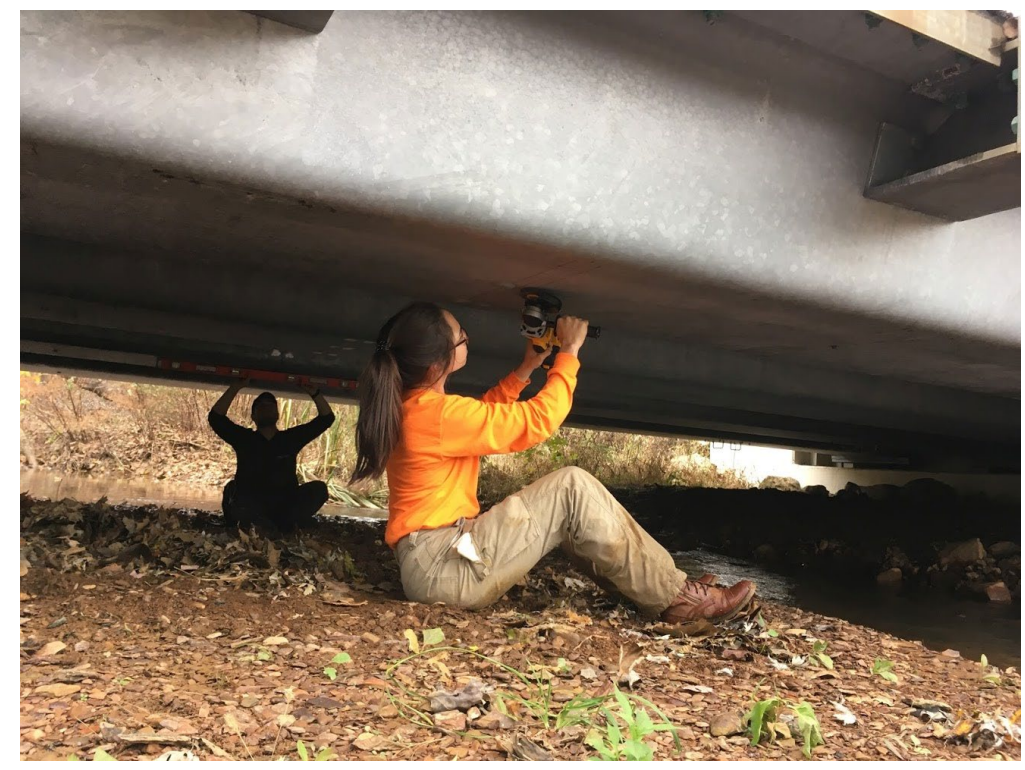

Figure 5.4: Disk Grinding of Girder Surface, Bottom Flange Girder 4, Looking Upstream

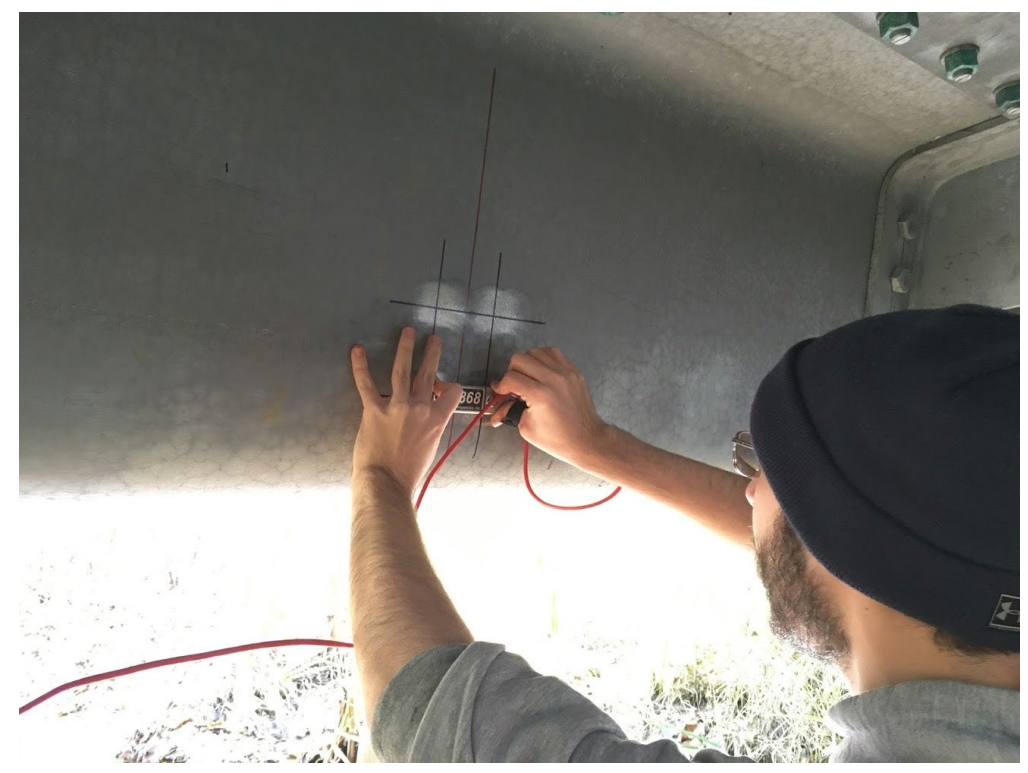

Figure 5.5: Adhering Strain Transducer Tabs to Girder, Left Web Girder 1, Looking Upstream 


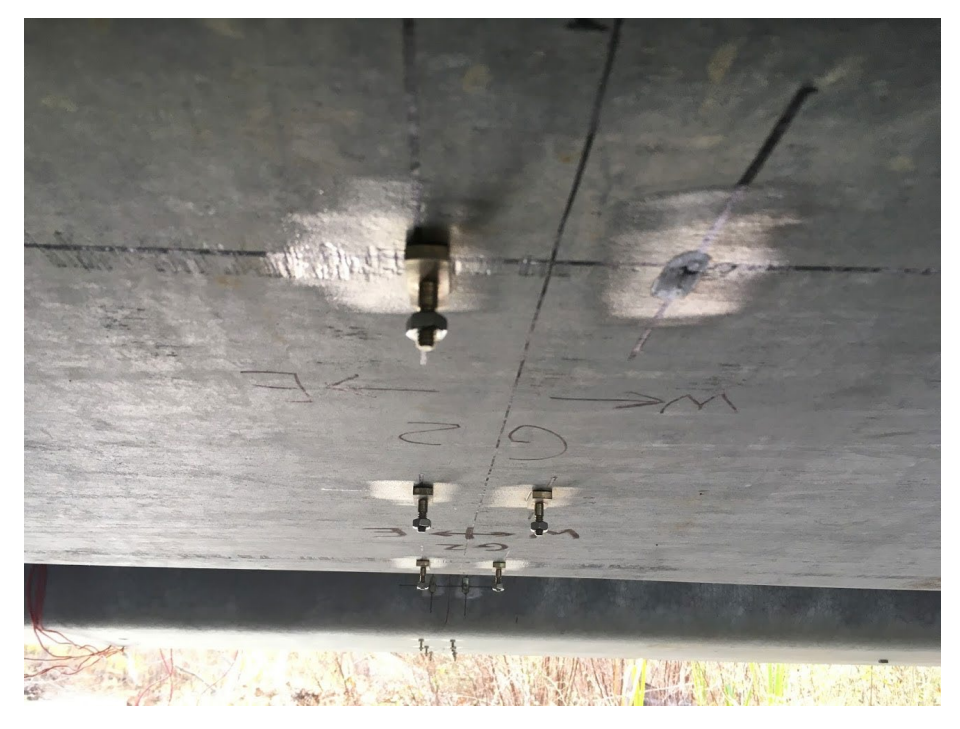

Figure 5.6: Failed Tab Connection, Bottom Flange Girder 2, Looking Upstream

After the tabs were connected, strain gages were assigned to each girder. The wireless 4channel nodes were held to the bridge railing using straps and clamps as appropriate. Strain transducers were assigned to the nodes. The nodes were then connected to the base station, four wirelessly and one through a wired connection. These connections were troubleshooted and the software checked on day two of the study. The base station was placed in a dry location to prevent any damage to the instrument. See Figure 5.7 for an image of the structure instrumentation.

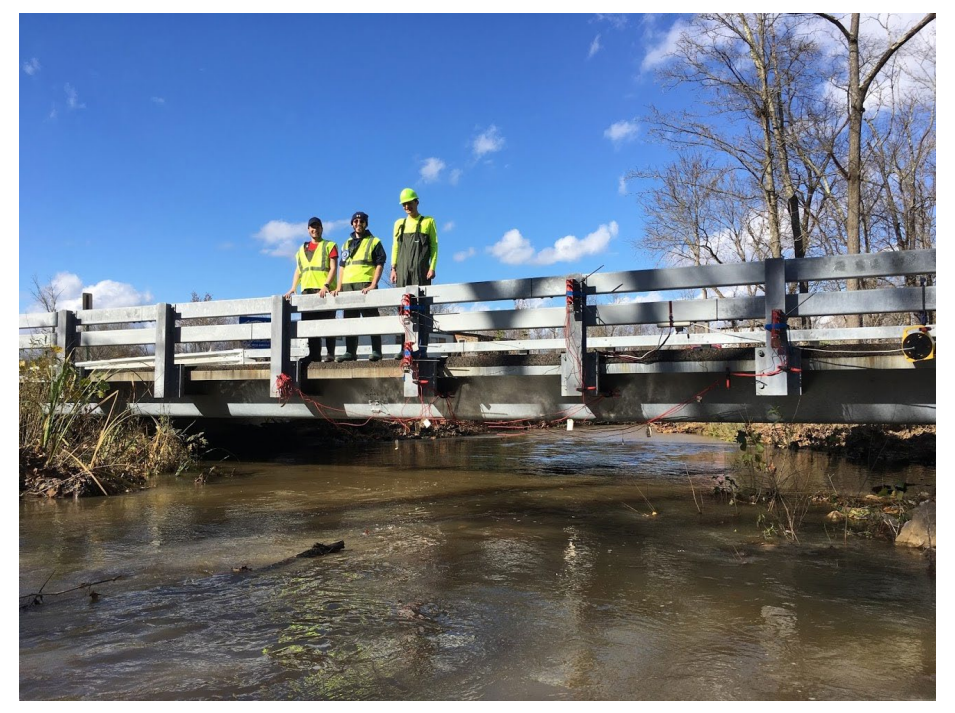

Figure 5.7: Nodes and Strain Transducer Attached to Bridge, Upstream Elevation 


\subsubsection{Live Load Path Delineation}

Day three of the study included the delineation of the load path on the deck of the structure for placement of the live load. Referencing Gibbs' work on the Amish Sawmill Bridge (2018) and AASHTO specifications for maximizing loads on individual girders, the following locations were determined for the five transverse truck runs on the tangent structure. Run placement dimensions were measured for the location of the centerline of the front right tire, Wheel 2. Run 1 of the truck was placed 2'-0" from the edge of the deck per AASHTO specifications for maximizing loads on the exterior girder. Run 4 was spaced 12' laterally from Run 1, 14'-0”' from upstream deck edge, to simulate two loaded lanes for data analysis. Run 2 was placed 2'-10" from the deck edge to maximize the load on the first interior girder. Run 5 was spaced 12' laterally from Run 2, 14'-10' from upstream deck edge, to simulate two loaded lanes for data analysis. The truck tires were placed for Run 3 such that the truck was centered on the structure, with the front right tire 8'-5" from deck edge. See Figure 5.8 for a schematic of the load placement discussed in this section.

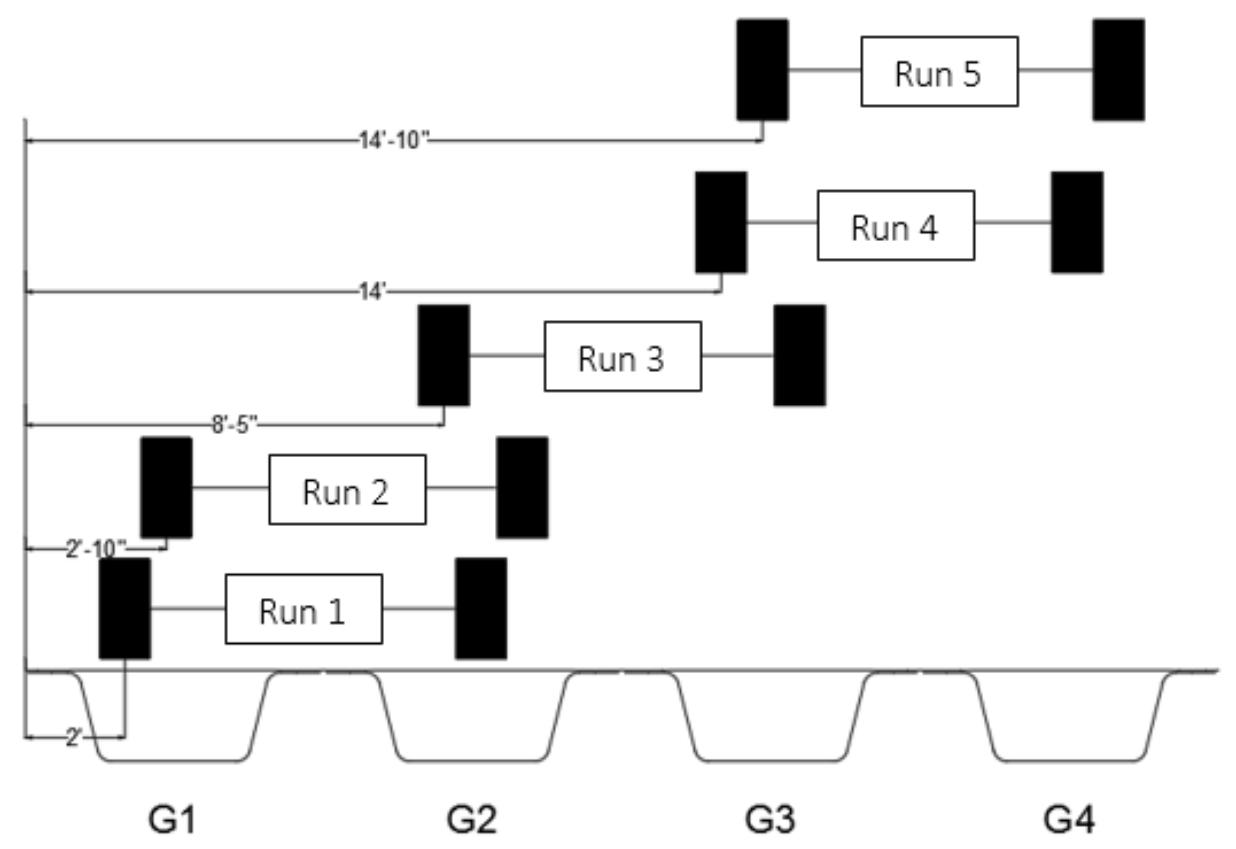

Figure 5.8: Live Load Truck Placement, Looking Back 
These load paths were delineated on the deck using construction string line. The midspan was determined at deck level. Using a square, the midspan mark from the girders was used to find the midspan of the structure; it was marked on the bridge rail. This was done on both sides of the structure. The location was then confirmed at deck level, by measuring from the deck level mark to the seal at the end of the structure. From the midspan mark, tenth points were marked every 5'-3' on either side using a square, see Figure 5.9. Once these marks were made, nails were placed in the deck at the respective tenth points on the upstream and downstream edges. String was stretched between each grid point across the structure. Special care was taken to ensure the string was taut between the two indicators, wrapping the string around the nail head several times. Starting at Abutment 1, the front right tire centerline locations were measured. The points where the lateral string from tenth point to tenth point intersected the longitudinal string denoted the location of the front right, rear tire where strain measurements were taken were grid points. These dimensions are provided in Figure 5.9. The final delineation of the bridge deck is shown in Figure 5.10 .

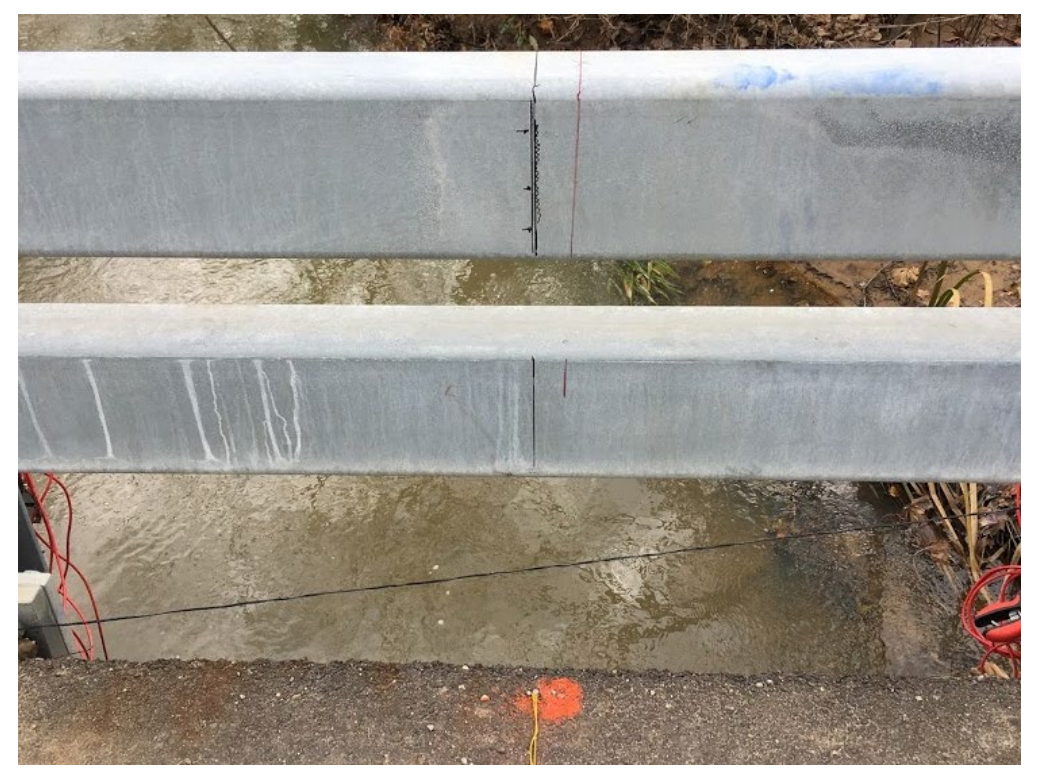

Figure 5.9: Midspan Measurement from Rail to Deck Edge, Looking Upstream 


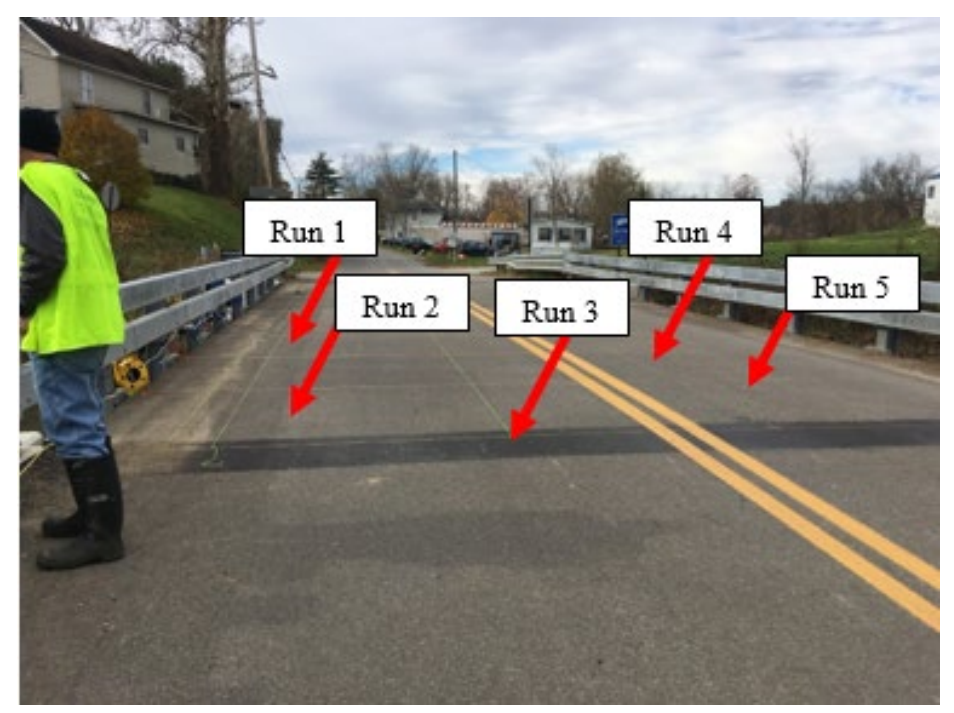

Figure 5.10: Final Delineation of Load Path, Looking Down Station from Abutment 2

\subsubsection{Live Load Testing}

The load truck provided on site was a tandem-axle dump truck. The truck met the AASHTO requirements to be considered an HS-20 design load truck, and thus was deemed suitable for the live load analysis. The dimensions of the truck and individual axle weights were taken at the bridge site for use in developing appropriate geometry and equivalent loads for finite element modeling. The truck was weighed in its entirety by the MCEO. This value, $53.02 \mathrm{kips}$, was used in the finite element analysis. See Section 4.3.5 for further details. Figure 5.11 provides the axle weights measured in the field.

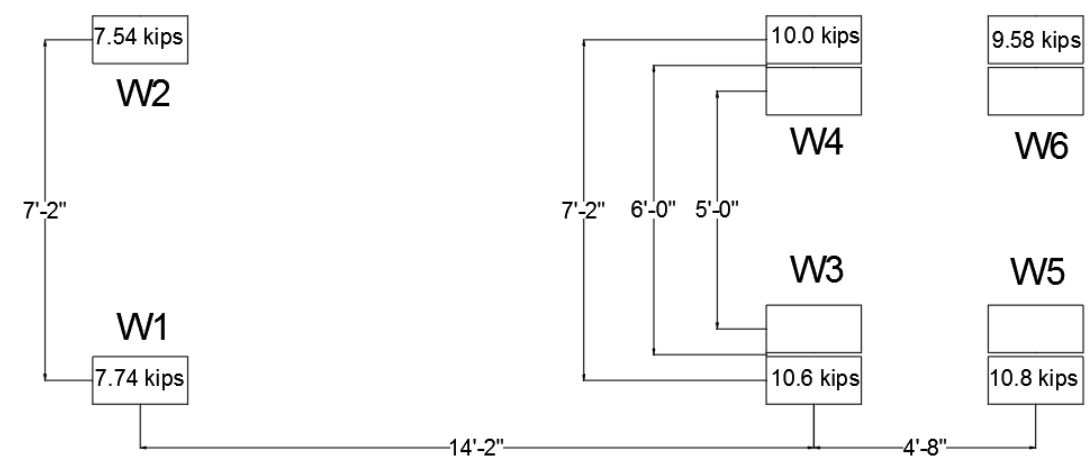

Figure 5.11: Truck Dimensions and Field Weight Measurements 
After the truck was weighed, the physical live load test of the bridge test was conducted. The truck was positioned off the bridge with the centerline of the front right tire, W2, on the run string line, see Section 5.2.2 and Figure 5.8. Once centered, the analysis was begun in the BDI software with a sampling frequency of $10 \mathrm{~Hz}$. Five measurements were taken to obtain a baseline measurement for the data collection. Then, the truck was driven onto the structure. At each grid point, the truck was stopped with W4 centered on the intersection, see Figure 5.12. Once the bridge returned to a static condition, five independent measurements were taken. This was completed for each grid point along the structure for each run.

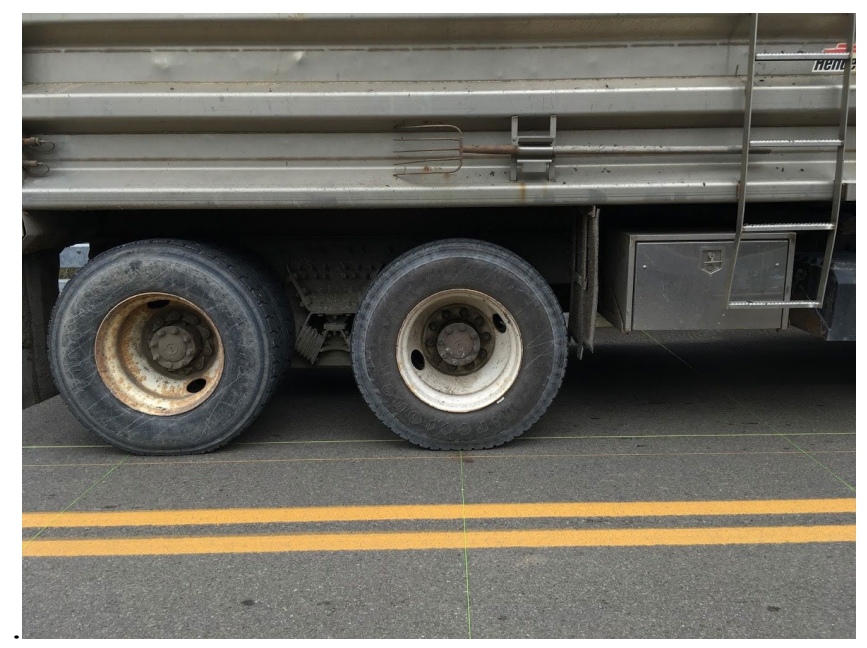

Figure 5.12: Run 5, Grid Point 2 Load Sample Location, Wheel 4, Looking Downstream 


\section{CHAPTER 6:RESULTS AND ANALYSIS}

\subsection{INTRODUCTION}

This chapter will present the results of both the live load field test and the finite element modeling analysis conducted on the Cannelville Road Bridge. Data will be compared from the field test and analytical modeling, including: midspan beam stresses, live load distribution factors, interior girder rating, and exterior girder rating. In addition, the results obtained in reference to AASHTO LRFD Specifications (2017) for LLDFs, interior girder rating, and exterior girder rating will be compared with the results of both the experimental testing and analytical modeling.

\subsection{COMPARISON OF RESUltS}

This section presents the results of both the finite element modeling analysis and the live load field test. Results for all truck runs yield similar conclusions. Due to the nature of the loading scenario, Truck Runs 2 and 4 are ideal for representing the response of the structure because both interior and exterior girders are loaded, with one side of the structure loaded more than the opposing. The results presented in this section are those from Truck Run 2. See Section 5.2.2 for more information regarding the location of Truck Run 2. The results from all truck runs are presented in Appendix A, including: results, tables, and graphs.

\subsubsection{Finite Element Modeling Results}

The following details the results from the finite element model developed of the Cannelville Road Bridge in Abaqus/CAE 6.14-1, discussed in Section 4.3. Figures 6.1 and 6.2 show an exaggerated response deflection (scale factor $=25$ ), contoured model for the strain values at grid point five, midspan for Run 2 . 


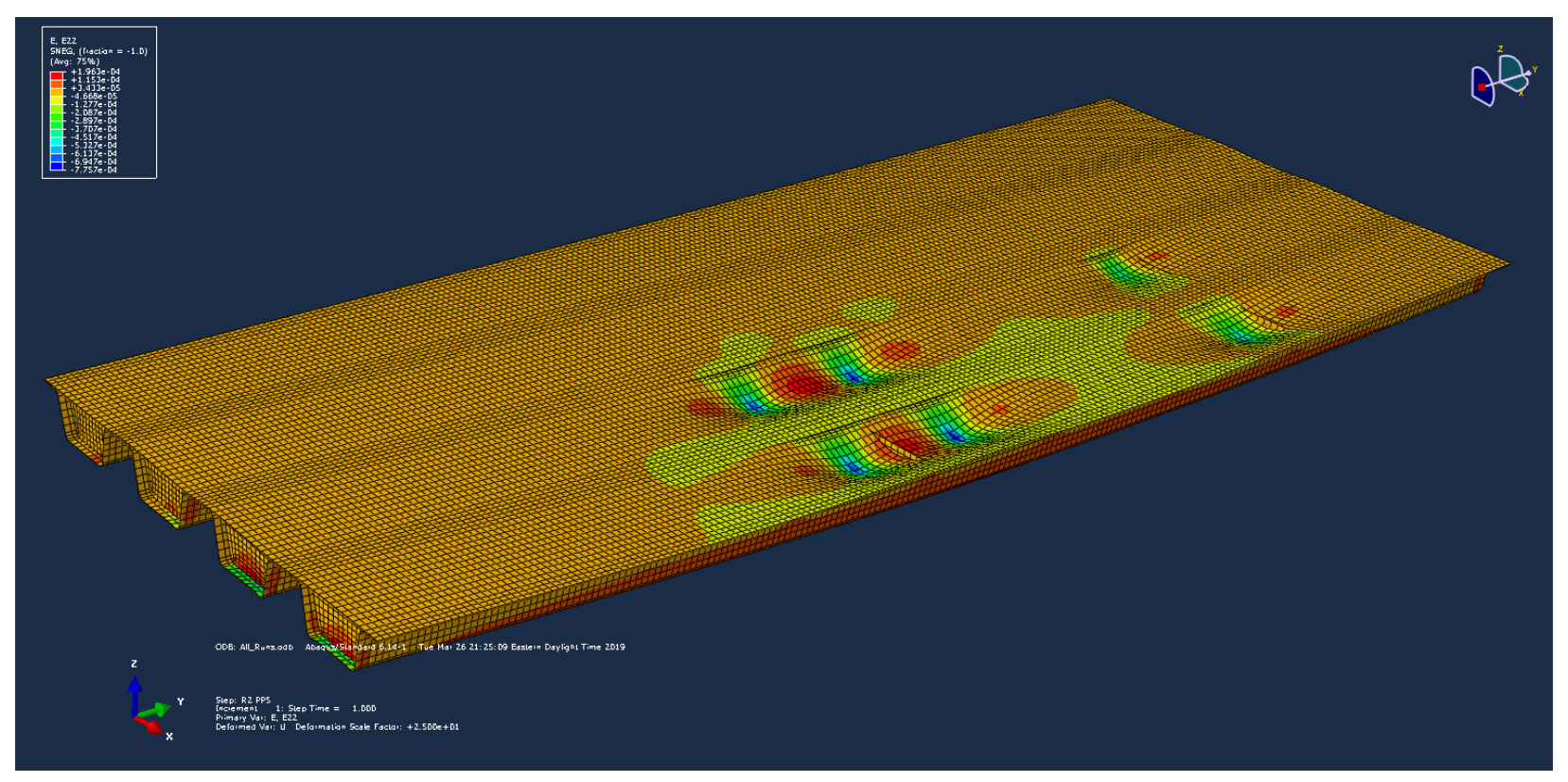

Figure 6.1: Longitudinal Strain, Run 2 - Grid Point 5 FEM Model, Looking Downstream

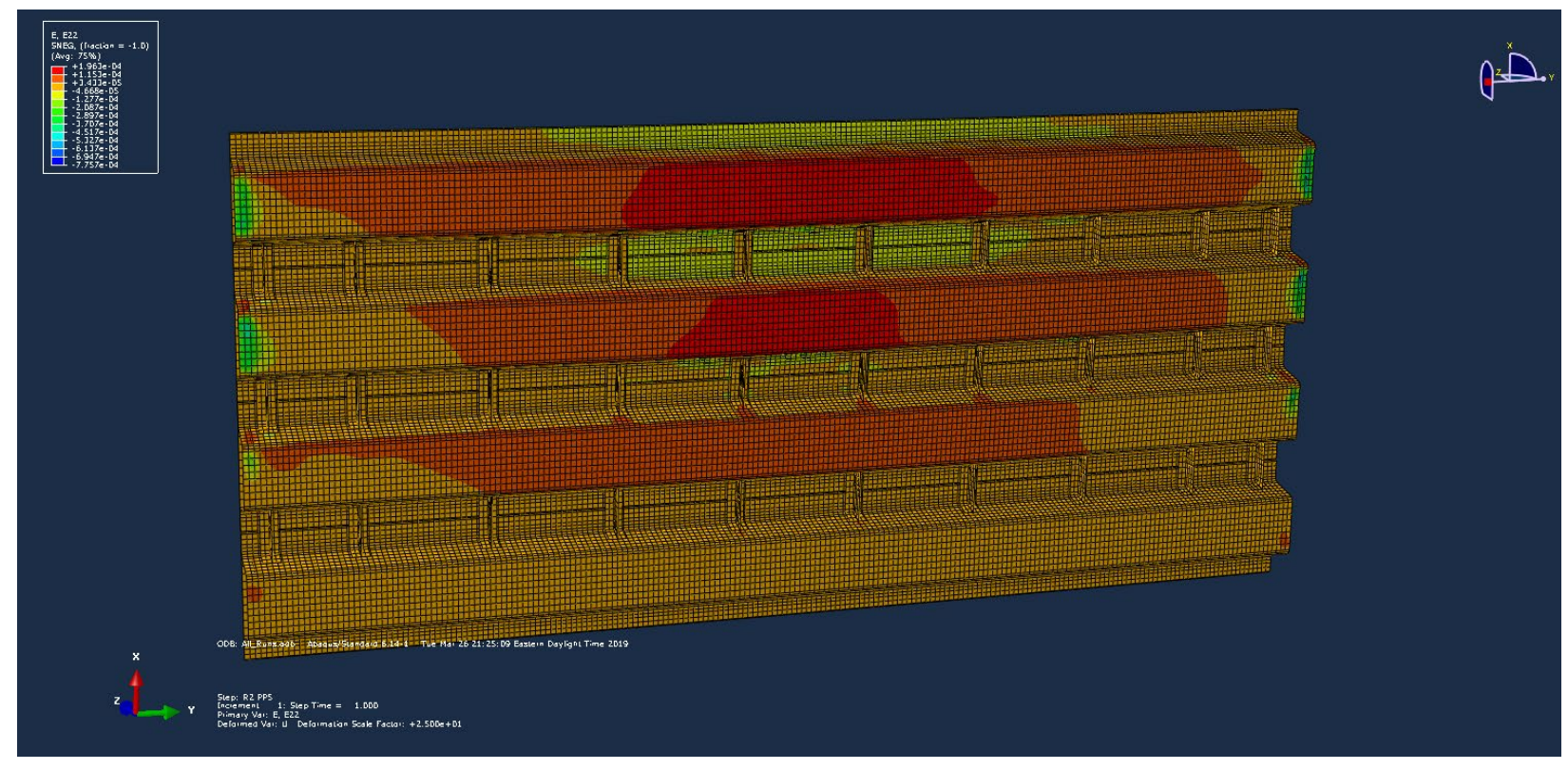

Figure 6.2: Longitudinal Strain, Run 2- Grid Point 5 FEM Model, Framing Plan 
The location of the wheels is evident in Figure 6.1, and the variations in strain between the girders along the bottom flange is evident in Figure 6.2. Additionally, note the difference in strain values between the girders. Girders 1 and 2 exhibit significantly higher strains than those seen in Girders 3 and 4.

\subsubsection{Midspan Beam Stress}

Bottom flange, midspan average stresses were calculated using the methods discussed in Section 4.4.1. Abaqus/CAE 6.14-1 has the capability of calculating and reporting stress values at specific locations. Despite this, to maintain consistency with procedure for processing the live load data, average strain values were used to compute midspan bending stresses. The results of this analysis are presented in Table 6.1.

\section{Table 6.1: Run 2 Bottom Flange Average Bending Stress, Finite Element Analysis}

\begin{tabular}{|c|c|c|c|c|c|}
\hline \multicolumn{6}{|c|}{ RUN 2, FEA RESULTS } \\
\hline \multicolumn{2}{|c|}{ GRID POINT } & \multicolumn{4}{|c|}{ AVERAGE STRESS (KSI) } \\
\hline $\mathrm{x}(\mathrm{ft})$ & $\mathrm{x} / \mathrm{L}$ & G1 & $\mathrm{G} 2$ & G3 & G4 \\
\hline 0.00 & 0.0 & 0.00 & 0.00 & 0.00 & 0.00 \\
\hline 5.25 & 0.1 & 1.42 & 1.24 & 0.77 & 0.39 \\
\hline 10.50 & 0.2 & 2.66 & 2.28 & 1.11 & 0.59 \\
\hline 15.75 & 0.3 & 3.31 & 2.83 & 1.38 & 0.73 \\
\hline 21.00 & 0.4 & 3.82 & 3.32 & 1.51 & 0.81 \\
\hline 26.25 & 0.5 & 4.44 & 3.97 & 1.46 & 0.82 \\
\hline 31.50 & 0.6 & 4.05 & 3.64 & 1.35 & 0.75 \\
\hline 36.75 & 0.7 & 2.78 & 2.44 & 1.18 & 0.62 \\
\hline 42.00 & 0.8 & 1.89 & 1.61 & 0.89 & 0.46 \\
\hline 47.25 & 0.9 & 1.05 & 0.89 & 0.62 & 0.30 \\
\hline 52.50 & 1.0 & 0.00 & 0.00 & 0.00 & 0.00 \\
\hline
\end{tabular}

As seen in Table 6.1, the bending stress in the bottom flange increases as the truck is placed closer to midspan, denoted grid point five. The bending stresses in Girders 1 and 2 are substantially higher than those in Girder 3 and 4 as is expected given the placement of the truck. 


\subsubsection{2 $\underline{\text { Live Load Distribution Factors }}$}

Live load distribution factors (LLDFs) were calculated using the methods discussed in Section 4.4.2. These values were calculated from the average strain values determined from the model output. Values for the single lane loaded, Run 2 condition are presented in Table 6.2. For two lane loaded conditions where Runs 2 and 5 are considered, see Appendix A.

Table 6.2: Run 2 Live Load Distribution Factors, Finite Element Analysis

\begin{tabular}{|c|c|c|c|c|c|c|c|c|c|}
\hline \multicolumn{10}{|c|}{ RUN 2, FEA RESULTS } \\
\hline \multicolumn{2}{|c|}{ GRID POINT } & \multicolumn{4}{|c|}{ AVERAGE MICROSTRAIN (IN/IN) } & \multicolumn{4}{|c|}{ DISTRIBUTION FACTORS } \\
\hline $\mathrm{x}(\mathrm{ft})$ & $\mathrm{x} / \mathrm{L}$ & G1 & $\mathrm{G} 2$ & G3 & G4 & G1 & $\mathrm{G} 2$ & G3 & G4 \\
\hline 0.00 & 0.0 & 0.00 & 0.00 & 0.00 & 0.00 & 0.000 & 0.000 & 0.000 & 0.000 \\
\hline 5.25 & 0.1 & 49.04 & 42.61 & 26.70 & 13.60 & 0.372 & 0.323 & 0.202 & 0.103 \\
\hline 10.50 & 0.2 & 91.62 & 78.56 & 38.36 & 20.19 & 0.401 & 0.343 & 0.168 & 0.088 \\
\hline 15.75 & 0.3 & 114.29 & 97.68 & 47.70 & 25.24 & 0.401 & 0.343 & 0.167 & 0.089 \\
\hline 21.00 & 0.4 & 131.72 & 114.41 & 52.10 & 28.00 & 0.404 & 0.351 & 0.160 & 0.086 \\
\hline 26.25 & 0.5 & 152.96 & 136.88 & 50.43 & 28.12 & 0.415 & 0.372 & 0.137 & 0.076 \\
\hline 31.50 & 0.6 & 139.70 & 125.60 & 46.48 & 25.77 & 0.414 & 0.372 & 0.138 & 0.076 \\
\hline 36.75 & 0.7 & 95.95 & 84.24 & 40.61 & 21.30 & 0.396 & 0.348 & 0.168 & 0.088 \\
\hline 42.00 & 0.8 & 65.13 & 55.51 & 30.85 & 15.75 & 0.389 & 0.332 & 0.184 & 0.094 \\
\hline 47.25 & 0.9 & 36.26 & 30.74 & 21.45 & 10.42 & 0.367 & 0.311 & 0.217 & 0.105 \\
\hline 52.50 & 1.0 & 0.00 & 0.00 & 0.00 & 0.00 & 0.000 & 0.000 & 0.000 & 0.000 \\
\hline & & & \multicolumn{3}{|c|}{ AVERAGE } & 0.395 & 0.344 & 0.171 & 0.090 \\
\hline & & & \multicolumn{3}{|c|}{ AVERAGE * MPF (1.2) } & 0.474 & 0.413 & 0.205 & 0.107 \\
\hline & & & \multicolumn{3}{|c|}{ STAND. DEVIATION } & 0.017 & 0.020 & 0.027 & 0.010 \\
\hline
\end{tabular}

The truck load is distributed to each of the girders in the percentages shown in Table 6.2, with the adjusted LLDF for each girder as follows: $47.4 \%$ to Girder 1, $41.3 \%$ to Girder 2, 20.5\% to Girder 3, and $10.7 \%$ to Girder 4. Note, again, that the loads in Girders 1 and 2 are much larger than those transferred to Girders 3 and 4. 


\subsubsection{Live Load Girder Rating}

Live load interior and exterior girder ratings were calculated using the methods and software discussed in Section 4.4.3. Bentley Lars CONNECT (LARS) reports the absolute minimum live load girder rating for each live load case. The maximum average live load distribution factors, calculated in Section 6.2.1.2, and their origin are as follows:

Interior Girder:

- Single Lane $=0.415($ Girder 3, Run 4)

- Multi-Lane $=0.516($ Girder 2, Runs 1+4)
Exterior Girder:

- Single Lane $=0.520($ Girder 4, Run 5)

- Multi-Lane $=0.524($ Girder 1, Runs 1+4)

The HL-93 Inventory, HL-93 Operating, and HS20 Permit ratings for both interior and exterior girders, generated using the LLDFs listed, are presented in Table 6.3. The exterior girder ratings are consistently less than the interior girder ratings. The multi-lane loaded ratings are slightly lower than the single lane loaded condition for exterior girders and noticeably lower for interior girders. This is consistent with the effect resulting from full use of the structure. The structure, in analysis of the finite element modeling analysis, meets the AASHTO criteria for a rating greater than or equal to 1.0

Table 6.3: Live Load Interior and Exterior Girder Ratings, Finite Element Analysis

\begin{tabular}{|c|c|c|c|r|r|r|}
\hline \multicolumn{5}{|c|}{ FINITE ELEMENT ANALYSIS - MOMENT LOAD RATING RESULTS } \\
\hline GIRDER & \multicolumn{3}{|c|}{ SINGLE LANE } & \multicolumn{3}{c|}{ MULTI-LANE } \\
\hline TRUCK & HL-93 INV. & HL-93 OPER. & HS20 & HL-93 INV. & HL-93 OPER. & \multicolumn{1}{c|}{ HS20 } \\
\hline INTERIOR GIRDER & 3.17 & 4.11 & 3.86 & 2.55 & 3.31 & 3.10 \\
\hline EXTERIOR GIRDER & 2.53 & 3.28 & 3.05 & 2.51 & 3.26 & 3.08 \\
\hline
\end{tabular}

The graphical results of the interior girder rating analysis and exterior girder rating analysis are presented in Figures 6.3 and 6.4 respectively. Note that the dead load applied to the interior and exterior girder are similar in magnitude. This is due to the girder spacing and resultant small overhang on the bridge. The live load moment, however, is substantially different due to the variation in LLDFs. 


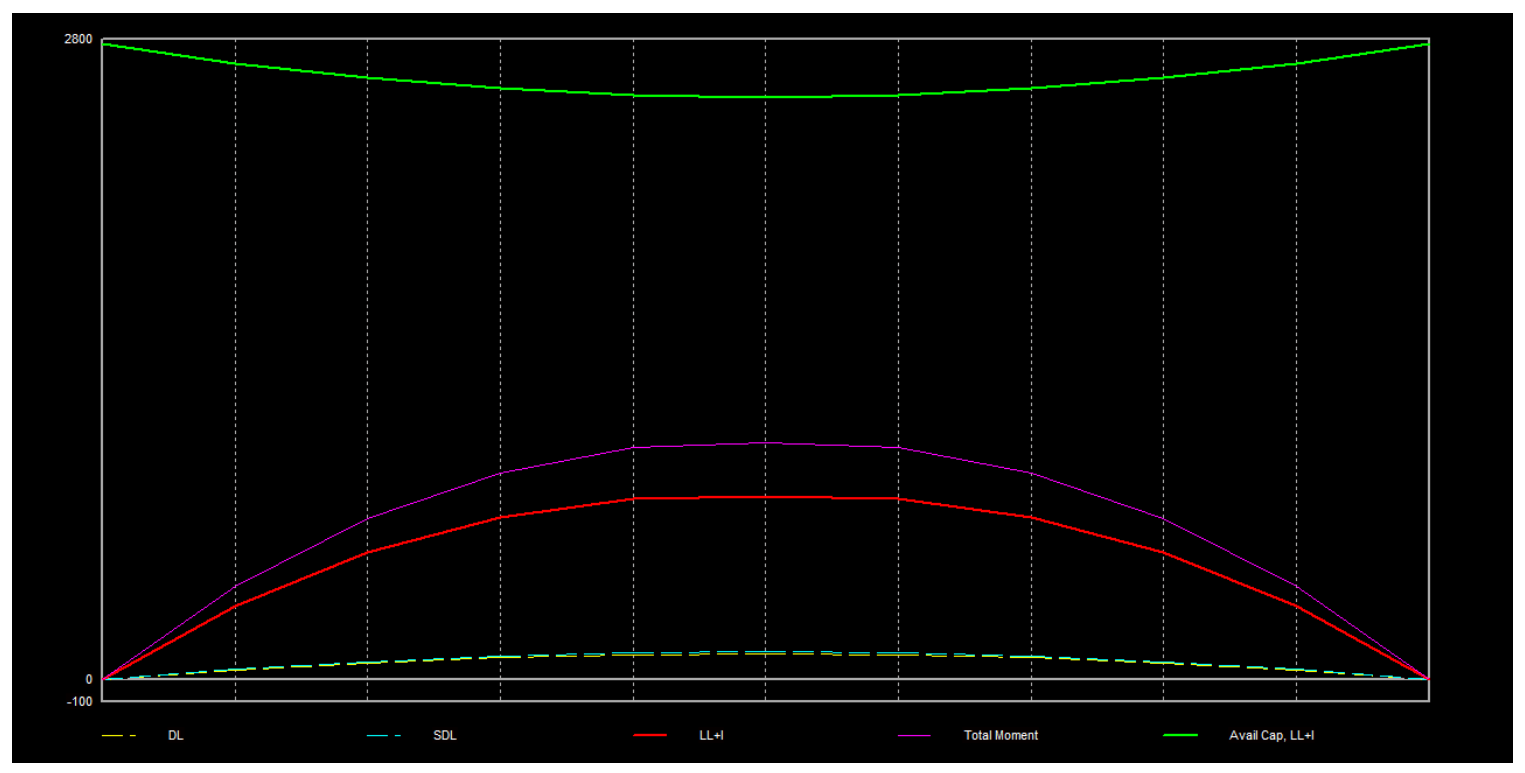

Figure 6.3: Interior Girder Load Rating - Moment Capacity vs. Load Applied, Finite Element Analysis

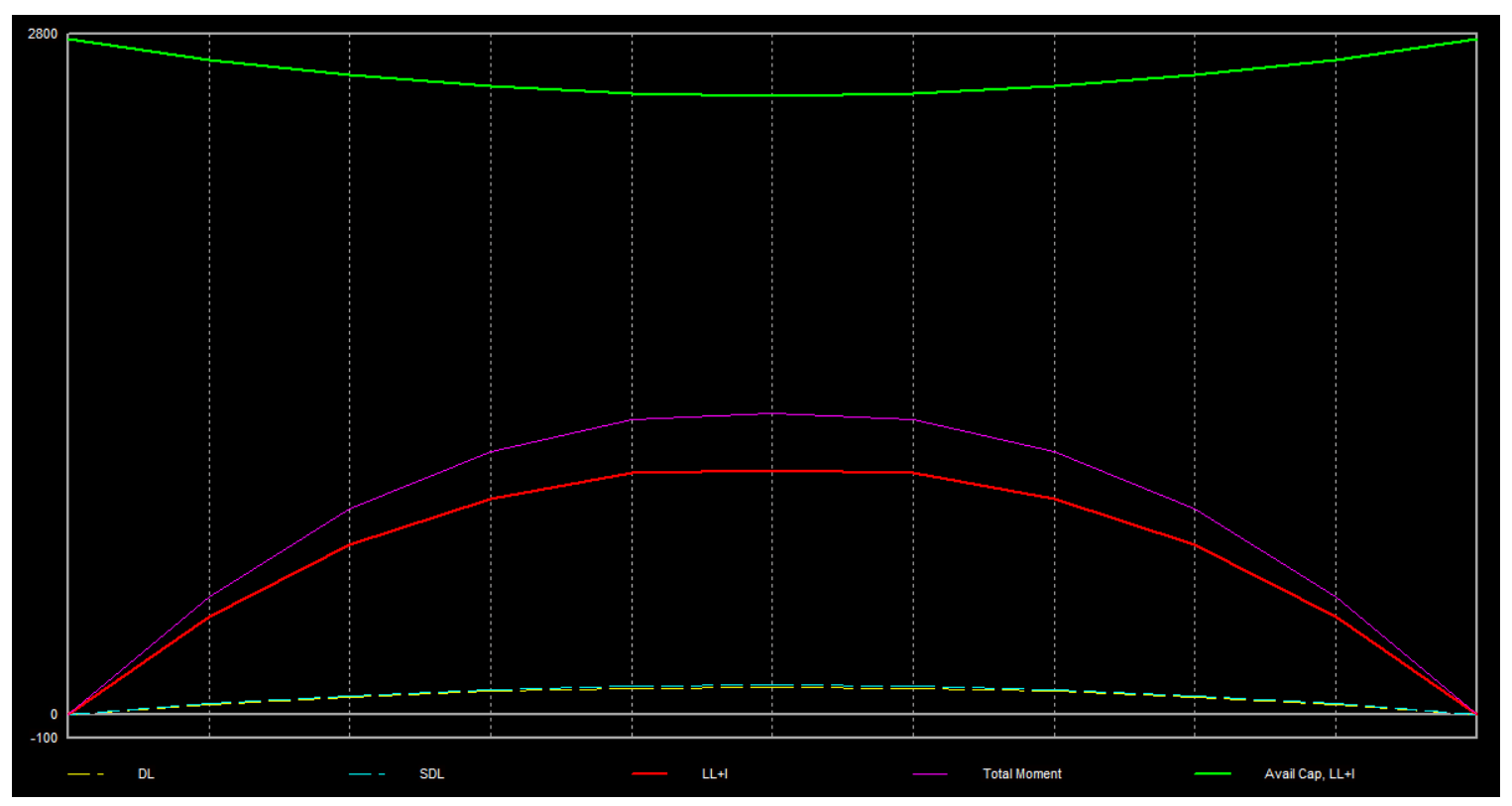

Figure 6.4: Exterior Girder Load Rating-Moment Capacity vs. Load Applied,

Finite Element Analysis 


\subsubsection{Live Load Field Test Results}

The following details the results from the live load field testing completed on the Cannelville Road Bridge using the BDI Data Acquisition System and Strain Transducers, discussed in Chapter 5. Note, one of the three strain transducers on Girder 3 was not functional. Therefore, only two data points were available to be averaged for each grid point in the following calculations for Girder 3.

\subsubsection{Midspan Beam Stress}

Bottom flange, midspan average stresses were calculated using the methods discussed in Section 4.4.1. Strain values obtained from the BDI software reports were averaged for each girder and used to generate these stresses. The results of this analysis are presented in Table 6.4.

Table 6.4: Run 2 Bottom Flange Average Bending Stress, Live Load Field Test

\begin{tabular}{|c|c|c|c|c|c|}
\hline \multicolumn{5}{|c|}{ RUN 2, FIELD RESULTS } \\
\hline \multicolumn{2}{|c|}{ GRID POINT } & \multicolumn{4}{c|}{ AVERAGE STRESS (KSI) } \\
\hline $\mathrm{x}(\mathrm{ft})$ & $\mathrm{x} / \mathrm{L}$ & $\mathrm{G} 1$ & $\mathrm{G} 2$ & $\mathrm{G} 3$ & $\mathrm{G} 4$ \\
\hline 0.00 & 0.0 & 0.00 & 0.00 & 0.00 & 0.00 \\
\hline 5.25 & 0.1 & 1.15 & 0.99 & 0.35 & 0.49 \\
\hline 10.50 & 0.2 & 2.16 & 1.78 & 0.53 & 0.79 \\
\hline 15.75 & 0.3 & 2.63 & 2.19 & 0.65 & 0.98 \\
\hline 21.00 & 0.4 & 3.00 & 2.57 & 0.71 & 1.10 \\
\hline 26.25 & 0.5 & 3.60 & 3.07 & 0.69 & 1.13 \\
\hline 31.50 & 0.6 & 3.25 & 2.81 & 0.64 & 1.03 \\
\hline 36.75 & 0.7 & 2.16 & 1.88 & 0.54 & 0.81 \\
\hline 42.00 & 0.8 & 1.40 & 1.19 & 0.40 & 0.59 \\
\hline 47.25 & 0.9 & 0.76 & 0.65 & 0.24 & 0.34 \\
\hline 52.50 & 1.0 & 0.00 & 0.00 & 0.00 & 0.00 \\
\hline
\end{tabular}


In Table 6.4, note that the bending stress within the bottom flange increases as the truck draws closer to midspan, grid point five, and then decreases again for each girder, just as it did in the finite element model. Again, the bending stresses in Girders 1 and 2 are substantially higher than those in Girder 3 and 4 as is expected given the placement of the truck.

\subsubsection{Live Load Distribution Factors}

Live load distribution factors (LLDFs) were calculated using the methods discussed in Section 4.4.2. These values were calculated from the average strain values as discussed in Section 6.2.2.1 and Section 4.4. Values for the single lane loaded, Run 2 condition are presented in Table 6.5. For two lane loaded conditions where Runs 2 and 5 are considered, see Appendix A.

Table 6.5: Run 2 Live Load Distribution Factors, Live Load Field Test

\begin{tabular}{|c|c|c|c|c|c|c|c|c|c|}
\hline \multicolumn{10}{|c|}{ RUN 2, FIELD RESULTS } \\
\hline \multicolumn{2}{|c|}{ GRID POINT } & \multicolumn{4}{|c|}{ AVERAGE MICROSTRAIN (IN/IN) } & \multicolumn{4}{|c|}{ DISTRIBUTION FACTORS } \\
\hline $\mathrm{x}(\mathrm{ft})$ & $\mathrm{x} / \mathrm{L}$ & G1 & $\mathrm{G} 2$ & G3 & G4 & G1 & G2 & G3 & G4 \\
\hline 0.00 & 0.0 & 0.00 & 0.00 & 0.00 & 0.00 & 0.000 & 0.000 & 0.000 & 0.000 \\
\hline 5.25 & 0.1 & 39.74 & 34.24 & 11.91 & 16.97 & 0.386 & 0.333 & 0.116 & 0.165 \\
\hline 10.50 & 0.2 & 74.64 & 61.40 & 18.11 & 27.12 & 0.412 & 0.339 & 0.100 & 0.150 \\
\hline 15.75 & 0.3 & 90.68 & 75.47 & 22.34 & 33.95 & 0.408 & 0.339 & 0.100 & 0.153 \\
\hline 21.00 & 0.4 & 103.37 & 88.48 & 24.40 & 37.84 & 0.407 & 0.348 & 0.096 & 0.149 \\
\hline 26.25 & 0.5 & 124.08 & 105.74 & 23.85 & 38.79 & 0.424 & 0.362 & 0.082 & 0.133 \\
\hline 31.50 & 0.6 & 112.15 & 97.05 & 21.97 & 35.41 & 0.421 & 0.364 & 0.082 & 0.133 \\
\hline 36.75 & 0.7 & 74.40 & 64.68 & 18.56 & 28.00 & 0.401 & 0.348 & 0.100 & 0.151 \\
\hline 42.00 & 0.8 & 48.23 & 40.95 & 13.80 & 20.19 & 0.392 & 0.332 & 0.112 & 0.164 \\
\hline 47.25 & 0.9 & 26.21 & 22.54 & 8.29 & 11.66 & 0.382 & 0.328 & 0.121 & 0.170 \\
\hline 52.50 & 1.0 & 0.00 & 0.00 & 0.00 & 0.00 & 0.000 & 0.000 & 0.000 & 0.000 \\
\hline & & & \multicolumn{3}{|c|}{ AVERAGE } & 0.404 & 0.344 & 0.101 & 0.152 \\
\hline & & & \multicolumn{3}{|c|}{ AVERAGE * MPF (1.2) } & 0.484 & 0.412 & 0.121 & 0.182 \\
\hline & & & \multicolumn{3}{|c|}{ STAND. DEVIATION } & 0.015 & 0.013 & 0.014 & 0.013 \\
\hline
\end{tabular}

The truck load is distributed to each of the girders in the percentages shown in Table 6.5, with the adjusted LLDF for each girder as follows: $48.4 \%$ to Girder 1, $41.2 \%$ to Girder 2, 12.1\% to Girder 3, and $18.2 \%$ to Girder 4. Note, again, that the loads in Girders 1 and 2 are much larger than those transferred to Girders 3 and 4. 


\subsubsection{Live Load Girder Rating}

Live load interior and exterior girder ratings were calculated using the methods and software discussed in Section 4.4.3. Bentley Lars CONNECT (LARS) reports the absolute minimum live load girder rating for each live load case. The maximum average live load distribution factors, calculated in Section 6.2.2.2, and their origin are as follows:

Interior Girder:

- Single Lane $=0.421($ Girder 3, Run 5)

- Multi-Lane $=0.502($ Girder 2, Runs 1+4)
Exterior Girder:

- Single Lane $=0.525($ Girder 1, Run 1)

- Multi-Lane $=0.552($ Girder 1, Runs 1+4)

The HL-93 Inventory, HL-93 Operating, and HS20 Permit ratings for both interior and exterior girders, generated using the LLDFs listed, are presented in Table 6.6. The exterior girder ratings are on average 0.5 less than the interior girder ratings. The multi-lane loaded ratings are also significantly lower that the single lane ratings in this case. The structure, in analysis of the live load field test results, meets the AASHTO criteria for a rating greater than or equal to 1.0.

Table 6.6: Live Load Interior and Exterior Girder Ratings, Field Test Results

\begin{tabular}{|c|c|c|c|r|r|r|}
\hline \multicolumn{3}{|c|}{ FIELD TEST RESULTS - MOMENT LOAD RATING RESULTS } \\
\hline GIRDER & \multicolumn{3}{|c|}{ SINGLE LANE } & \multicolumn{3}{c|}{ MULTI-LANE } \\
\hline TRUCK & HL-93 INV. & HL-93 OPER. & HS20 & HL-93 INV. & HL-93 OPER. & HS20 \\
\hline INTERIOR GIRDER & 3.13 & 4.06 & 3.80 & 2.62 & 3.40 & 3.19 \\
\hline EXTERIOR GIRDER & 2.51 & 3.25 & 3.05 & 2.39 & 3.09 & 2.90 \\
\hline
\end{tabular}

The graphical results of the interior girder rating analysis and exterior girder rating analysis are presented in Figures 6.5 and 6.6 respectively. Note that the dead load applied in each case has is similar. This is due to the girder spacing and resultant small overhang on the bridge. The live load moment, however, is substantially different due to the variation in LLDFs between interior and exterior girders. 


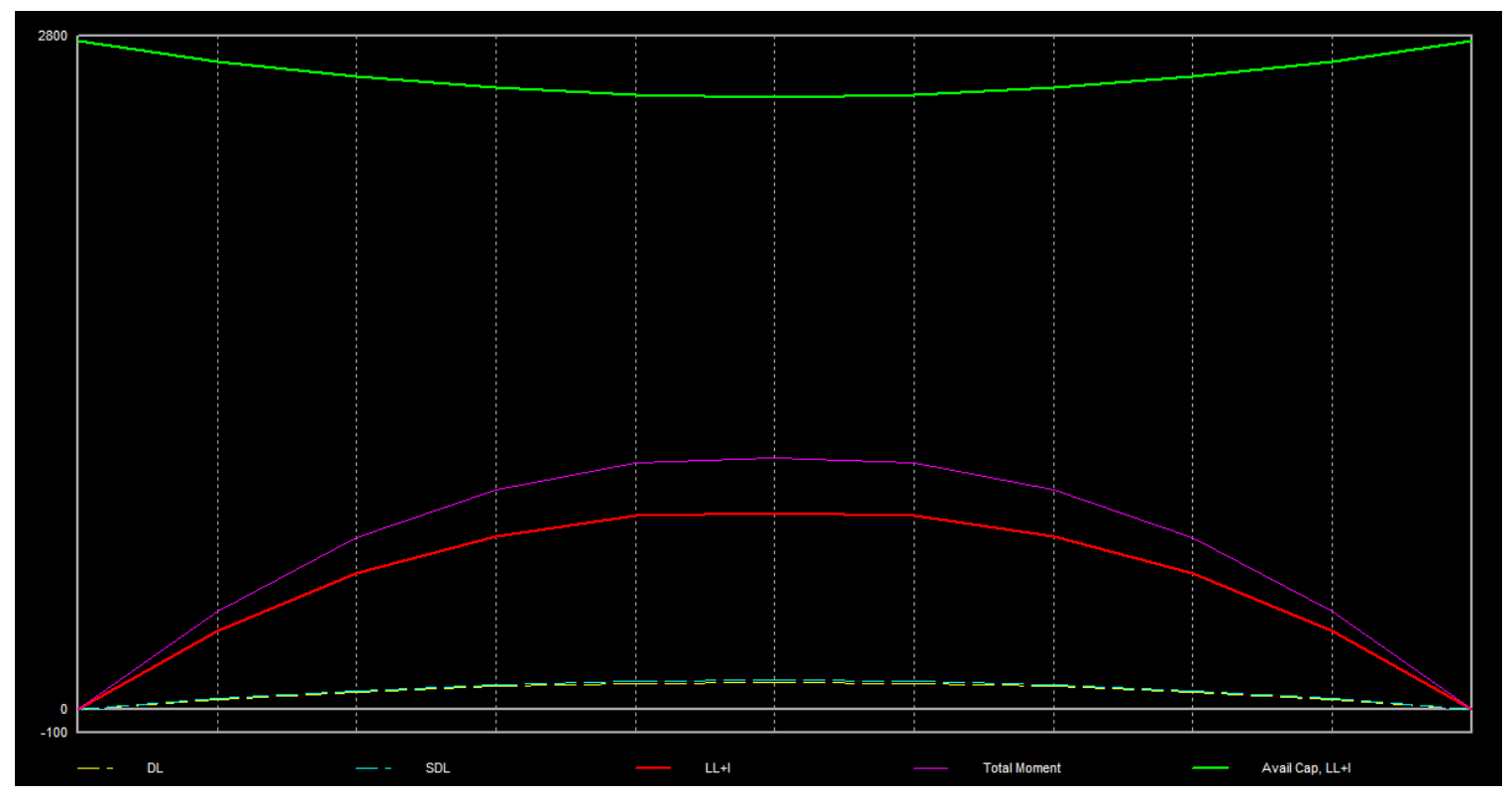

Figure 6.5:Interior Girder Load Rating - Moment Capacity vs. Load Applied, Field Test Results

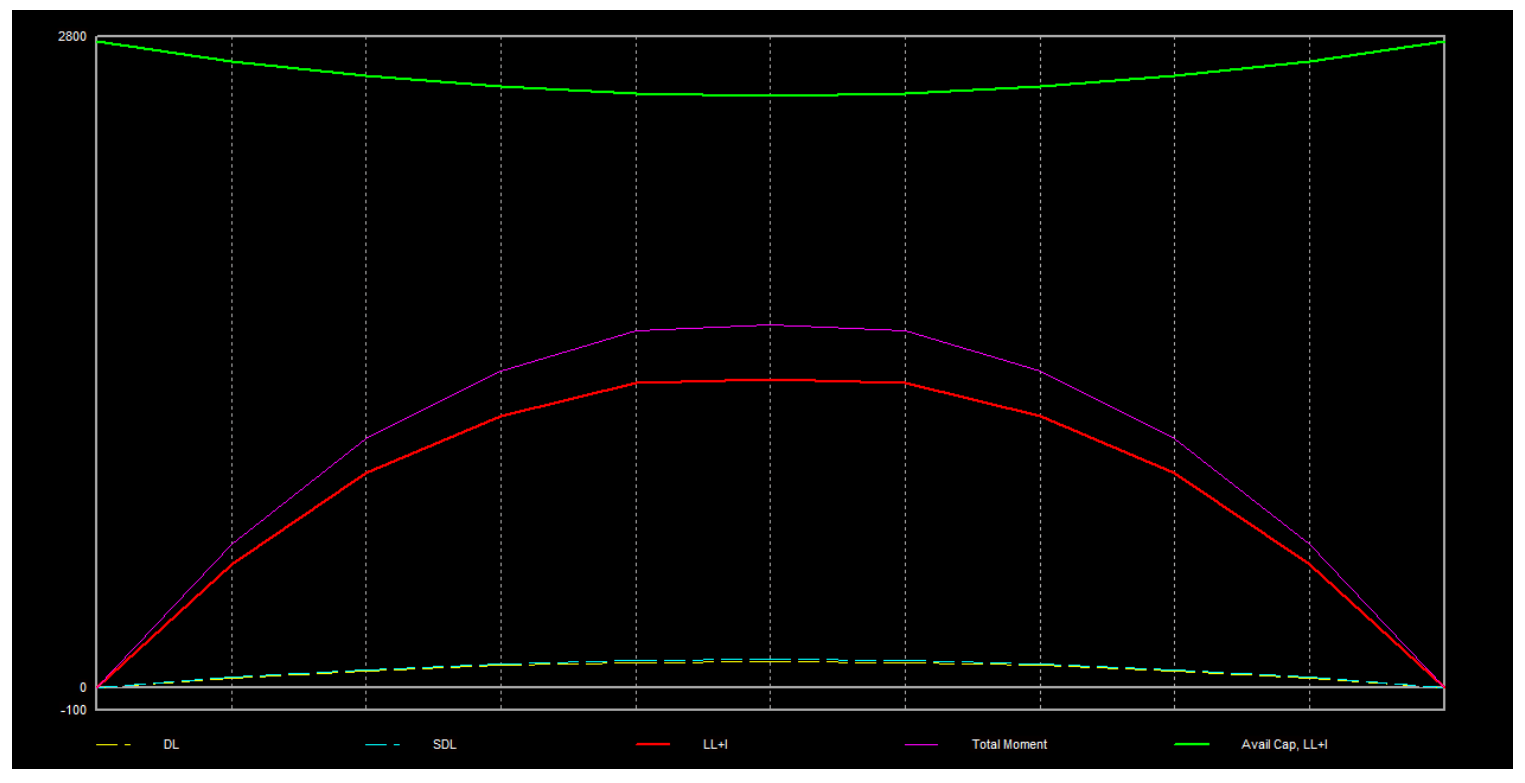

Figure 6.6: Exterior Girder Load Rating - Moment Capacity vs. Load Applied, Field Test Results 


\subsubsection{Comparison of Analytical and Experimental Results}

This section will provide a comparison of the finite element model analysis and live load field test results for the following: midspan beam stress, live load distribution factors, interior girder rating, and exterior girder rating. Overall, the results are similar. There are discrepancies in the stress values, this is likely due to the variation in boundary conditions and bracing connections seen in the field versus those assigned in the model. See Section 4.3 for more information regarding boundary condition assignments.

\subsubsection{Midspan Beam Stress}

The midspan beam stress calculations from the two cases, finite element model and live load field test, for Run 2 calculated in Sections 6.2.1 and 6.2.2 respectively are presented in Table 6.7 .

Table 6.7: Run 2 Bottom Flange Average Bending Stress, Live Load Field Test vs. Finite Element Analysis

\begin{tabular}{|c|c|c|c|c|c|c|c|c|c|}
\hline \multicolumn{10}{|c|}{ RUN 2, AVERAGE MIDSPAN BENDING STRESS (KSI) } \\
\hline \multicolumn{1}{|c|}{ GRID POINT } & \multicolumn{2}{|c|}{ LIVE LOAD FIELD TEST } & \multicolumn{3}{c|}{ FINITE ELEMENT ANALYSIS } \\
\hline $\mathrm{x}(\mathrm{ft})$ & $\mathrm{x} / \mathrm{L}$ & $\mathrm{G} 1$ & $\mathrm{G} 2$ & $\mathrm{G} 3$ & $\mathrm{G} 4$ & $\mathrm{G} 1$ & $\mathrm{G} 2$ & $\mathrm{G} 3$ & $\mathrm{G} 4$ \\
\hline 0.00 & 0.0 & 0.00 & 0.00 & 0.00 & 0.00 & 0.00 & 0.00 & 0.00 & 0.00 \\
\hline 5.25 & 0.1 & 1.15 & 0.99 & 0.35 & 0.49 & 1.42 & 1.24 & 0.77 & 0.39 \\
\hline 10.50 & 0.2 & 2.16 & 1.78 & 0.53 & 0.79 & 2.66 & 2.28 & 1.11 & 0.59 \\
\hline 15.75 & 0.3 & 2.63 & 2.19 & 0.65 & 0.98 & 3.31 & 2.83 & 1.38 & 0.73 \\
\hline 21.00 & 0.4 & 3.00 & 2.57 & 0.71 & 1.10 & 3.82 & 3.32 & 1.51 & 0.81 \\
\hline 26.25 & 0.5 & 3.60 & 3.07 & 0.69 & 1.13 & 4.44 & 3.97 & 1.46 & 0.82 \\
\hline 31.50 & 0.6 & 3.25 & 2.81 & 0.64 & 1.03 & 4.05 & 3.64 & 1.35 & 0.75 \\
\hline 36.75 & 0.7 & 2.16 & 1.88 & 0.54 & 0.81 & 2.78 & 2.44 & 1.18 & 0.62 \\
\hline 42.00 & 0.8 & 1.40 & 1.19 & 0.40 & 0.59 & 1.89 & 1.61 & 0.89 & 0.46 \\
\hline 47.25 & 0.9 & 0.76 & 0.65 & 0.24 & 0.34 & 1.05 & 0.89 & 0.62 & 0.30 \\
\hline 52.50 & 1.0 & 0.00 & 0.00 & 0.00 & 0.00 & 0.00 & 0.00 & 0.00 & 0.00 \\
\hline
\end{tabular}

To improve the ability to notice trends in the data, the Figure 6.7 and 6.8 were generated. It is evident in these figures, that the model is predicting stresses moderately higher than those determined by the live load field test. This is most likely due to varying boundary conditions 
between the two systems. Note, however, the curves are highly similar. This suggests that the model is a good indicator of the load distribution behavior of the structure. See Section 6.2.3.2 for further details regarding load distribution factors and the similarities between the two analyses.

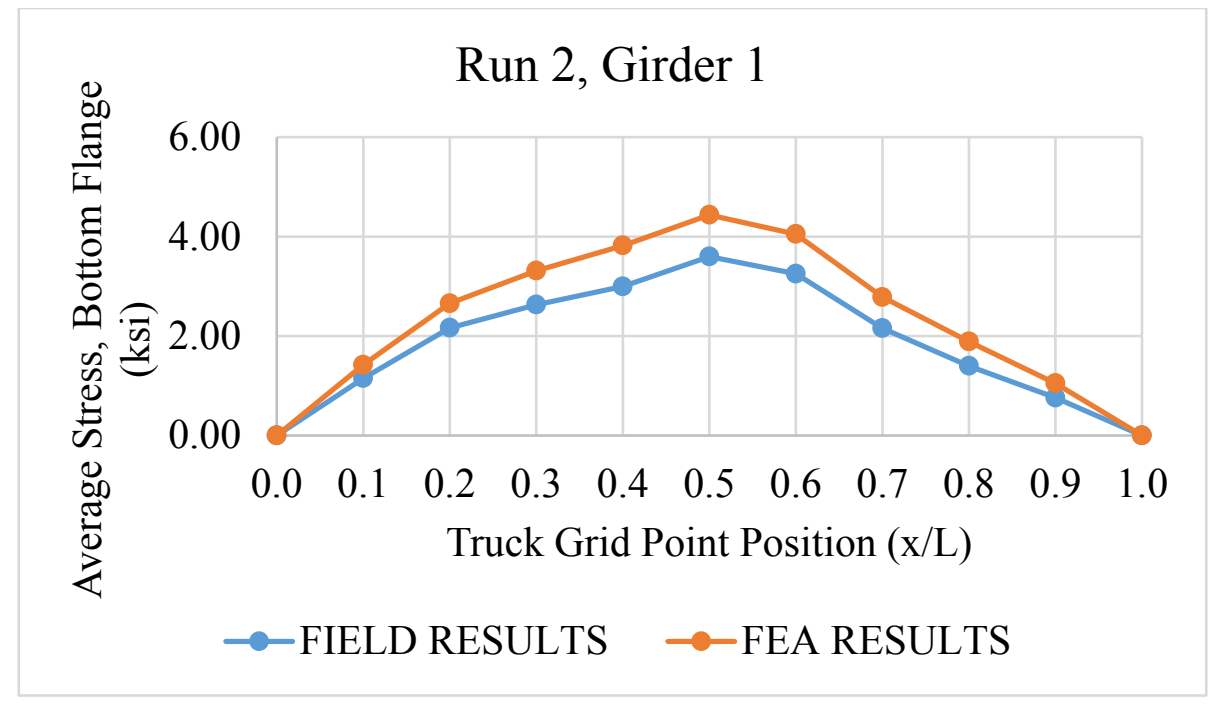

Figure 6.7: Run 2, Girder 1 Bottom Flange Average Bending Stress, Live Load Field Test vs. Finite Element Analysis

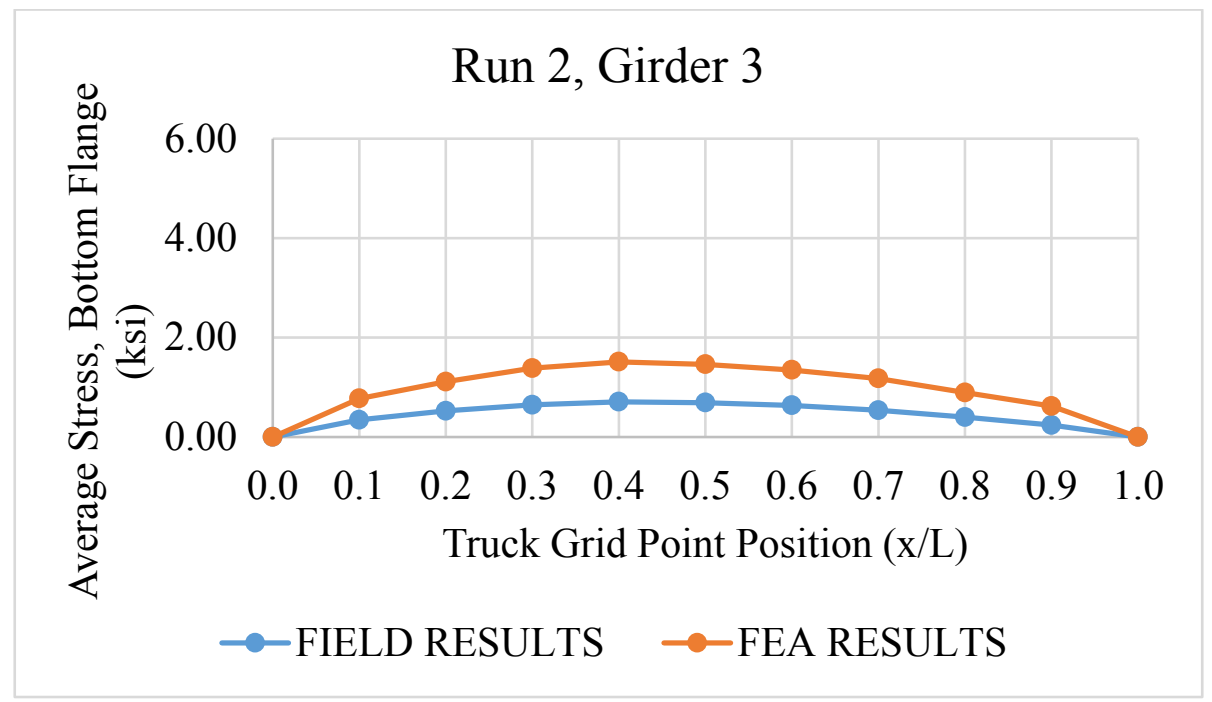

Figure 6.8: Run 2, Girder 3 Bottom Flange Average Bending Stress, Live Load Field Test vs. Finite Element Analysis 
Similar trends hold true for the simulated two-lane loaded cases. Presented in Figures 6.9 and 6.10, the average midspan bending stresses determined from the model are higher than those determined from field measurements. However, the load distribution trends, shape of the curve, are similar between the two systems.

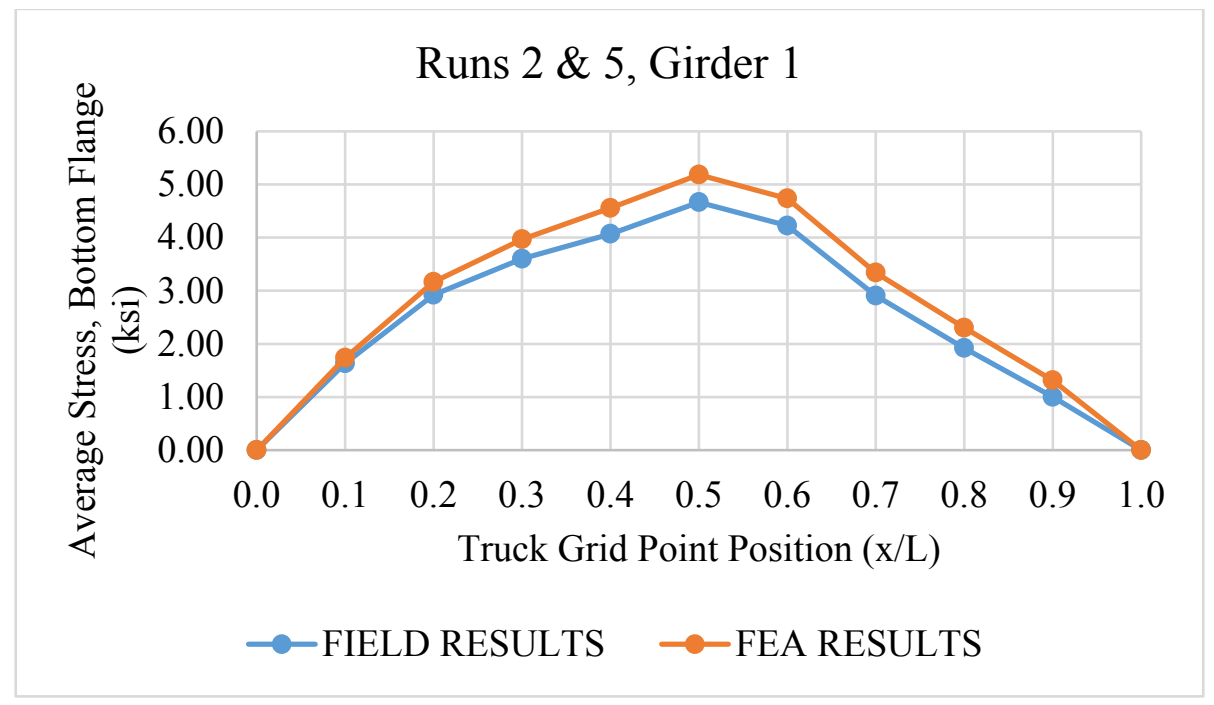

Figure 6.9: Runs 2 and 5, Girder 1 Bottom Flange Average Bending Stress, Live Load Field Test vs. Finite Element Analysis

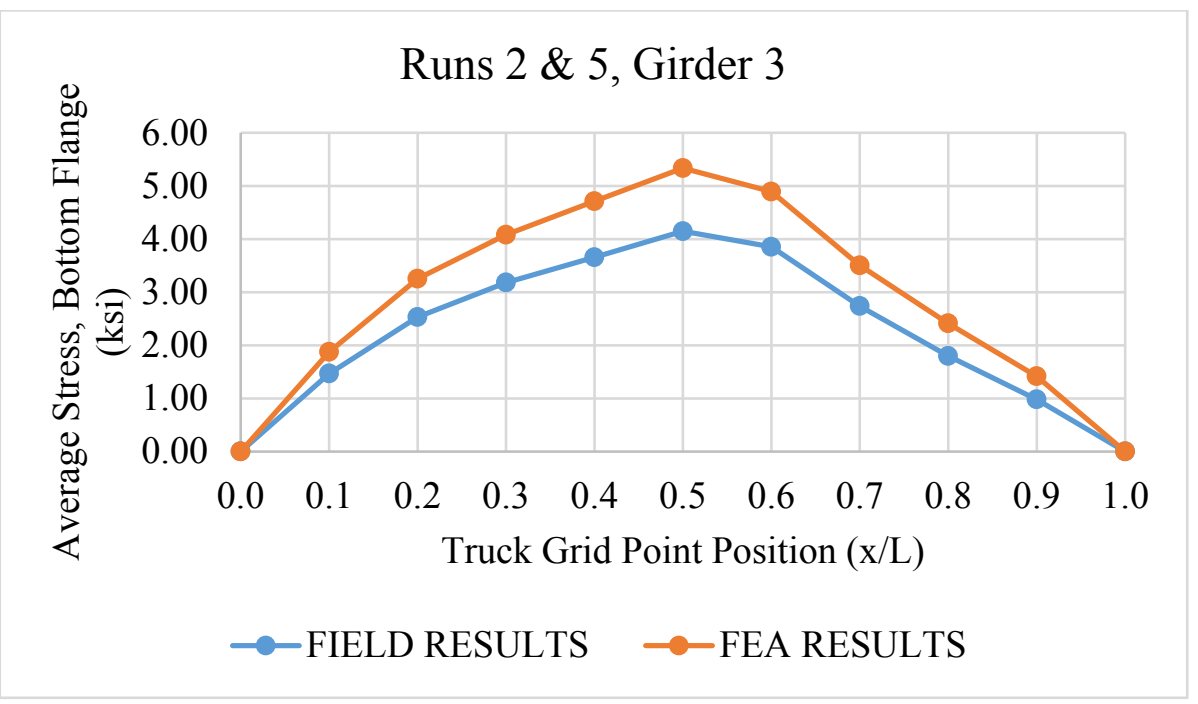

Figure 6.10: Runs 2 and 5, Girder 3 Bottom Flange Average Bending Stress, Live Load Field Test vs. Finite Element Analysis 


\section{$\underline{\text { 6.2.3.2 }} \underline{\text { Live Load Distribution Factors }}$}

The required multiple presence factor for a single loaded lane, 1.2, is applied as necessary in all the following information. The average live load distribution factor calculations from the two cases, finite element model and live load field test, for Run 2 calculated in Sections 6.2.1 and 6.2.2 are presented in Table 6.8 and Figures 6.11 and 6.12.

Table 6.8: Run 2 Average Live Load Distribution Factors, Live Load Field Test vs. Finite Element Analysis

\begin{tabular}{|r|c|c|c|c|c|c|c|c|}
\hline \multicolumn{8}{|c|}{ RUN 2 AVERAGE LIVE LOAD DISTRIBUTION FACTORS (LLDFs) } \\
\hline & \multicolumn{7}{|c|}{ LIVE LOAD FIELD TEST } & \multicolumn{3}{c|}{ FINITE ELEMENT ANALYSIS } \\
\cline { 2 - 9 } & G1 & G2 & G3 & G4 & G1 & G2 & G3 & G4 \\
\hline AVERAGE & 0.404 & 0.344 & 0.101 & 0.152 & 0.395 & 0.344 & 0.171 & 0.090 \\
\hline AVERAGE * MPF (1.2) & 0.484 & 0.412 & 0.121 & 0.182 & 0.474 & 0.413 & 0.205 & 0.107 \\
\hline STAND. DEVIATION & 0.015 & 0.013 & 0.014 & 0.013 & 0.017 & 0.020 & 0.027 & 0.010 \\
\hline
\end{tabular}

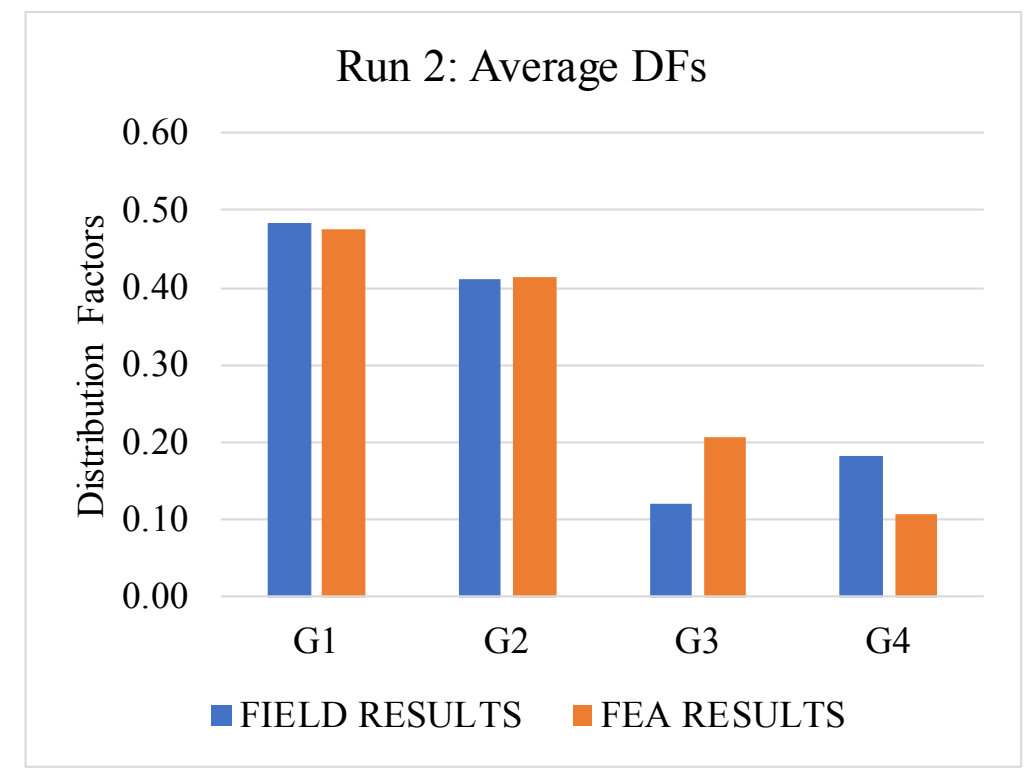

Figure 6.11: Run 2, Average Live Load Distribution Factors with Multiple Presence Factor, Live Load Field Test vs. Finite Element Analysis 
Note that the average LLDFs calculated from each set of data are comparable. Both data sets, live load field test and finite element model, exhibit similar load transfer within the system where Girders 1 and 2 are loaded more, proportionally, than Girders 3 and 4. The Q-Q plot in Figure 6.12 emphasizes these assertions by plotting the experimental results against the analytical results. Again, the variation between the values is most likely due to the modeling of the bracing and boundary conditions.

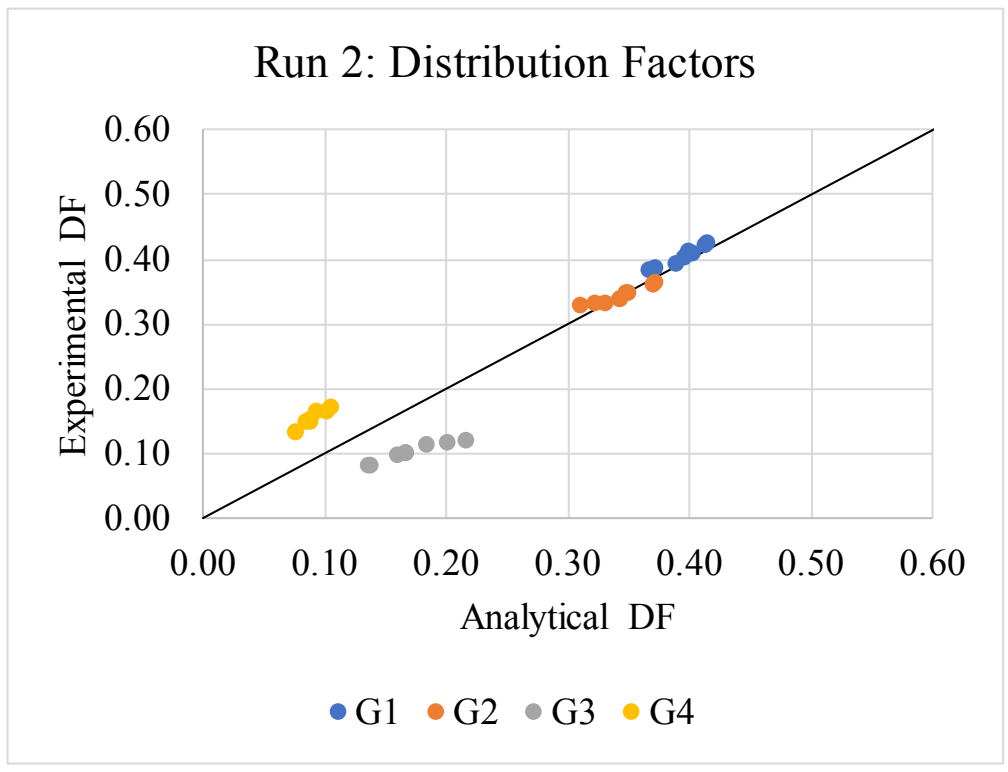

Figure 6.12: Run 2, Average Live Load Distribution Factors with Multiple Presence Factor, Q-Q Plot Live Load Field Test vs. Finite Element Analysis

The similarity in LLDFs holds true for the remainder of the load cases and the simulated load cases, see Figures 6.13 and 6.14. Run 3 results, show that the load is predominately proportioned towards the center of the bridge which is consistent with the loading condition. The two-lane loaded scenario, Runs 2 and 5, is also consistent with the conditions of the combined loading case. Note the moderate variation in the distribution values, suggesting that the model is a fair approximation of field conditions. See Chapter 5 for further details regarding loading conditions. 


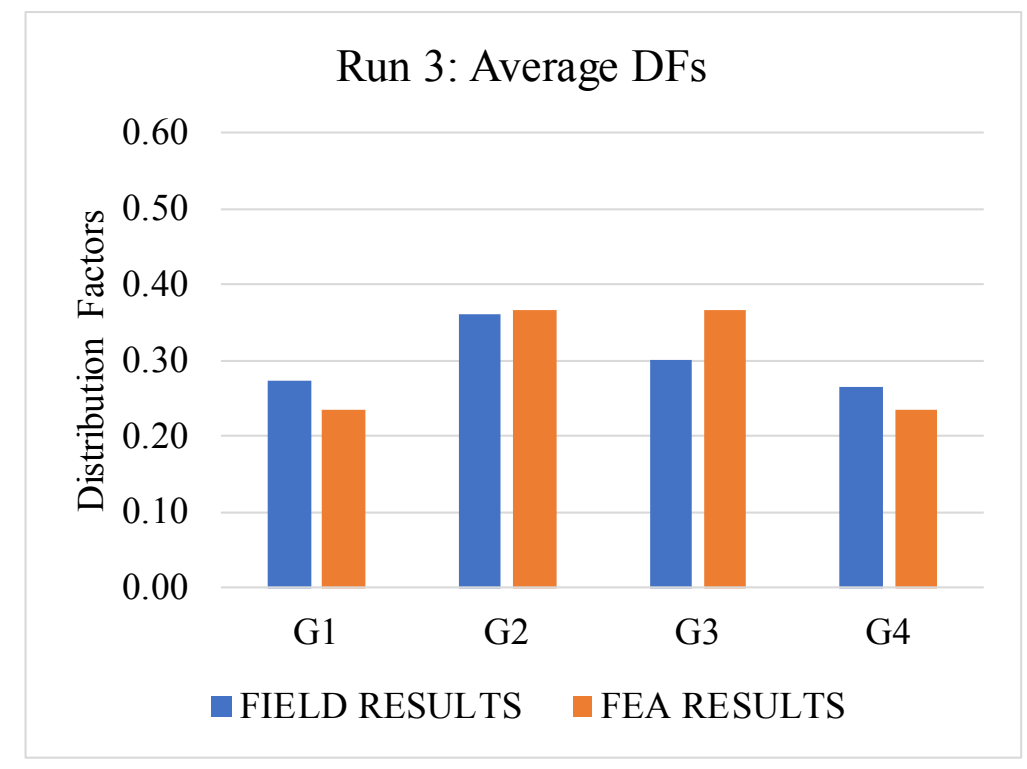

Figure 6.13: Run 3, Average Live Load Distribution Factors with Multiple Presence Factor, Live Load Field Test vs. Finite Element Analysis

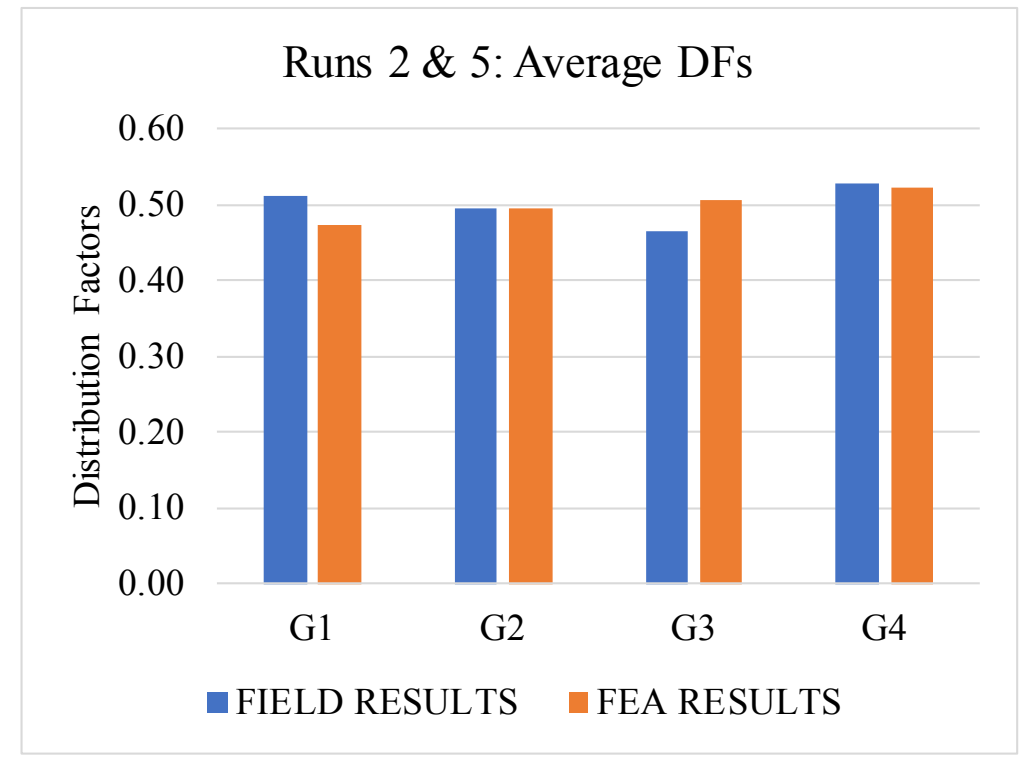

Figure 6.14: Runs 2 and 5, Average Live Load Distribution Factors with Multiple Presence Factor, Live Load Field Test vs. Finite Element Analysis

Finally, a Q-Q plot of all calculated average distribution factors was generated for review, see Figure 6.15. This plot contains both the single-lane and two-lane loaded scenarios and has a 
high fit, proving that the model is a fair approximation of the live load testing conditions and may be used to further understand the structure's behavior.

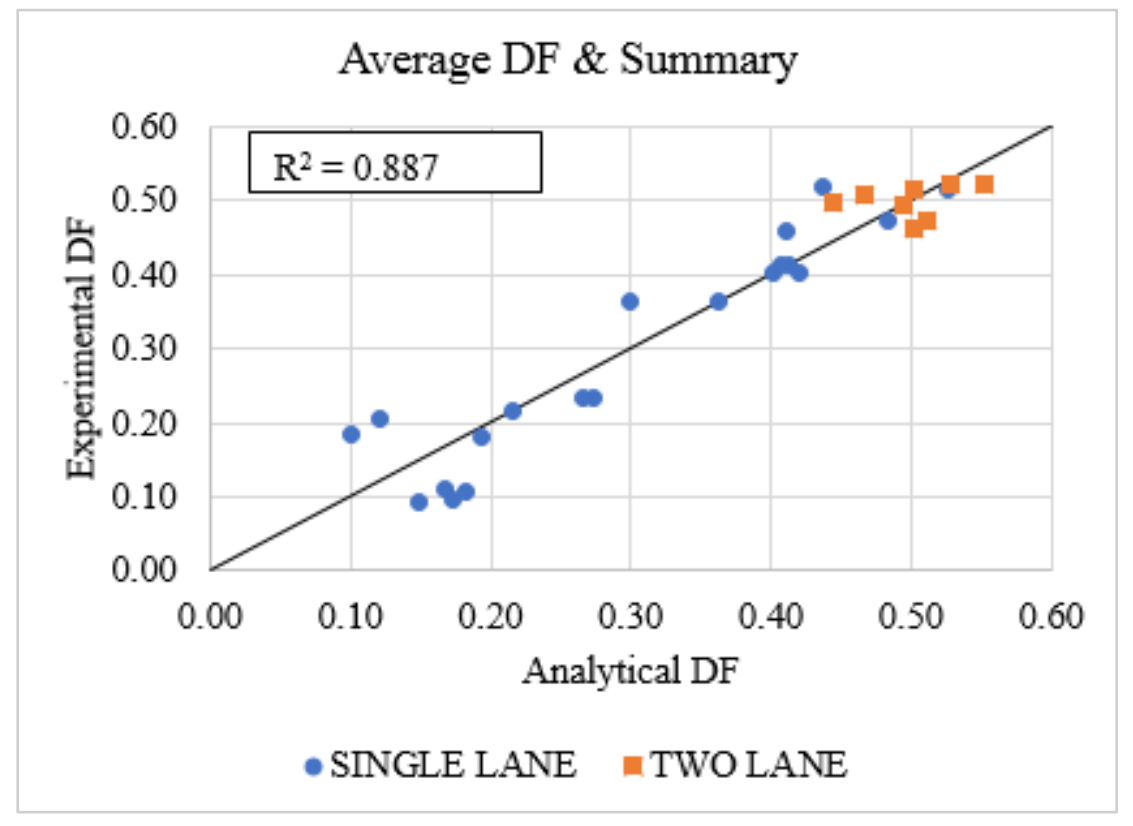

Figure 6.15: All Runs, Average Live Load Distribution Factors with Multiple Presence Factor, Q-Q Plot Live Load Field Test vs. Finite Element Analysis

\subsubsection{Live Load Girder Rating}

The results of the live load girder ratings performed for the two cases, finite element model and live load field test, are presented in Figures 6.16. and 6.17. Note that the ratings are very similar between the two samples. The ratings generated by the finite element analysis are nominally larger than those developed from the field test results. These results are consistent with the conclusions of Section 6.2.3.2. All girders meet the requirements of AASHTO Specifications for inventory and operating rating. 


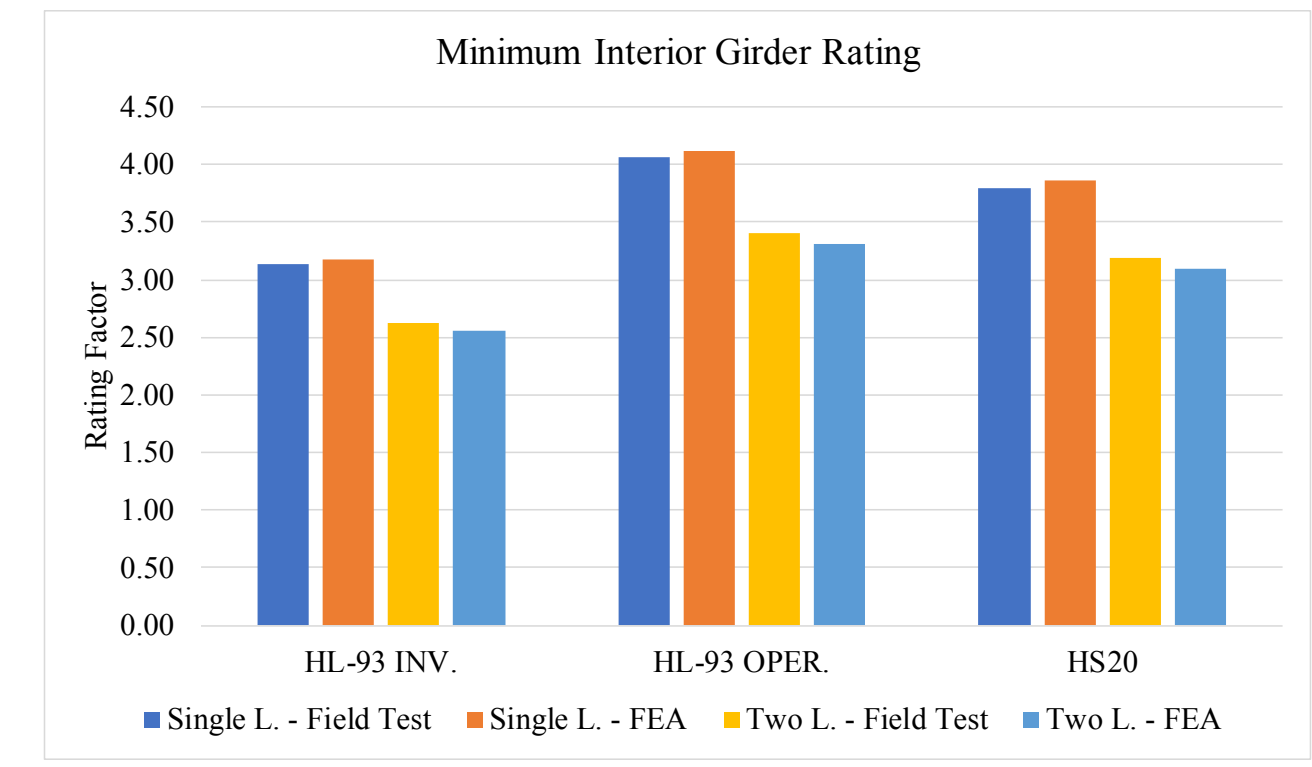

Figure 6.16: Minimum Interior Girder Single and Multi-Lane Loaded Ratings, Live Load Field Test vs. Finite Element Analysis

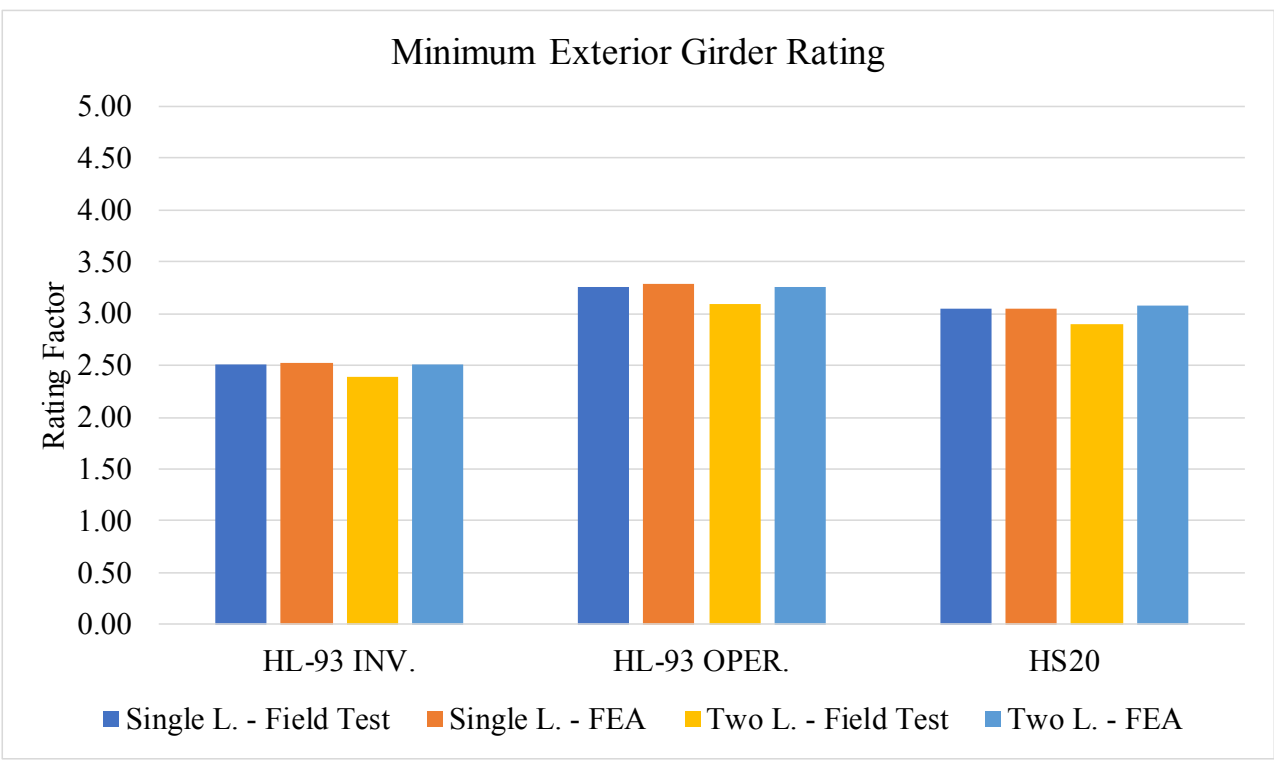

Figure 6.17: Minimum Exterior Girder Single and Multi-Lane Loaded Ratings, Live Load Field Test vs. Finite Element Analysis 


\subsection{COMPARISON OF LiVE LOAd Distribution FACTORS WITH AASHTO SPECIFICATIONS}

This section presents the results of the finite element modeling analysis and the live load field test in comparison with the calculations performed in accordance with AASHTO Specifications (2017). Results for all truck runs yield similar conclusions. See Section 4.4 for AASHTO calculations and Section 5.2.2 for more information regarding the truck run locations. The results presented in this section are those from Run 2. The results from all truck runs are presented in Appendix A, including: results, tables, and graphs.

\subsubsection{Live Load Distribution Factors}

The required multiple presence factor for a single loaded lane, 1.2, is applied as necessary in all the following information. The average live load distribution factor calculations for Run 2 from the finite element model (Section 6.1), live load field test (Section 6.2), and AASHTO LLDF's (Section 4.4) are compared in the following discussion. Note, that the AASHTO LLDFs are much larger than the factors calculated from either the finite element model or live load field test data. Therefore, the use of AASHTO Specifications for the calculation of LLDFs is conservative for the single lane loaded condition. The results are presented in Table 6.9 and Figure 6.18 .

Table 6.9: Run 2, Average Live Load Distribution Factors, Live Load Field Test, Finite Element Analysis, AASHTO Calculations

\begin{tabular}{|r|c|c|c|c|}
\hline \multicolumn{4}{|c|}{ RUN 2 AVERAGE LIVE LOAD DISTRIBUTION FACTORS (LLDFs) } \\
\hline & G1 & G2 & G3 & G4 \\
\hline LIVE LOAD FIELD TEST & 0.484 & 0.412 & 0.121 & 0.182 \\
\hline FINITE ELEMENT ANALYSIS & 0.474 & 0.413 & 0.205 & 0.107 \\
\hline AASHTO LRFD CACLUATIONS & 0.688 & 0.688 & 0.688 & 0.688 \\
\hline
\end{tabular}




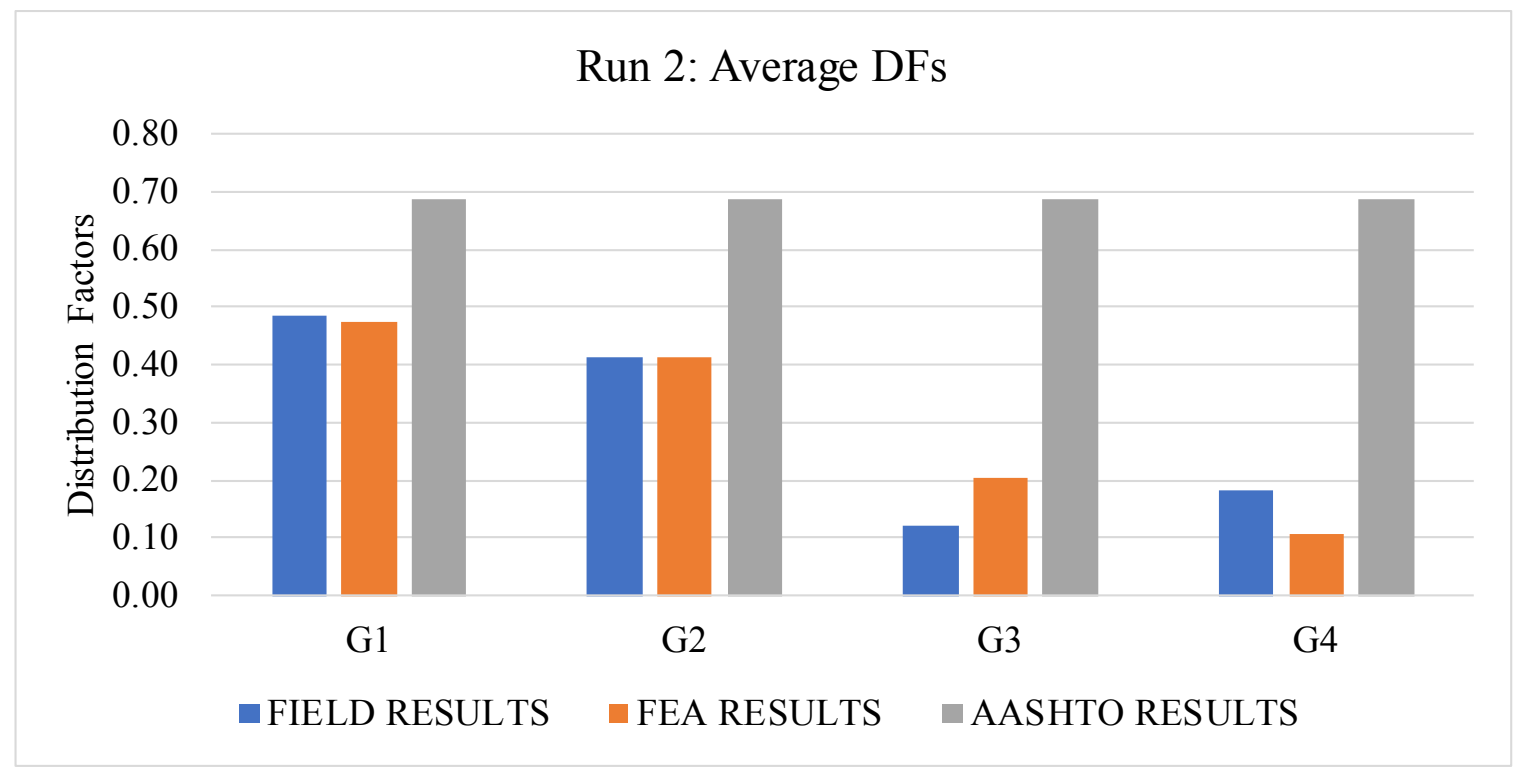

Figure 6.18: Run 2, Average Live Load Distribution Factors, Live Load Field Test, Finite Element Analysis, AASHTO Calculations

The average live load distribution factor calculations for the sum of Runs 2 and 5 from the finite element model (Section 6.1), live load field test (Section 6.2), and AASHTO LLDF's (Section 4.4) are compared in Table 6.10 and Figure 6.19. Again, the AASHTO LLDFs are larger than the factors calculated from either the finite element model or live load field test data. Therefore, the use of AASHTO Specifications for the calculation of LLDFs will be conservative for the two lane loaded condition.

Table 6.10: Runs 2 and 5, Average Live Load Distribution Factors, Live Load Field Test, Finite Element Analysis, AASHTO Calculations

SUM: RUN 2 AND RUN 5 AVERAGE LIVE LOAD DISTRIBUTION FACTORS (LLDFs)

\begin{tabular}{|r|c|c|c|c|}
\hline & G1 & G2 & G3 & G4 \\
\hline LIVE LOAD FIELD TEST & 0.512 & 0.495 & 0.466 & 0.527 \\
\hline FINITE ELEMENT ANALYSIS & 0.475 & 0.496 & 0.507 & 0.523 \\
\hline AASHTO RESULTS & 0.688 & 0.688 & 0.688 & 0.688 \\
\hline
\end{tabular}




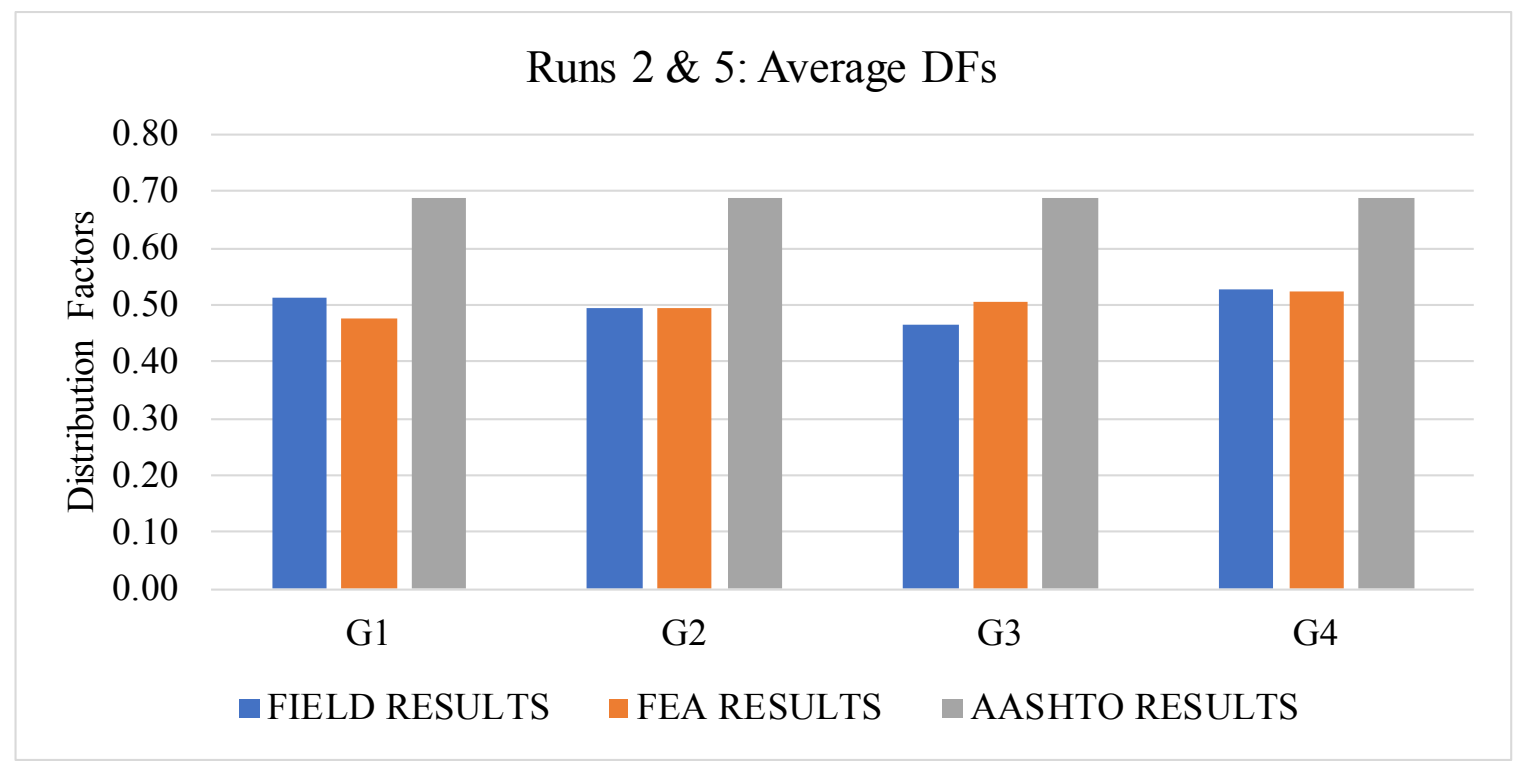

Figure 6.19: Runs 2 and 5, Average Live Load Distribution Factors, Live Load Field Test, Finite Element Analysis, AASHTO Calculations

\subsubsection{Live Load Girder Rating}

The interior and exterior live load girder ratings from the finite element model (Section 6.1), live load field test (Section 6.2), and AASHTO LLDF's (Section 4.4) are compared in the following discussion. Note, that the AASHTO LLDFs are much larger than the factors calculated in Sections 6.2.1 and 6.2.2, and therefore the resultant rating will be lower than the finite element model or live load field test data. The LLDFs computed by AASHTO are constant, therefore the ratings for both interior and exterior girders with either a single lane loaded, or two lanes loaded is the same. The ratings are as follows:

$$
\begin{aligned}
& \text { HL-93 }(\text { Inventory) }=1.92 \\
& \text { HL-93 }(\text { Operating })=2.49 \\
& \text { HS20 }(\text { Permit })=2.33
\end{aligned}
$$


Figures 6.20 and 6.21 present the results for interior and exterior girder ratings respectively. The use of AASHTO Specifications for the calculation of LLDFs is conservative per the conclusions of Section 6.3.1. As LLDFs are used to compute live load girder ratings, it follows that the AASHTO Specifications for the live load rating of girders are also conservative for structures of this type as evidenced by the results.

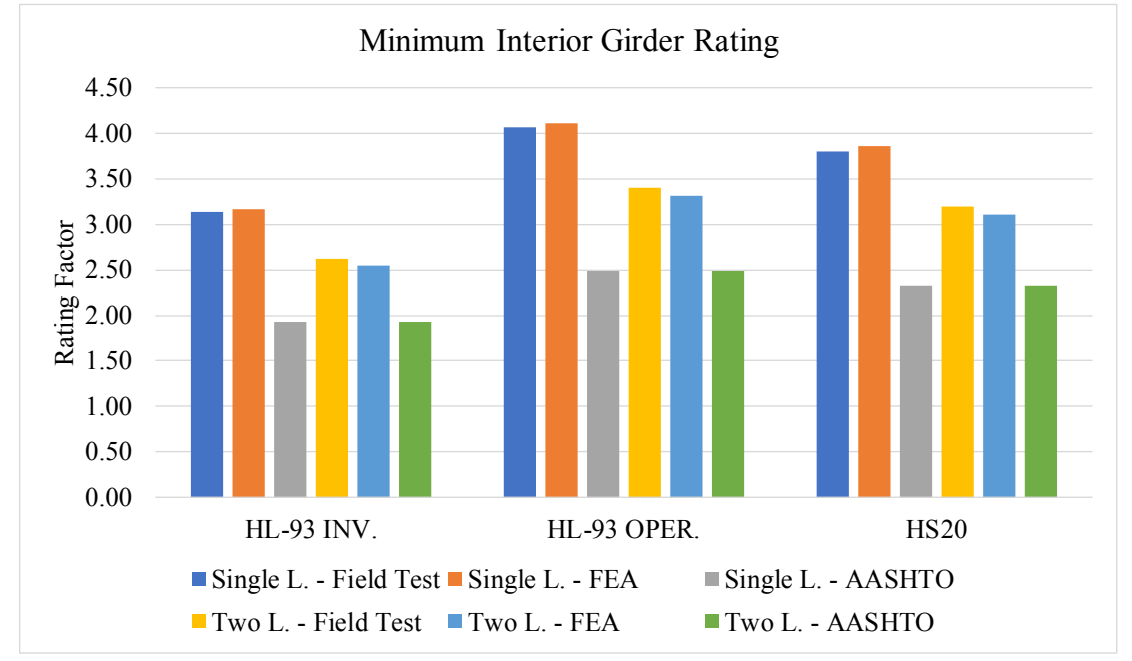

Figure 6.20: Minimum Interior Single and Multi-Lane Girder Rating, Live Load Field Test, Finite Element Analysis, AASHTO Calculations

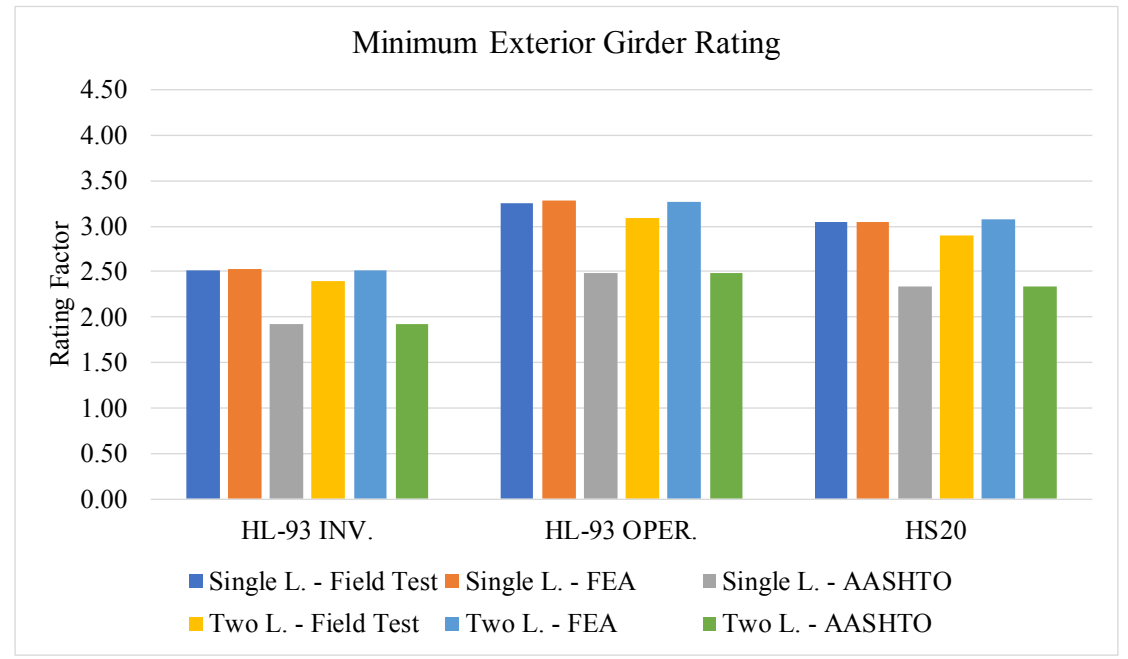

Figure 6.21: Minimum Exterior Single and Multi-Lane Girder Rating, Live Load Field Test, Finite Element Analysis, AASHTO Calculations 
For interior girders, the smallest difference between the single lane live load rating factors calculated from the two data sets, analytical and experimental, is 1.23. AASHTO, therefore, underestimates the performance of the interior girder by $64 \%$. The smallest difference between the multi-lane loading factors calculated from the field test data and analytical model is 0.67 . The difference is over $34 \%$ more than the factor computed using current AASHTO Specifications. In the exterior girder rating, the smallest difference between the single lane live load rating factors calculated from the two sets and AASHTO is 0.60 , with AASHTO computations $31 \%$ less. The difference between the multi-lane loading live load rating factors calculated is 0.53 . The difference is $27 \%$ more than the factor computed using current AASHTO Specifications. 


\subsection{CONCLUSIONS}

The content of this chapter provided an overview of the data collected during the live load field test with the data generated from the finite element analysis. This comparison revealed the bending stresses generated by the model exceeded those calculated from the live load field test data. The variation in bending stress can be attributed to variations in boundary conditions and bracing connections between the field case and finite element model. Despite these discrepancies, the LLDFs computed for either set were nearly equivalent, with similar proportions of the live load being attributed to each girder. These LLDFs were used to generate load ratings for both the interior and exterior girders of the structure. The results of this analysis found that the structure is performing well and is exceeding the AASHTO requirements for operation. Additionally, due to the relationships between LLDFs and girder live load rating, the interior and exterior ratings of the structure using the results of the finite element analysis and field test results were similar.

In addition to a comparative analysis between the live load test and finite element analysis, the results were also considered against AASHTO LRFD (2017) calculations for LLDFs for beam slab girder systems with concrete decks, interior girder rating, and exterior girder rating. These results revealed that the LLDF values calculated using AASHTO standards were larger than those determined for both the single and two lane loaded conditions. This suggests that the specifications are conservative for beam slab bridges with an SPS ${ }^{\circ}$ system. These LLDF values were used to generate load ratings, see Section 4.4 for calculation procedure, and the results revealed that the AASHTO methods are conservative in comparison with both the field and finite element model results for the girder system. 


\section{CHAPTER 7: CONCLUSIONS AND RECOMMENDATIONS}

\subsection{Project Summary ANd Conclusions}

The scope of this thesis was to assess the field performance of a modular press-brakeformed steel tub girder with sandwich plate steel (SPS ${ }^{\circledR}$ ) deck system and to compare the field performance with finite element analysis. The results of these tests evidence that the use of finite element analysis is adequate in mirroring the performance of a modular press-brake-formed steel tub girder system. The bending stress varied between the two conditions, similar to Gibbs' work (2017); however, this can be accounted for given the variation in boundary conditions and bracing specifications within the model. The LLDFs calculated from the live load field test data and finite element model analysis were nearly equivalent. Therefore, the interior and exterior girder ratings for either case were similar.

In addition to analyzing the efficacy of finite element analysis in modeling the modular system, the study also sought to provide an analysis of the applicability of AASHTO Standard Specifications (2017) to structures of this type. The analysis revealed that current methods result in conservative LLDFs in comparison with those generated from both live load field assessments and finite element analysis. This is consistent with Gibbs' (2017) work conducted on the Amish Sawmill Bridge, a press-brake-formed steel tub girder with composite concrete deck. The study also compared interior and exterior girder ratings computed from the testing data with those generated in accordance with AASHTO LRFD Standards. LLDFs calculated from the live load field test data and the finite element analysis were comparable. Both exceeded the LLDFs calculated from the AASHTO LRFD Specifications for systems of a similar type. The live load interior and exterior girder ratings met AASHTO requirements for serviceability and strength. Ratings computed using the MBE and AASTHO LRFD Standards were significantly less than the performance determined from both the live load field test data and finite element analysis. The conclusions of this study are current AASHTO regulation conservatively measures the capacity of systems of this type. 


\subsection{RECOMMENDATIONS FOR CONTINUED WORK}

The following are recommended for future work in this area:

- Present results and conclusions of this and similar work at technical meetings and conferences to increase awareness of the applicability and efficacy of this short span steel solution.

- Develop a competitive cost study for this short span steel solution in comparison with other short span bridge options of similar and dissimilar material types, including the following: engineering cost, material cost, and construction costs.

- Develop education programs for contractors seeking to enter the industry by providing information regarding the advantages and challenges of press-brakeformed steel tub girder bridge construction.

- Further research into the cost effectiveness and structural durability of sandwich plate steel $($ SPS $®)$ deck systems, specifically longevity and economy in comparison with more traditional deck systems. 


\section{REFERENCES}

(2014). AASHTO LRFD Bridge Design Specifications. Washington, DC: American Association of State Highway and Transportation Officials.

(2017). AASHTO LRFD bridge design specifications. Washington, DC: American Association of State Highway and Transportation Officials.

Barth, K. E., Barth, A. S., Michaelson, G. K., Gibbs, C. L., \& Tennant, R. M. (2017). Evaluation of SMDI short span steel bridge design standards.

Bentley Software, Inc. (n.d.). LARS ${ }^{T M}$ Bridge User Manual. Exton, PA.

Bertoldi, A. G. (2009). A strength and serviceability assessement of high performance steel bridge 10462 (Master's thesis). Available from ProQuest.

Bridge Diagnostics, Inc. (n.d.). STS-WiFI Operations Manual. Boulder, CO.

Bridge Engineering Software \& Technology (BEST) Center. (2000). Report on the Determination of Redundancy of the U.S. Bridge Corporation Bridge 3000. University of Maryland, Civil Engineering.

Burgueño, R., \& Pavlich, B. S. (2008). Evaluation of prefabricated composite steel box girder systems for rapid bridge construction. (Report No. RC-1507).

Burner, K. A. (2010). Experimental investigation of folded plate girders and slap joints used in modular construction (Master's Thesis). Available from University of Nebraska-Lincoln Database.

Chandar, G., Hyzak, M. D., \& Wolf, L. M. (2010). Rapid, economical bridge replacement. Available from Modern Steel Construction.

Connor, R. J., Dexter, R., \& Mahmoud, H. (2005). NCHRP Synthesis 354: Inspection and Management of Bridges with Fracture-Critical Details. National Cooperative Highway Research Program. 
Culmo, M. P. (2011). Accelerated bridge construction: Experience in design, fabrication and erection of prefabricated bridge elements and systems (Report No. FHWA-HIF-12-013). U. S. Department of Transportation, Federal Highway Administration.

Dassault Systèmes (n.d.) Abaqus/CAE User's Guide. Providence, RI.

Galambos, T., Leon, T., \& French, C. (1992). Inelastic Rating Procedures for Steel beam and Girder Bridges. Washington, D.C.: TRB

Gibbs, C. L. (2017). Field performance assessment of press-brake-formed steel tub girder superstructures (Master's thesis). Available from ProQuest.

Glaser, L. A. (2010). Constructability testing of folded plate girders (Master's Thesis). Available from University of Nebraska-Lincoln Database.

Graybeal, B.A. and Swenty, M., "UHPFRC for Prefabricated Bridge Component Connections," Proceedings of Hipermat 2012 3rd International Symposium on UHPC and Nanotechnology for High Performance Construction Materials, Ed., Schmidt, M., Fehling, E., Glotzbach, C., Fröhlich, S., and Piotrowski, S., Kassel University Press, Kassel, Germany, 2012, pp. 663-668.

Helwig, T. A., \& Fan, Z. (2000). Field and computational studies of steel trapezoidal box girder bridges (Report No. 1395-3). Austin, Texas: Texas Department of Transportation.

Intelligent Engineering (n.d.) Sandwich Plate Steel Project Portfolio. Ottowa, Canada.

Kassimali, A. (2015). Structural analysis (5th ed.). Stamford, CT: Cengage Learning.

Kelly, L. T. (2014). Experimental evaluation of non-composite shallow press-brake-formed steel tub girders (Master's thesis). Available from ProQuest.

Kozhokin, P. (2016). Evaluation of modular press-brake-formed tub girders with UHPC joints (Master's thesis). Available from ProQuest.

(2018) Manual for Bridge Evaluation. Washington, DC: American Association of State Highway and Transportation Officials. 
Michaelson, G. K. (2010). Live Load Distribution Factors for Exterior Girders in Steel I-Girder Bridges (Master's thesis). Available from ProQuest.

Michaelson, G. K. (2014). Development and feasibility assessment of shallow press-brake-formed steel tub girders for short-span bridge applications (Doctoral dissertation). Available from ProQuest.

Nakamura, S. (2002). Bending behavior of composite girders with cold formed steel U section. ASCE Journal of Structural Engineering, 128(9), 1169-1176. Doi: 10.1061-(ASCE)07339455(2002)128:9(1169).

National Steel Bridge Alliance. (2010). Redundancy. In NSBA, Steel Bridge Design Handbook.

Phares, B., Deng, Y., \& Steffens, O. (2017). Evaluation of a folded plate girder bridge system. (Report No. InTrans Project 13-458).

Taly, N. B., \& GangaRao, H. V. S. (1976). Development and design of standardized short span bridge superstructural. (Report No. FHWA-WV-76-5).

Tennant, R. M. (2018). Fatigue Performance of Uncoated and Galvanized Composite PressBrake-Formed Tub Girders (Master's thesis). Available from ProQuest.

Tricon Engineering Group, Ltd. (2008). Standard design and details of press-brake-formed steel tub girder. Tricon Engineering Group: Michigan.

U. S. Department of Transportation, Federal Highway Administration. (2014). Accelerated Innovation Deployment Demonstration Program. 


\section{APPENDiX A: RESUltS FOR AlL TRUCK RUNS}

This appendix includes the following: results, tables, and graphs, generated from both the live load field test and finite element analysis of the Cannelville Road Bridge. The data presented is for all gages, for all load runs.

The following is the order that the data is presented:

- Average Midspan Bending Stress Tables

$\bigcirc \quad$ Live Load Test Data

○ Finite Element Analysis

○ Results Comparison: Live Load Test Data vs. Finite Element Analysis

- Live Load Distribution Factors (LLDFs)

○ Live Load Test Data

○ Finite Element Analysis

○ Results Comparison: Live Load Test Data vs. Finite Element Analysis

○ Results Comparison: Live Load, FEA, \& AASHTO LRFD 


\section{A.1 Average Midspan Bending Stress}

\section{A.1.1 Live Load Field Test Results}

\begin{tabular}{|c|c|c|c|c|c|}
\hline \multicolumn{6}{|c|}{ RUN 1, FIELD RESULTS } \\
\hline \multicolumn{2}{|c|}{ GRID POINT } & \multicolumn{4}{|c|}{ AVERAGE STRESS (KSI) } \\
\hline $\mathrm{x}(\mathrm{ft})$ & $\mathrm{x} / \mathrm{L}$ & G1 & $\mathrm{G} 2$ & G3 & G4 \\
\hline 0.00 & 0.0 & 0.00 & 0.00 & 0.00 & 0.00 \\
\hline 5.25 & 0.1 & 1.23 & 0.95 & 0.29 & 0.44 \\
\hline 10.50 & 0.2 & 2.15 & 1.65 & 0.44 & 0.72 \\
\hline 15.75 & 0.3 & 2.69 & 2.07 & 0.57 & 0.94 \\
\hline 21.00 & 0.4 & 3.10 & 2.39 & 0.61 & 1.03 \\
\hline 26.25 & 0.5 & 3.71 & 2.83 & 0.57 & 1.03 \\
\hline 31.50 & 0.6 & 3.34 & 2.56 & 0.51 & 0.92 \\
\hline 36.75 & 0.7 & 2.16 & 1.64 & 0.39 & 0.69 \\
\hline 42.00 & 0.8 & 1.38 & 1.03 & 0.28 & 0.48 \\
\hline 47.25 & 0.9 & 0.68 & 0.51 & 0.13 & 0.24 \\
\hline 52.50 & 1.0 & 0.00 & 0.00 & 0.00 & 0.00 \\
\hline
\end{tabular}

\begin{tabular}{|c|c|c|c|c|c|}
\hline \multicolumn{6}{|c|}{ RUN 2, FIELD RESULTS } \\
\hline \multicolumn{2}{|c|}{ GRID POINT } & \multicolumn{4}{c|}{ AVERAGE STRESS (KSI) } \\
\hline $\mathrm{x}(\mathrm{ft})$ & $\mathrm{x} / \mathrm{L}$ & $\mathrm{G} 1$ & $\mathrm{G} 2$ & $\mathrm{G} 3$ & $\mathrm{G} 4$ \\
\hline 0.00 & 0.0 & 0.00 & 0.00 & 0.00 & 0.00 \\
\hline 5.25 & 0.1 & 1.15 & 0.99 & 0.35 & 0.49 \\
\hline 10.50 & 0.2 & 2.16 & 1.78 & 0.53 & 0.79 \\
\hline 15.75 & 0.3 & 2.63 & 2.19 & 0.65 & 0.98 \\
\hline 21.00 & 0.4 & 3.00 & 2.57 & 0.71 & 1.10 \\
\hline 26.25 & 0.5 & 3.60 & 3.07 & 0.69 & 1.13 \\
\hline 31.50 & 0.6 & 3.25 & 2.81 & 0.64 & 1.03 \\
\hline 36.75 & 0.7 & 2.16 & 1.88 & 0.54 & 0.81 \\
\hline 42.00 & 0.8 & 1.40 & 1.19 & 0.40 & 0.59 \\
\hline 47.25 & 0.9 & 0.76 & 0.65 & 0.24 & 0.34 \\
\hline 52.50 & 1.0 & 0.00 & 0.00 & 0.00 & 0.00 \\
\hline
\end{tabular}




\begin{tabular}{|c|c|c|c|c|c|}
\hline \multicolumn{7}{|c|}{ RUN 3, FIELD RESULTS } \\
\hline \multicolumn{2}{|c|}{ GRID POINT } & \multicolumn{4}{|c|}{ AVERAGE STRESS (KSI) } \\
\hline $\mathrm{x}(\mathrm{ft})$ & $\mathrm{x} / \mathrm{L}$ & $\mathrm{G} 1$ & $\mathrm{G} 2$ & $\mathrm{G} 3$ & $\mathrm{G} 4$ \\
\hline 0.00 & 0.0 & 0.00 & 0.00 & 0.00 & 0.00 \\
\hline 5.25 & 0.1 & 0.75 & 0.88 & 0.71 & 0.70 \\
\hline 10.50 & 0.2 & 1.25 & 1.65 & 1.43 & 1.16 \\
\hline 15.75 & 0.3 & 1.61 & 2.02 & 1.72 & 1.52 \\
\hline 21.00 & 0.4 & 1.81 & 2.31 & 1.87 & 1.72 \\
\hline 26.25 & 0.5 & 1.80 & 2.73 & 2.25 & 1.71 \\
\hline 31.50 & 0.6 & 1.60 & 2.46 & 2.12 & 1.55 \\
\hline 36.75 & 0.7 & 1.21 & 1.63 & 1.38 & 1.20 \\
\hline 42.00 & 0.8 & 0.78 & 0.97 & 0.79 & 0.79 \\
\hline 47.25 & 0.9 & 0.35 & 0.47 & 0.36 & 0.38 \\
\hline 52.50 & 1.0 & 0.00 & 0.00 & 0.00 & 0.00 \\
\hline
\end{tabular}

\begin{tabular}{|c|c|c|c|c|c|}
\hline \multicolumn{7}{|c|}{ RUN 4, FIELD RESULTS } \\
\hline \multicolumn{2}{|c|}{ GRID POINT } & \multicolumn{4}{|c|}{ AVERAGE STRESS (KSI) } \\
\hline $\mathrm{x}(\mathrm{ft})$ & $\mathrm{x} / \mathrm{L}$ & $\mathrm{G} 1$ & $\mathrm{G} 2$ & $\mathrm{G} 3$ & $\mathrm{G} 4$ \\
\hline 0.00 & 0.0 & 0.00 & 0.00 & 0.00 & 0.00 \\
\hline 5.25 & 0.1 & 0.49 & 0.62 & 1.06 & 1.06 \\
\hline 10.50 & 0.2 & 0.79 & 0.98 & 1.81 & 1.97 \\
\hline 15.75 & 0.3 & 1.01 & 1.26 & 2.39 & 2.43 \\
\hline 21.00 & 0.4 & 1.17 & 1.46 & 2.83 & 2.81 \\
\hline 26.25 & 0.5 & 1.17 & 1.45 & 3.22 & 3.42 \\
\hline 31.50 & 0.6 & 1.03 & 1.30 & 2.98 & 3.15 \\
\hline 36.75 & 0.7 & 0.81 & 1.06 & 2.11 & 2.05 \\
\hline 42.00 & 0.8 & 0.56 & 0.75 & 1.31 & 1.27 \\
\hline 47.25 & 0.9 & 0.31 & 0.45 & 0.70 & 0.65 \\
\hline 52.50 & 1.0 & 0.00 & 0.00 & 0.00 & 0.00 \\
\hline
\end{tabular}




\begin{tabular}{|c|c|c|c|c|c|}
\hline \multicolumn{7}{|c|}{ RUN 5, FIELD RESULTS } \\
\hline \multicolumn{2}{|c|}{ GRID POINT } & \multicolumn{4}{|c|}{ AVERAGE STRESS (KSI) } \\
\hline $\mathrm{x}(\mathrm{ft})$ & $\mathrm{x} / \mathrm{L}$ & $\mathrm{G} 1$ & $\mathrm{G} 2$ & $\mathrm{G} 3$ & $\mathrm{G} 4$ \\
\hline 0.00 & 0.0 & 0.00 & 0.00 & 0.00 & 0.00 \\
\hline 5.25 & 0.1 & 0.48 & 0.59 & 1.12 & 1.20 \\
\hline 10.50 & 0.2 & 0.76 & 0.92 & 2.01 & 2.15 \\
\hline 15.75 & 0.3 & 0.97 & 1.19 & 2.53 & 2.63 \\
\hline 21.00 & 0.4 & 1.07 & 1.34 & 2.95 & 3.03 \\
\hline 26.25 & 0.5 & 1.07 & 1.32 & 3.46 & 3.64 \\
\hline 31.50 & 0.6 & 0.97 & 1.21 & 3.22 & 3.40 \\
\hline 36.75 & 0.7 & 0.75 & 0.98 & 2.20 & 2.22 \\
\hline 42.00 & 0.8 & 0.52 & 0.72 & 1.40 & 1.41 \\
\hline 47.25 & 0.9 & 0.24 & 0.39 & 0.74 & 0.73 \\
\hline 52.50 & 1.0 & 0.00 & 0.00 & 0.00 & 0.00 \\
\hline
\end{tabular}

\begin{tabular}{|c|c|c|c|c|c|}
\hline \multicolumn{5}{|c|}{ SUM: RUN 1 AND RUN 4, FIELD RESULTS } \\
\hline \multicolumn{2}{|c|}{ GRID POINT } & \multicolumn{4}{|c|}{ AVERAGE STRESS (KSI) } \\
\hline $\mathrm{x}(\mathrm{ft})$ & $\mathrm{x} / \mathrm{L}$ & $\mathrm{G} 1$ & $\mathrm{G} 2$ & $\mathrm{G} 3$ & $\mathrm{G} 4$ \\
\hline 0.00 & 0.0 & 0.00 & 0.00 & 0.00 & 0.00 \\
\hline 5.25 & 0.1 & 1.71 & 1.58 & 1.35 & 1.51 \\
\hline 10.50 & 0.2 & 2.94 & 2.63 & 2.25 & 2.69 \\
\hline 15.75 & 0.3 & 3.70 & 3.33 & 2.96 & 3.37 \\
\hline 21.00 & 0.4 & 4.26 & 3.84 & 3.44 & 3.84 \\
\hline 26.25 & 0.5 & 4.87 & 4.28 & 3.79 & 4.44 \\
\hline 31.50 & 0.6 & 4.37 & 3.86 & 3.49 & 4.07 \\
\hline 36.75 & 0.7 & 2.97 & 2.70 & 2.50 & 2.74 \\
\hline 42.00 & 0.8 & 1.94 & 1.78 & 1.60 & 1.75 \\
\hline 47.25 & 0.9 & 0.99 & 0.96 & 0.83 & 0.89 \\
\hline 52.50 & 1.0 & 0.00 & 0.00 & 0.00 & 0.00 \\
\hline
\end{tabular}




\begin{tabular}{|c|c|c|c|c|c|}
\hline \multicolumn{5}{|c|}{ SUM: RUN 2 AND RUN 5, FIELD RESULTS } \\
\hline \multicolumn{2}{|c|}{ GRID POINT } & \multicolumn{4}{|c|}{ AVERAGE STRESS (KSI) } \\
\hline $\mathrm{x}(\mathrm{ft})$ & $\mathrm{x} / \mathrm{L}$ & $\mathrm{G} 1$ & $\mathrm{G} 2$ & $\mathrm{G} 3$ & $\mathrm{G} 4$ \\
\hline 0.00 & 0.0 & 0.00 & 0.00 & 0.00 & 0.00 \\
\hline 5.25 & 0.1 & 1.63 & 1.59 & 1.47 & 1.69 \\
\hline 10.50 & 0.2 & 2.92 & 2.70 & 2.53 & 2.94 \\
\hline 15.75 & 0.3 & 3.60 & 3.38 & 3.18 & 3.61 \\
\hline 21.00 & 0.4 & 4.07 & 3.90 & 3.66 & 4.13 \\
\hline 26.25 & 0.5 & 4.67 & 4.38 & 4.15 & 4.76 \\
\hline 31.50 & 0.6 & 4.22 & 4.02 & 3.85 & 4.42 \\
\hline 36.75 & 0.7 & 2.91 & 2.86 & 2.74 & 3.04 \\
\hline 42.00 & 0.8 & 1.92 & 1.90 & 1.80 & 1.99 \\
\hline 47.25 & 0.9 & 1.00 & 1.05 & 0.98 & 1.07 \\
\hline 52.50 & 1.0 & 0.00 & 0.00 & 0.00 & 0.00 \\
\hline
\end{tabular}




\section{A.1.2 Finite Element Analysis Results}

\begin{tabular}{|c|c|c|c|c|c|}
\hline \multicolumn{7}{|c|}{ RUN 1, FEA RESULTS } \\
\hline \multicolumn{2}{|c|}{ GRID POINT } & \multicolumn{4}{|c|}{ AVERAGE STRESS (KSI) } \\
\hline $\mathrm{x}(\mathrm{ft})$ & $\mathrm{x} / \mathrm{L}$ & $\mathrm{G} 1$ & $\mathrm{G} 2$ & $\mathrm{G} 3$ & $\mathrm{G} 4$ \\
\hline 0.00 & 0.0 & 0.00 & 0.00 & 0.00 & 0.00 \\
\hline 5.25 & 0.1 & 1.66 & 1.20 & 0.65 & 0.32 \\
\hline 10.50 & 0.2 & 2.86 & 2.28 & 0.98 & 0.51 \\
\hline 15.75 & 0.3 & 3.53 & 2.82 & 1.26 & 0.66 \\
\hline 21.00 & 0.4 & 4.04 & 3.27 & 1.40 & 0.74 \\
\hline 26.25 & 0.5 & 4.64 & 3.92 & 1.37 & 0.75 \\
\hline 31.50 & 0.6 & 4.26 & 3.59 & 1.26 & 0.69 \\
\hline 36.75 & 0.7 & 3.02 & 2.37 & 1.07 & 0.56 \\
\hline 42.00 & 0.8 & 2.06 & 1.56 & 0.81 & 0.42 \\
\hline 47.25 & 0.9 & 1.22 & 0.84 & 0.53 & 0.26 \\
\hline 52.50 & 1.0 & 0.00 & 0.00 & 0.00 & 0.00 \\
\hline
\end{tabular}

\begin{tabular}{|c|c|c|c|c|c|}
\hline \multicolumn{7}{|c|}{ RUN 2, FEA RESULTS } \\
\hline \multicolumn{2}{|c|}{ GRID POINT } & \multicolumn{4}{|c|}{ AVERAGE STRESS (KSI) } \\
\hline $\mathrm{x}(\mathrm{ft})$ & $\mathrm{x} / \mathrm{L}$ & $\mathrm{G} 1$ & $\mathrm{G} 2$ & $\mathrm{G} 3$ & $\mathrm{G} 4$ \\
\hline 0.00 & 0.0 & 0.00 & 0.00 & 0.00 & 0.00 \\
\hline 5.25 & 0.1 & 1.42 & 1.24 & 0.77 & 0.39 \\
\hline 10.50 & 0.2 & 2.66 & 2.28 & 1.11 & 0.59 \\
\hline 15.75 & 0.3 & 3.31 & 2.83 & 1.38 & 0.73 \\
\hline 21.00 & 0.4 & 3.82 & 3.32 & 1.51 & 0.81 \\
\hline 26.25 & 0.5 & 4.44 & 3.97 & 1.46 & 0.82 \\
\hline 31.50 & 0.6 & 4.05 & 3.64 & 1.35 & 0.75 \\
\hline 36.75 & 0.7 & 2.78 & 2.44 & 1.18 & 0.62 \\
\hline 42.00 & 0.8 & 1.89 & 1.61 & 0.89 & 0.46 \\
\hline 47.25 & 0.9 & 1.05 & 0.89 & 0.62 & 0.30 \\
\hline 52.50 & 1.0 & 0.00 & 0.00 & 0.00 & 0.00 \\
\hline
\end{tabular}




\begin{tabular}{|c|c|c|c|c|c|}
\hline \multicolumn{7}{|c|}{ RUN 3, FEA RESULTS } \\
\hline \multicolumn{2}{|c|}{ GRID POINT } & \multicolumn{4}{|c|}{ AVERAGE STRESS (KSI) } \\
\hline $\mathrm{x}(\mathrm{ft})$ & $\mathrm{x} / \mathrm{L}$ & $\mathrm{G} 1$ & $\mathrm{G} 2$ & $\mathrm{G} 3$ & $\mathrm{G} 4$ \\
\hline 0.00 & 0.0 & 0.00 & 0.00 & 0.00 & 0.00 \\
\hline 5.25 & 0.1 & 0.84 & 1.08 & 1.08 & 0.84 \\
\hline 10.50 & 0.2 & 1.28 & 2.04 & 2.04 & 1.28 \\
\hline 15.75 & 0.3 & 1.62 & 2.52 & 2.52 & 1.62 \\
\hline 21.00 & 0.4 & 1.78 & 2.96 & 2.96 & 1.79 \\
\hline 26.25 & 0.5 & 1.74 & 3.62 & 3.62 & 1.74 \\
\hline 31.50 & 0.6 & 1.59 & 3.32 & 3.32 & 1.59 \\
\hline 36.75 & 0.7 & 1.36 & 2.17 & 2.17 & 1.36 \\
\hline 42.00 & 0.8 & 1.02 & 1.41 & 1.41 & 1.02 \\
\hline 47.25 & 0.9 & 0.68 & 0.75 & 0.75 & 0.68 \\
\hline 52.50 & 1.0 & 0.00 & 0.00 & 0.00 & 0.00 \\
\hline
\end{tabular}

\begin{tabular}{|c|c|c|c|c|c|}
\hline \multicolumn{7}{|c|}{ RUN 4, FEA RESULTS } \\
\hline \multicolumn{2}{|c|}{ GRID POINT } & \multicolumn{4}{|c|}{ AVERAGE STRESS (KSI) } \\
\hline $\mathrm{x}(\mathrm{ft})$ & $\mathrm{x} / \mathrm{L}$ & $\mathrm{G} 1$ & $\mathrm{G} 2$ & $\mathrm{G} 3$ & $\mathrm{G} 4$ \\
\hline 0.00 & 0.0 & 0.00 & 0.00 & 0.00 & 0.00 \\
\hline 5.25 & 0.1 & 0.42 & 0.82 & 1.25 & 1.33 \\
\hline 10.50 & 0.2 & 0.62 & 1.17 & 2.26 & 2.57 \\
\hline 15.75 & 0.3 & 0.77 & 1.44 & 2.83 & 3.23 \\
\hline 21.00 & 0.4 & 0.85 & 1.57 & 3.32 & 3.73 \\
\hline 26.25 & 0.5 & 0.85 & 1.52 & 3.97 & 4.35 \\
\hline 31.50 & 0.6 & 0.77 & 1.40 & 3.65 & 3.96 \\
\hline 36.75 & 0.7 & 0.64 & 1.22 & 2.47 & 2.69 \\
\hline 42.00 & 0.8 & 0.47 & 0.93 & 1.63 & 1.82 \\
\hline 47.25 & 0.9 & 0.32 & 0.65 & 0.91 & 0.99 \\
\hline 52.50 & 1.0 & 0.00 & 0.00 & 0.00 & 0.00 \\
\hline
\end{tabular}




\begin{tabular}{|c|c|c|c|c|c|}
\hline \multicolumn{7}{|c|}{ RUN 5, FEA RESULTS } \\
\hline \multicolumn{2}{|c|}{ GRID POINT } & \multicolumn{4}{|c|}{ AVERAGE STRESS (KSI) } \\
\hline $\mathrm{x}(\mathrm{ft})$ & $\mathrm{x} / \mathrm{L}$ & $\mathrm{G} 1$ & $\mathrm{G} 2$ & $\mathrm{G} 3$ & $\mathrm{G} 4$ \\
\hline 0.00 & 0.0 & 0.00 & 0.00 & 0.00 & 0.00 \\
\hline 5.25 & 0.1 & 0.31 & 0.64 & 1.19 & 1.68 \\
\hline 10.50 & 0.2 & 0.51 & 0.97 & 2.27 & 2.88 \\
\hline 15.75 & 0.3 & 0.65 & 1.25 & 2.81 & 3.55 \\
\hline 21.00 & 0.4 & 0.74 & 1.39 & 3.27 & 4.06 \\
\hline 26.25 & 0.5 & 0.75 & 1.37 & 3.91 & 4.66 \\
\hline 31.50 & 0.6 & 0.68 & 1.25 & 3.58 & 4.28 \\
\hline 36.75 & 0.7 & 0.56 & 1.06 & 2.36 & 3.03 \\
\hline 42.00 & 0.8 & 0.41 & 0.80 & 1.56 & 2.08 \\
\hline 47.25 & 0.9 & 0.26 & 0.53 & 0.84 & 1.24 \\
\hline 52.50 & 1.0 & 0.00 & 0.00 & 0.00 & 0.00 \\
\hline
\end{tabular}

\begin{tabular}{|c|c|c|c|c|c|}
\hline \multicolumn{5}{|c|}{ SUM: RUN 1 AND RUN 4, FEA RESULTS } \\
\hline \multicolumn{2}{|c|}{ GRID POINT } & \multicolumn{4}{|c|}{ AVERAGE STRESS (KSI) } \\
\hline $\mathrm{x}(\mathrm{ft})$ & $\mathrm{x} / \mathrm{L}$ & $\mathrm{G} 1$ & $\mathrm{G} 2$ & $\mathrm{G} 3$ & $\mathrm{G} 4$ \\
\hline 0.00 & 0.0 & 0.00 & 0.00 & 0.00 & 0.00 \\
\hline 5.25 & 0.1 & 2.08 & 2.02 & 1.90 & 1.65 \\
\hline 10.50 & 0.2 & 3.48 & 3.45 & 3.25 & 3.08 \\
\hline 15.75 & 0.3 & 4.29 & 4.26 & 4.08 & 3.89 \\
\hline 21.00 & 0.4 & 4.89 & 4.84 & 4.72 & 4.47 \\
\hline 26.25 & 0.5 & 5.49 & 5.44 & 5.34 & 5.10 \\
\hline 31.50 & 0.6 & 5.04 & 4.99 & 4.90 & 4.65 \\
\hline 36.75 & 0.7 & 3.66 & 3.59 & 3.54 & 3.25 \\
\hline 42.00 & 0.8 & 2.53 & 2.49 & 2.44 & 2.24 \\
\hline 47.25 & 0.9 & 1.54 & 1.49 & 1.45 & 1.25 \\
\hline 52.50 & 1.0 & 0.00 & 0.00 & 0.00 & 0.00 \\
\hline
\end{tabular}




\begin{tabular}{|c|c|c|c|c|c|}
\hline \multicolumn{5}{|c|}{ SUM: RUN 2 AND RUN 5, FEA RESULTS } \\
\hline \multicolumn{2}{|c|}{ GRID POINT } & \multicolumn{4}{|c|}{ AVERAGE STRESS (KSI) } \\
\hline $\mathrm{x}(\mathrm{ft})$ & $\mathrm{x} / \mathrm{L}$ & $\mathrm{G} 1$ & $\mathrm{G} 2$ & $\mathrm{G} 3$ & $\mathrm{G} 4$ \\
\hline 0.00 & 0.0 & 0.00 & 0.00 & 0.00 & 0.00 \\
\hline 5.25 & 0.1 & 1.74 & 1.87 & 1.97 & 2.07 \\
\hline 10.50 & 0.2 & 3.17 & 3.25 & 3.39 & 3.46 \\
\hline 15.75 & 0.3 & 3.97 & 4.08 & 4.19 & 4.28 \\
\hline 21.00 & 0.4 & 4.56 & 4.71 & 4.78 & 4.87 \\
\hline 26.25 & 0.5 & 5.18 & 5.33 & 5.38 & 5.47 \\
\hline 31.50 & 0.6 & 4.74 & 4.89 & 4.93 & 5.03 \\
\hline 36.75 & 0.7 & 3.34 & 3.50 & 3.54 & 3.65 \\
\hline 42.00 & 0.8 & 2.30 & 2.41 & 2.45 & 2.53 \\
\hline 47.25 & 0.9 & 1.31 & 1.42 & 1.46 & 1.54 \\
\hline 52.50 & 1.0 & 0.00 & 0.00 & 0.00 & 0.00 \\
\hline
\end{tabular}



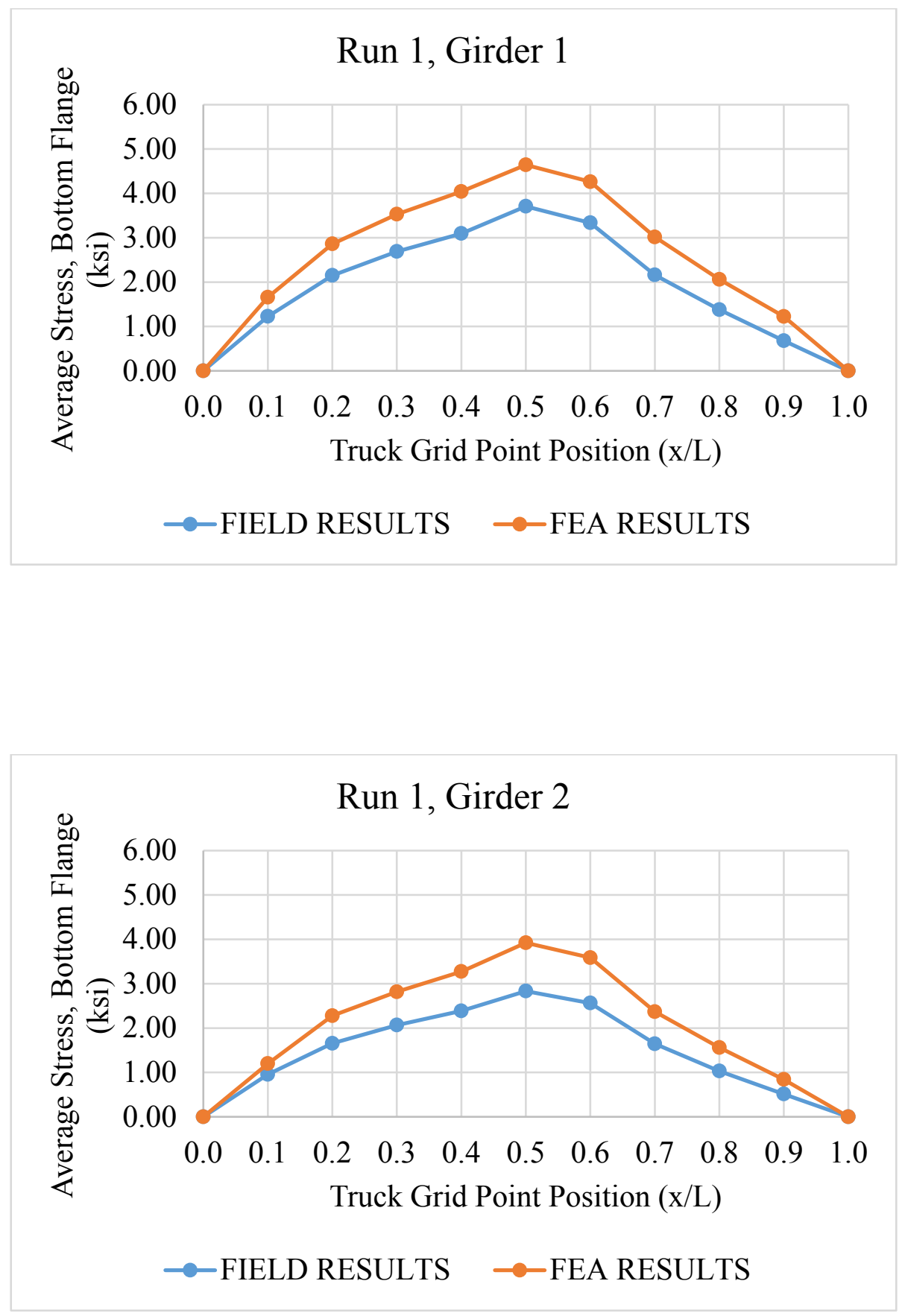

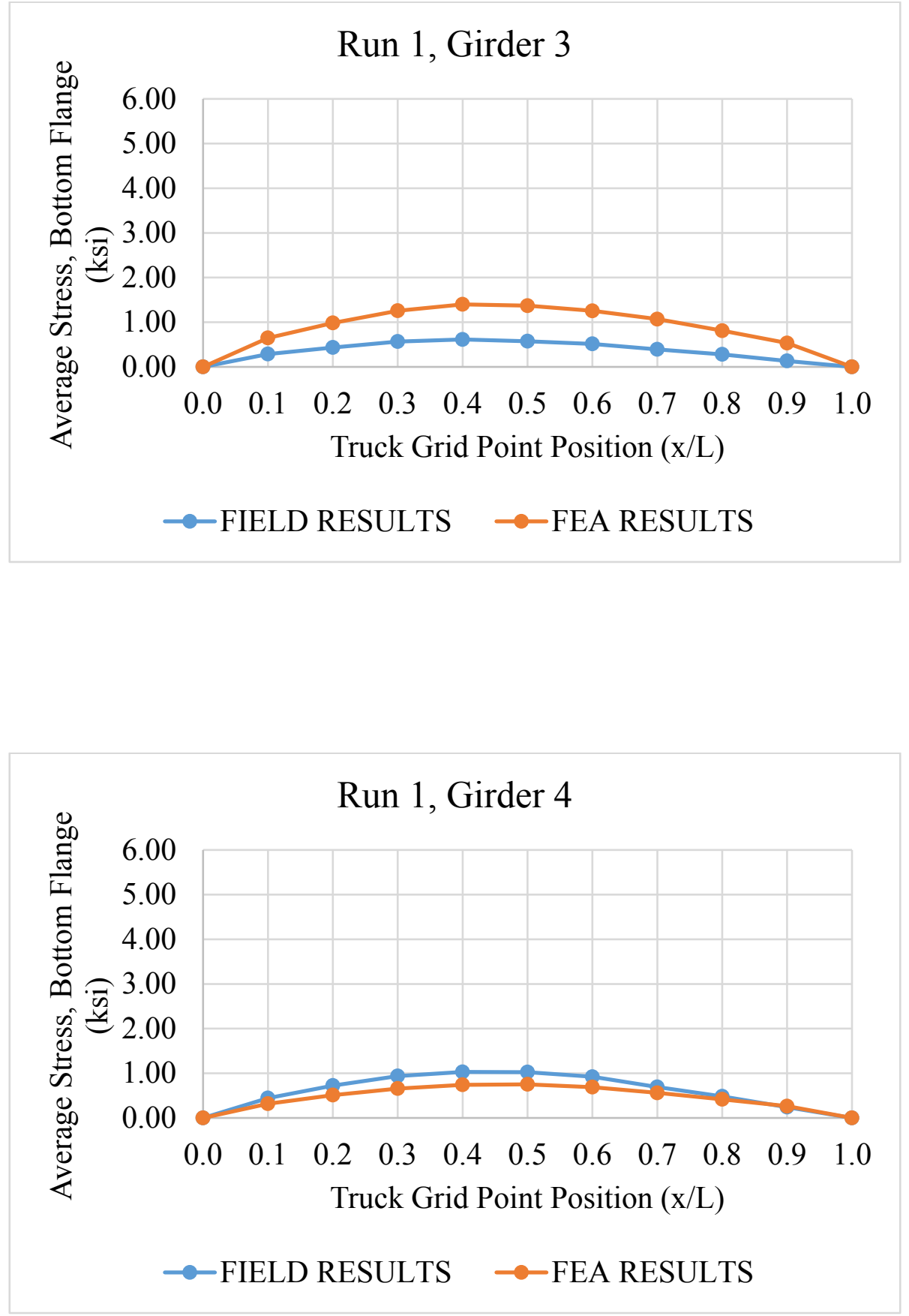

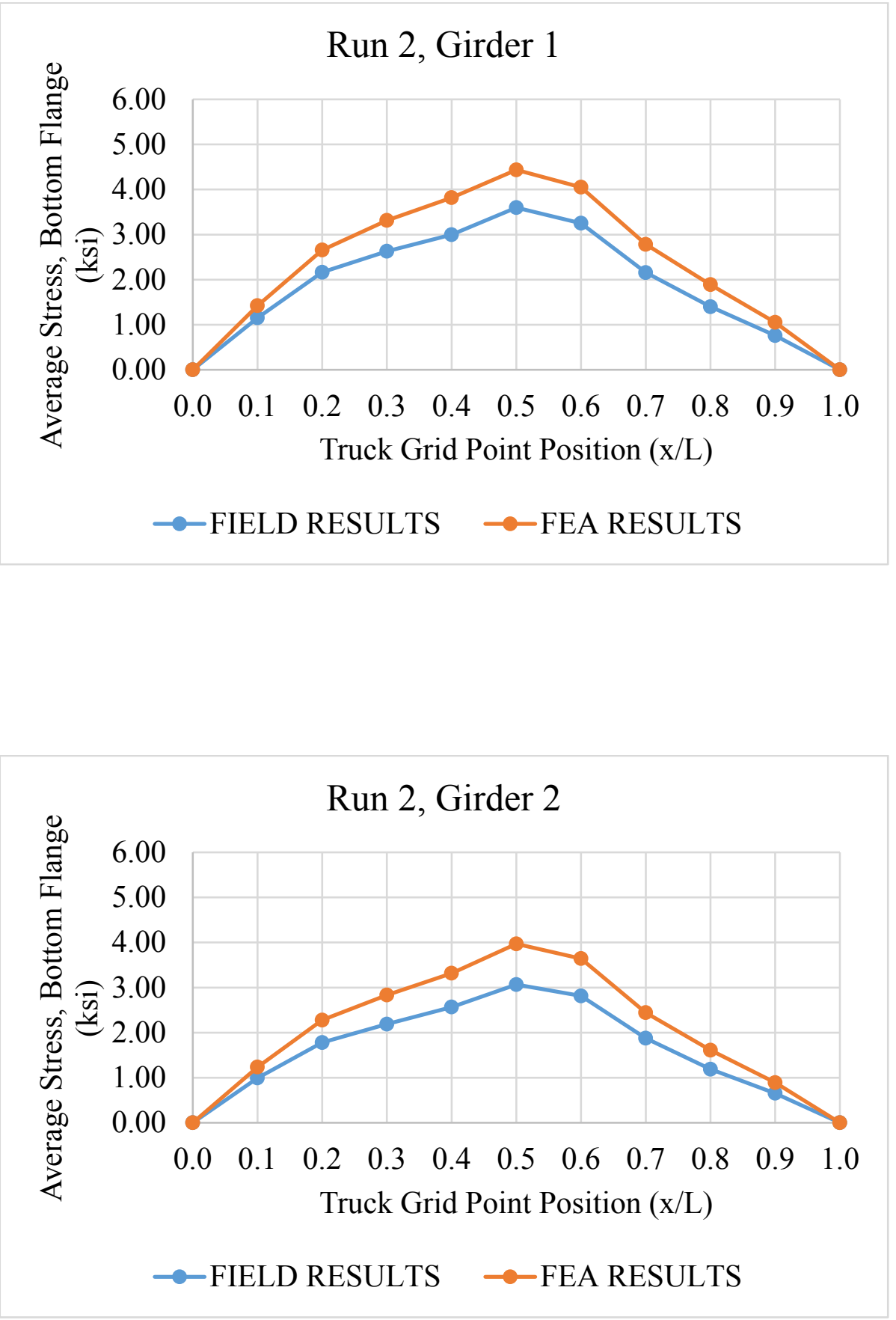

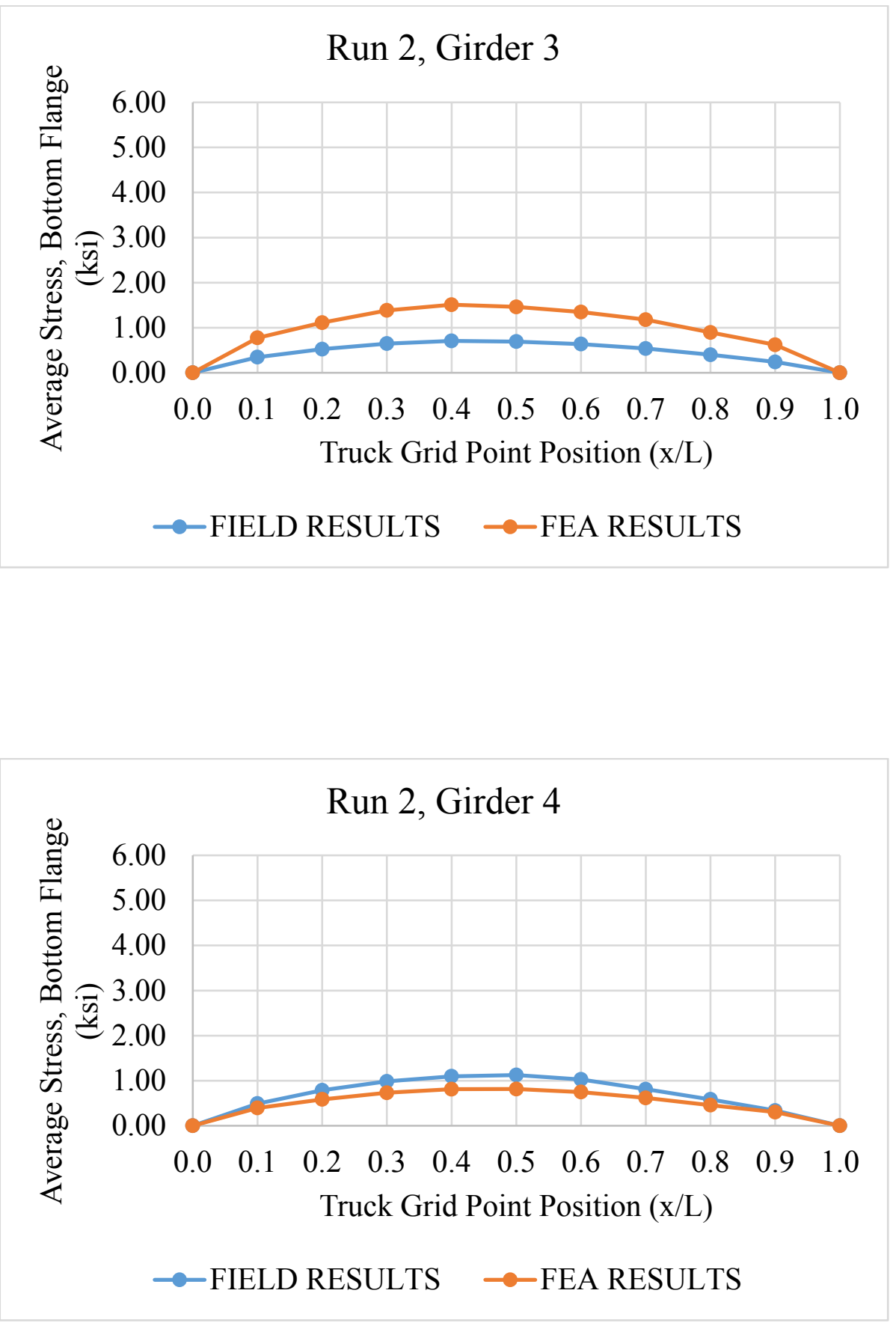

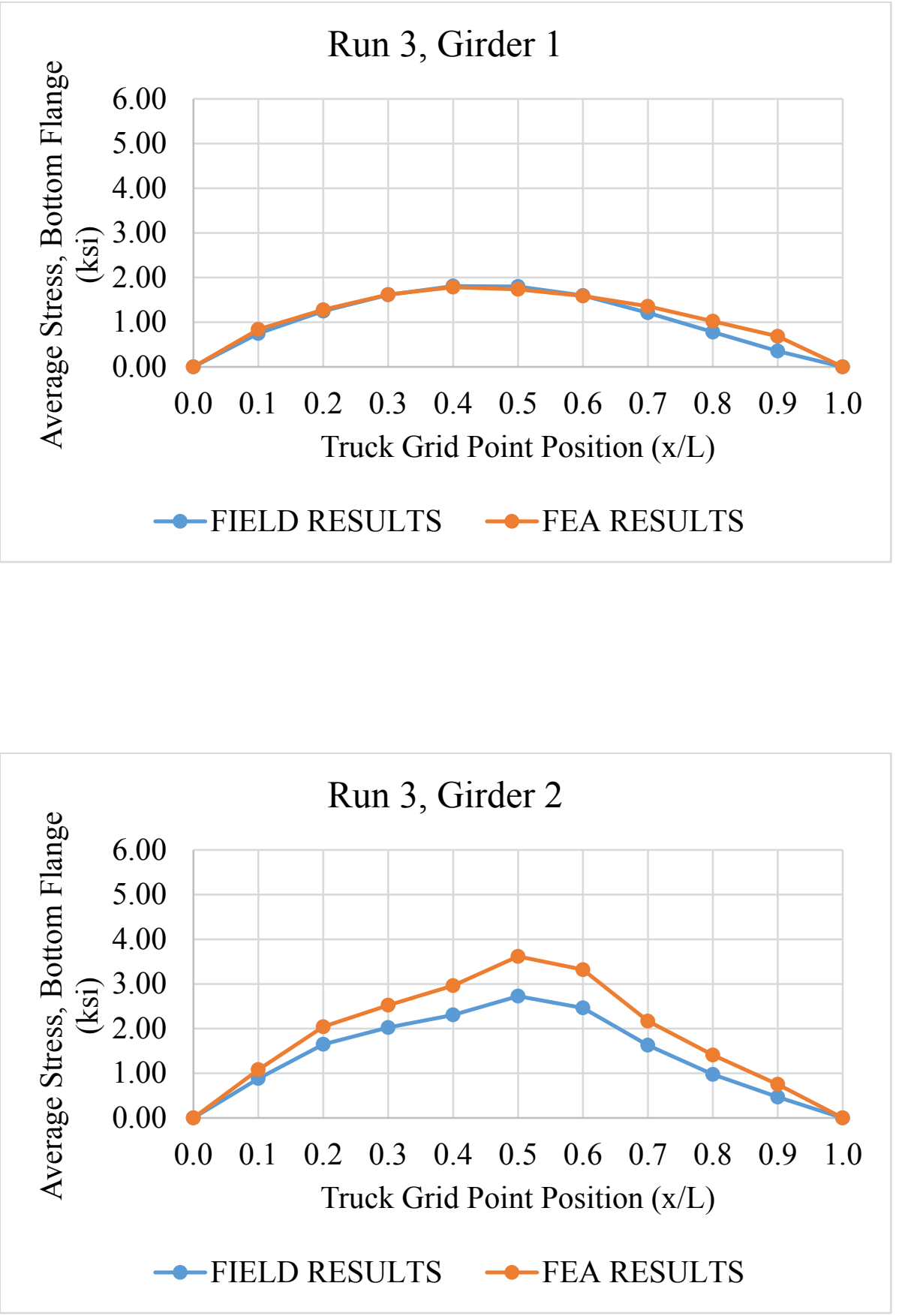

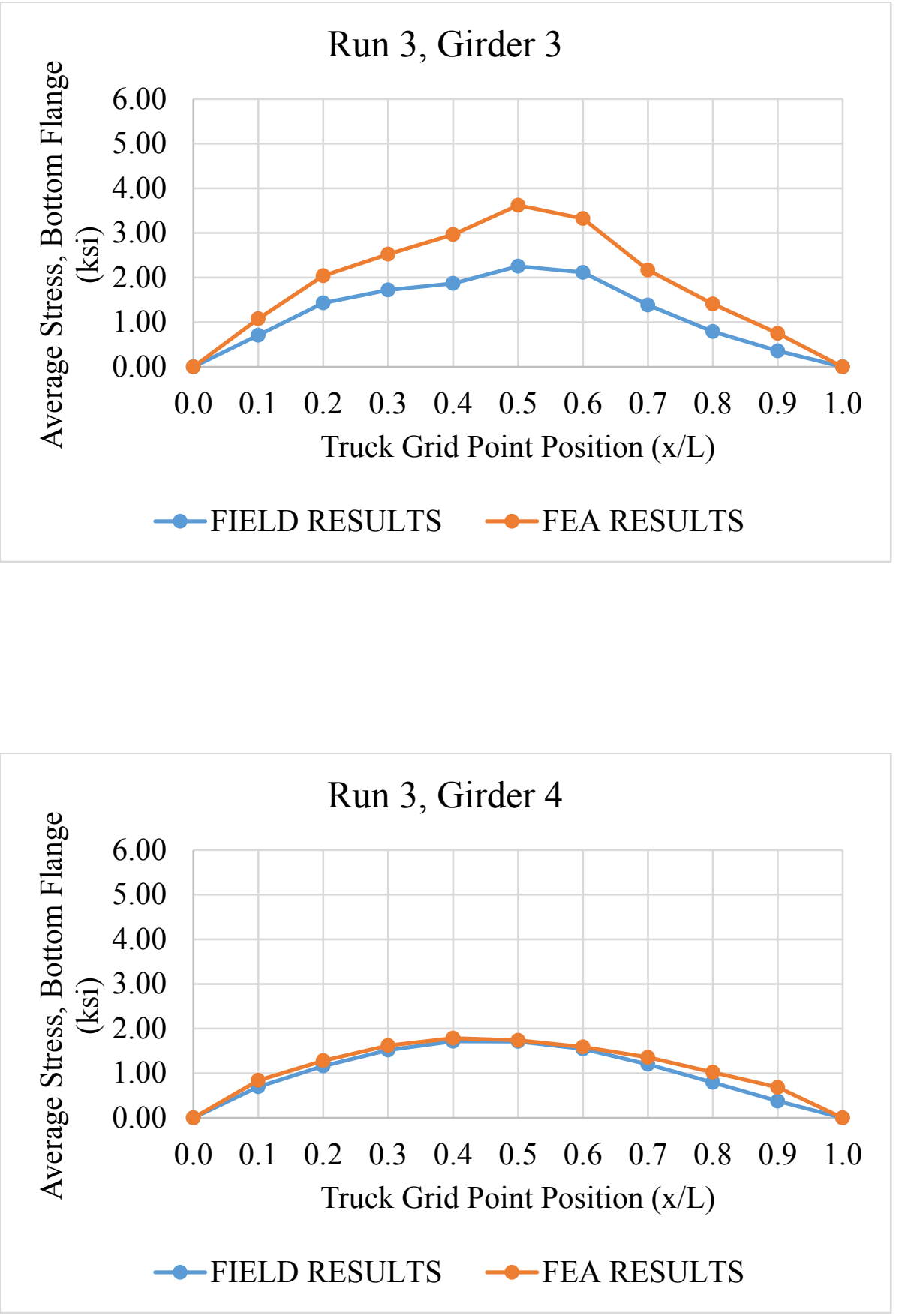

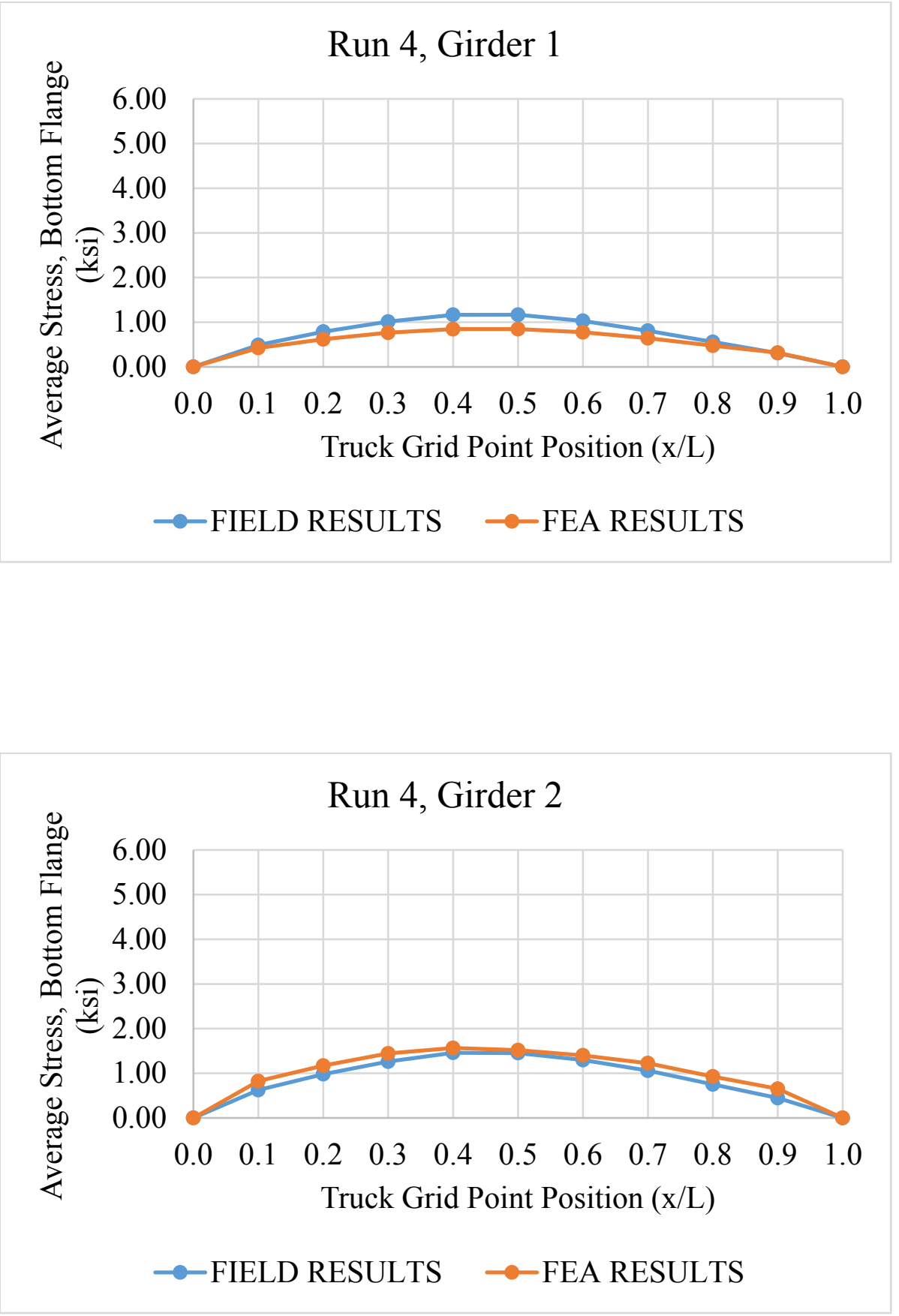

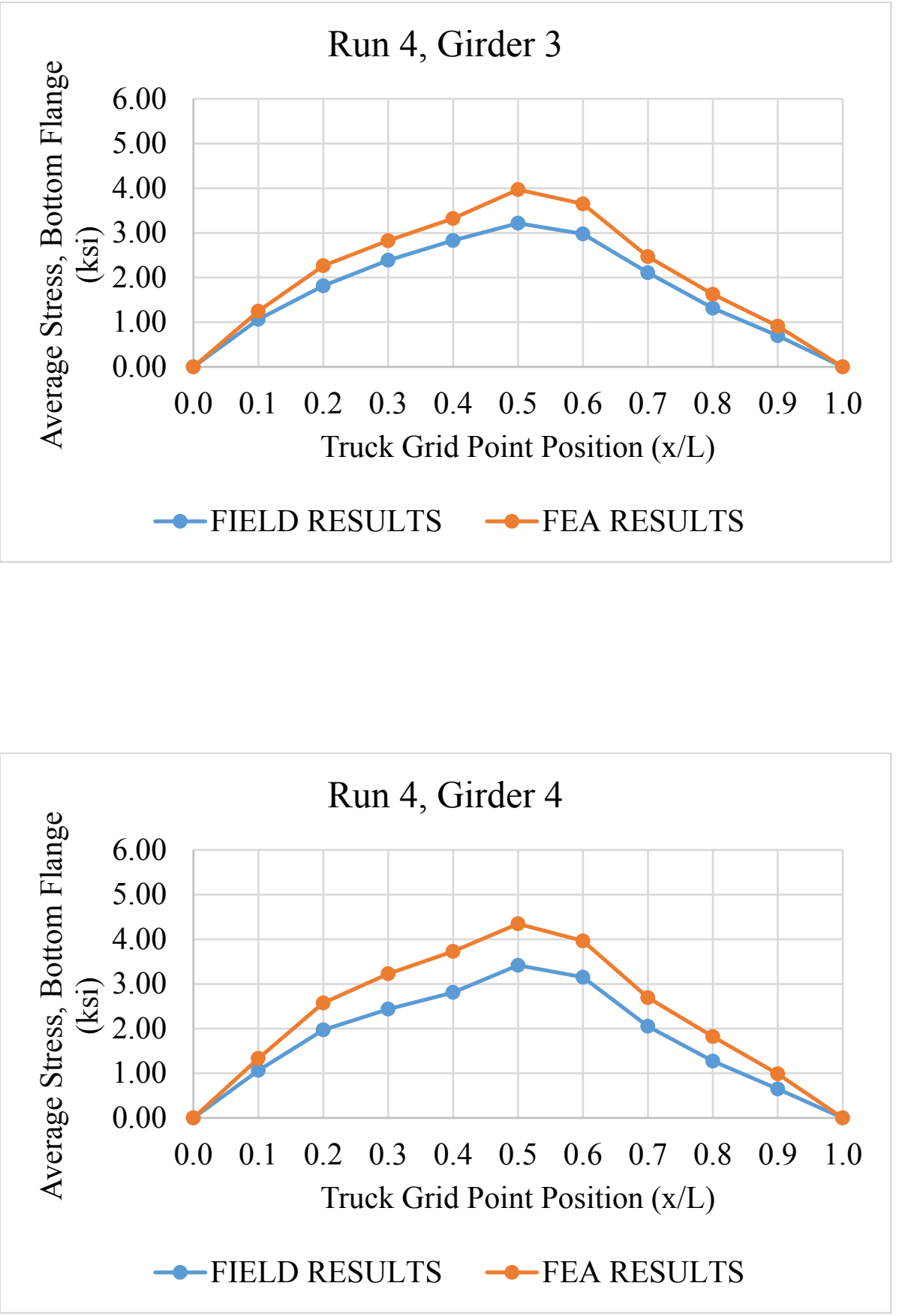

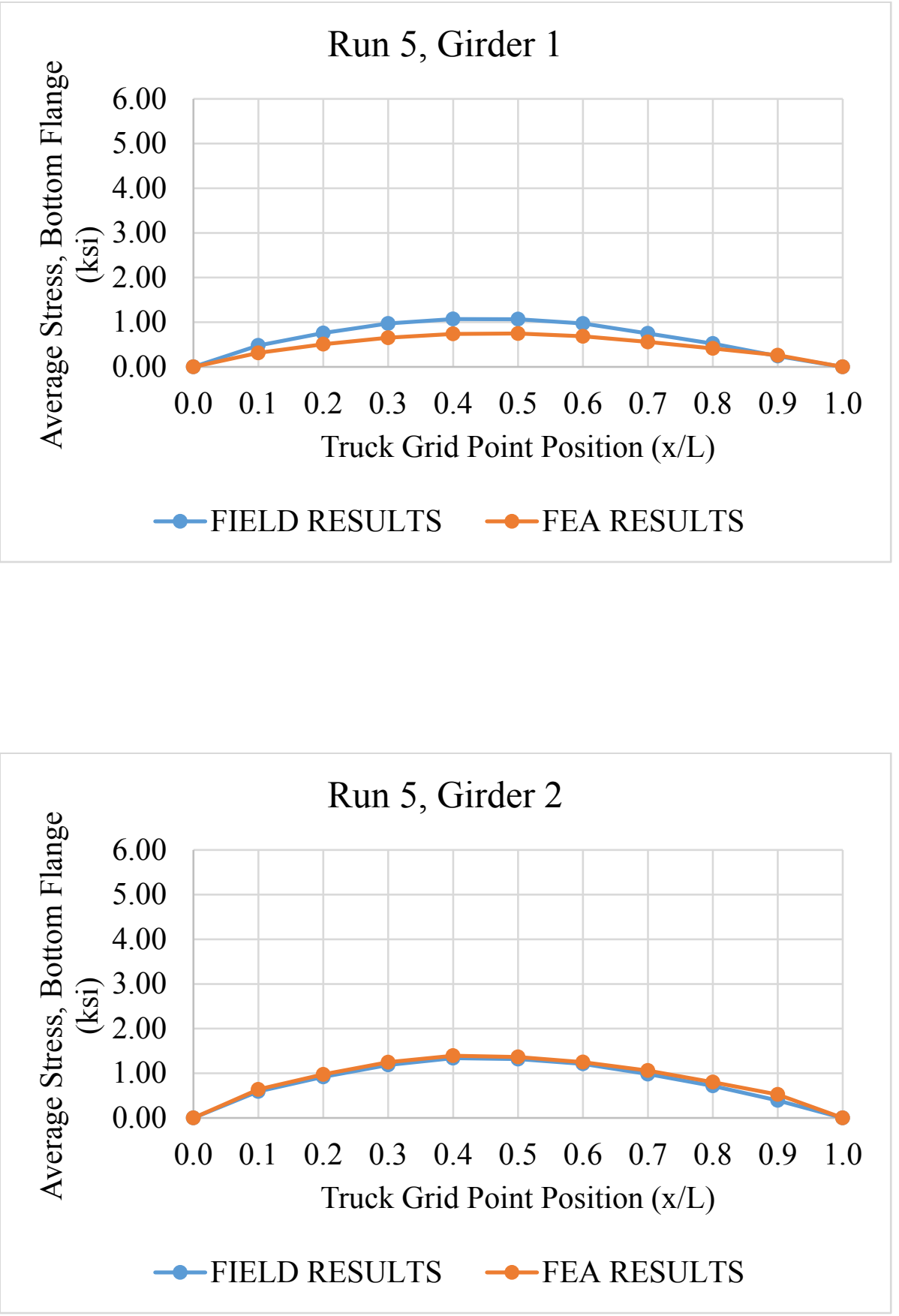

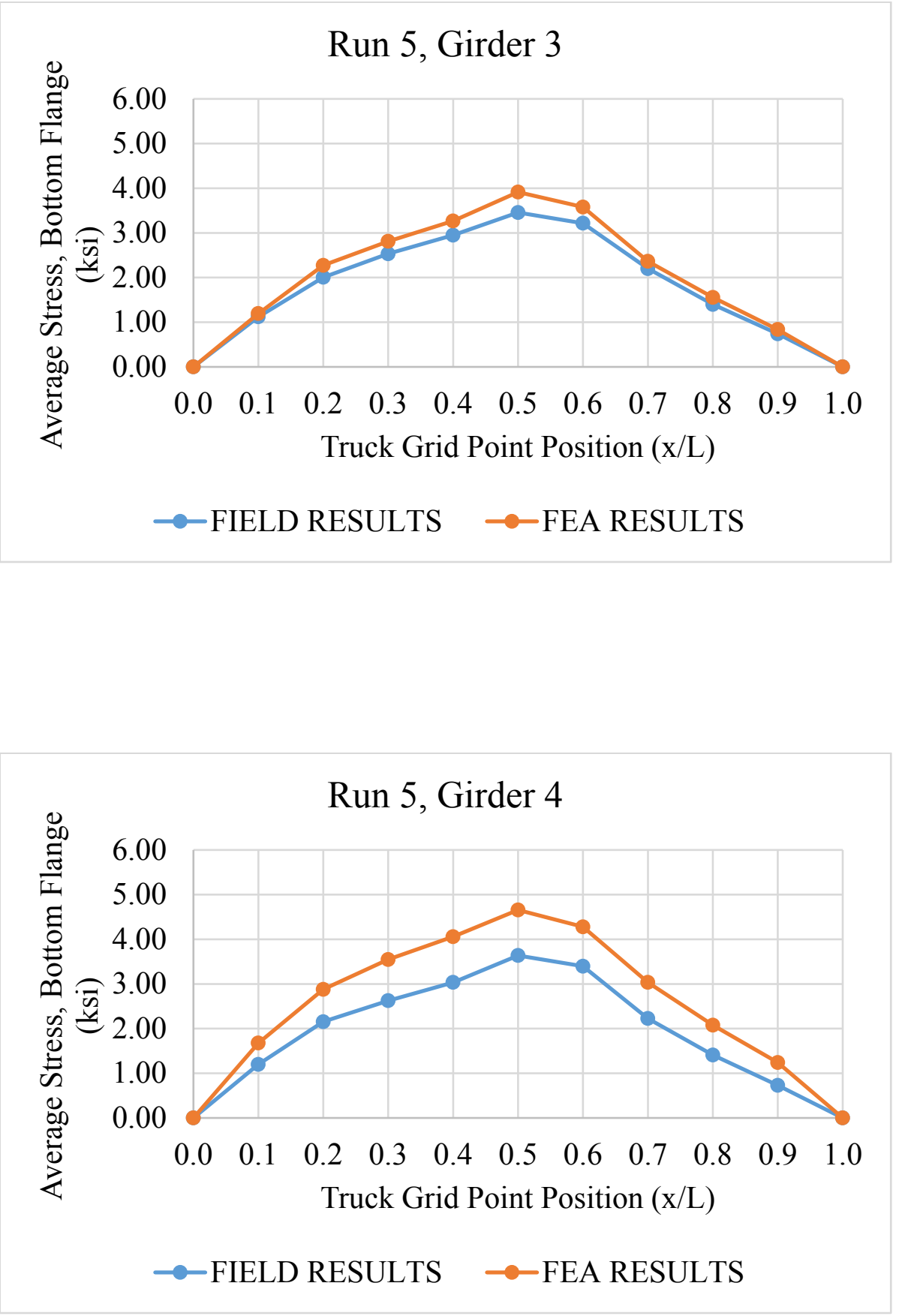

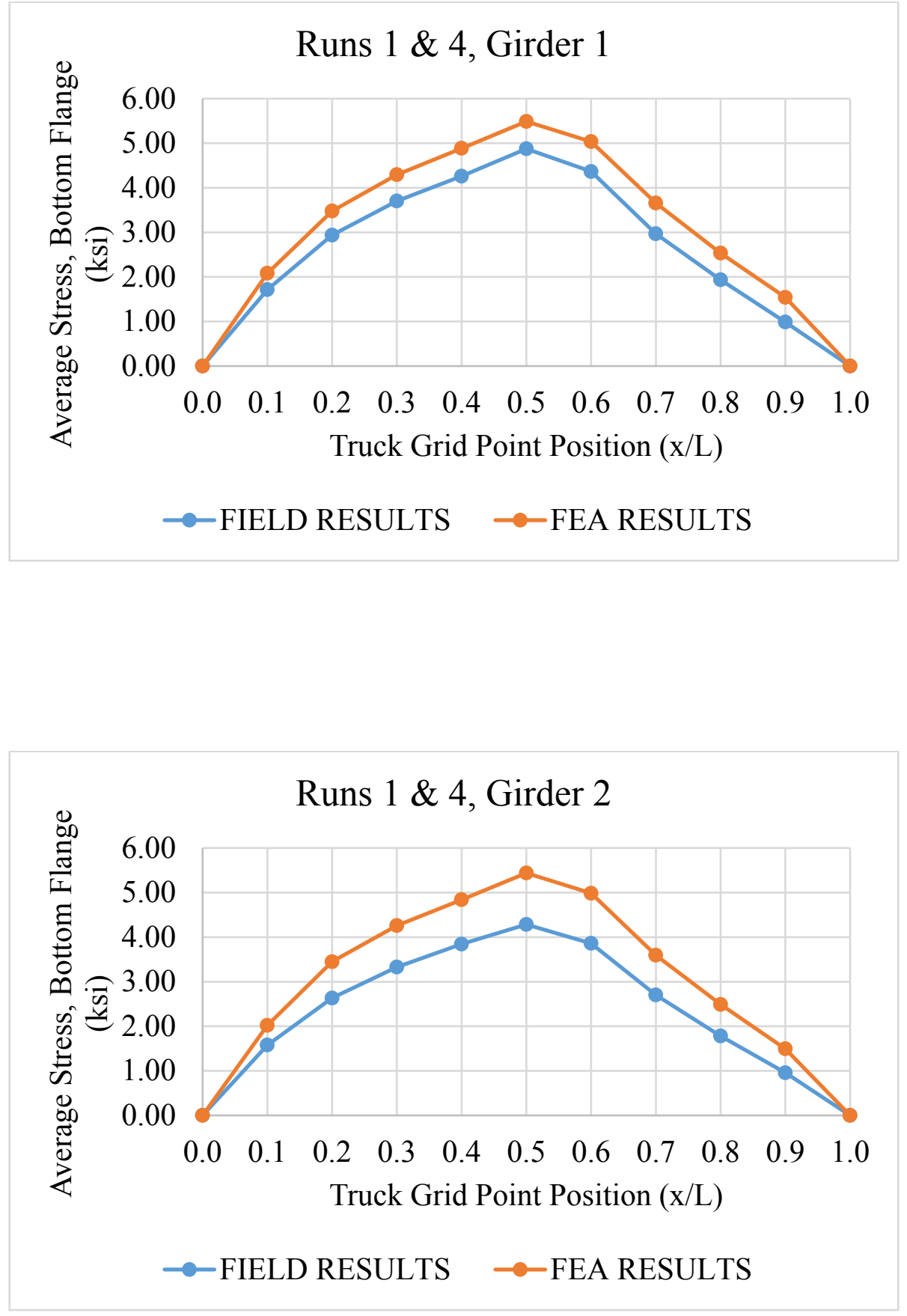

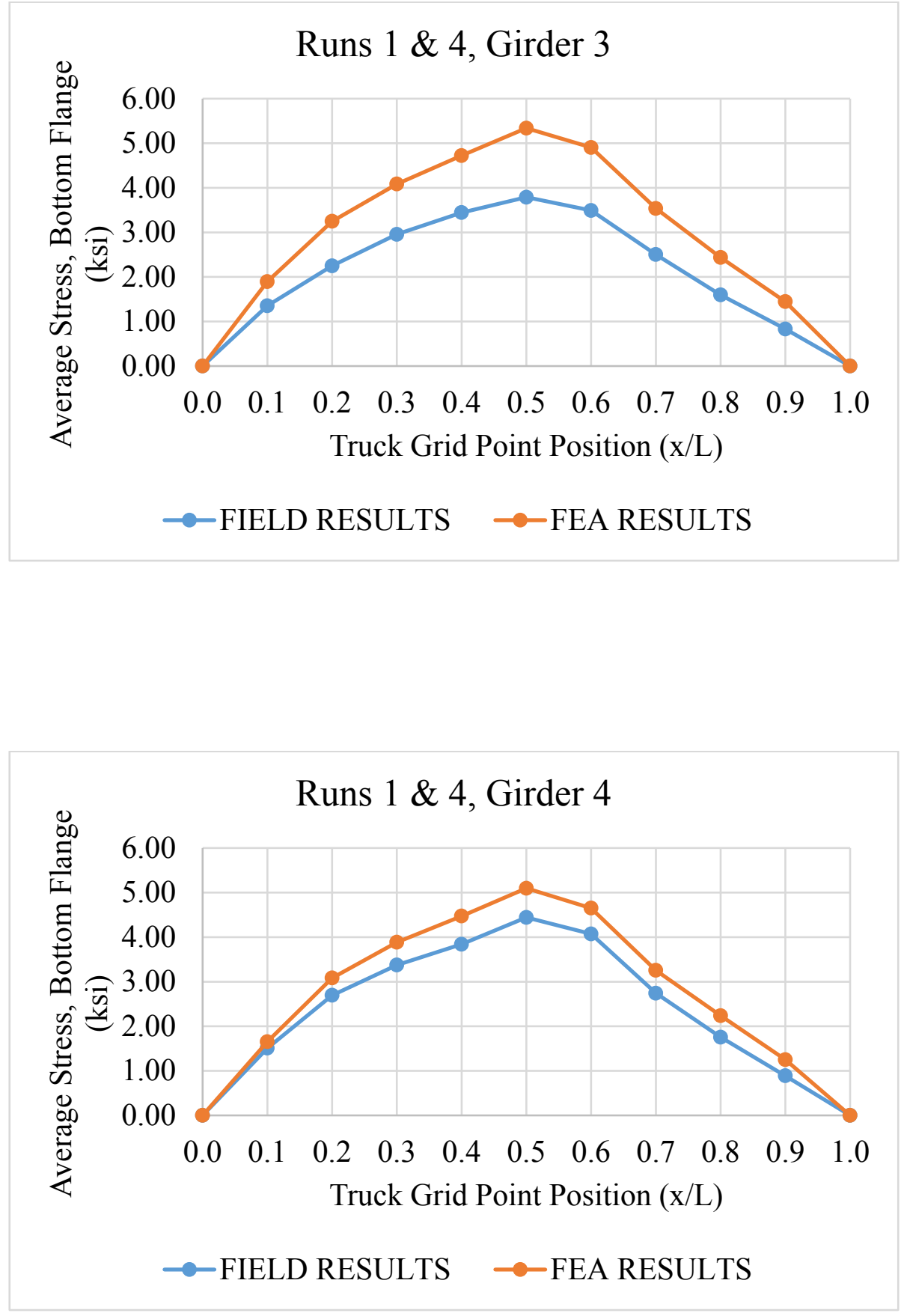

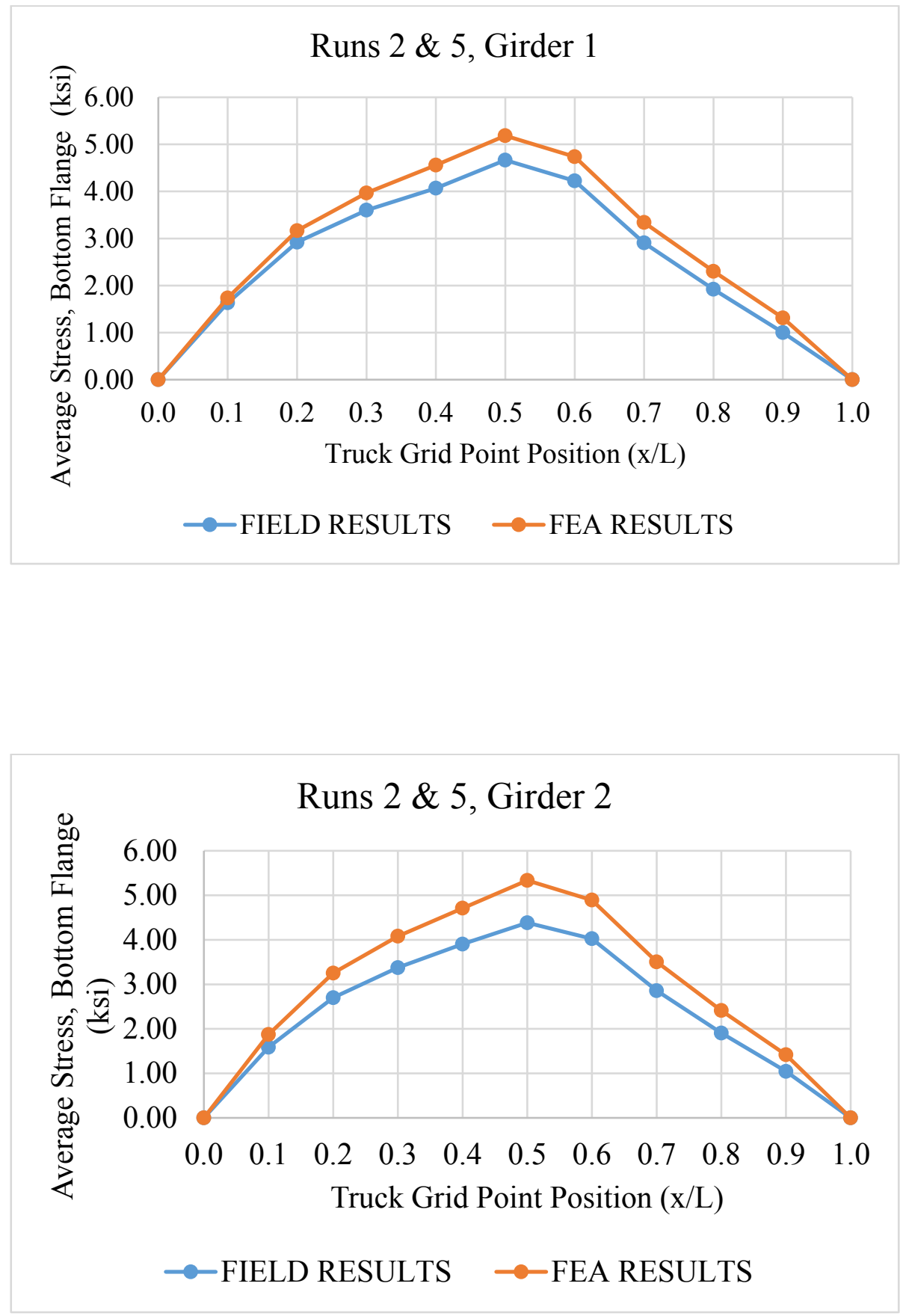

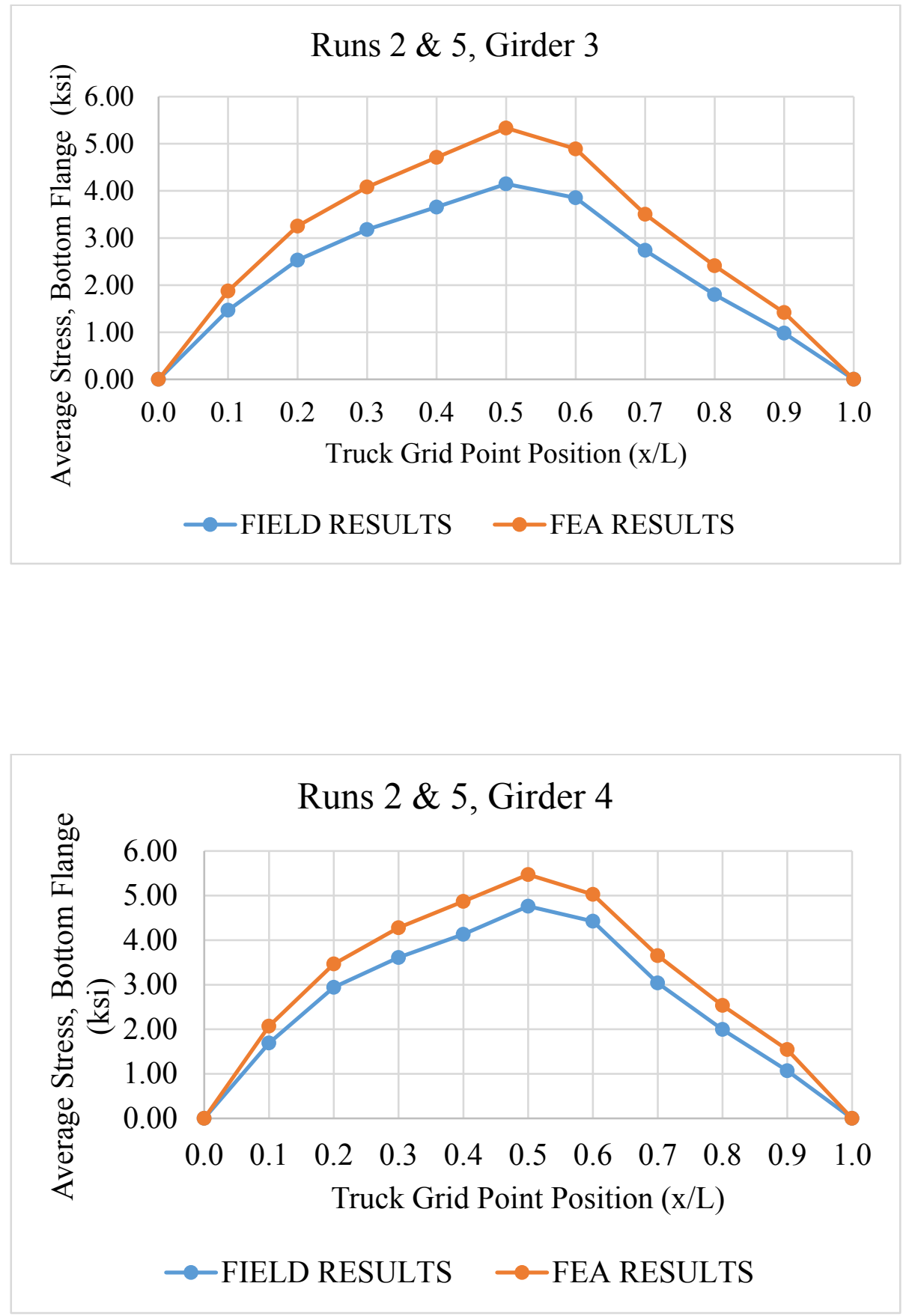


\title{
A.2 LiVE LOAD DistribUtion FACTORS
}

\author{
A.2.1 Live Load Field Test Results
}

\begin{tabular}{|c|c|c|c|c|c|c|c|c|c|}
\hline \multicolumn{10}{|c|}{ RUN 1, FIELD RESULTS } \\
\hline \multicolumn{2}{|c|}{ GRID POINT } & \multicolumn{4}{|c|}{ AVERAGE MICROSTRAIN (IN/IN) } & \multicolumn{4}{|c|}{ DISTRIBUTION FACTORS } \\
\hline $\mathrm{x}(\mathrm{ft})$ & $\mathrm{x} / \mathrm{L}$ & G1 & $\mathrm{G} 2$ & $\overline{G 3}$ & G4 & G1 & $\mathrm{G} 2$ & G3 & $\overline{\mathrm{G} 4}$ \\
\hline 0.00 & 0.0 & 0.00 & 0.00 & 0.00 & 0.00 & 0.000 & 0.000 & 0.000 & 0.000 \\
\hline 5.25 & 0.1 & 42.30 & 32.92 & 9.94 & 15.32 & 0.421 & 0.328 & 0.099 & 0.152 \\
\hline 10.50 & 0.2 & 74.13 & 57.04 & 15.00 & 24.95 & 0.433 & 0.333 & 0.088 & 0.146 \\
\hline 15.75 & 0.3 & 92.72 & 71.25 & 19.59 & 32.37 & 0.429 & 0.330 & 0.091 & 0.150 \\
\hline 21.00 & 0.4 & 106.73 & 82.27 & 21.19 & 35.53 & 0.434 & 0.335 & 0.086 & 0.145 \\
\hline 26.25 & 0.5 & 127.84 & 97.67 & 19.78 & 35.35 & 0.456 & 0.348 & 0.070 & 0.126 \\
\hline 31.50 & 0.6 & 115.03 & 88.36 & 17.73 & 31.79 & 0.455 & 0.349 & 0.070 & $\overline{0.126}$ \\
\hline 36.75 & 0.7 & 74.48 & 56.67 & 13.55 & 23.88 & 0.442 & 0.336 & 0.080 & 0.142 \\
\hline 42.00 & 0.8 & 47.51 & 35.50 & 9.67 & 16.64 & 0.435 & 0.325 & 0.088 & 0.152 \\
\hline 47.25 & 0.9 & 23.41 & 17.63 & 4.59 & 8.31 & 0.434 & 0.327 & 0.085 & 0.154 \\
\hline 52.50 & 1.0 & 0.00 & 0.00 & 0.00 & 0.00 & 0.000 & 0.000 & 0.000 & 0.000 \\
\hline & & & \multicolumn{3}{|c|}{ AVERAGE } & 0.438 & 0.335 & 0.084 & 0.144 \\
\hline & & & \multicolumn{3}{|c|}{ AVERAGE * MPF (1.2) } & 0.525 & 0.401 & 0.101 & 0.172 \\
\hline & & & \multicolumn{3}{|c|}{ STAND. DEVIATION } & 0.011 & 0.009 & 0.009 & 0.011 \\
\hline
\end{tabular}

\begin{tabular}{|c|c|c|c|c|c|c|c|c|c|}
\hline \multicolumn{10}{|c|}{ RUN 2, FIELD RESULTS } \\
\hline \multicolumn{2}{|c|}{ GRID POINT } & \multicolumn{4}{|c|}{ AVERAGE MICROSTRAIN (IN/IN) } & \multicolumn{4}{|c|}{ DISTRIBUTION FACTORS } \\
\hline $\mathrm{x}(\mathrm{ft})$ & $\mathrm{x} / \mathrm{L}$ & G1 & $\mathrm{G} 2$ & G3 & G4 & G1 & $\mathrm{G} 2$ & G3 & G4 \\
\hline 0.00 & 0.0 & 0.00 & 0.00 & 0.00 & 0.00 & 0.000 & 0.000 & 0.000 & 0.000 \\
\hline 5.25 & 0.1 & 39.74 & 34.24 & 11.91 & 16.97 & 0.386 & 0.333 & 0.116 & 0.165 \\
\hline 10.50 & 0.2 & 74.64 & 61.40 & 18.11 & 27.12 & 0.412 & 0.339 & 0.100 & 0.150 \\
\hline 15.75 & 0.3 & 90.68 & 75.47 & 22.34 & 33.95 & 0.408 & 0.339 & 0.100 & 0.153 \\
\hline 21.00 & 0.4 & 103.37 & 88.48 & 24.40 & 37.84 & 0.407 & 0.348 & 0.096 & 0.149 \\
\hline 26.25 & 0.5 & 124.08 & 105.74 & 23.85 & 38.79 & 0.424 & 0.362 & 0.082 & 0.133 \\
\hline 31.50 & 0.6 & 112.15 & 97.05 & 21.97 & 35.41 & 0.421 & 0.364 & 0.082 & 0.133 \\
\hline 36.75 & 0.7 & 74.40 & 64.68 & 18.56 & 28.00 & 0.401 & 0.348 & 0.100 & 0.151 \\
\hline 42.00 & 0.8 & 48.23 & 40.95 & 13.80 & 20.19 & 0.392 & 0.332 & 0.112 & 0.164 \\
\hline 47.25 & 0.9 & 26.21 & 22.54 & 8.29 & 11.66 & 0.382 & 0.328 & 0.121 & 0.170 \\
\hline 52.50 & 1.0 & 0.00 & 0.00 & 0.00 & 0.00 & 0.000 & 0.000 & 0.000 & 0.000 \\
\hline & & & \multicolumn{3}{|c|}{ AVERAGE } & 0.404 & 0.344 & 0.101 & 0.152 \\
\hline & & & \multicolumn{3}{|c|}{ AVERAGE * MPF (1.2) } & 0.484 & 0.412 & 0.121 & 0.182 \\
\hline & & & \multicolumn{3}{|c|}{ STAND. DEVIATION } & 0.015 & 0.013 & 0.014 & 0.013 \\
\hline
\end{tabular}




\begin{tabular}{|c|c|c|c|c|c|c|c|c|c|}
\hline \multicolumn{10}{|c|}{ RUN 3, FIELD RESULTS } \\
\hline \multicolumn{2}{|c|}{ GRID POINT } & \multicolumn{4}{|c|}{ AVERAGE MICROSTRAIN (IN/IN) } & \multicolumn{4}{|c|}{ DISTRIBUTION FACTORS } \\
\hline $\mathrm{x}(\mathrm{ft})$ & $\mathrm{x} / \mathrm{L}$ & G1 & $\mathrm{G} 2$ & G3 & $\overline{\mathrm{G} 4}$ & G1 & $\mathrm{G} 2$ & G3 & G4 \\
\hline 0.00 & 0.0 & 0.00 & 0.00 & 0.00 & 0.00 & 0.000 & 0.000 & 0.000 & 0.000 \\
\hline 5.25 & 0.1 & 25.80 & 30.43 & 24.46 & 24.02 & 0.246 & 0.291 & 0.234 & 0.229 \\
\hline 10.50 & 0.2 & 43.01 & 56.86 & 49.35 & 40.07 & 0.227 & 0.300 & 0.261 & 0.212 \\
\hline 15.75 & 0.3 & 55.66 & 69.80 & 59.36 & 52.37 & 0.235 & 0.294 & 0.250 & 0.221 \\
\hline 21.00 & 0.4 & 62.37 & 79.52 & 64.42 & 59.17 & 0.235 & 0.300 & 0.243 & 0.223 \\
\hline 26.25 & 0.5 & 62.01 & 94.01 & 77.73 & 59.04 & 0.212 & 0.321 & 0.265 & 0.202 \\
\hline 31.50 & 0.6 & 55.11 & 84.94 & 72.93 & 53.29 & 0.207 & 0.319 & 0.274 & 0.200 \\
\hline 36.75 & 0.7 & 41.74 & 56.12 & 47.71 & 41.42 & 0.223 & 0.300 & 0.255 & 0.221 \\
\hline 42.00 & 0.8 & 26.86 & 33.61 & 27.31 & 27.41 & 0.233 & 0.292 & 0.237 & 0.238 \\
\hline 47.25 & 0.9 & 12.19 & 16.13 & 12.39 & 12.99 & 0.227 & 0.300 & 0.231 & 0.242 \\
\hline 52.50 & 1.0 & 0.00 & 0.00 & 0.00 & 0.00 & 0.000 & 0.000 & 0.000 & 0.000 \\
\hline & & & \multicolumn{3}{|c|}{ AVERAGE } & 0.227 & 0.302 & 0.250 & 0.221 \\
\hline & & & \multicolumn{3}{|c|}{ AVERAGE * MPF (1.2) } & 0.273 & 0.362 & 0.300 & 0.265 \\
\hline & & & \multicolumn{3}{|c|}{ STAND. DEVIATION } & 0.012 & 0.011 & 0.015 & 0.015 \\
\hline
\end{tabular}

\begin{tabular}{|c|c|c|c|c|c|c|c|c|c|}
\hline \multicolumn{10}{|c|}{ RUN 4, FIELD RESULTS } \\
\hline \multicolumn{2}{|c|}{ GRID POINT } & \multicolumn{4}{|c|}{ AVERAGE MICROSTRAIN (IN/IN) } & \multicolumn{4}{|c|}{ DISTRIBUTIONFACTORS } \\
\hline $\mathrm{x}(\mathrm{ft})$ & $\mathrm{x} / \mathrm{L}$ & G1 & $\mathrm{G} 2$ & G3 & G4 & $\overline{\text { G1 }}$ & $\mathrm{G} 2$ & G3 & G4 \\
\hline 0.00 & 0.0 & 0.00 & 0.00 & 0.00 & 0.00 & 0.000 & 0.000 & 0.000 & 0.000 \\
\hline 5.25 & 0.1 & 16.83 & 21.53 & 36.69 & 36.68 & 0.151 & 0.193 & 0.328 & 0.328 \\
\hline 10.50 & 0.2 & 27.19 & 33.77 & 62.56 & 67.94 & 0.142 & 0.176 & 0.327 & 0.355 \\
\hline 15.75 & 0.3 & 34.94 & 43.53 & 82.33 & 83.96 & 0.143 & 0.178 & 0.336 & 0.343 \\
\hline 21.00 & 0.4 & 40.18 & 50.29 & 97.58 & 96.92 & 0.141 & 0.176 & 0.342 & 0.340 \\
\hline 26.25 & 0.5 & 40.26 & 50.07 & 110.88 & 117.84 & 0.126 & 0.157 & 0.348 & 0.369 \\
\hline 31.50 & 0.6 & 35.51 & 44.74 & 102.65 & 108.64 & 0.122 & 0.153 & 0.352 & 0.373 \\
\hline 36.75 & 0.7 & 27.86 & 36.50 & 72.74 & 70.69 & 0.134 & 0.176 & 0.350 & 0.340 \\
\hline 42.00 & 0.8 & 19.26 & 25.90 & 45.34 & 43.86 & 0.143 & 0.193 & 0.337 & 0.326 \\
\hline 47.25 & 0.9 & 10.61 & 15.36 & 24.10 & 22.36 & 0.147 & 0.212 & 0.333 & 0.309 \\
\hline 52.50 & 1.0 & 0.00 & 0.00 & 0.00 & 0.00 & 0.000 & 0.000 & 0.000 & 0.000 \\
\hline & & & \multicolumn{3}{|c|}{ AVERAGE } & 0.139 & 0.179 & 0.339 & 0.343 \\
\hline & & & \multicolumn{3}{|c|}{ AVERAGE * MPF (1.2) } & 0.166 & 0.215 & 0.407 & 0.411 \\
\hline & & & \multicolumn{3}{|c|}{ STAND. DEVIATION } & 0.009 & 0.018 & 0.009 & 0.021 \\
\hline
\end{tabular}




\begin{tabular}{|c|c|c|c|c|c|c|c|c|c|}
\hline \multicolumn{10}{|c|}{ RUN 5, FIELD RESULTS } \\
\hline \multicolumn{2}{|c|}{ GRID POINT } & \multicolumn{4}{|c|}{ AVERAGE MICROSTRAIN (IN/IN) } & \multicolumn{4}{|c|}{ DISTRIBUTION FACTORS } \\
\hline $\mathrm{x}(\mathrm{ft})$ & $\mathrm{x} / \mathrm{L}$ & G1 & G2 & G3 & G4 & G1 & G2 & G3 & G4 \\
\hline 0.00 & 0.0 & 0.00 & 0.00 & 0.00 & 0.00 & 0.000 & 0.000 & 0.000 & 0.000 \\
\hline 5.25 & 0.1 & 16.54 & 20.47 & 38.65 & 41.35 & 0.141 & 0.175 & 0.330 & 0.353 \\
\hline 10.50 & 0.2 & 26.12 & 31.69 & 69.18 & 74.28 & 0.130 & 0.157 & 0.344 & 0.369 \\
\hline 15.75 & 0.3 & 33.50 & 40.91 & 87.32 & 90.54 & 0.133 & 0.162 & 0.346 & 0.359 \\
\hline 21.00 & 0.4 & 36.92 & 46.16 & 101.68 & 104.63 & 0.128 & 0.160 & 0.351 & 0.362 \\
\hline 26.25 & 0.5 & 36.79 & 45.42 & 119.18 & 125.39 & 0.113 & 0.139 & 0.365 & 0.384 \\
\hline 31.50 & 0.6 & 33.51 & 41.73 & 110.91 & 117.12 & 0.110 & 0.138 & 0.366 & 0.386 \\
\hline 36.75 & 0.7 & 25.83 & 33.85 & 75.85 & 76.72 & 0.122 & 0.159 & 0.357 & 0.361 \\
\hline 42.00 & 0.8 & 17.99 & 24.73 & 48.20 & 48.57 & 0.129 & 0.177 & 0.346 & 0.348 \\
\hline 47.25 & 0.9 & 8.33 & 13.52 & 25.56 & 25.19 & 0.115 & 0.186 & 0.352 & 0.347 \\
\hline 52.50 & 1.0 & 0.00 & 0.00 & 0.00 & 0.00 & 0.000 & 0.000 & 0.000 & 0.000 \\
\hline & & & \multicolumn{3}{|c|}{ AVERAGE } & 0.124 & 0.162 & 0.351 & 0.363 \\
\hline & & & \multicolumn{3}{|c|}{ AVERAGE * MPF (1.2) } & 0.149 & 0.194 & 0.421 & 0.436 \\
\hline & & & \multicolumn{3}{|c|}{ STAND. DEVIATION } & 0.010 & 0.016 & 0.011 & 0.014 \\
\hline
\end{tabular}

\begin{tabular}{|c|c|c|c|c|c|c|c|c|c|}
\hline \multicolumn{10}{|c|}{ SUM: RUN 1 AND RUN 4, FIELD RESULTS } \\
\hline \multicolumn{2}{|c|}{ GRID POINT } & \multicolumn{4}{|c|}{ AVERAGE MICROSTRAIN (IN/IN) } & \multicolumn{4}{|c|}{ DISTRIBUTION FACTORS } \\
\hline $\mathrm{x}(\mathrm{ft})$ & $\mathrm{x} / \mathrm{L}$ & G1 & $\mathrm{G} 2$ & $\overline{\mathrm{G} 3}$ & G4 & G1 & G2 & G3 & G4 \\
\hline 0.00 & 0.0 & 0.00 & 0.00 & 0.00 & 0.00 & 0.000 & 0.000 & 0.000 & 0.000 \\
\hline 5.25 & 0.1 & 59.13 & 54.46 & 46.63 & 52.00 & 0.557 & 0.513 & 0.439 & 0.490 \\
\hline 10.50 & 0.2 & 101.32 & 90.81 & 77.56 & 92.89 & 0.559 & 0.501 & 0.428 & 0.512 \\
\hline 15.75 & 0.3 & 127.66 & 114.78 & 101.92 & 116.33 & 0.554 & 0.498 & 0.442 & 0.505 \\
\hline 21.00 & 0.4 & 146.91 & 132.57 & 118.77 & 132.45 & 0.554 & 0.500 & 0.448 & 0.499 \\
\hline 26.25 & 0.5 & 168.10 & 147.74 & 130.67 & 153.19 & 0.561 & 0.493 & 0.436 & 0.511 \\
\hline 31.50 & 0.6 & 150.53 & 133.10 & 120.38 & 140.43 & 0.553 & 0.489 & 0.442 & 0.516 \\
\hline 36.75 & 0.7 & 102.34 & 93.17 & 86.29 & 94.57 & 0.544 & 0.495 & 0.459 & 0.503 \\
\hline 42.00 & 0.8 & 66.77 & 61.41 & 55.01 & 60.50 & 0.548 & 0.504 & 0.451 & 0.497 \\
\hline 47.25 & 0.9 & 34.02 & 32.99 & 28.68 & 30.67 & 0.538 & 0.522 & 0.454 & 0.485 \\
\hline 52.50 & 1.0 & 0.00 & 0.00 & 0.00 & 0.00 & 0.000 & 0.000 & 0.000 & 0.000 \\
\hline & & & \multicolumn{3}{|c|}{ AVERAGE } & 0.552 & 0.502 & 0.444 & 0.502 \\
\hline & & & \multicolumn{3}{|c|}{ AVERAGE * MPF (1.0) } & 0.552 & 0.502 & 0.444 & 0.502 \\
\hline & & & \multicolumn{3}{|c|}{ STAND. DEVIATION } & 0.007 & 0.010 & 0.010 & 0.010 \\
\hline
\end{tabular}




\begin{tabular}{|c|c|c|c|c|c|c|c|c|c|}
\hline \multicolumn{10}{|c|}{ SUM: RUN 2 AND RUN 5, FIELD RESULTS } \\
\hline \multicolumn{2}{|c|}{ GRID POINT } & \multicolumn{4}{|c|}{ AVERAGE MICROSTRAIN (IN/IN) } & \multicolumn{4}{|c|}{ DISTRIBUTION FACTORS } \\
\hline $\mathrm{x}(\mathrm{ft})$ & $\mathrm{x} / \mathrm{L}$ & G1 & $\mathrm{G} 2$ & G3 & G4 & G1 & $\mathrm{G} 2$ & G3 & G4 \\
\hline 0.00 & 0.0 & 0.00 & 0.00 & 0.00 & 0.00 & 0.000 & 0.000 & 0.000 & 0.000 \\
\hline 5.25 & 0.1 & 56.28 & 54.70 & 50.56 & 58.32 & 0.512 & 0.498 & 0.460 & 0.530 \\
\hline 10.50 & 0.2 & 100.76 & 93.09 & 87.29 & 101.40 & 0.527 & 0.487 & 0.456 & 0.530 \\
\hline 15.75 & 0.3 & 124.18 & 116.38 & 109.66 & 124.49 & 0.523 & 0.490 & 0.462 & 0.524 \\
\hline 21.00 & 0.4 & 140.30 & 134.64 & 126.07 & 142.46 & 0.516 & 0.495 & 0.464 & 0.524 \\
\hline 26.25 & 0.5 & 160.87 & 151.16 & 143.03 & 164.18 & 0.520 & 0.488 & 0.462 & 0.530 \\
\hline 31.50 & 0.6 & 145.66 & 138.78 & 132.87 & 152.53 & 0.511 & 0.487 & 0.466 & 0.535 \\
\hline 36.75 & 0.7 & 100.23 & 98.53 & 94.41 & 104.72 & 0.504 & 0.495 & 0.475 & 0.526 \\
\hline 42.00 & 0.8 & 66.22 & 65.69 & 62.00 & 68.76 & 0.504 & 0.500 & 0.472 & 0.524 \\
\hline 47.25 & 0.9 & 34.54 & 36.05 & 33.84 & 36.84 & 0.489 & 0.510 & 0.479 & 0.522 \\
\hline 52.50 & 1.0 & 0.00 & 0.00 & 0.00 & 0.00 & 0.000 & 0.000 & 0.000 & 0.000 \\
\hline & & & \multicolumn{3}{|c|}{ AVERAGE } & 0.512 & 0.495 & 0.466 & 0.527 \\
\hline & & & \multicolumn{3}{|c|}{ AVERAGE * MPF (1.0) } & 0.512 & 0.495 & 0.466 & 0.527 \\
\hline & & & \multicolumn{3}{|c|}{ STAND. DEVIATION } & 0.012 & 0.008 & 0.007 & 0.004 \\
\hline
\end{tabular}




\begin{tabular}{|c|c|c|c|c|c|c|c|c|c|}
\hline \multicolumn{10}{|c|}{ RUN 1, FEA RESULTS } \\
\hline \multicolumn{2}{|c|}{ GRID POINT } & \multicolumn{4}{|c|}{ AVERAGE MICROSTRAIN (IN/IN) } & \multicolumn{4}{|c|}{ DISTRIBUTION FACTORS } \\
\hline $\mathrm{x}(\mathrm{ft})$ & $\mathrm{x} / \mathrm{L}$ & $\overline{\text { G1 }}$ & $\overline{\mathrm{G} 2}$ & G3 & G4 & G1 & $\overline{\mathrm{G} 2}$ & G3 & G4 \\
\hline 0.00 & 0.0 & 0.00 & 0.00 & 0.00 & 0.00 & 0.000 & 0.000 & 0.000 & 0.000 \\
\hline 5.25 & 0.1 & 57.21 & 41.30 & 22.33 & 11.01 & 0.434 & 0.313 & 0.169 & 0.084 \\
\hline 10.50 & 0.2 & 98.66 & 78.53 & 33.92 & 17.60 & 0.431 & 0.343 & 0.148 & 0.077 \\
\hline 15.75 & 0.3 & 121.70 & 97.10 & 43.35 & 22.71 & 0.427 & 0.341 & 0.152 & 0.080 \\
\hline 21.00 & 0.4 & 139.35 & 112.89 & 48.25 & 25.61 & 0.427 & 0.346 & 0.148 & 0.079 \\
\hline 26.25 & 0.5 & 160.08 & 135.24 & 47.23 & 25.93 & 0.434 & 0.367 & 0.128 & 0.070 \\
\hline 31.50 & 0.6 & 146.95 & 123.66 & 43.30 & 23.76 & 0.435 & 0.366 & 0.128 & 0.070 \\
\hline 36.75 & 0.7 & 104.02 & 81.70 & 36.87 & 19.38 & 0.430 & 0.338 & 0.152 & 0.080 \\
\hline 42.00 & 0.8 & 71.04 & 53.83 & 27.93 & 14.39 & 0.425 & 0.322 & 0.167 & 0.086 \\
\hline 47.25 & 0.9 & 42.24 & 29.03 & 18.42 & 9.12 & 0.427 & 0.294 & 0.186 & 0.092 \\
\hline 52.50 & 1.0 & 0.00 & 0.00 & 0.00 & 0.00 & 0.000 & 0.000 & 0.000 & 0.000 \\
\hline & & & \multicolumn{3}{|c|}{ AVERAGE } & 0.430 & 0.337 & 0.153 & 0.080 \\
\hline & & & \multicolumn{3}{|c|}{ AVERAGE * MPF (1.2) } & 0.516 & 0.404 & 0.184 & 0.096 \\
\hline & & & \multicolumn{3}{|c|}{ STAND. DEVIATION } & 0.004 & 0.024 & 0.019 & 0.007 \\
\hline
\end{tabular}

\begin{tabular}{|c|c|c|c|c|c|c|c|c|c|}
\hline \multicolumn{10}{|c|}{ RUN 2, FEA RESULTS } \\
\hline \multicolumn{2}{|c|}{ GRID POINT } & \multicolumn{4}{|c|}{ AVERAGE MICROSTRAIN (IN/IN) } & \multicolumn{4}{|c|}{ DISTRIBUTION FACTORS } \\
\hline $\mathrm{x}(\mathrm{ft})$ & $\mathrm{x} / \mathrm{L}$ & G1 & $\mathrm{G} 2$ & G3 & G4 & G1 & $\mathrm{G} 2$ & G3 & G4 \\
\hline 0.00 & 0.0 & 0.00 & 0.00 & 0.00 & 0.00 & 0.000 & 0.000 & 0.000 & 0.000 \\
\hline 5.25 & 0.1 & 49.04 & 42.61 & 26.70 & 13.60 & 0.372 & 0.323 & 0.202 & 0.103 \\
\hline 10.50 & 0.2 & 91.62 & 78.56 & 38.36 & 20.19 & 0.401 & 0.343 & 0.168 & 0.088 \\
\hline 15.75 & 0.3 & 114.29 & 97.68 & 47.70 & 25.24 & 0.401 & 0.343 & 0.167 & 0.089 \\
\hline 21.00 & 0.4 & 131.72 & 114.41 & 52.10 & 28.00 & 0.404 & 0.351 & 0.160 & 0.086 \\
\hline 26.25 & 0.5 & 152.96 & 136.88 & 50.43 & 28.12 & 0.415 & 0.372 & 0.137 & 0.076 \\
\hline 31.50 & 0.6 & 139.70 & 125.60 & 46.48 & 25.77 & 0.414 & 0.372 & 0.138 & 0.076 \\
\hline 36.75 & 0.7 & 95.95 & 84.24 & 40.61 & 21.30 & 0.396 & 0.348 & 0.168 & 0.088 \\
\hline 42.00 & 0.8 & 65.13 & 55.51 & 30.85 & 15.75 & 0.389 & 0.332 & 0.184 & 0.094 \\
\hline 47.25 & 0.9 & 36.26 & 30.74 & 21.45 & 10.42 & 0.367 & 0.311 & 0.217 & 0.105 \\
\hline 52.50 & 1.0 & 0.00 & 0.00 & 0.00 & 0.00 & 0.000 & 0.000 & 0.000 & 0.000 \\
\hline & & & \multicolumn{3}{|c|}{ AVERAGE } & 0.395 & 0.344 & 0.171 & 0.090 \\
\hline & & & \multicolumn{3}{|c|}{ AVERAGE $*$ MPF (1.2) } & 0.474 & 0.413 & 0.205 & 0.107 \\
\hline & & & \multicolumn{3}{|c|}{ STAND. DEVIATION } & 0.017 & 0.020 & 0.027 & 0.010 \\
\hline
\end{tabular}




\begin{tabular}{|c|c|c|c|c|c|c|c|c|c|}
\hline \multicolumn{10}{|c|}{ RUN 3, FEA RESULTS } \\
\hline \multicolumn{2}{|c|}{ GRID POINT } & \multicolumn{4}{|c|}{ AVERAGE MICROSTRAIN (IN/IN) } & \multicolumn{4}{|c|}{ DISTRIBUTION FACTORS } \\
\hline $\mathrm{x}(\mathrm{ft})$ & $\mathrm{x} / \mathrm{L}$ & G1 & $\mathrm{G} 2$ & G3 & $\overline{\mathrm{G} 4}$ & G1 & $\mathrm{G} 2$ & G3 & G4 \\
\hline 0.00 & 0.0 & 0.00 & 0.00 & 0.00 & 0.00 & 0.000 & 0.000 & 0.000 & 0.000 \\
\hline 5.25 & 0.1 & 28.97 & 37.27 & 37.19 & 28.95 & 0.219 & 0.282 & 0.281 & 0.219 \\
\hline 10.50 & 0.2 & 44.15 & 70.40 & 70.34 & 44.16 & 0.193 & 0.307 & 0.307 & 0.193 \\
\hline 15.75 & 0.3 & 55.84 & 87.02 & 87.00 & 55.87 & 0.195 & 0.305 & 0.304 & 0.196 \\
\hline 21.00 & 0.4 & 61.54 & 102.16 & 102.19 & 61.57 & 0.188 & 0.312 & 0.312 & 0.188 \\
\hline 26.25 & 0.5 & 59.88 & 124.71 & 124.80 & 59.92 & 0.162 & 0.338 & 0.338 & 0.162 \\
\hline 31.50 & 0.6 & 54.75 & 114.45 & 114.53 & 54.79 & 0.162 & 0.338 & 0.338 & 0.162 \\
\hline 36.75 & 0.7 & 46.75 & 74.77 & 74.78 & 46.77 & 0.192 & 0.308 & 0.308 & 0.192 \\
\hline 42.00 & 0.8 & 35.25 & 48.60 & 48.58 & 35.26 & 0.210 & 0.290 & 0.290 & 0.210 \\
\hline 47.25 & 0.9 & 23.60 & 25.97 & 25.91 & 23.60 & 0.238 & 0.262 & 0.262 & 0.238 \\
\hline 52.50 & 1.0 & 0.00 & 0.00 & 0.00 & 0.00 & 0.000 & 0.000 & 0.000 & 0.000 \\
\hline & & & \multicolumn{3}{|c|}{ AVERAGE } & 0.196 & 0.305 & 0.304 & 0.196 \\
\hline & & & \multicolumn{3}{|c|}{ AVERAGE * MPF (1.2) } & 0.235 & 0.365 & 0.365 & 0.235 \\
\hline & & & \multicolumn{3}{|c|}{ STAND. DEVIATION } & 0.025 & 0.025 & 0.025 & 0.025 \\
\hline
\end{tabular}

\begin{tabular}{|c|c|c|c|c|c|c|c|c|c|}
\hline \multicolumn{10}{|c|}{ RUN 4, FEA RESULTS } \\
\hline \multicolumn{2}{|c|}{ GRID POINT } & \multicolumn{4}{|c|}{ AVERAGE MICROSTRAIN (IN/IN) } & \multicolumn{4}{|c|}{ DISTRIBUTION FACTORS } \\
\hline $\mathrm{x}(\mathrm{ft})$ & $\mathrm{x} / \mathrm{L}$ & G1 & $\mathrm{G} 2$ & G3 & G4 & $\overline{\text { G1 }}$ & $\mathrm{G} 2$ & G3 & G4 \\
\hline 0.00 & 0.0 & 0.00 & 0.00 & 0.00 & 0.00 & 0.000 & 0.000 & 0.000 & 0.000 \\
\hline 5.25 & 0.1 & 14.59 & 28.41 & 43.05 & 45.98 & 0.111 & 0.215 & 0.326 & 0.348 \\
\hline 10.50 & 0.2 & 21.28 & 40.39 & 78.09 & 88.73 & 0.093 & 0.177 & 0.342 & 0.388 \\
\hline 15.75 & 0.3 & 26.38 & 49.77 & 97.46 & 111.26 & 0.093 & 0.175 & 0.342 & 0.391 \\
\hline 21.00 & 0.4 & 29.14 & 54.02 & 114.58 & 128.61 & 0.089 & 0.166 & 0.351 & 0.394 \\
\hline 26.25 & 0.5 & 29.18 & 52.29 & 136.86 & 149.85 & 0.079 & 0.142 & 0.372 & 0.407 \\
\hline 31.50 & 0.6 & 26.72 & 48.25 & 125.81 & 136.64 & 0.079 & 0.143 & 0.373 & 0.405 \\
\hline 36.75 & 0.7 & 22.13 & 42.21 & 85.08 & 92.84 & 0.091 & 0.174 & 0.351 & 0.383 \\
\hline 42.00 & 0.8 & 16.35 & 32.01 & 56.07 & 62.81 & 0.098 & 0.191 & 0.335 & 0.376 \\
\hline 47.25 & 0.9 & 10.91 & 22.52 & 31.44 & 34.01 & 0.110 & 0.228 & 0.318 & 0.344 \\
\hline 52.50 & 1.0 & 0.00 & 0.00 & 0.00 & 0.00 & 0.000 & 0.000 & 0.000 & 0.000 \\
\hline & & & \multicolumn{3}{|c|}{ AVERAGE } & 0.094 & 0.179 & 0.346 & 0.382 \\
\hline & & & \multicolumn{3}{|c|}{ AVERAGE * MPF (1.2) } & 0.112 & 0.215 & 0.415 & 0.458 \\
\hline & & & \multicolumn{3}{|c|}{ STAND. DEVIATION } & 0.011 & 0.029 & 0.019 & 0.022 \\
\hline
\end{tabular}




\begin{tabular}{|c|c|c|c|c|c|c|c|c|c|}
\hline \multicolumn{10}{|c|}{ RUN 5, FEA RESULTS } \\
\hline \multicolumn{2}{|c|}{ GRID POINT } & \multicolumn{4}{|c|}{ AVERAGE MICROSTRAIN (IN/IN) } & \multicolumn{4}{|c|}{ DISTRIBUTION FACTORS } \\
\hline $\mathrm{x}(\mathrm{ft})$ & $\mathrm{x} / \mathrm{L}$ & G1 & G2 & G3 & G4 & G1 & G2 & G3 & G4 \\
\hline 0.00 & 0.0 & 0.00 & 0.00 & 0.00 & 0.00 & 0.000 & 0.000 & 0.000 & 0.000 \\
\hline 5.25 & 0.1 & 10.82 & 22.01 & 41.17 & 57.80 & 0.082 & 0.167 & 0.312 & 0.439 \\
\hline 10.50 & 0.2 & 17.53 & 33.59 & 78.39 & 99.25 & 0.077 & 0.147 & 0.343 & 0.434 \\
\hline 15.75 & 0.3 & 22.53 & 43.03 & 96.92 & 122.31 & 0.079 & 0.151 & 0.340 & 0.429 \\
\hline 21.00 & 0.4 & 25.45 & 48.03 & 112.66 & 139.93 & 0.078 & 0.147 & 0.346 & 0.429 \\
\hline 26.25 & 0.5 & 25.78 & 47.09 & 134.94 & 160.56 & 0.070 & 0.128 & 0.366 & 0.436 \\
\hline 31.50 & 0.6 & 23.62 & 43.08 & 123.41 & 147.51 & 0.070 & 0.128 & 0.366 & 0.437 \\
\hline 36.75 & 0.7 & 19.24 & 36.59 & 81.48 & 104.60 & 0.080 & 0.151 & 0.337 & 0.432 \\
\hline 42.00 & 0.8 & 14.26 & 27.62 & 53.65 & 71.61 & 0.085 & 0.165 & 0.321 & 0.428 \\
\hline 47.25 & 0.9 & 8.98 & 18.11 & 28.88 & 42.80 & 0.091 & 0.183 & 0.292 & 0.433 \\
\hline 52.50 & 1.0 & 0.00 & 0.00 & 0.00 & 0.00 & 0.000 & 0.000 & 0.000 & 0.000 \\
\hline & & & \multicolumn{3}{|c|}{ AVERAGE } & 0.079 & 0.152 & 0.336 & 0.433 \\
\hline & & & \multicolumn{3}{|c|}{ AVERAGE * MPF (1.2) } & 0.095 & 0.182 & 0.403 & 0.520 \\
\hline & & & \multicolumn{3}{|c|}{ STAND. DEVIATION } & 0.007 & 0.018 & 0.024 & 0.004 \\
\hline
\end{tabular}

SUM: RUN 1 AND RUN 4, FEA RESULTS

\begin{tabular}{|c|c|c|c|c|c|c|c|c|c|}
\hline \multicolumn{10}{|c|}{ SUM: RUN 1 AND RUN 4, FEA RESULTS } \\
\hline \multicolumn{2}{|c|}{ GRID POINT } & \multicolumn{4}{|c|}{ AVERAGE MICROSTRAIN (IN/IN) } & \multicolumn{4}{|c|}{ DISTRIBUTION FACTORS } \\
\hline $\mathrm{x}(\mathrm{ft})$ & $\mathrm{x} / \mathrm{L}$ & G1 & $\mathrm{G} 2$ & G3 & G4 & G1 & $\mathrm{G} 2$ & G3 & G4 \\
\hline 0.00 & 0.0 & 0.00 & 0.00 & 0.00 & 0.00 & 0.000 & 0.000 & 0.000 & 0.000 \\
\hline 5.25 & 0.1 & 71.80 & 69.71 & 65.38 & 57.00 & 0.544 & 0.528 & 0.496 & 0.432 \\
\hline 10.50 & 0.2 & 119.94 & 118.92 & 112.01 & 106.34 & 0.525 & 0.520 & 0.490 & 0.465 \\
\hline 15.75 & 0.3 & 148.08 & 146.88 & 140.81 & 133.97 & 0.520 & 0.516 & 0.494 & 0.470 \\
\hline 21.00 & 0.4 & 168.49 & 166.91 & 162.83 & 154.22 & 0.516 & 0.512 & 0.499 & 0.473 \\
\hline 26.25 & 0.5 & 189.26 & 187.53 & 184.09 & 175.78 & 0.514 & 0.509 & 0.500 & 0.477 \\
\hline 31.50 & 0.6 & 173.67 & 171.91 & 169.11 & 160.39 & 0.515 & 0.509 & 0.501 & 0.475 \\
\hline 36.75 & 0.7 & 126.14 & 123.91 & 121.95 & 112.21 & 0.521 & 0.512 & 0.504 & 0.463 \\
\hline 42.00 & 0.8 & 87.39 & 85.84 & 84.00 & 77.20 & 0.523 & 0.513 & 0.502 & 0.462 \\
\hline 47.25 & 0.9 & 53.15 & 51.55 & 49.86 & 43.13 & 0.538 & 0.522 & 0.504 & 0.436 \\
\hline 52.50 & 1.0 & 0.00 & 0.00 & 0.00 & 0.00 & 0.000 & 0.000 & 0.000 & 0.000 \\
\hline & & & \multicolumn{3}{|c|}{ AVERAGE } & 0.524 & 0.516 & 0.499 & 0.462 \\
\hline & & & \multicolumn{3}{|c|}{ AVERAGE * MPF (1.0) } & 0.524 & 0.516 & 0.499 & 0.462 \\
\hline & & & \multicolumn{3}{|c|}{ STAND. DEVIATION } & 0.010 & 0.006 & 0.005 & 0.016 \\
\hline
\end{tabular}




\begin{tabular}{|c|c|c|c|c|c|c|c|c|c|}
\hline \multicolumn{10}{|c|}{ SUM: RUN 2 AND RUN 5, FEA RESULTS } \\
\hline \multicolumn{2}{|c|}{ GRID POINT } & \multicolumn{4}{|c|}{ AVERAGE MICROSTRAIN (IN/IN) } & \multicolumn{4}{|c|}{ DISTRIBUTION FACTORS } \\
\hline $\mathrm{x}(\mathrm{ft})$ & $\mathrm{x} / \mathrm{L}$ & G1 & $\mathrm{G} 2$ & G3 & G4 & G1 & G2 & G3 & G4 \\
\hline 0.00 & 0.0 & 0.00 & 0.00 & 0.00 & 0.00 & 0.000 & 0.000 & 0.000 & 0.000 \\
\hline 5.25 & 0.1 & 59.86 & 64.62 & 67.88 & 71.41 & 0.454 & 0.490 & 0.515 & 0.541 \\
\hline 10.50 & 0.2 & 109.16 & 112.14 & 116.75 & 119.44 & 0.477 & 0.490 & 0.510 & 0.522 \\
\hline 15.75 & 0.3 & 136.82 & 140.72 & 144.62 & 147.54 & 0.480 & 0.494 & 0.508 & 0.518 \\
\hline 21.00 & 0.4 & 157.16 & 162.44 & 164.76 & 167.93 & 0.482 & 0.498 & 0.505 & 0.515 \\
\hline 26.25 & 0.5 & 178.74 & 183.96 & 185.37 & 188.67 & 0.485 & 0.499 & 0.503 & 0.512 \\
\hline 31.50 & 0.6 & 163.32 & 168.68 & 169.89 & 173.28 & 0.484 & 0.500 & 0.503 & 0.513 \\
\hline 36.75 & 0.7 & 115.19 & 120.83 & 122.09 & 125.91 & 0.476 & 0.499 & 0.504 & 0.520 \\
\hline 42.00 & 0.8 & 79.39 & 83.13 & 84.50 & 87.35 & 0.475 & 0.497 & 0.505 & 0.522 \\
\hline 47.25 & 0.9 & 45.24 & 48.85 & 50.33 & 53.22 & 0.458 & 0.494 & 0.509 & 0.539 \\
\hline 52.50 & 1.0 & 0.00 & 0.00 & 0.00 & 0.00 & 0.000 & 0.000 & 0.000 & 0.000 \\
\hline & & & \multicolumn{3}{|c|}{ AVERAGE } & 0.475 & 0.496 & 0.507 & 0.523 \\
\hline & & & \multicolumn{3}{|c|}{ AVERAGE * MPF (1.0) } & 0.475 & 0.496 & 0.507 & 0.523 \\
\hline & & & \multicolumn{3}{|c|}{ STAND. DEVIATION } & 0.011 & 0.004 & 0.004 & 0.011 \\
\hline
\end{tabular}


A.2.3 Results Comparison: Live Load Field Test vs. Finite Element Analysis
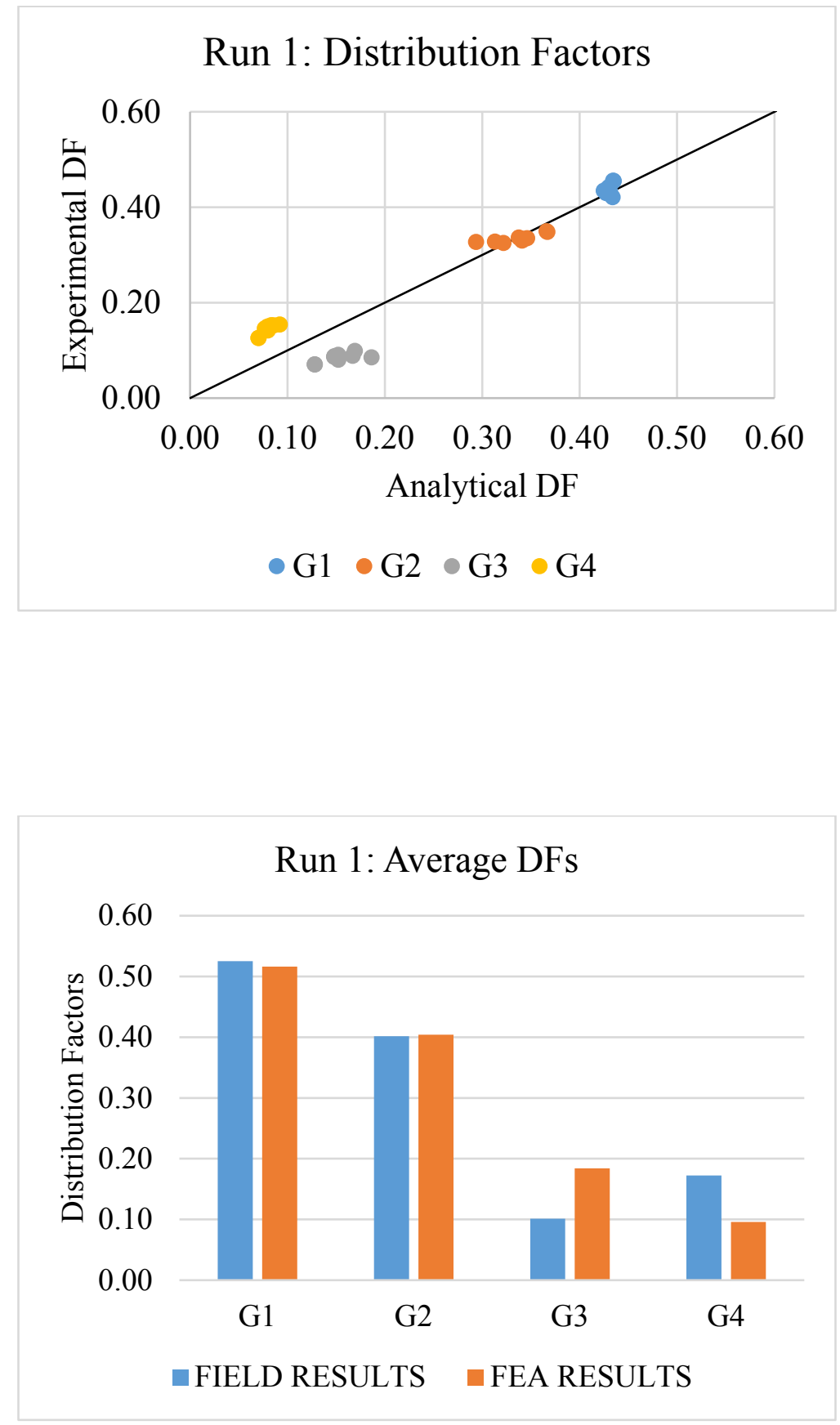

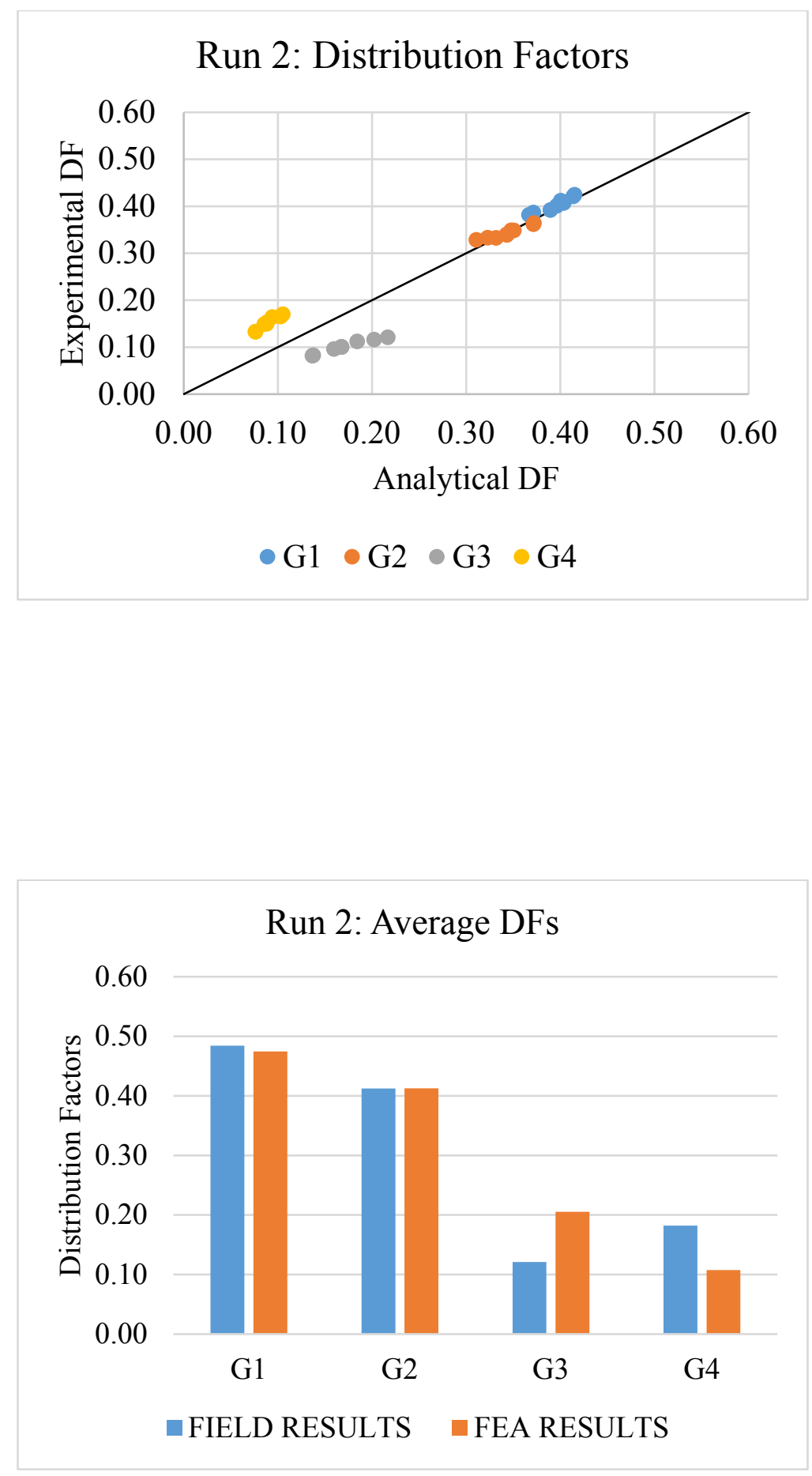

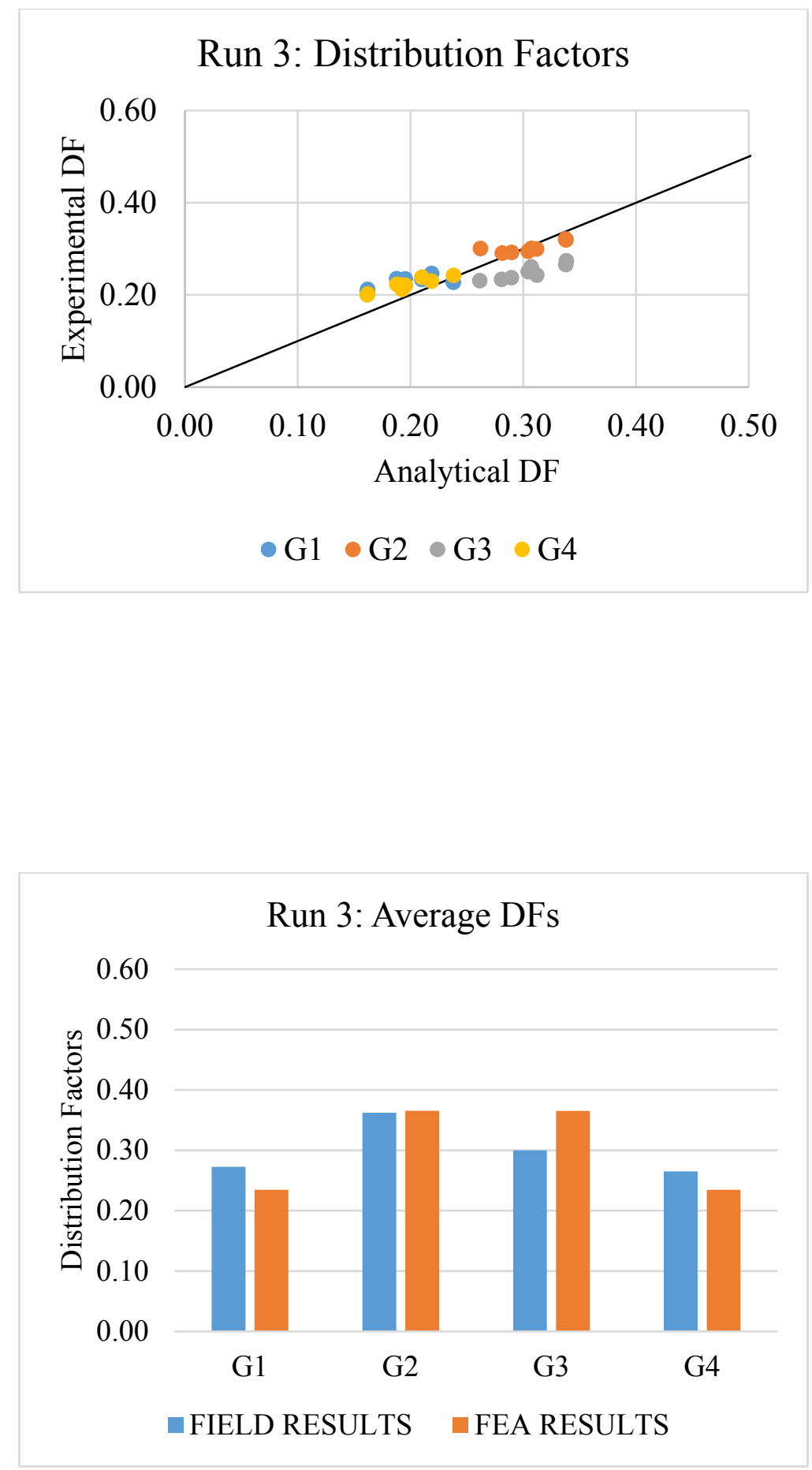

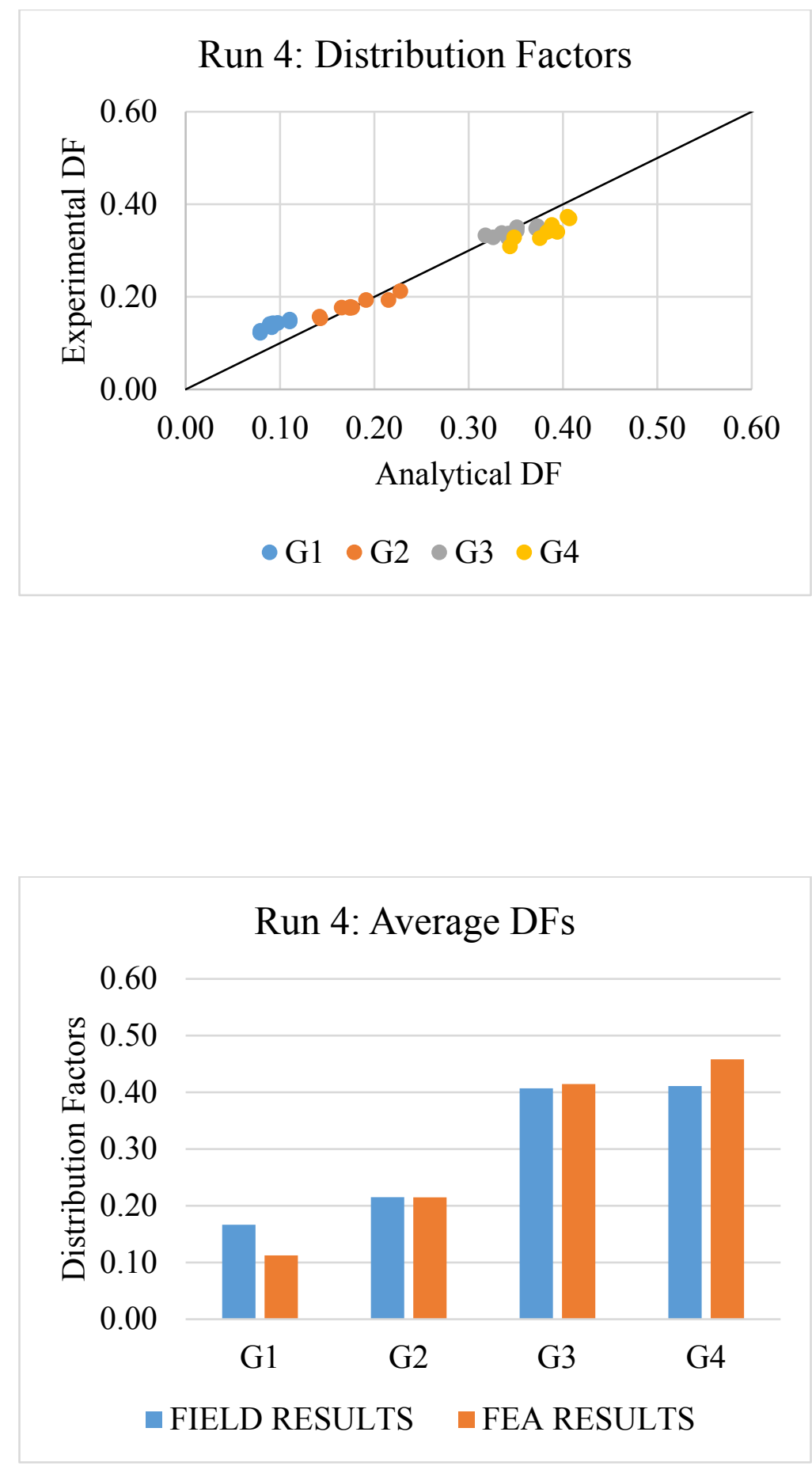

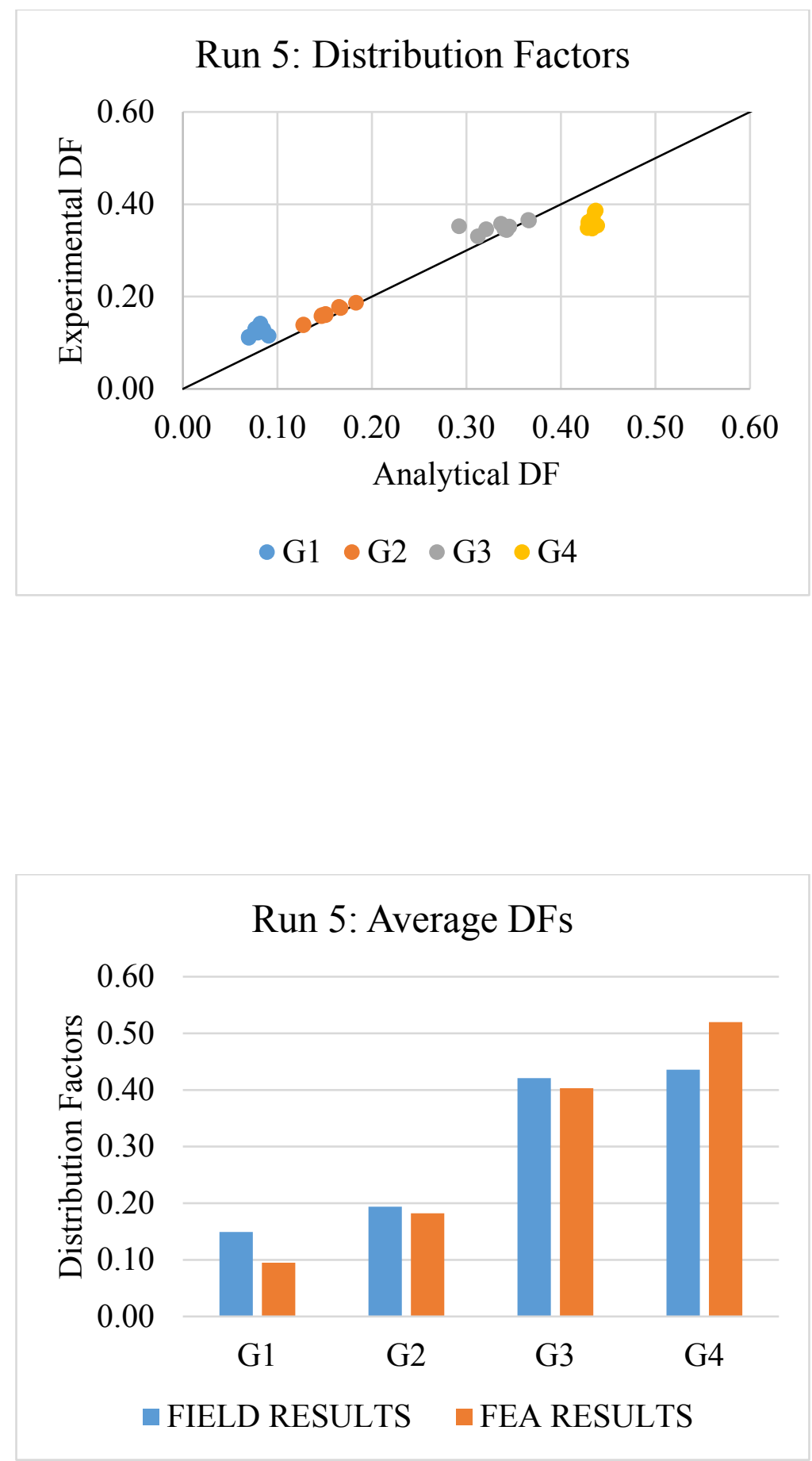

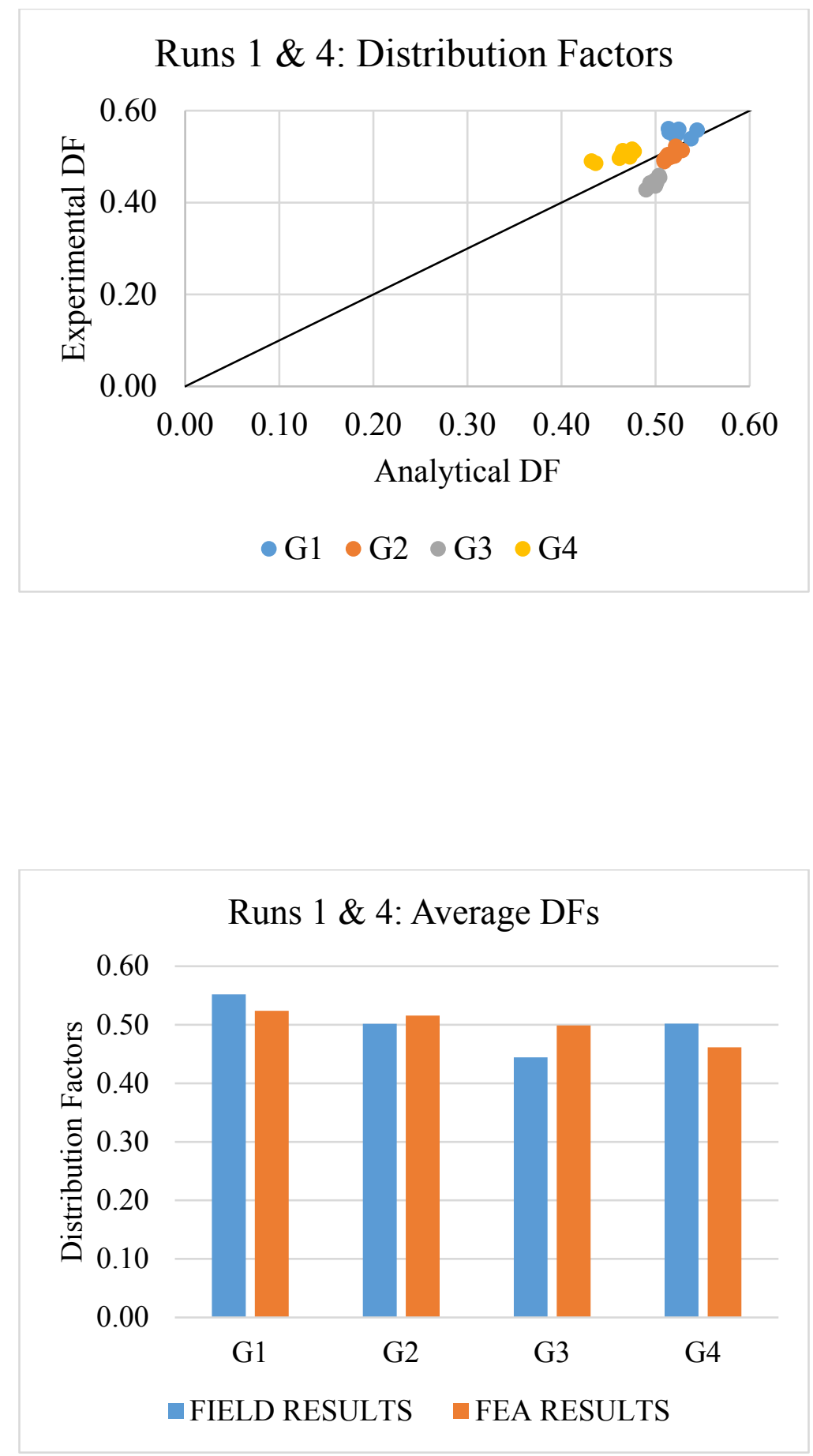

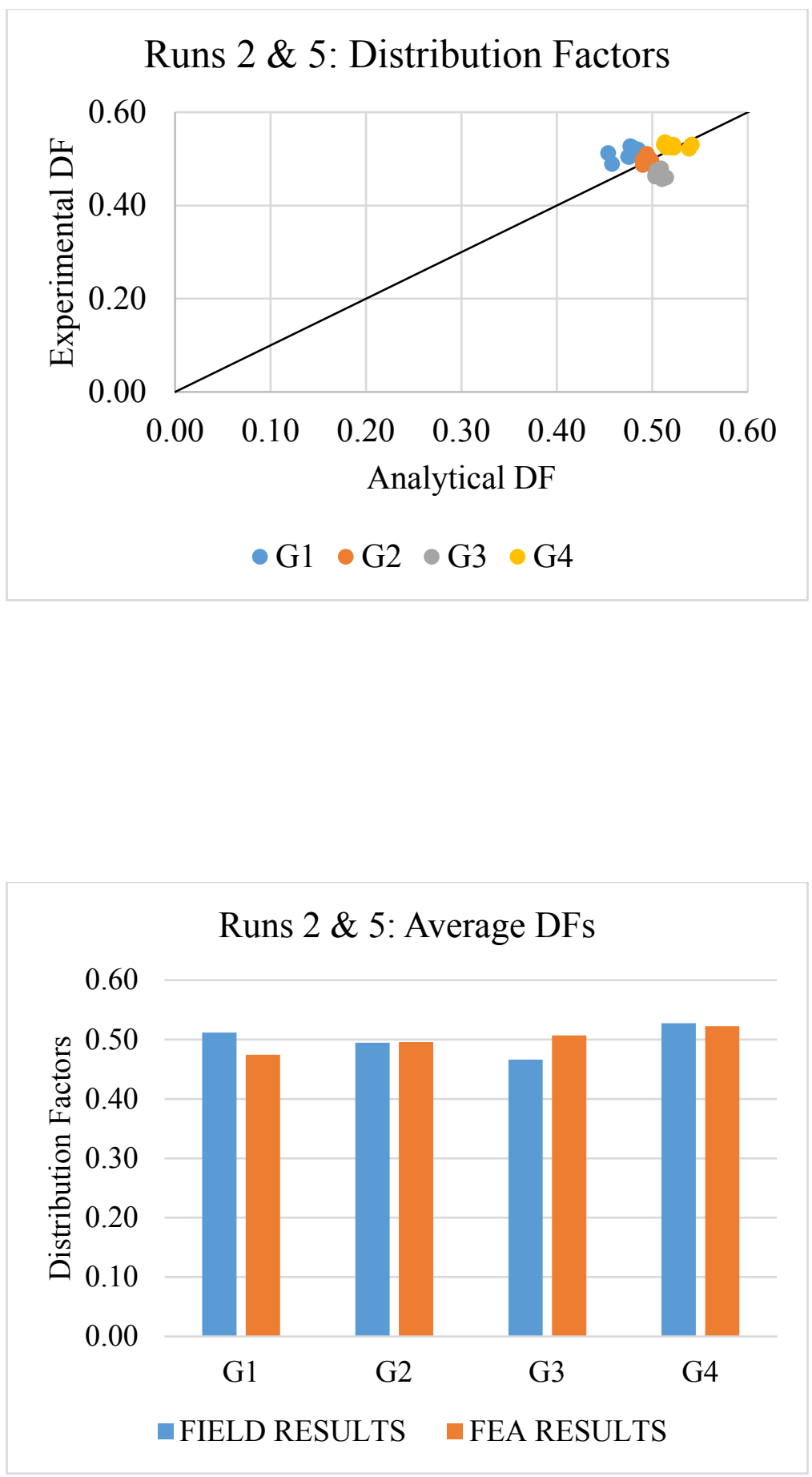


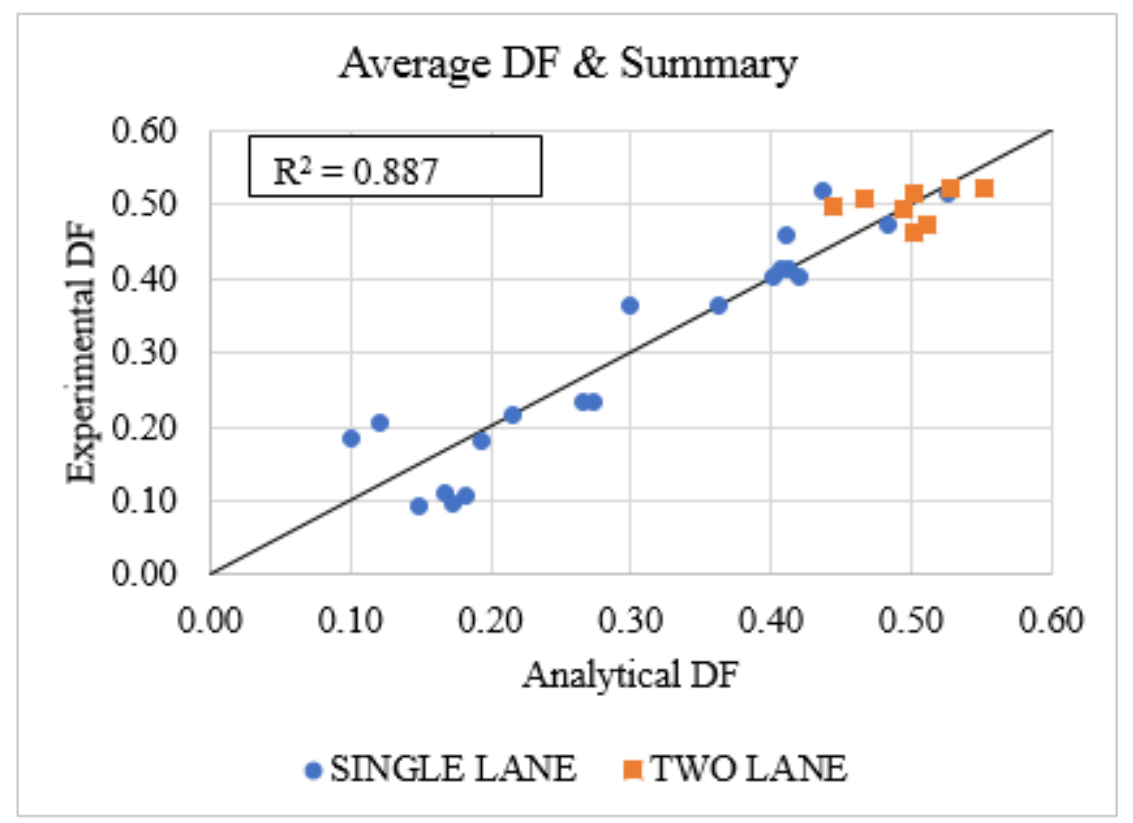

A.2.4 Results Comparison: Live Load Field Test, Finite Element Analysis, AASHTO Calculations

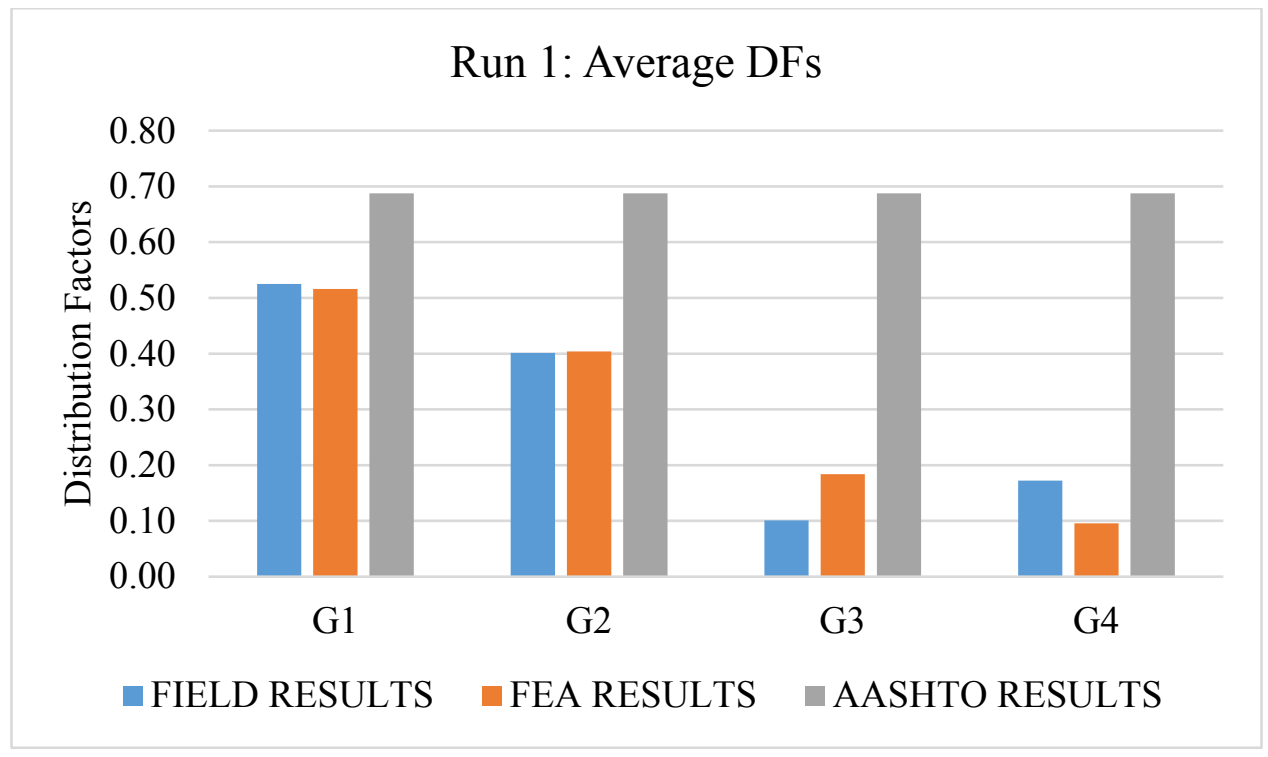



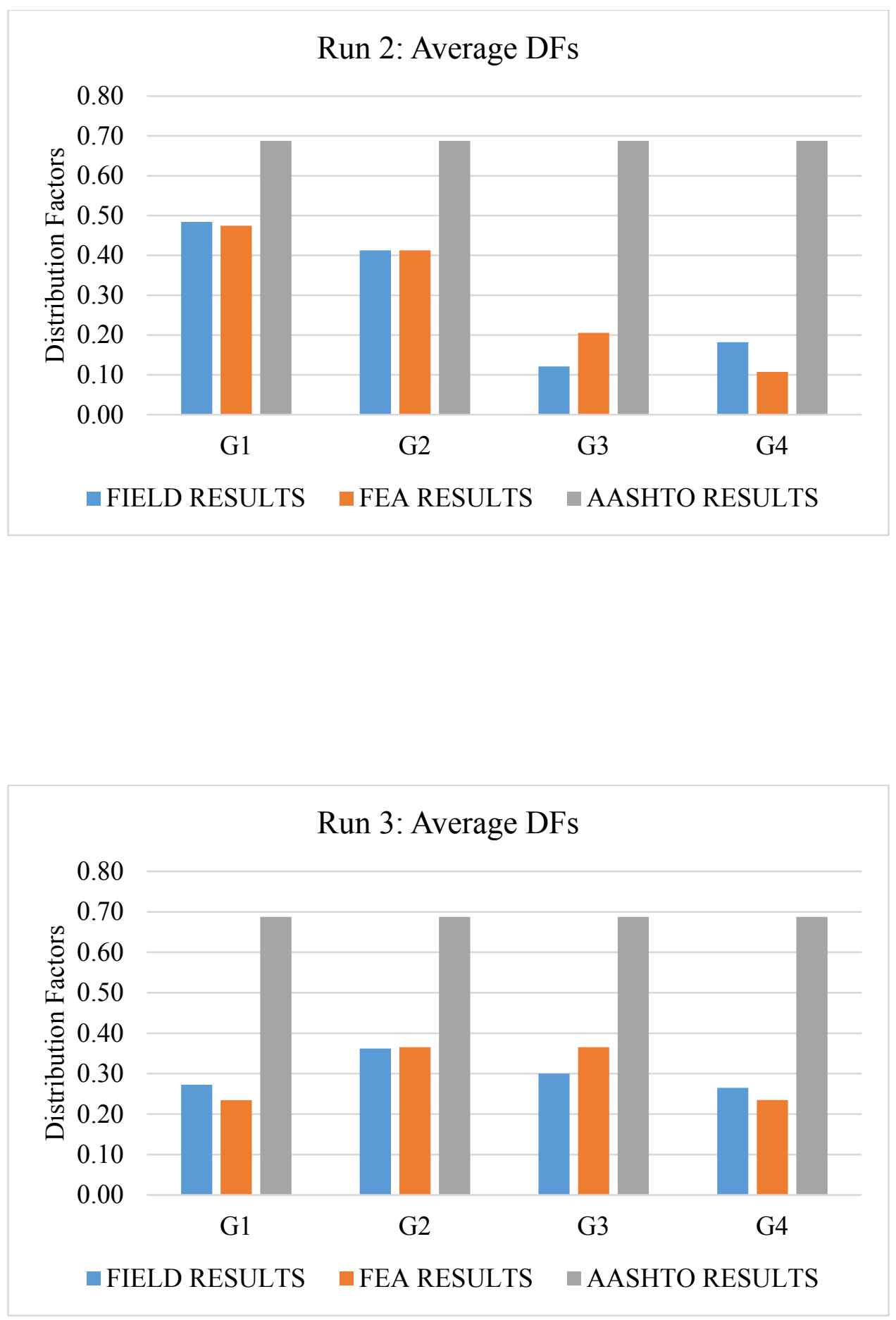

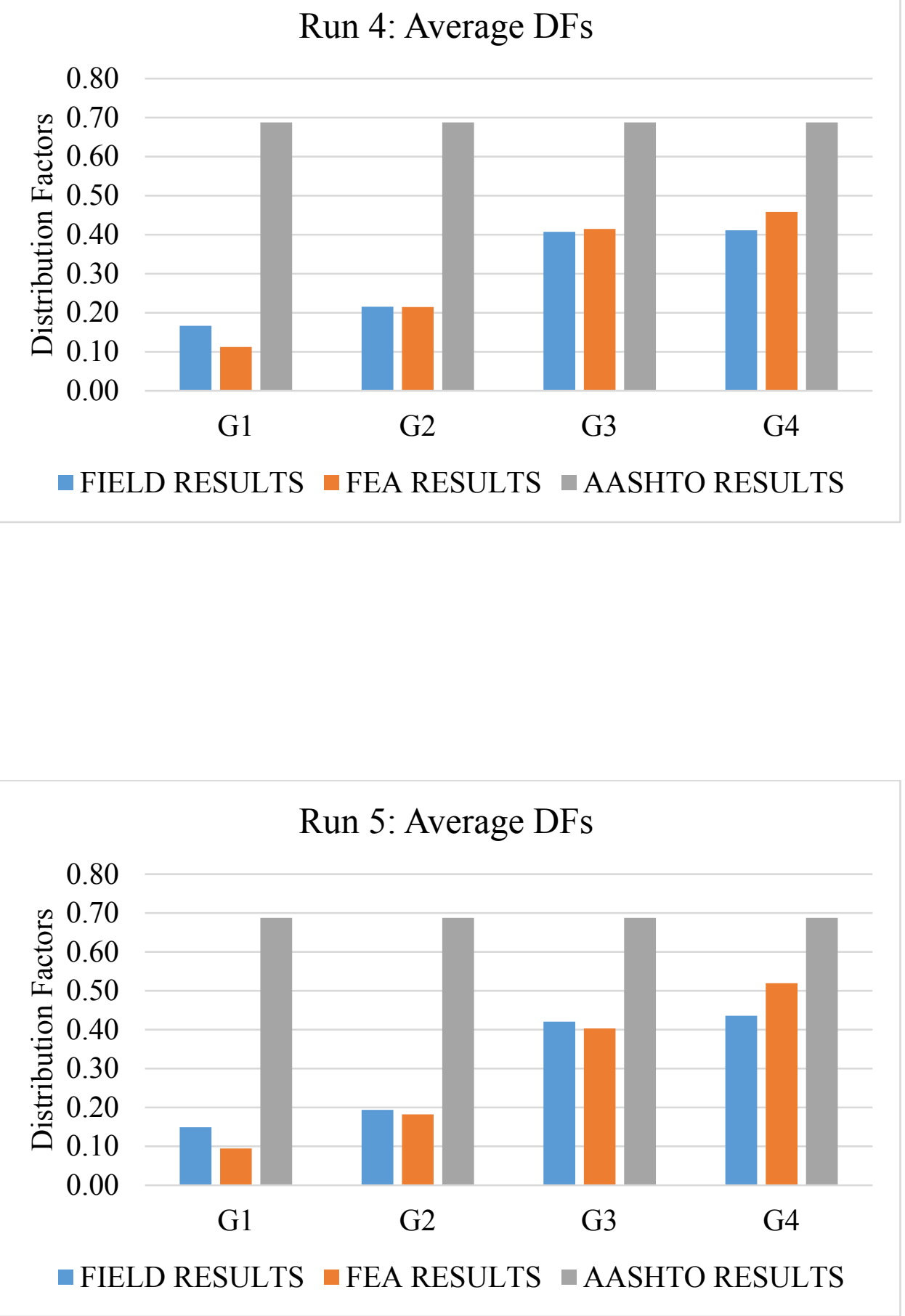

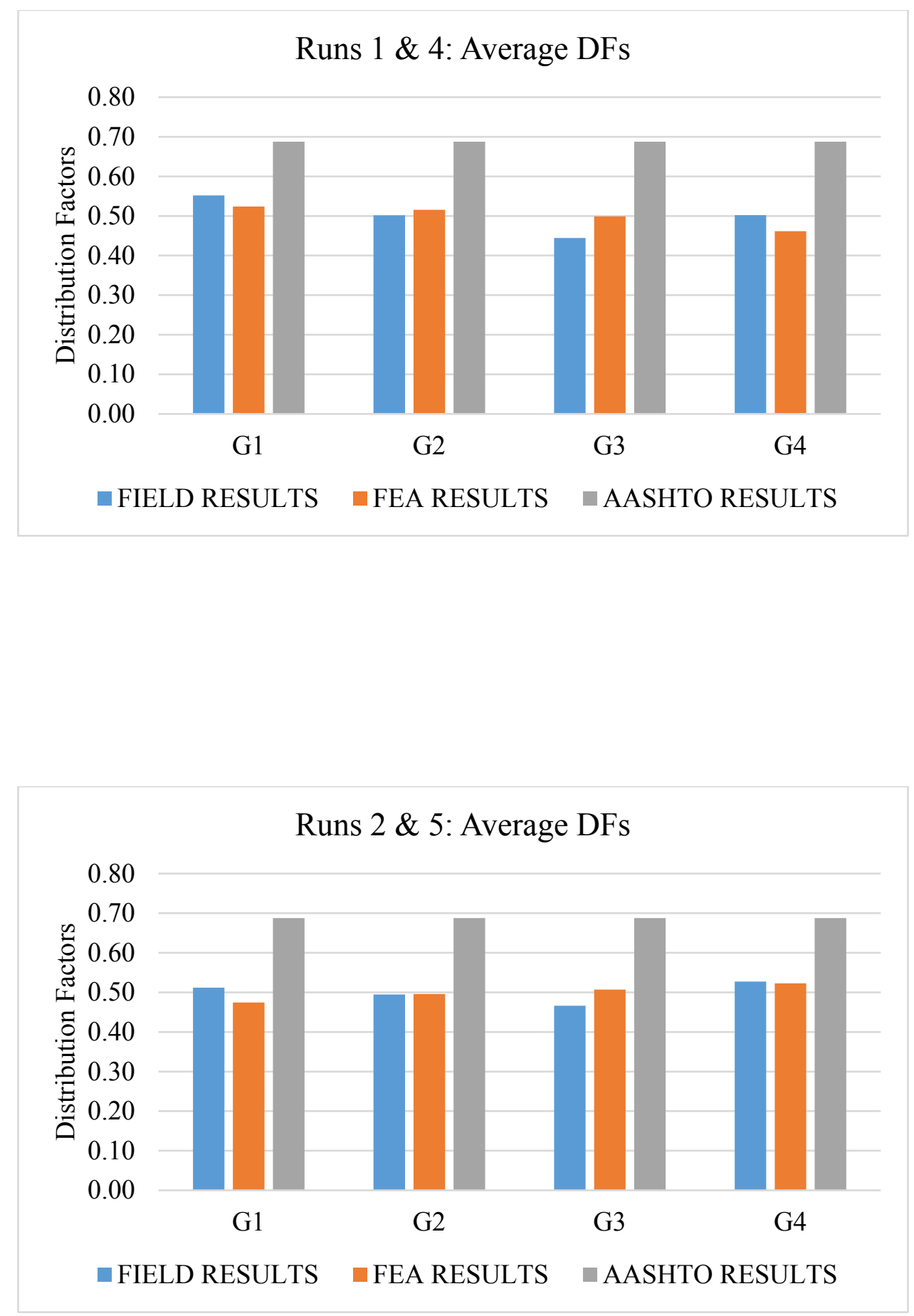


\section{APPENDIX B: LARS BRIDGE CONNECT LOAD RATING OUTPUT}

The following appendix includes the summary report output from Bentley LARS Bridge CONNECT. 


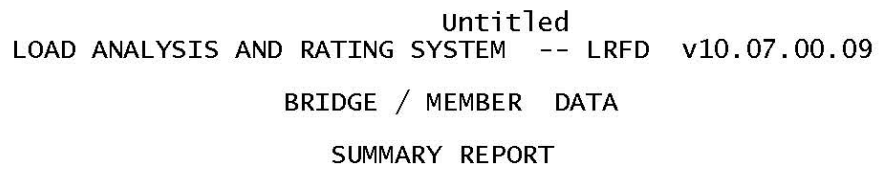

Bridge ID

CANNELVILLE_ROAD_BRIDGE

Facility Carried

CANNELVILLE ROAD

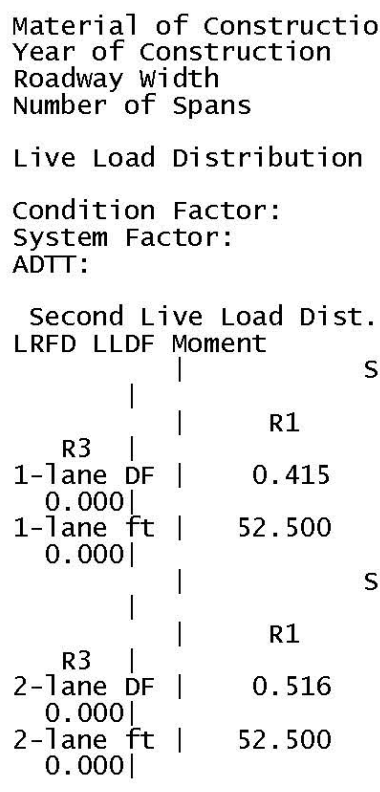

CSC
2017
24.000
1
0.415
1.000
1.000
1000
0.516

. Factor

।

R2 R3 ।

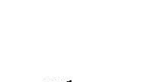

Span 2

I

Span 3

R2

R3 |

R1

R2

$0.000 \quad 0.000 \mid$

0.000

0.000

$0.000 \mid$

0.000

0.000

$0.000 \quad 0.000 \mid$

0.000

0.000

0.000

0.000

0.000

Span 1

R2

Span 2

।

Span 3

R3 | R1

R2

R3 I

R1

R2

$2-1$ ane $\mathrm{D}$
0.000

0.000

$\begin{array}{lll}0.000 & 0.000 \mid & 0.000 \\ 0.000 & 0.000 \mid & 0.000\end{array}$

0.000

$0.000 \mid$

0.000

0.000

0.000

0.000

0.000

0.000

LRFD LLDF shear

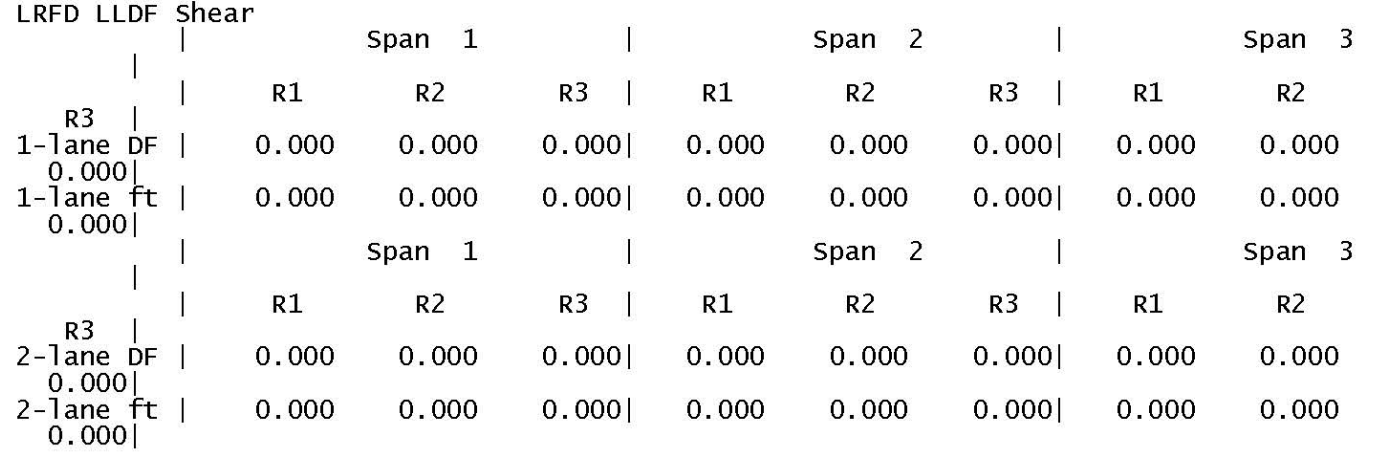

Page 1 
Comments:

Member ID

Symmetry:

Span Length:

G1 INTERIOR - FEA

$\operatorname{Span}_{52.500} 1$

$\underset{0.000}{2}$

Span
0.000

Span
0.000

Span 5

Moment

C.P.

Rating

Factor

Rating

value

$$
\begin{gathered}
\text { Load } \\
\text { Resistance } \\
\text { (tons) }
\end{gathered}
$$

1.500 INV. Truck: HL93

1.500 INV. Truck: ${ }_{\text {HL93 }}^{2.55}$

HS 51.07

91.9 (2-Lane)

HS 63.49

114.3 (1-Lane)

1.500 OPER. Truck: HL93

1.500 OPER. Truck: HL 93.31

HS 66.20119 .2 (2-Lane)

HS 82.31

148.2 (1-Lane)

1.500 POST. Truck: HS20

1.500 POST. Truck: HS20

0.00111 .6 (2-Lane)

$0.00 \quad 138.8$ (1-Lane)

1.400 POST. Truck: 3S2
1.400 POST. Truck: 352

1.500 POST. Truck: 3-3

1.500 POST. Truck: $3-3$.

$0.00 \quad 154.5$ (2-Lane)

$0.00 \quad 192.1$ (1-Lane)

0.00189 .0 (2-Lane)

$0.00 \quad 235.0$ (1-Lane)

\begin{tabular}{|c|c|c|c|c|c|c|}
\hline C.P. & & & $\underset{(-)}{\text { Rating }}$ & $\underset{(+)}{\text { Factor }}$ & Rating value & Load Resistance \\
\hline & INV. & Truck: & $\begin{array}{l}\text { HL93 } \\
28.59\end{array}$ & 999.00 & HS999.00 & 999.00 (2-Lane) \\
\hline 2.000 & INV. & Truck: & $\begin{array}{l}\text { HL93 } \\
35.54\end{array}$ & 999.00 & HS999.00 & 999.00 (1-Lane) \\
\hline & OPER. & & $\begin{array}{l}\text { HL93 } \\
37.06\end{array}$ & 999.00 & HS999.00 & 999.00 (2-Lane) \\
\hline 000 & OPEF & Tru & $\begin{array}{l}\text { HL93 } \\
46.07\end{array}$ & 999.00 & HS999.00 & 999.00 (1-Lane) \\
\hline
\end{tabular}

Shear

Page 2 


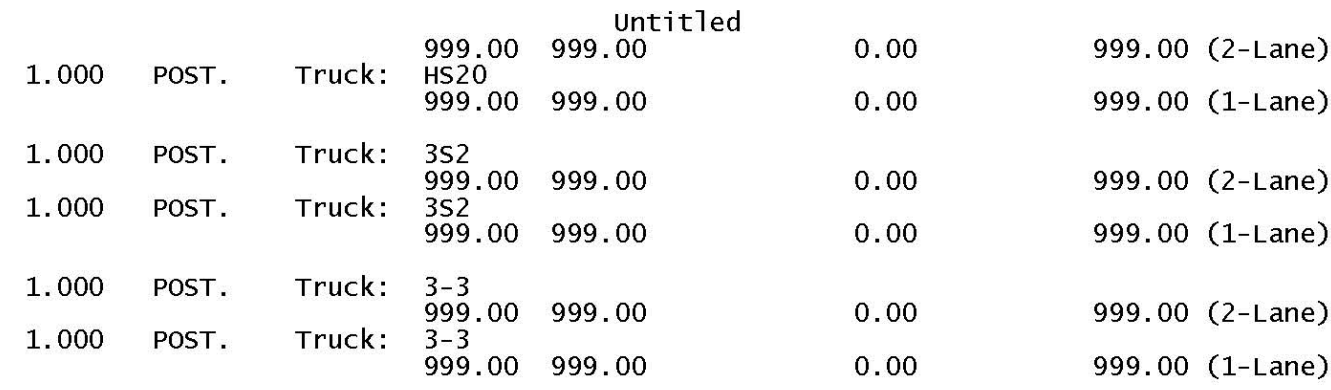

\begin{tabular}{|c|c|c|c|c|c|}
\hline \multirow{2}{*}{ C.P. } & & \multicolumn{4}{|c|}{ Service } \\
\hline & & & $\begin{array}{l}\text { Rating } \\
\text { Factor }\end{array}$ & $\begin{array}{l}\text { Rating } \\
\text { Va1ue }\end{array}$ & $\begin{array}{l}\text { Load } \\
\text { Resistance } \\
\text { (tons) }\end{array}$ \\
\hline $\begin{array}{l}1.500 \\
1.500\end{array}$ & $\begin{array}{l}\text { INV. } \\
\text { INV. }\end{array}$ & $\begin{array}{l}\text { Truck: } \\
\text { Truck: }\end{array}$ & $\begin{array}{l}\text { HL93 } \\
3.20 \\
\text { HL } 93 \\
\quad 3.98\end{array}$ & $\begin{array}{l}\text { HS } 64.05 \\
\text { HS } 79.63\end{array}$ & $\begin{array}{l}115.3 \text { (2-Lane) } \\
143.3 \text { (1-Lane) }\end{array}$ \\
\hline $\begin{array}{l}1.500 \\
1.500\end{array}$ & $\begin{array}{l}\text { OPER. } \\
\text { OPER. }\end{array}$ & $\begin{array}{l}\text { Truck: } \\
\text { Truck: }\end{array}$ & $\begin{array}{l}\text { HL93 } \\
\quad 4.16 \\
\text { HL93 } \\
5.18\end{array}$ & $\begin{array}{l}\text { HS } 83.26 \\
\text { HS } 103.52\end{array}$ & $\begin{array}{l}149.9 \text { (2-Lane) } \\
186.3 \text { (1-Lane) }\end{array}$ \\
\hline $\begin{array}{l}1.500 \\
1.500\end{array}$ & $\begin{array}{l}\text { POST. } \\
\text { POST. }\end{array}$ & $\begin{array}{l}\text { Truck: } \\
\text { Truck: }\end{array}$ & $\begin{array}{c}\mathrm{HS} 20 \\
4.00 \\
\mathrm{HS} 20 \\
4.97\end{array}$ & $\begin{array}{l}0.00 \\
0.00\end{array}$ & $\begin{array}{l}144.0 \text { (2-Lane) } \\
179.1 \text { (1-Lane) }\end{array}$ \\
\hline $\begin{array}{l}1.400 \\
1.400\end{array}$ & $\begin{array}{l}\text { POST. } \\
\text { POST. }\end{array}$ & $\begin{array}{l}\text { Truck: } \\
\text { Truck: }\end{array}$ & $\begin{array}{r}3 \mathrm{~s} 2 \\
5.53 \\
3 \mathrm{~s} 2 \\
6.88\end{array}$ & $\begin{array}{l}0.00 \\
0.00\end{array}$ & $\begin{array}{l}199.1 \text { (2-Lane) } \\
247.6 \text { (1-Lane) }\end{array}$ \\
\hline $\begin{array}{l}1.500 \\
1.500\end{array}$ & $\begin{array}{l}\text { POST. } \\
\text { POST. }\end{array}$ & $\begin{array}{l}\text { Truck: } \\
\text { Truck: }\end{array}$ & $\begin{array}{r}3-3 \\
6.09 \\
3-3.58 \\
7.58\end{array}$ & $\begin{array}{l}0.00 \\
0.00\end{array}$ & $\begin{array}{l}243.8 \text { (2-Lane) } \\
303.1 \text { (1-Lane) }\end{array}$ \\
\hline
\end{tabular}

LOAD ANALYSIS AND RATING SYSTEM -- LRFD V10.07.00.09

BRIDGE / MEMBER DATA

SUMMARY REPORT

Bridge ID

CANNELVILLE_ROAD_BRIDGE

Facility Carried

CANNELVILLE ROAD

Material of construction

$\operatorname{CSC}$

Page 3 


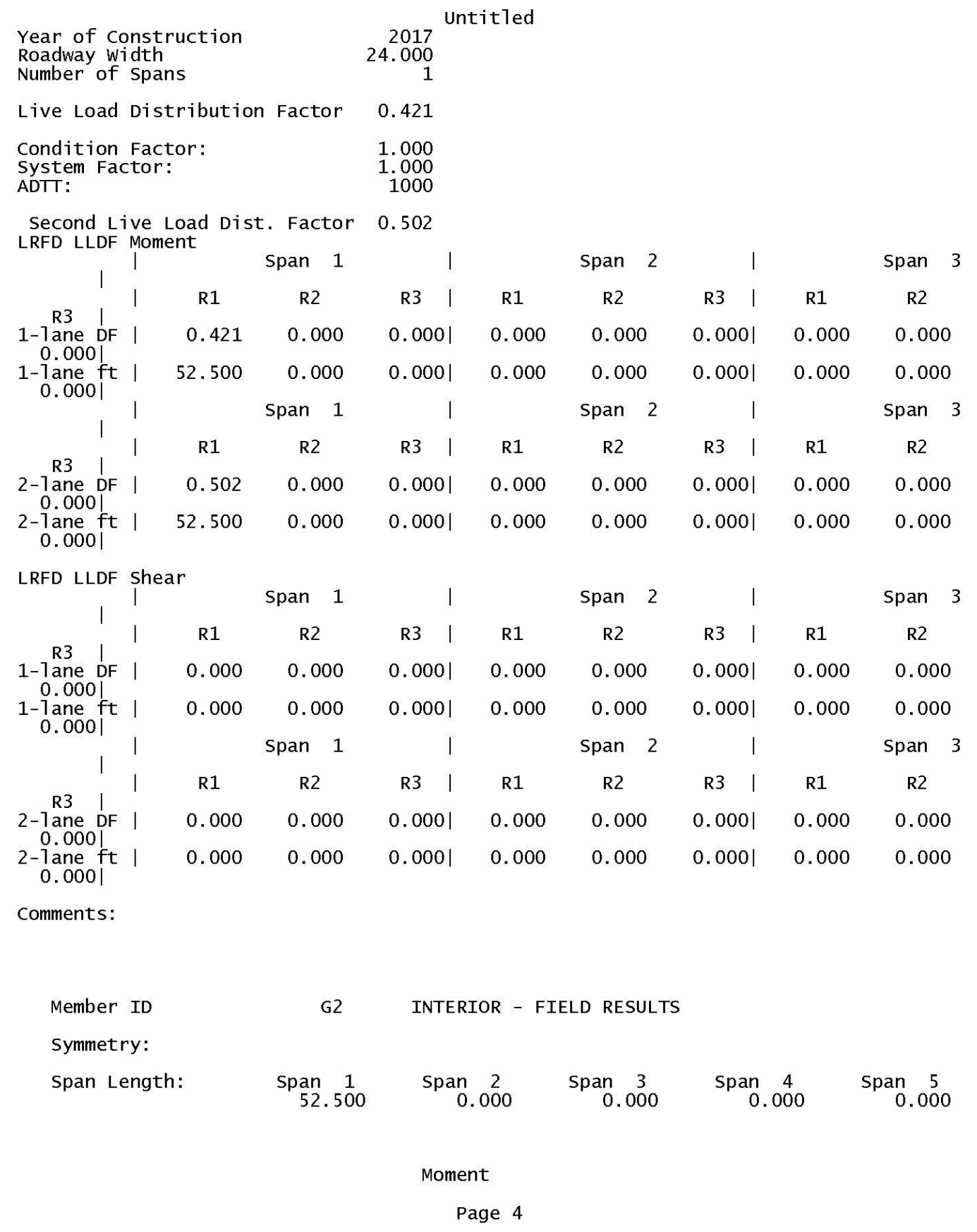




\begin{tabular}{|c|c|c|c|c|c|c|c|}
\hline \multirow{2}{*}{$\begin{array}{l}\text { C.P. } \\
1.500 \\
1.500\end{array}$} & \multirow[b]{2}{*}{$\begin{array}{l}\text { INV. } \\
\text { INV. }\end{array}$} & \multirow[b]{2}{*}{$\begin{array}{l}\text { Truck: } \\
\text { Truck: }\end{array}$} & \multirow{2}{*}{$\begin{array}{c}\text { Rating } \\
\text { Factor } \\
\text { HL93 } \\
2.62 \\
\text { HL93 } \\
3.13\end{array}$} & \multicolumn{2}{|c|}{$\begin{array}{l}\text { Untitled } \\
\text { Rating } \\
\text { Value }\end{array}$} & $\begin{array}{l}\text { Load } \\
\text { Resistance } \\
\text { (tons) }\end{array}$ & \\
\hline & & & & $\begin{array}{l}\text { HS } \\
\text { HS }\end{array}$ & $\begin{array}{l}52.49 \\
62.59\end{array}$ & $\begin{array}{r}94.5 \text { (2-Lane) } \\
112.7 \text { (1-Lane) }\end{array}$ & \\
\hline $\begin{array}{l}1.500 \\
1.500\end{array}$ & $\begin{array}{l}\text { OPER. } \\
\text { OPER. }\end{array}$ & $\begin{array}{l}\text { Truck: } \\
\text { Truck: }\end{array}$ & $\begin{array}{l}\text { HL } 93 \\
3.40 \\
\text { HL93 } \\
\quad 4.06\end{array}$ & $\begin{array}{l}\text { HS } \\
\text { HS }\end{array}$ & $\begin{array}{l}68.04 \\
81.13\end{array}$ & $\begin{array}{l}122.5 \text { (2-Lane) } \\
146.0 \text { (1-Lane) }\end{array}$ & \\
\hline $\begin{array}{l}1.500 \\
1.500\end{array}$ & $\begin{array}{l}\text { POST. } \\
\text { POST. }\end{array}$ & $\begin{array}{l}\text { Truck: } \\
\text { Truck: }\end{array}$ & $\begin{array}{l}\text { HS } 20 \\
3.19 \\
\text { HS } 20 \\
3.80\end{array}$ & & $\begin{array}{l}0.00 \\
0.00\end{array}$ & $\begin{array}{l}114.8 \text { (2-Lane) } \\
136.8 \text { (1-Lane) }\end{array}$ & \\
\hline $\begin{array}{l}1.400 \\
1.400\end{array}$ & $\begin{array}{l}\text { POST. } \\
\text { POST. }\end{array}$ & $\begin{array}{l}\text { Truck: } \\
\text { Truck: }\end{array}$ & $\begin{array}{l}3 \mathrm{~S} 2 \\
4.41 \\
3 \mathrm{~s} 2 \\
5.26\end{array}$ & & $\begin{array}{l}0.00 \\
0.00\end{array}$ & $\begin{array}{l}158.8 \text { (2-Lane) } \\
189.3 \text { ( } 1 \text {-Lane) }\end{array}$ & \\
\hline $\begin{array}{l}1.500 \\
1.500\end{array}$ & $\begin{array}{l}\text { POST. } \\
\text { POST. }\end{array}$ & $\begin{array}{l}\text { Truck: } \\
\text { Truck: }\end{array}$ & $\begin{array}{l}3-3 \\
\quad 4.86 \\
3-3.79 \\
5.79\end{array}$ & & $\begin{array}{l}0.00 \\
0.00\end{array}$ & $\begin{array}{l}194.3 \text { (2-Lane) } \\
231.6 \text { (1-Lane) }\end{array}$ & \\
\hline & & & & & & Shear & \\
\hline C.P. & & & $\underset{(-)}{\text { Rating }}$ & $\begin{array}{r}\text { Facto } \\
(+)\end{array}$ & & Rating value & Load Resistance \\
\hline $\begin{array}{l}2.000 \\
2.000\end{array}$ & $\begin{array}{l}\text { INV. } \\
\text { INV. }\end{array}$ & $\begin{array}{l}\text { Truck: } \\
\text { Truck: }\end{array}$ & $\begin{array}{l}\text { HL93 } \\
29.38 \\
\text { HL93 } \\
35.04\end{array}$ & $\begin{array}{l}999.0 \\
999.0\end{array}$ & & $\begin{array}{l}\text { HS999.00 } \\
\text { HS999.00 }\end{array}$ & $\begin{array}{l}999.00 \text { (2-Lane) } \\
999.00 \text { (1-Lane) }\end{array}$ \\
\hline $\begin{array}{l}2.000 \\
2.000\end{array}$ & $\begin{array}{l}\text { OPER. } \\
\text { OPER. }\end{array}$ & $\begin{array}{l}\text { Truck: } \\
\text { Truck: }\end{array}$ & $\begin{array}{l}\text { HL93 } \\
38.09 \\
\text { HL93 } \\
45.42\end{array}$ & $\begin{array}{l}999.0 \\
999.0\end{array}$ & & $\begin{array}{l}\text { HS999.00 } \\
\text { HS999.00 }\end{array}$ & $\begin{array}{l}999.00 \text { (2-Lane) } \\
999.00 \text { (1-Lane) }\end{array}$ \\
\hline $\begin{array}{l}1.000 \\
1.000\end{array}$ & $\begin{array}{l}\text { POST. } \\
\text { POST. }\end{array}$ & $\begin{array}{l}\text { Truck: } \\
\text { Truck: }\end{array}$ & $\begin{array}{l}\text { HS20 } \\
999.00 \\
\text { HS20 } \\
999.00\end{array}$ & $\begin{array}{l}999.0 \\
999.0\end{array}$ & & $\begin{array}{l}0.00 \\
0.00\end{array}$ & $\begin{array}{l}999.00 \text { (2-Lane) } \\
999.00 \text { (1-Lane) }\end{array}$ \\
\hline $\begin{array}{l}1.000 \\
1.000\end{array}$ & $\begin{array}{l}\text { POST. } \\
\text { POST. }\end{array}$ & $\begin{array}{l}\text { Truck: } \\
\text { Truck: }\end{array}$ & $\begin{array}{l}352 \\
999.00 \\
352 \\
999.00\end{array}$ & $\begin{array}{l}999.0 \\
999.0\end{array}$ & & $\begin{array}{l}0.00 \\
0.00\end{array}$ & $\begin{array}{l}999.00 \text { (2-Lane) } \\
999.00 \text { (1-Lane) }\end{array}$ \\
\hline $\begin{array}{l}1.000 \\
1.000\end{array}$ & $\begin{array}{l}\text { POST. } \\
\text { POST. }\end{array}$ & $\begin{array}{l}\text { Truck: } \\
\text { Truck: }\end{array}$ & $\begin{array}{l}3-3 \\
999.00 \\
3-3 \\
999.00\end{array}$ & $\begin{array}{l}999.0 \\
999.0\end{array}$ & & $\begin{array}{l}0.00 \\
0.00\end{array}$ & $\begin{array}{l}999.00 \text { (2-Lane) } \\
999.00 \text { (1-Lane) }\end{array}$ \\
\hline
\end{tabular}




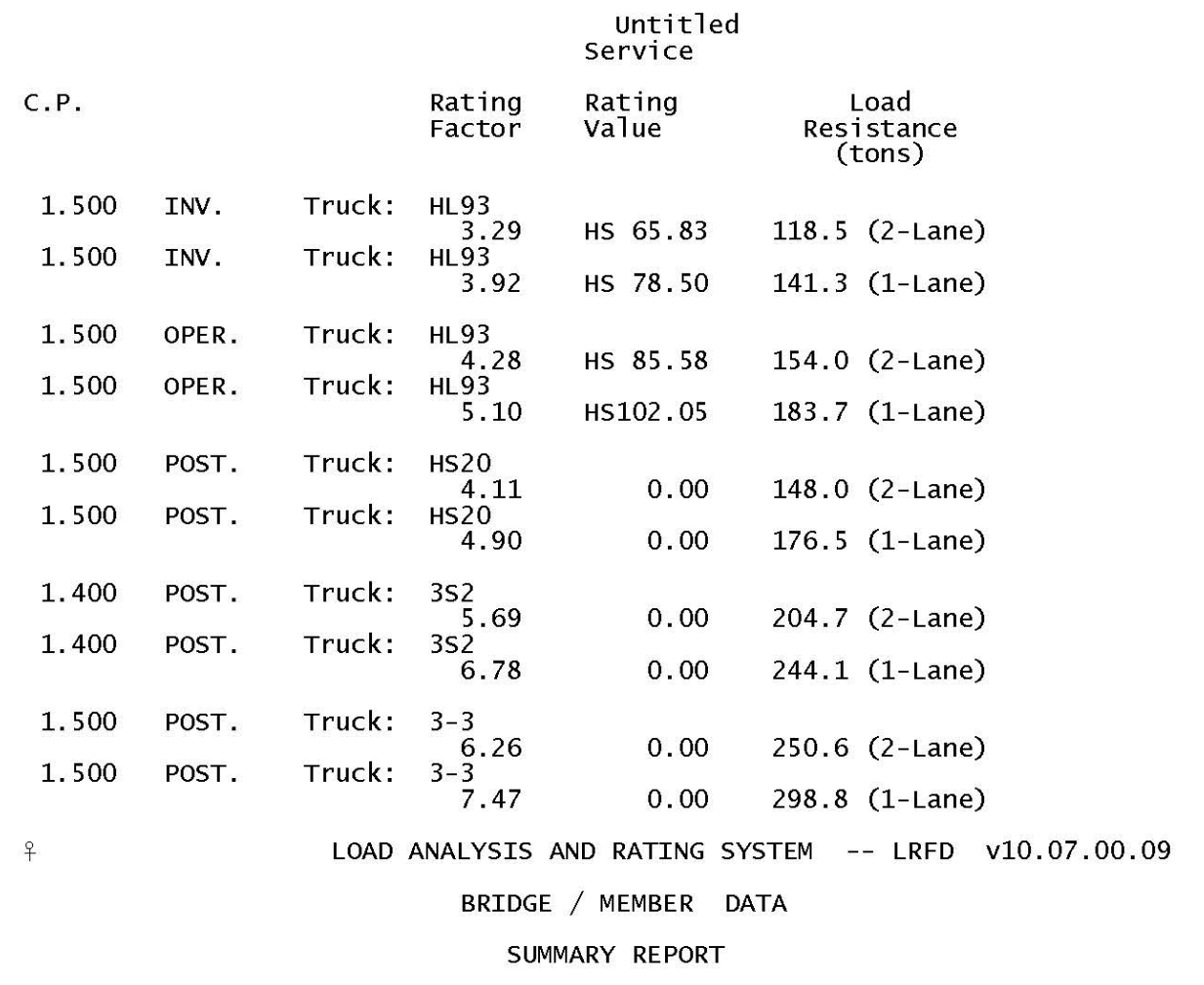

Bridge ID

CANNELVILLE_ROAD_BRIDGE

Facility Carried CANNELVILLE ROAD

Material of Construction

Year of Construction

Roadway width

Number of Spans

CSC

24.000

Live Load Distribution Factor 0.687

Condition Factor: $\quad 1.000$

$\begin{array}{lr}\text { System Factor: } & 1.000 \\ \text { ADTT: } & 1000\end{array}$

1000

Second Live Load Dist. Factor 0.687 LRFD LLDF Moment

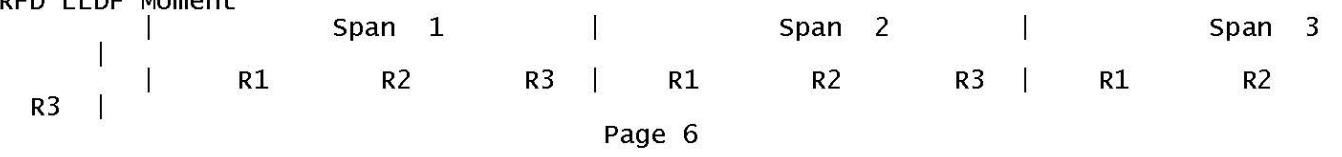




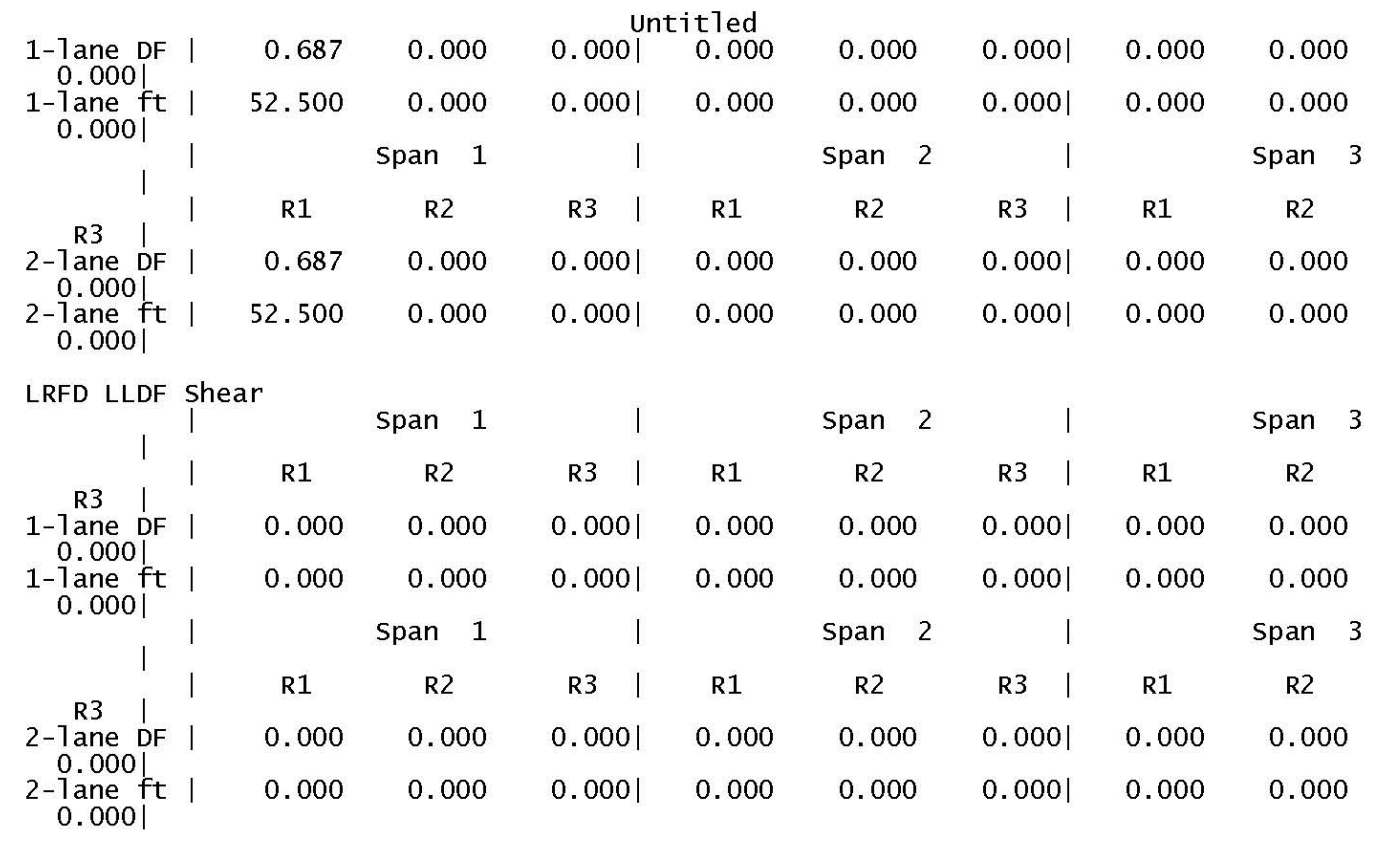

Comments:

Member ID

Symmetry:

Span Length:
G3 INTERIOR - AASHTO

\begin{tabular}{|c|c|c|c|}
\hline $\operatorname{Span}_{52.500} \stackrel{1}{500}$ & $\underset{0.000}{\operatorname{span}}{ }^{2}$ & $\begin{array}{c}\text { Span } \\
0.000\end{array}$ & $\begin{array}{c}\text { Span } \\
0.000\end{array}$ \\
\hline
\end{tabular}

$\begin{array}{lllllll}\text { C.P. } & & & \begin{array}{c}\text { Rating } \\ \text { Factor }\end{array} & \begin{array}{l}\text { Rating } \\ \text { Value }\end{array} & \begin{array}{c}\text { Load } \\ \text { Resistance } \\ \text { (tons) }\end{array} \\ 1.500 & \text { INV. } & \text { Truck: } \begin{array}{c}\text { HL93 } \\ 1.92\end{array} & \text { HS } 38.35 & 69.0 \text { (2-Lane) } \\ 1.500 & \text { INV. } & \text { Truck: } \begin{array}{c}\text { HL93 } \\ 1.92\end{array} & \text { HS } 38.35 & 69.0 \text { (1-Lane) } \\ 1.500 & \text { OPER. } & \text { Truck: } \begin{array}{c}\text { HL93 } \\ 2.49\end{array} & \text { HS } 49.72 & 89.5 \text { (2-Lane) } \\ 1.500 & \text { OPER. } & \text { Truck: } \begin{array}{c}\text { HL93 } \\ 2.49\end{array} & \text { HS } 49.72 & 89.5 \text { (1-Lane) } \\ 1.500 & \text { POST. } & \text { Truck: } \begin{array}{c}\text { HS20 } \\ 2.33\end{array} & \begin{array}{c}0.00 \\ \text { Page } 7\end{array} & 83.9 \text { (2-Lane) }\end{array}$




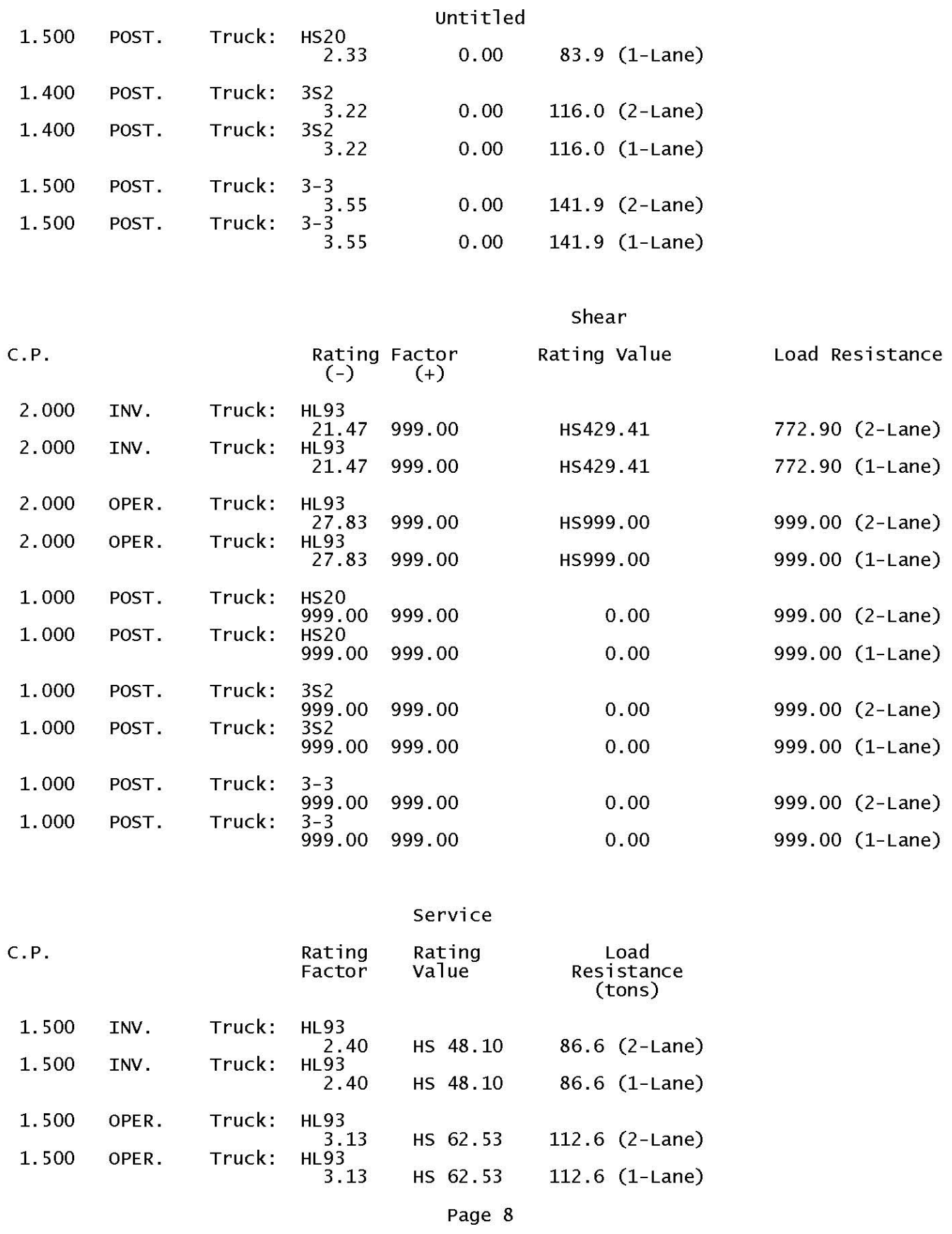




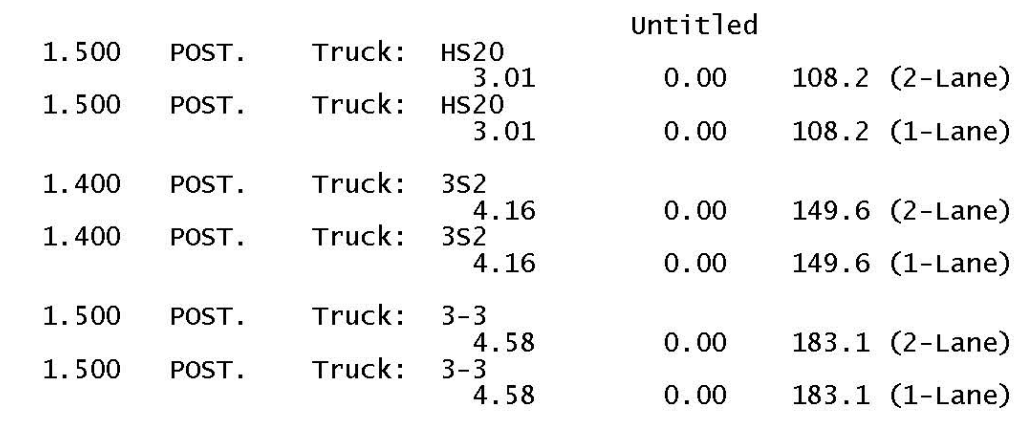

우 LOAD ANALYSIS AND RATING SYSTEM -- LRFD V10.07.00.09

BRIDGE / MEMBER DATA

SUMMARY REPORT

Bridge ID

CANNELVILLE_ROAD_BRIDGE

Facility Carried

CANNELVILLE ROAD

$\begin{array}{lr}\text { Material of Construction } & \text { CSC } \\ \text { Year of Construction } & 2017 \\ \text { Roadway width } & 24.000\end{array}$

Number of Spans

24.000

Live Load Distribution Factor

0.520

Condition Factor:

System Factor:

1.000

1.000

ADTT:

1000

Second Live Load Dist. Factor 0.524 LRFD LLDF Moment

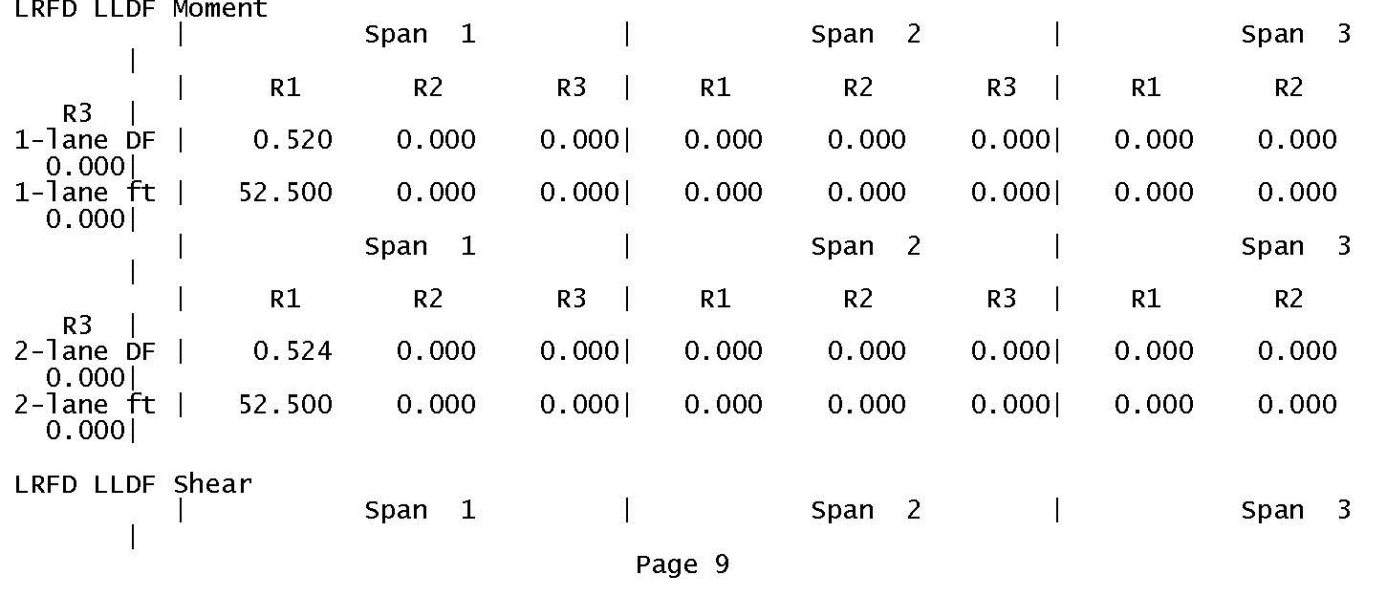




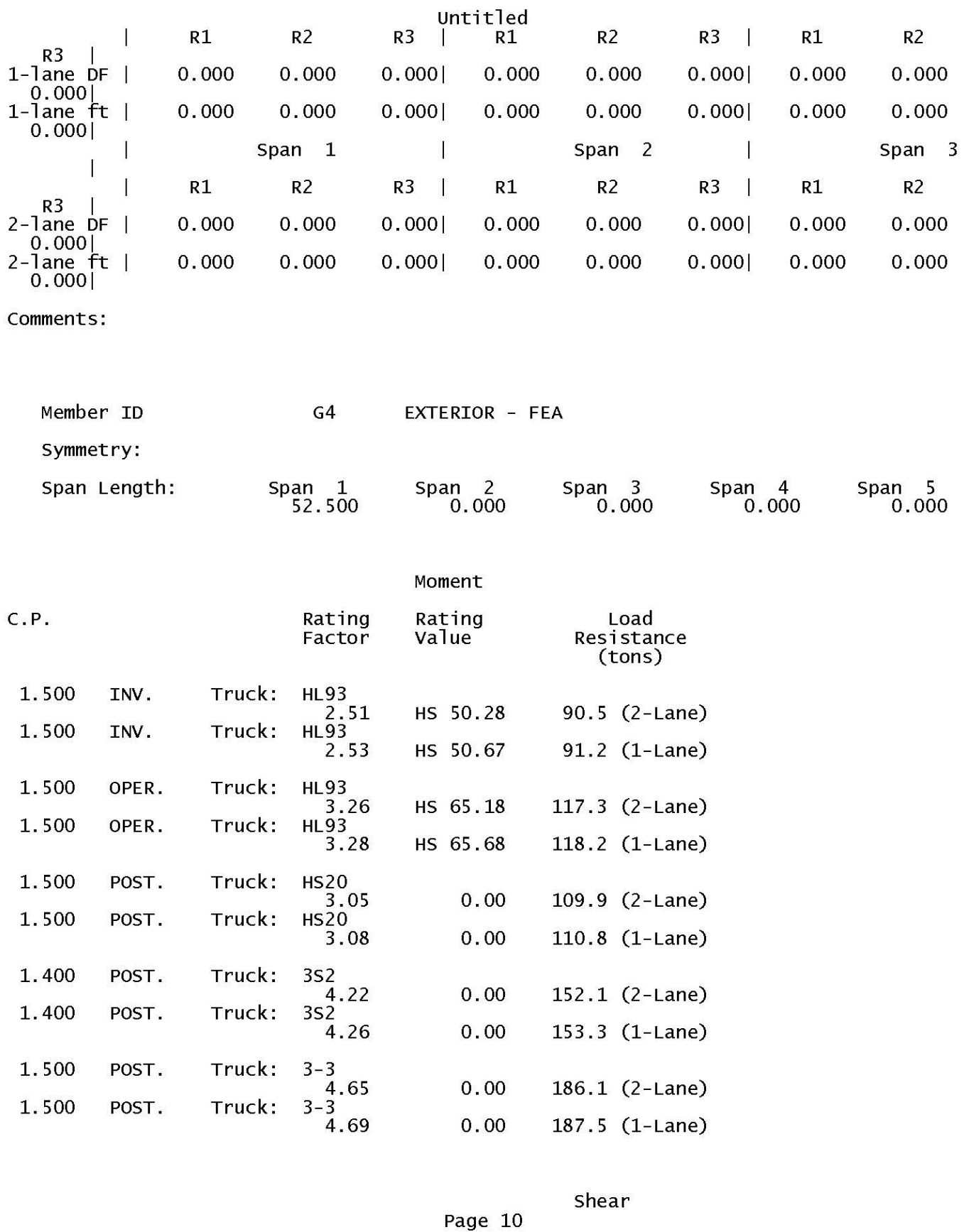


Untitled

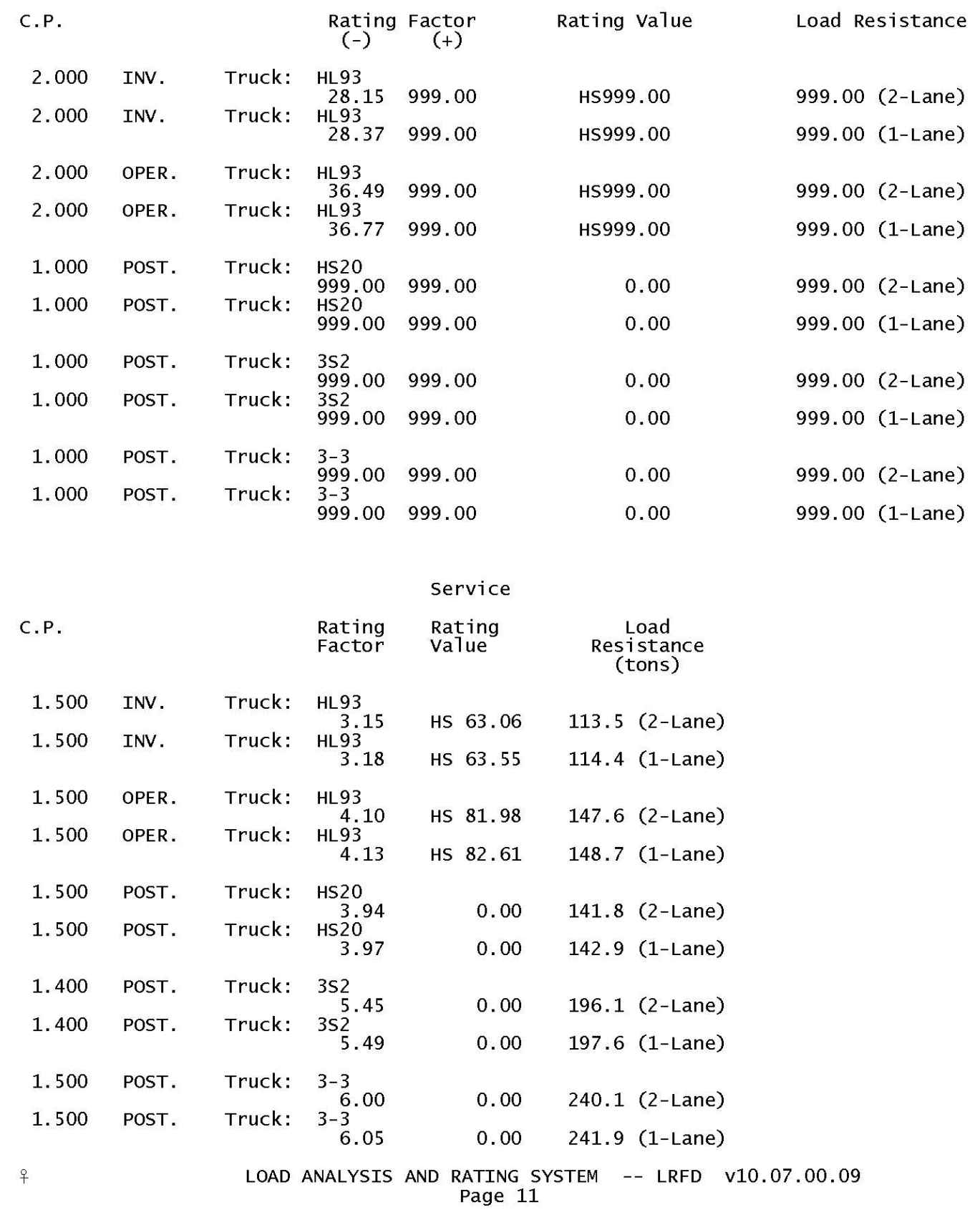


Untitled

BRIDGE / MEMBER DATA

SUMMARY REPORT

Bridge ID

Facility Carried
CANNELVILLE_ROAD_BRIDGE

CANNELVILLE ROAD
Material of Construction
Year of Construction
Roadway width
Number of Spans

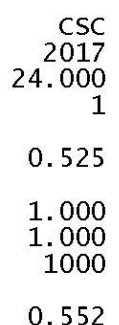

0.552

LRFD LLDF Moment
Condition Factor:

System Factor:

ADTT:

\section{$\mathrm{SC}$}

1

525

000

000

Dist. Factor

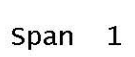

R2

R1

0.525

52.500

0.000

0.000

span 1

R1

0.552

R2

0.000

0.000

52.500

R3 ।

R3 I

0.000 ㅇ

0.0001

0.000

0.000

R3 ।

R3

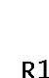

0.0001

0.000

0.000 |

0.000
LRFD LLDF shear

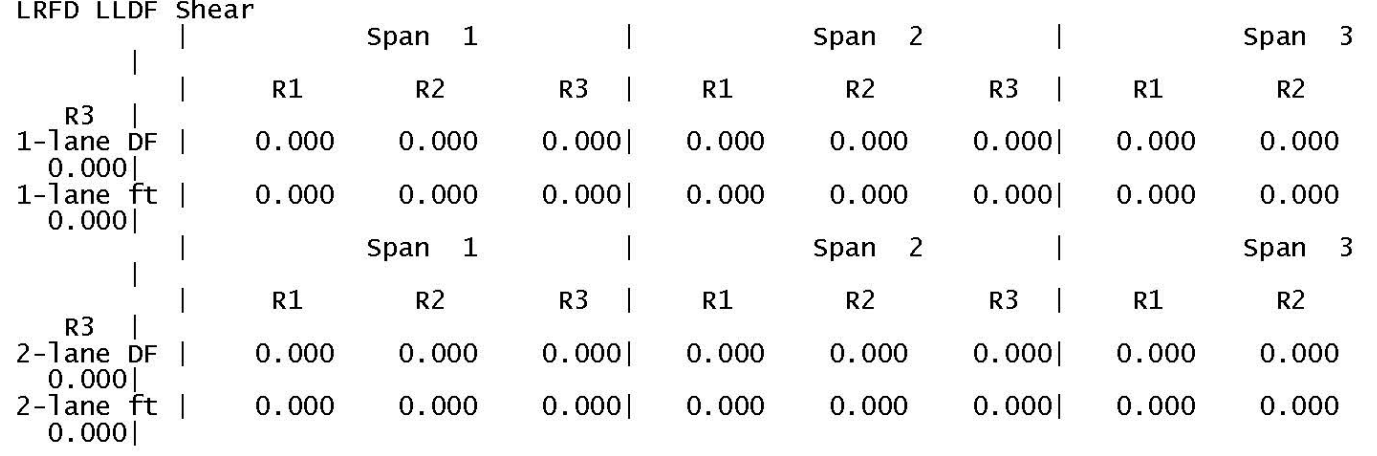

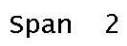

0.000

0.000

0.000

0.000

0.000

0.000

Span 2

R2

R3 |

R1

Span 3

0.000

0.000

0.000

0.000

0.000

0.000

0.000

R2

comments: 
Untitled

Member ID

G5

EXTERIOR - FIELD RESULTS

Symmetry:

Span Length:

$$
\operatorname{Span}_{52.500} \stackrel{1}{1}
$$

Span
0.000

$\underset{0.000}{3}$

Span
0.000

Span
0.000

C.P.

Moment

Rating

Rating

Factor

value

$$
\begin{gathered}
\text { Load } \\
\text { Resistance } \\
\text { (tons) }
\end{gathered}
$$

1.500 INV. Truck: HL93

1.500 INV. Truck: HL93

HS 47.73

85.9 (2-Lane)

1.500 OPER. Truck: HL93

1.500 OPER. Truck: HL93 3.09

HS 50.18

90.3 (1-Lane)

1.500 OPER. Truck: HL93 3.25

HS $61.87 \quad 111.4$ (2-Lane)

1.500 POST. Truck: HS20

1.500 POST. Truck: HS 20

HS $65.05 \quad 117.1$ (1-Lane)

1.400 POST. Truck: 352

1. 400 POST. Truck: 352 4.01

1.400 POST. Truck: 3S2

1.500 POST. Truck: $3-3$

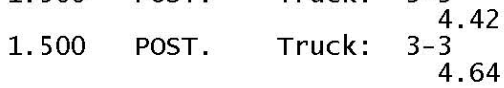

$0.00 \quad 104.4$ (2-Lane)

$0.00 \quad 109.7$ (1-Lane)

$0.00 \quad 144.4$ (2-Lane)

$0.00 \quad 151.8$ (1-Lane)

0.00176 .6 (2-Lane)

$0.00 \quad 185.7$ (1-Lane)

C.P.

2.000 INV. Truck: HL93

$\begin{array}{lll}26.72 & 999.00\end{array}$

2.000 INV. Truck: HL93 28.10999 .00

2.000 OPER. Truck: HL93

2.000 OPER. TruCK: 34.64999 .00

2.000 OPER. Truck: HL93

36.42999 .00

1.000 POST. Truck: HS2O
$999.00 \quad 999.00$

Page 13

\section{shear}

Rating value

HS534. 44

HS999.00

HS999.00

HS999. 00

0.00
Load Resistance

962.00 (2-Lane)

999.00 (1-Lane)

999.00 (2-Lane)

999.00 (1-Lane)

999.00 (2-Lane) 


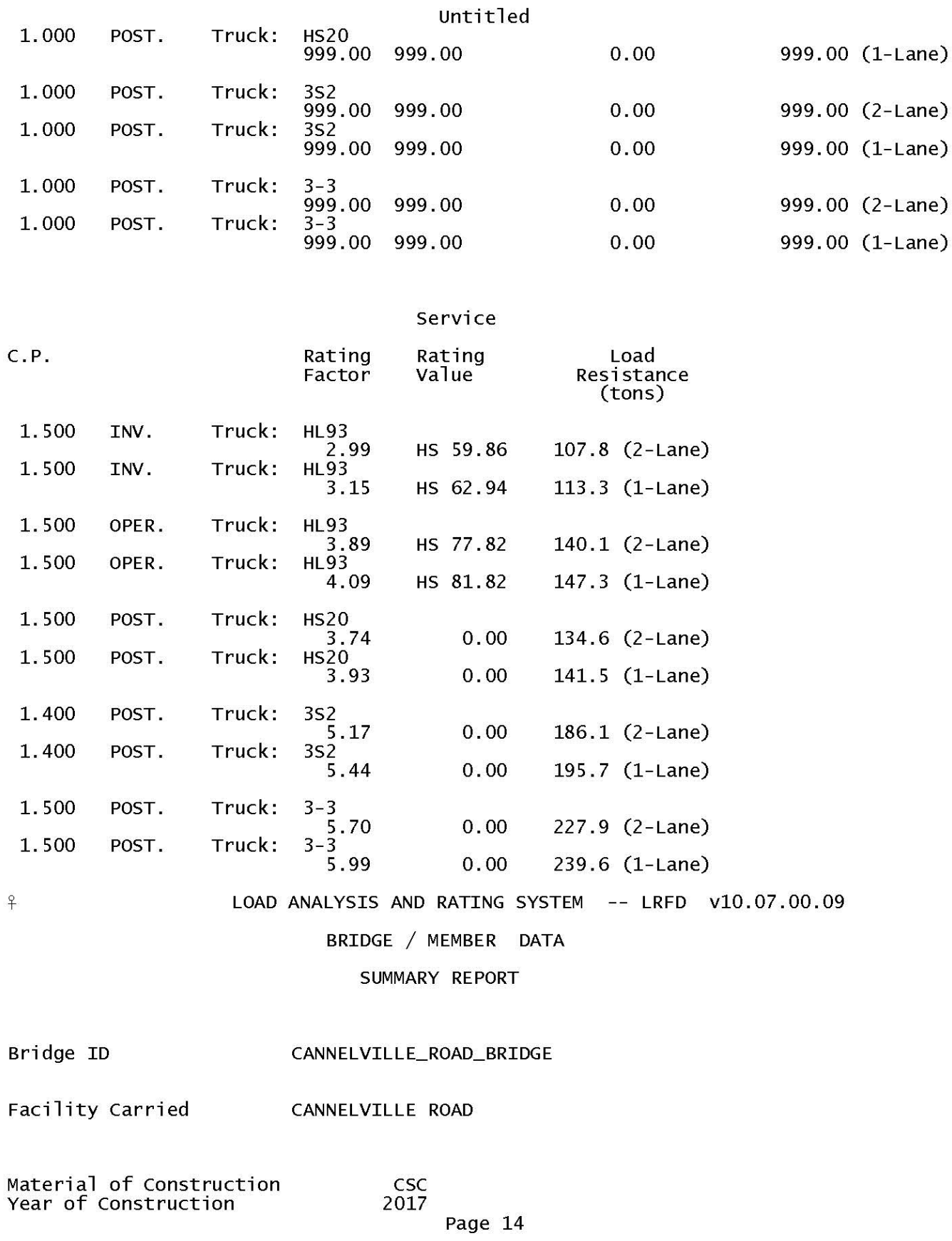




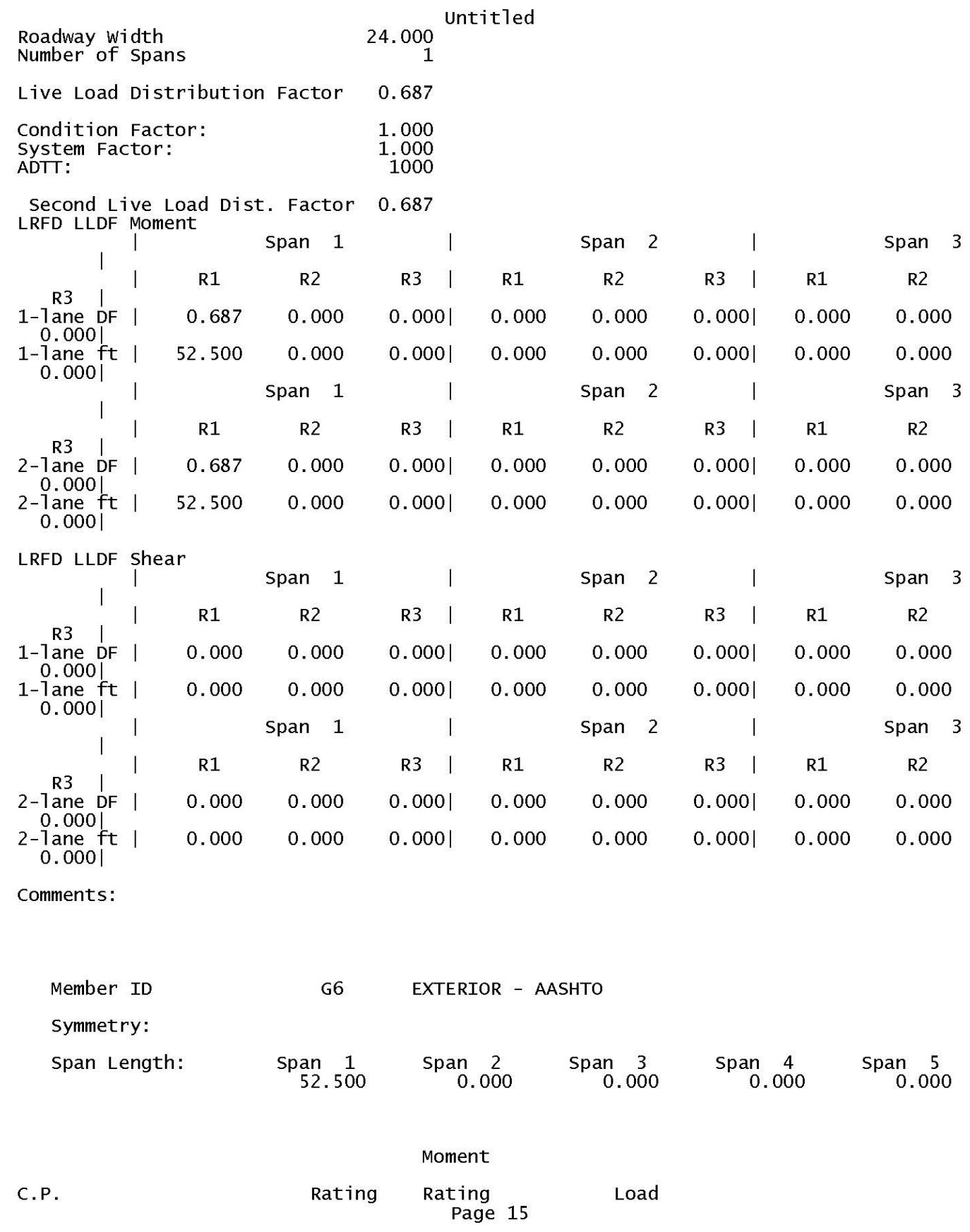




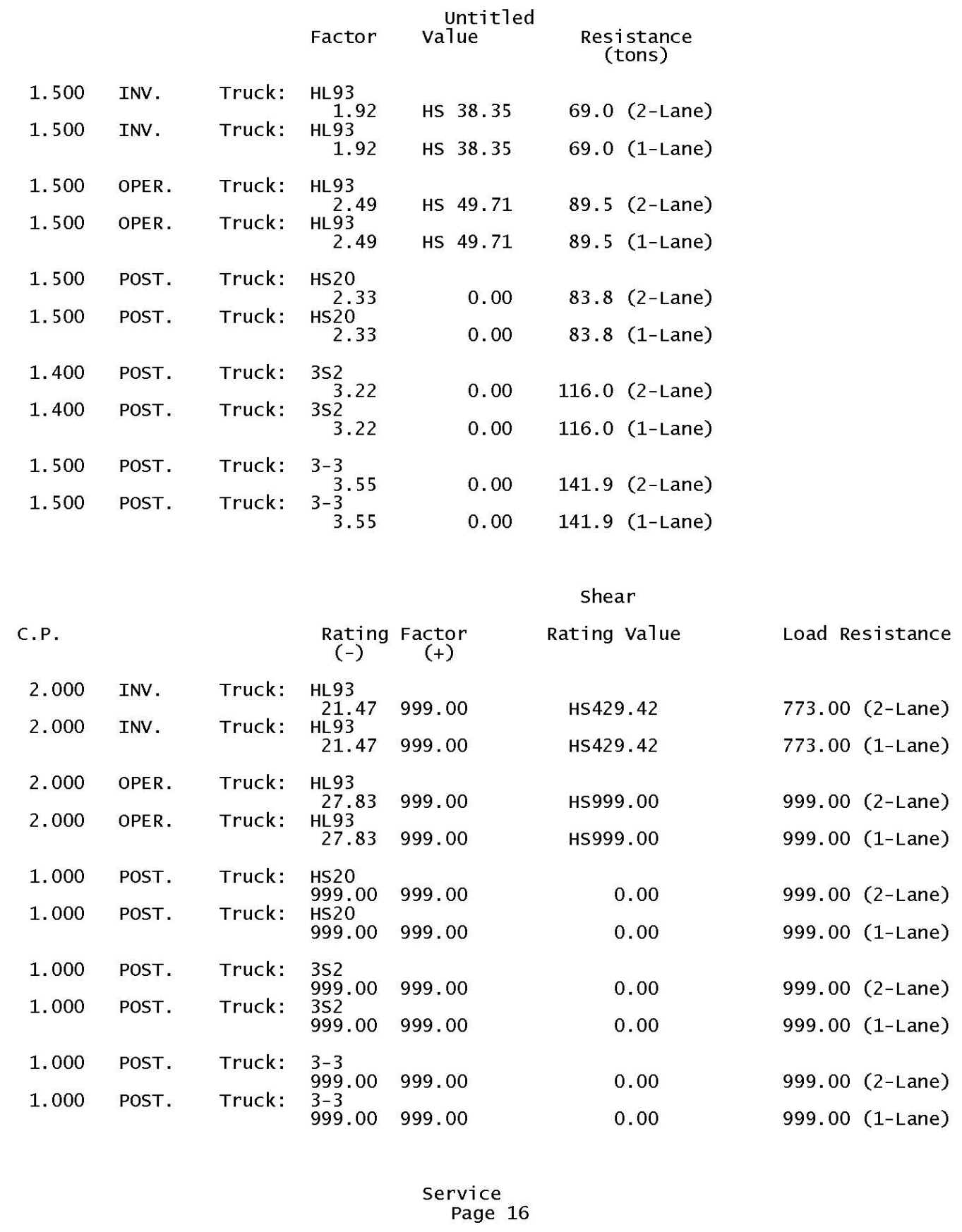




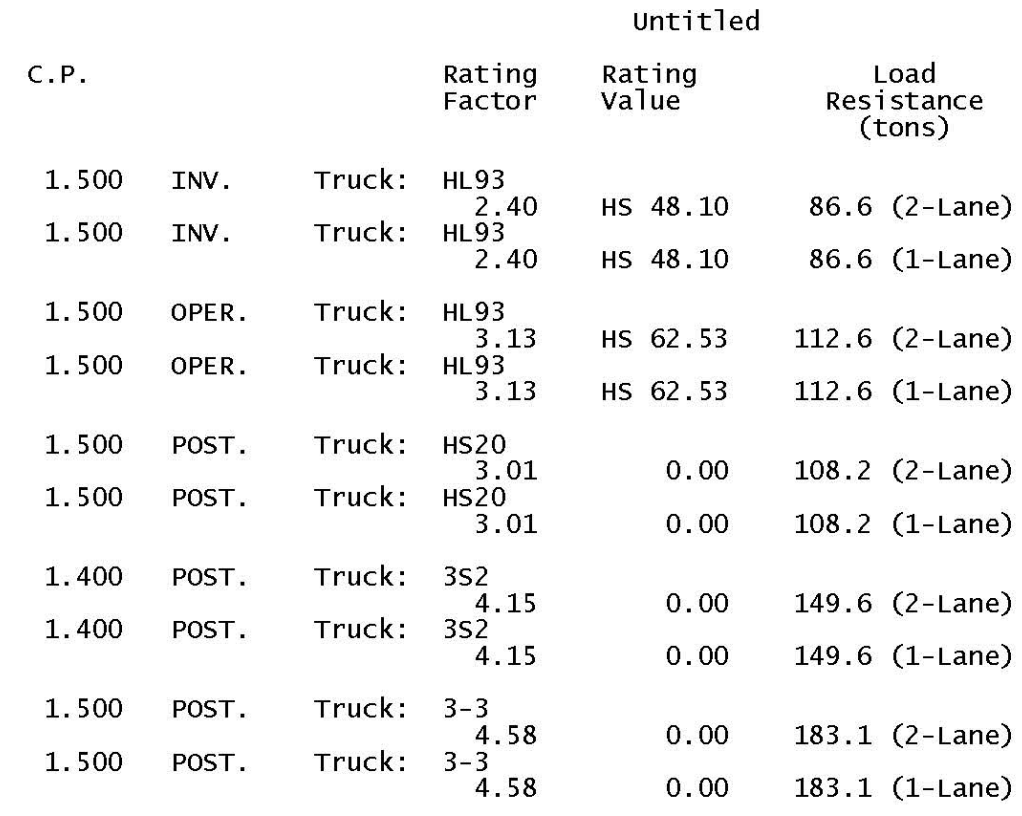

Page 17 


\section{Appendix C: Cannelville Road Bridge Design Plans}

The following appendix includes the detail plans from Intelligent Engineering Ltd., for the Cannelville Road Bridge. These plans are not the final construction plans on file with the Muskingum County Engineer's Office. Note that these plans have been converted from their original 11 "x 17 " format to $8 \frac{1}{12}$ " $\times 11$ " for presentation in this report. 


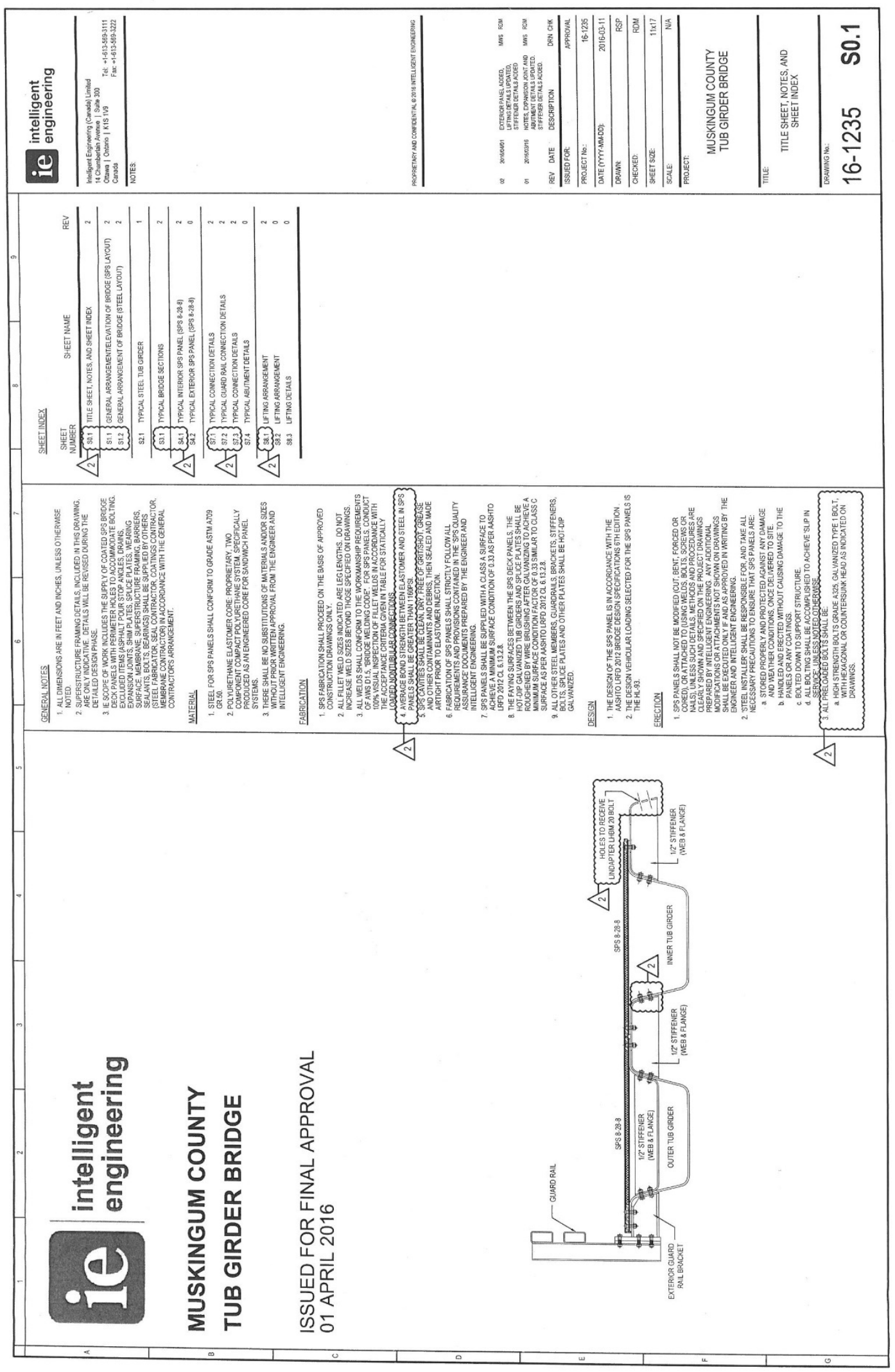




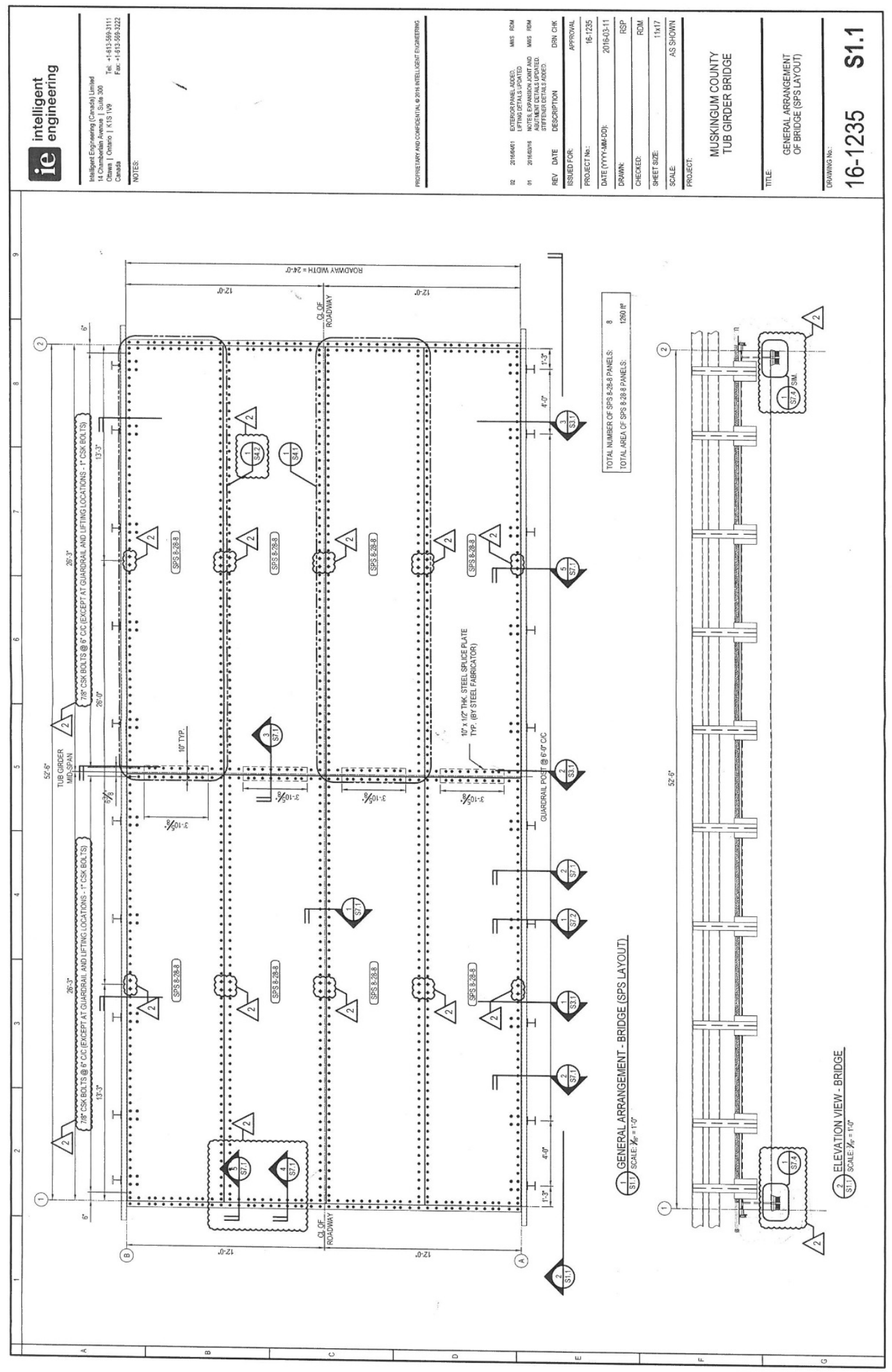




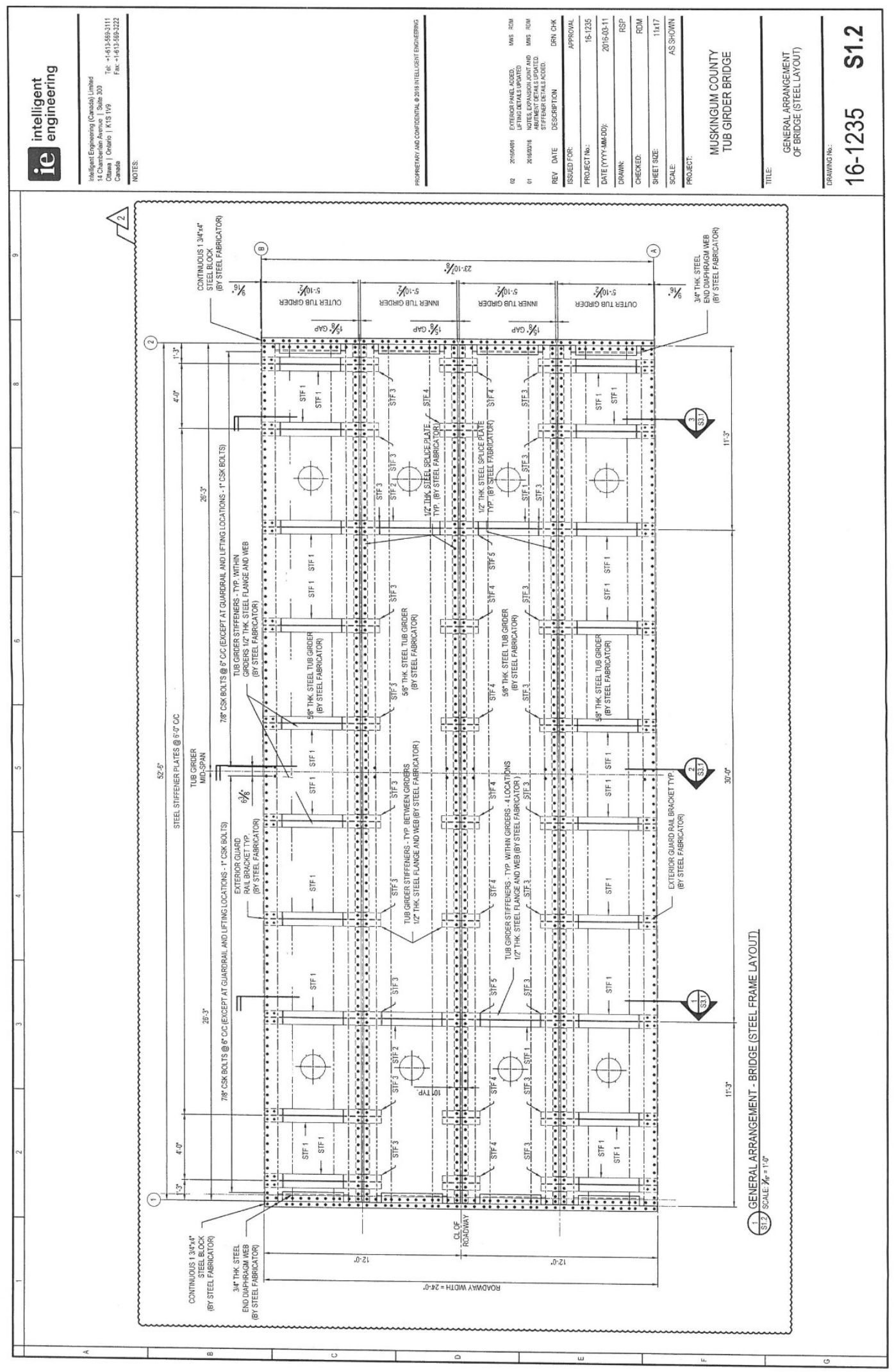




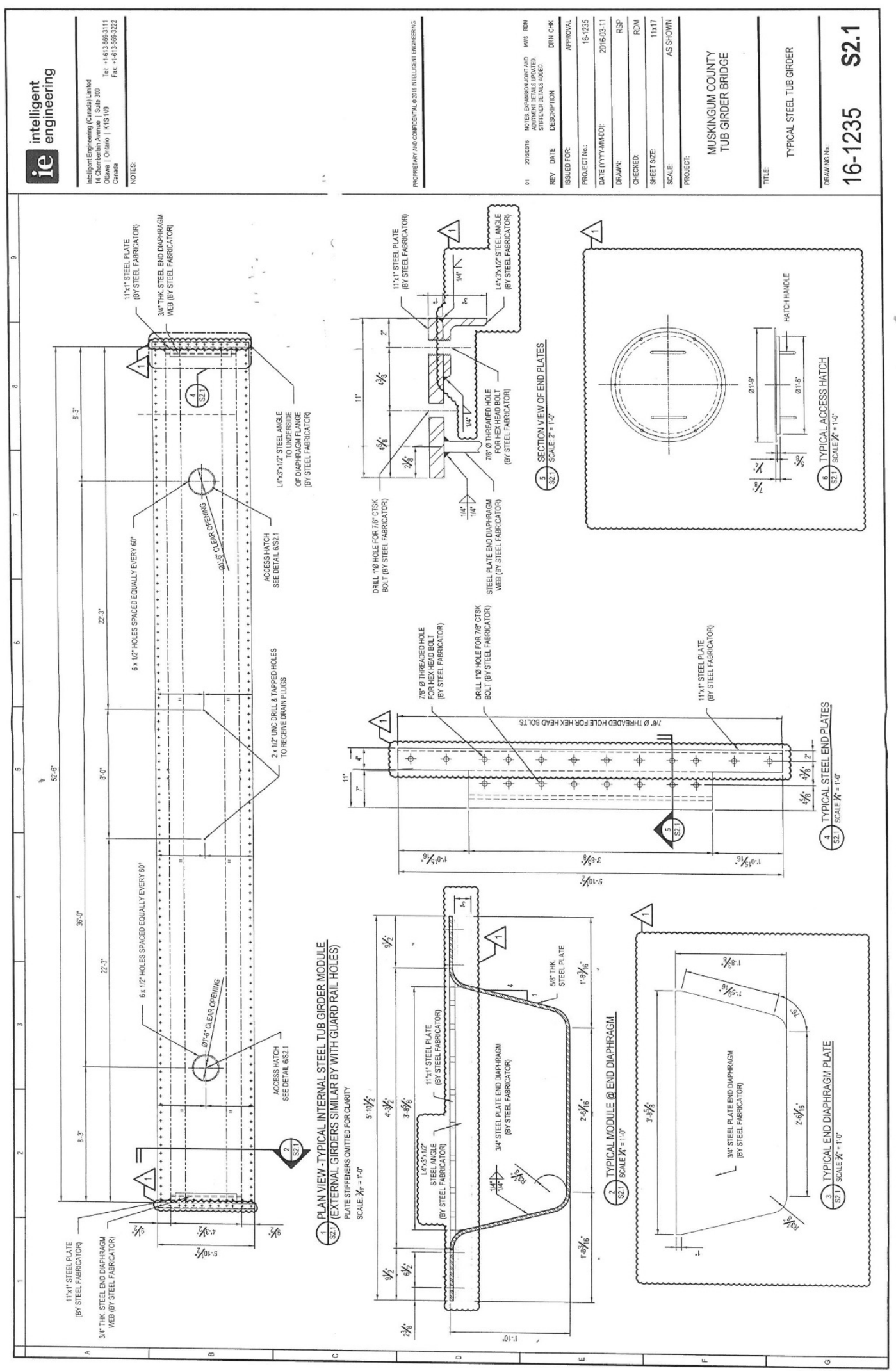




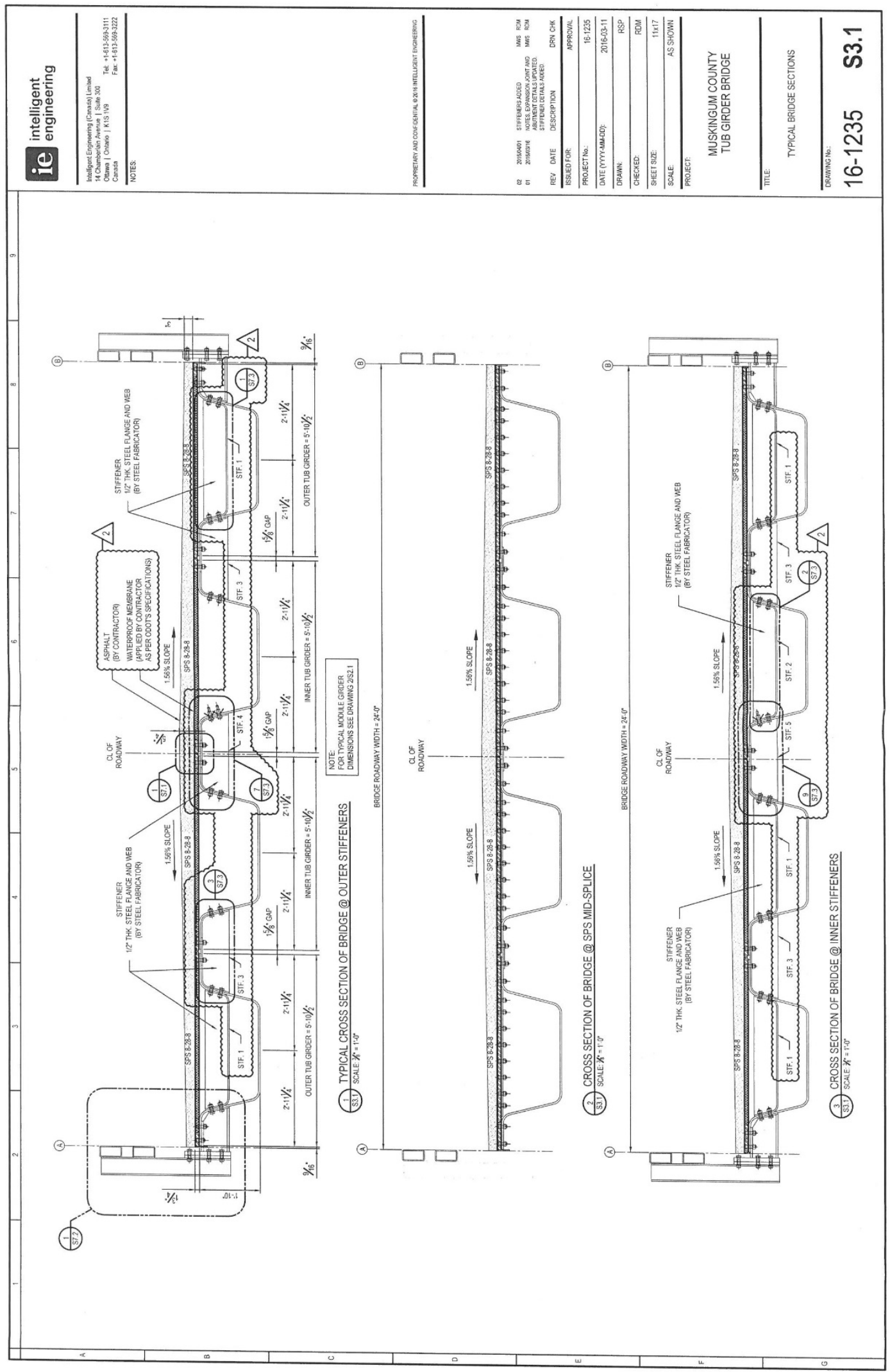




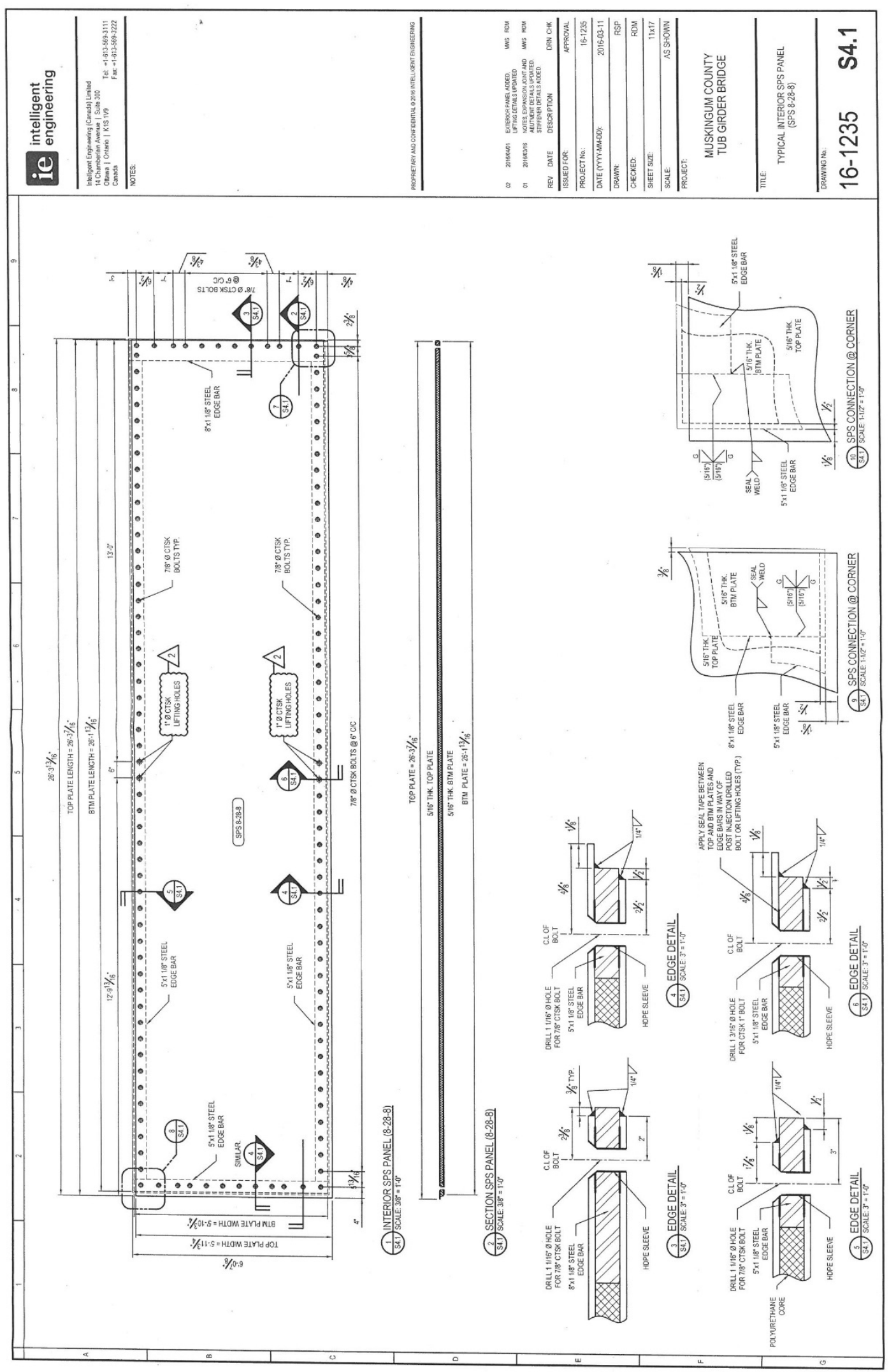




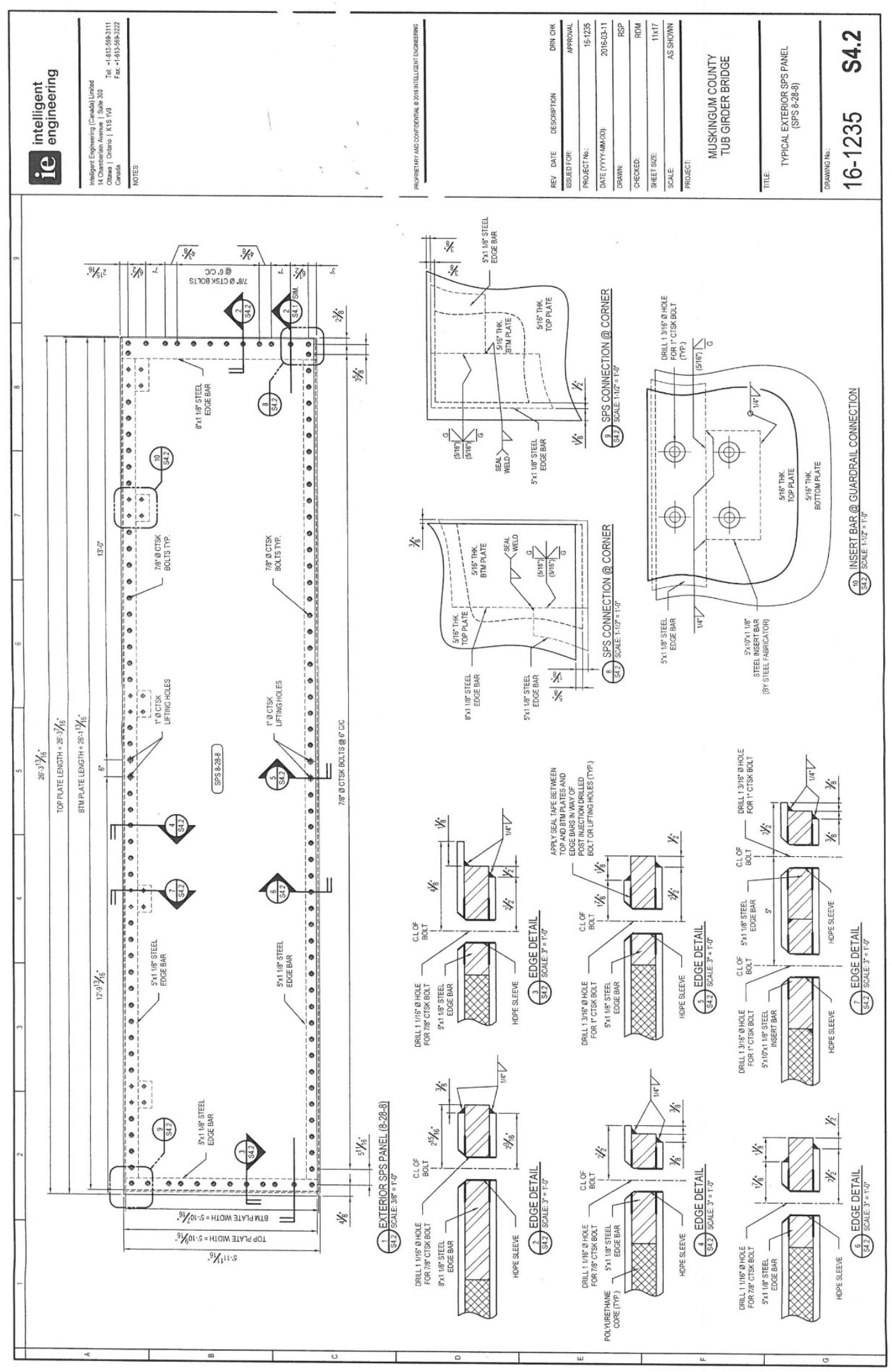




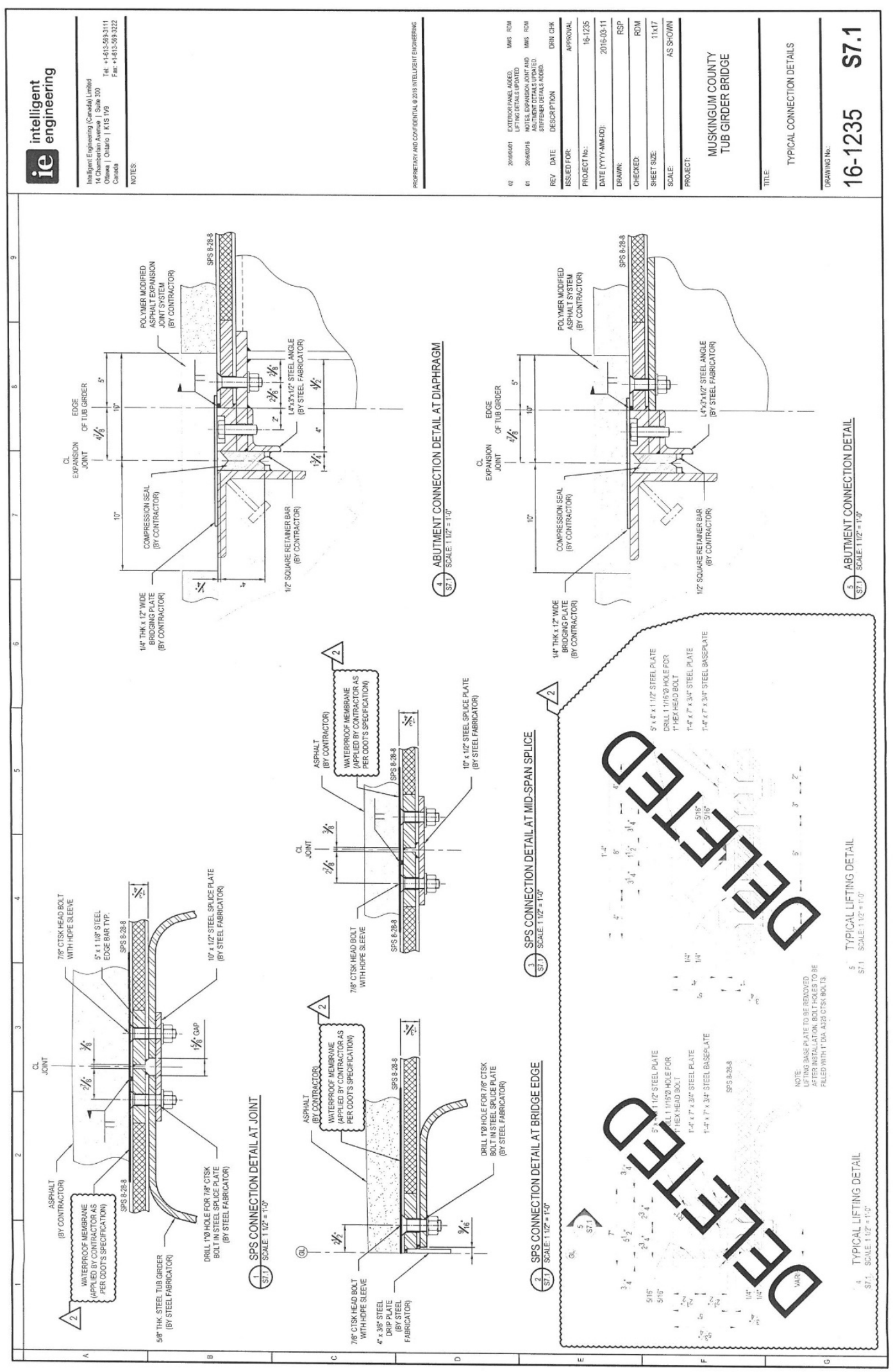




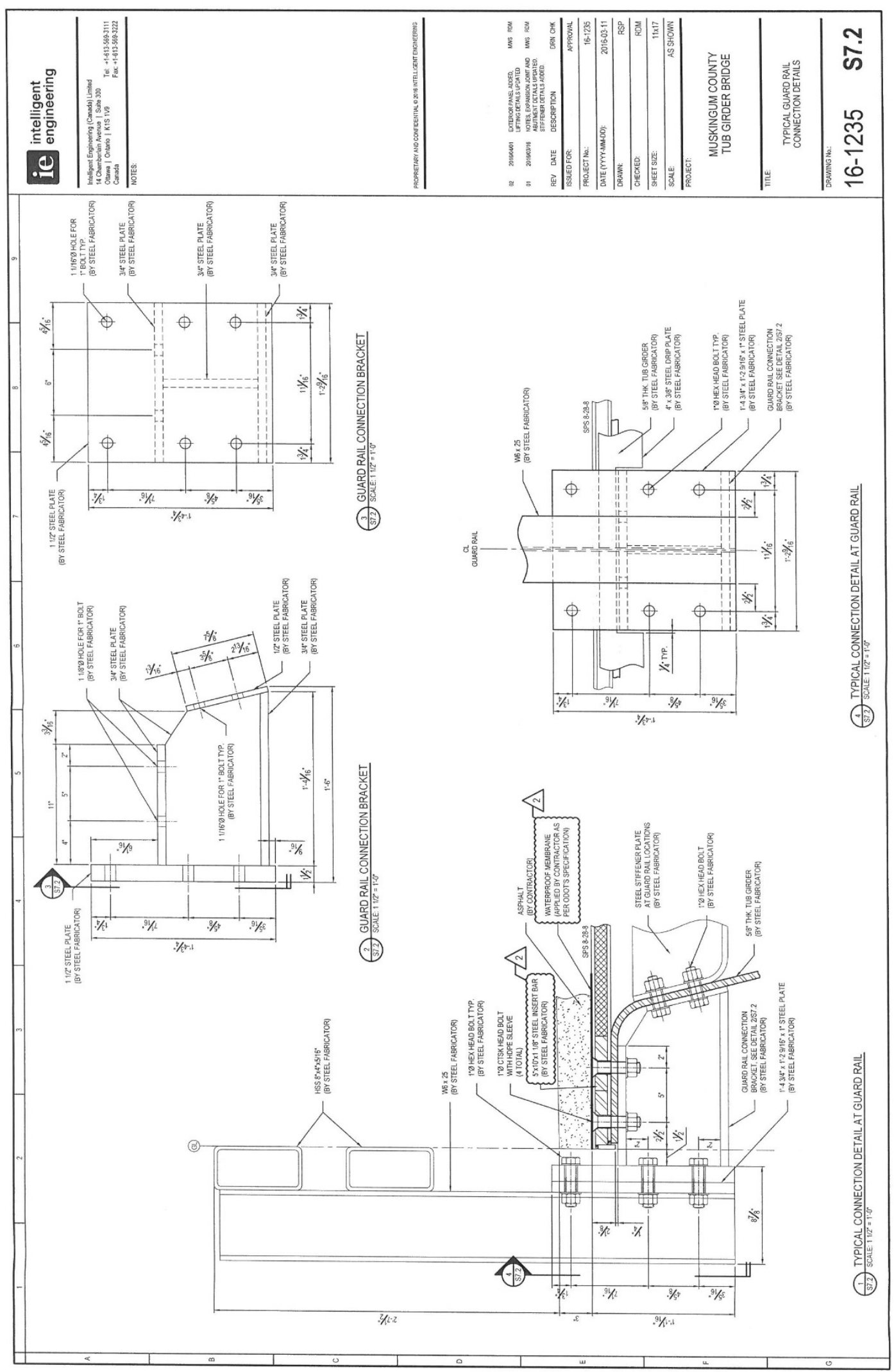




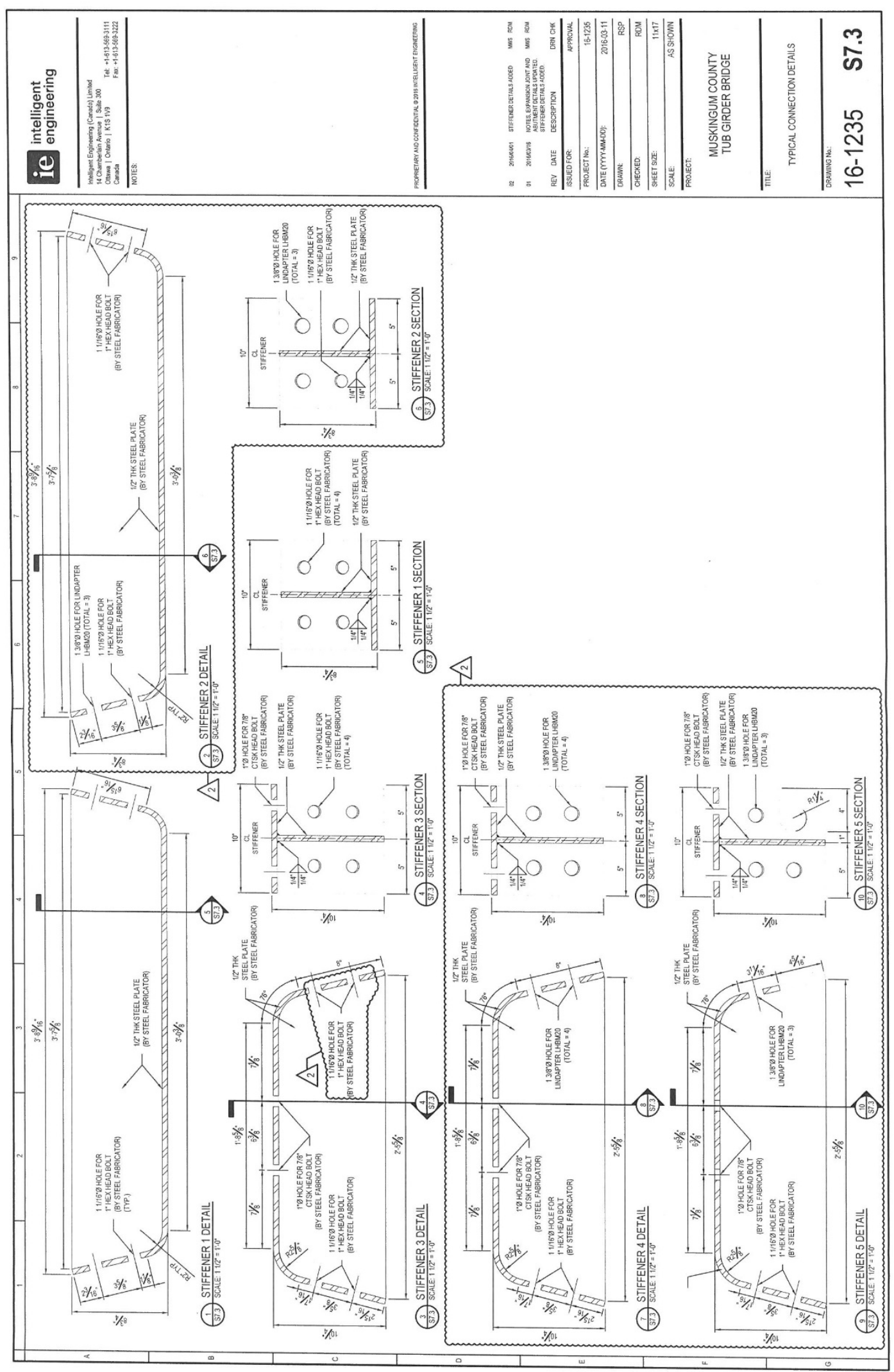




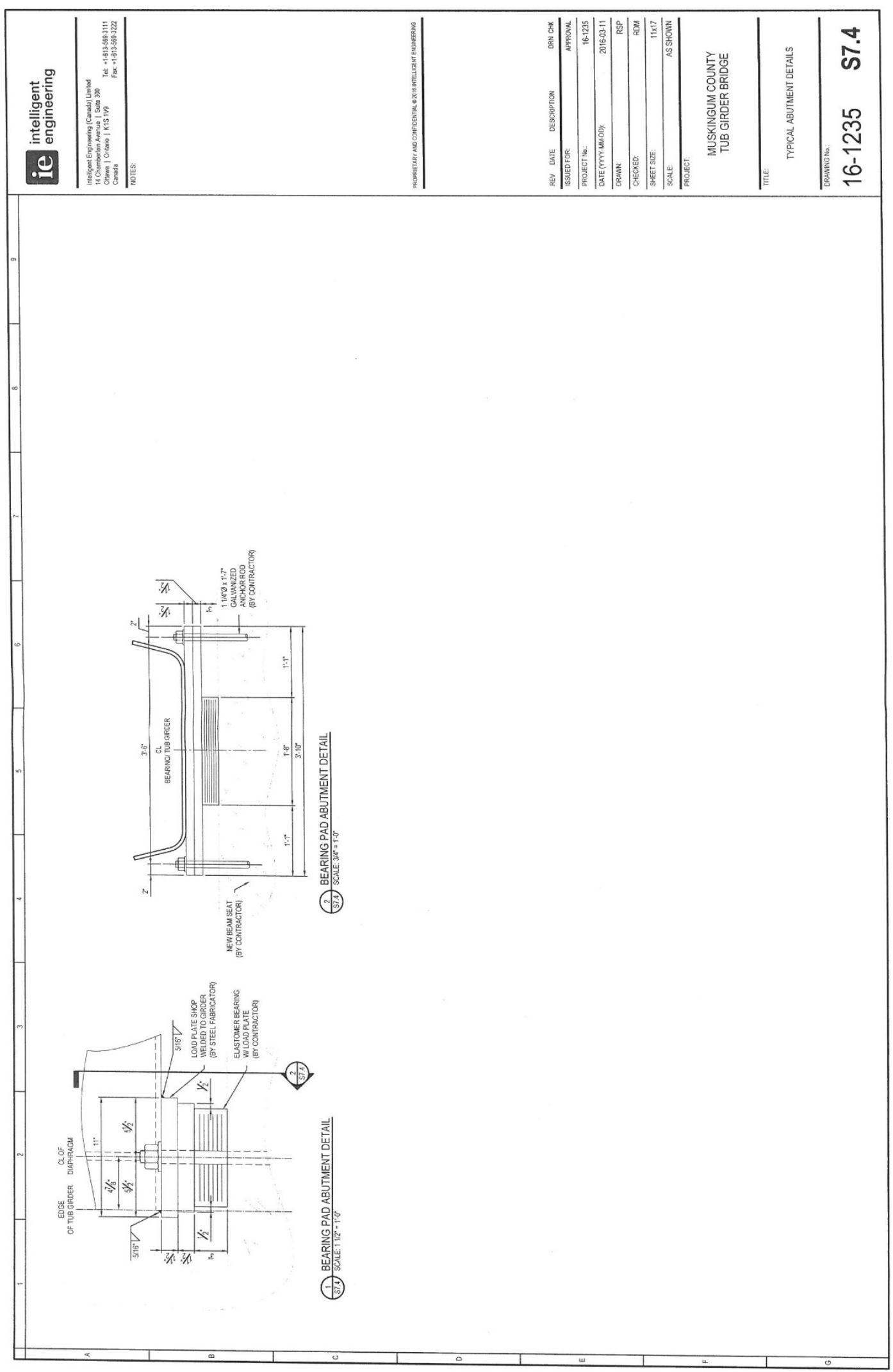




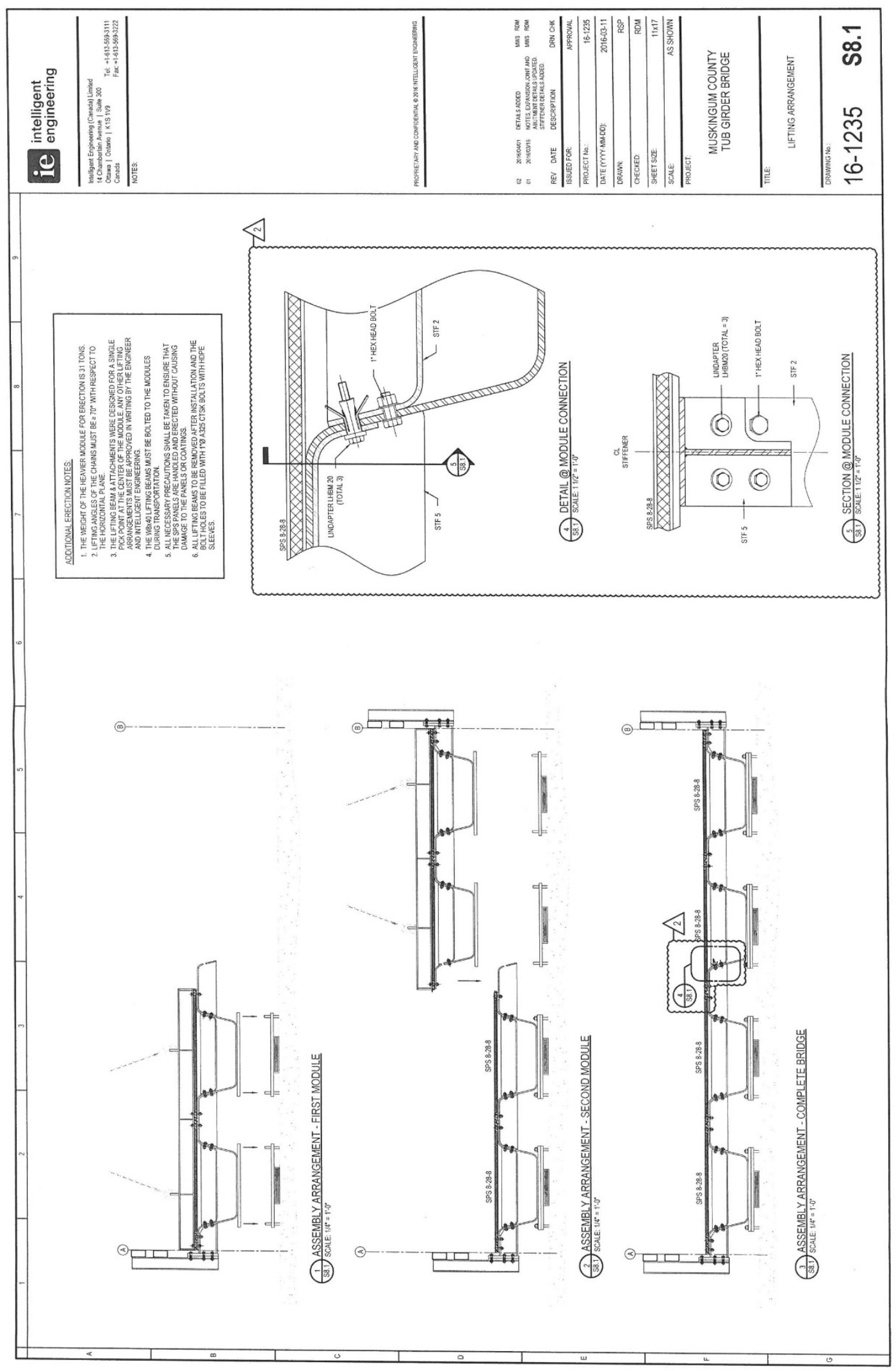




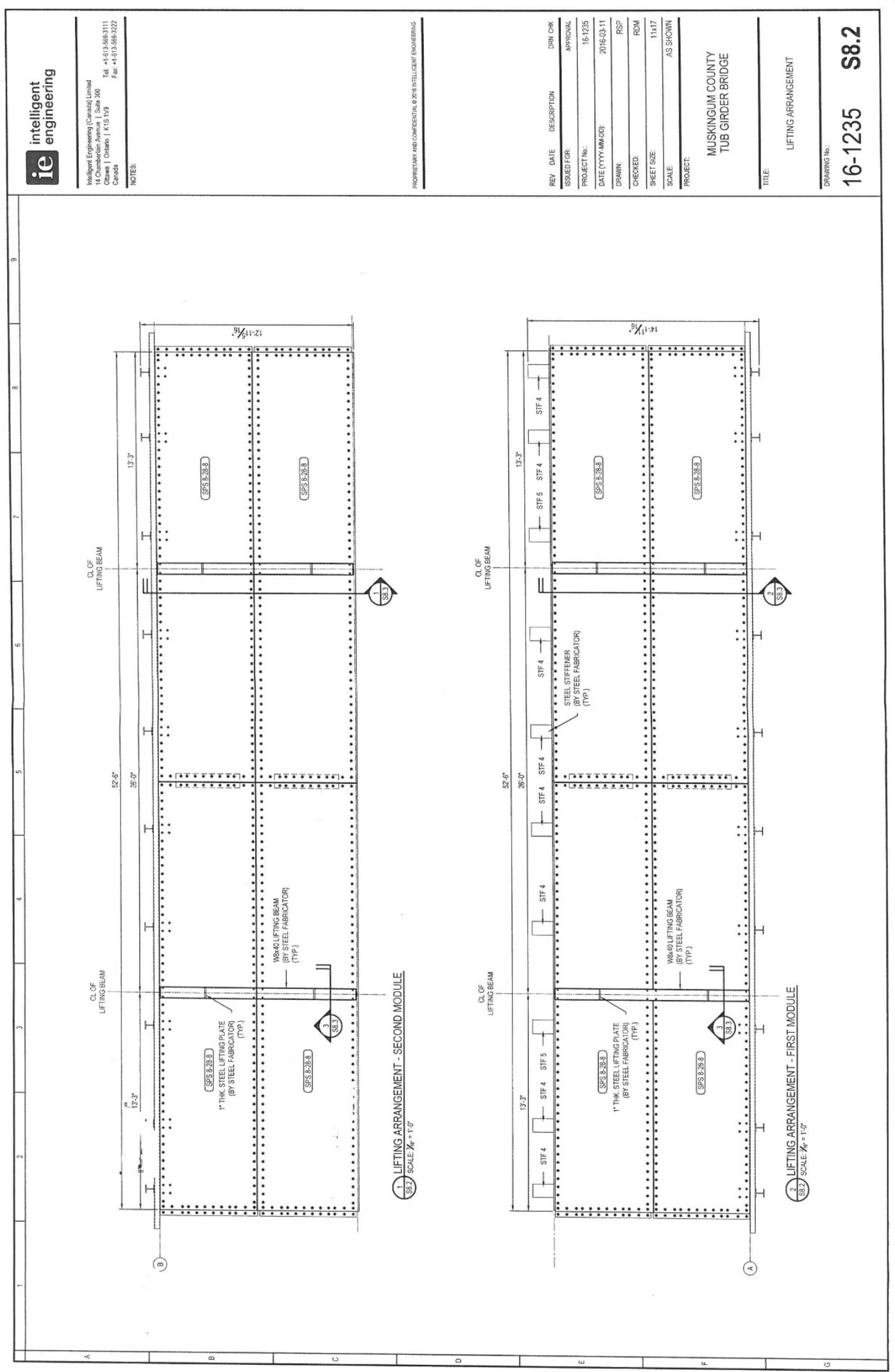




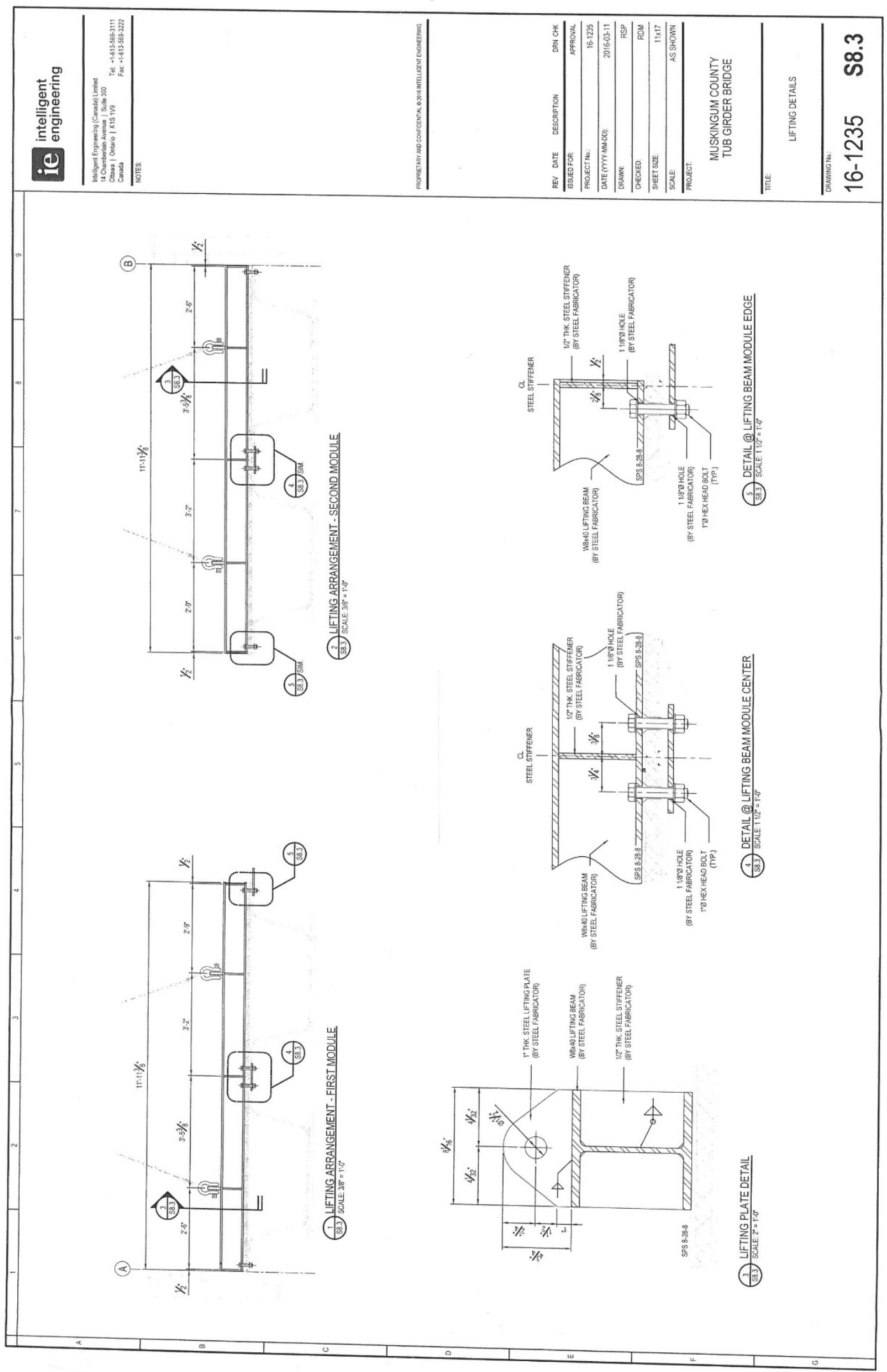

